UNIVERSIDADE DE SÃO PAULO
ESCOLA DE COMUNICAÇÕES E ARTES
PROGRAMA DE PÓS-GRADUAÇÃO EM CIÊNCIA DA INFORMAÇÃO

ANDERSON DE SANTANA

Avaliação bibliométrica individual:

Internacionalização e perfis contextualizados nas

Geociências

São Paulo 



\author{
UNIVERSIDADE DE SÃO PAULO \\ ESCOLA DE COMUNICAÇÕES E ARTES \\ PROGRAMA DE PÓS-GRADUAÇÃO EM CIÊNCIA DA INFORMAÇÃO
}

ANDERSON DE SANTANA

\title{
Avaliação bibliométrica individual: \\ Internacionalização e perfis contextualizados nas \\ Geociências
}

Dissertação apresentada à Escola de Comunicações e Artes da Universidade de São Paulo, como requisito para obtenção do título de Mestre em Ciências.

Área de Concentração: Organização, Mediação e Circulação da Informação

Orientador: Prof. Dr. Rogério Mugnaini 
Autorizo a reprodução e divulgação total ou parcial deste trabalho, por qualquer meio convencional ou eletrônico, para fins de estudo e pesquisa, desde que citada a fonte.

Catalogação na Publicação

Serviço de Biblioteca e Documentação

Escola de Comunicações e Artes da Universidade de São Paulo

Dados inseridos pelo(a) autor(a)

Santana, Anderson de

Avaliação bibliométrica individual: internacionalização e

perfis contextualizados nas Geociências / Anderson de

Santana ; orientador, Rogério Mugnaini. -- São Paulo, 2018.

289 p.: il.

Dissertação (Mestrado Profissional) - Escola de

Comunicações e Artes / Universidade de São Paulo.

Bibliografia

Versão corrigida

1. Avaliação bibliométrica individual 2. Bibliometria 3.

Internacionalização 4. Avaliação Institucional 5. Geociências

I. Mugnaini, Rogério II. Título.

CDD 21.ed. - 020 
SANTANA, A. Avaliação bibliométrica individual: internacionalização e perfis contextualizados nas Geociências. Dissertação apresentada à Escola de Comunicações e Artes da Universidade de São Paulo, como requisito para obtenção do título de Mestre em Ciências.

Defesa realizada em: $28 / \underline{08 / 2018}$.

\section{Banca Examinadora:}

Prof. Dr. Rogério Mugnaini (Orientador) Instituição: USP / ECA

Julgamento:

Assinatura

Profa. Dra. Asa Fujino

Instituição: USP / ECA

Julgamento:

Assinatura

Dra. Elisabeth Adriana Dudziak

Instituição: SIBi / USP

Julgamento:

Assinatura

Profa. Dra. Ely Francina Tannuri de Oliveira Instituição: UNESP / FFC

Julgamento:

Assinatura 

A Ana Lucia e Gabriel, que tornaram minha vida plena e que estão presentes em cada batida do meu coração. 



\section{AGRADECIMENTOS}

Àquele que admirava antes de conhecer e que ao conhecer e conviver, transformou a admiração em amizade fraternal. Obrigado Rogério por sua paciência, respeito e conhecimentos compartilhados.

A todos os amigos da Biblioteca do Instituto de Geociências, Antonio, Brenda, Cintia, Estela, Fabiola, Hellen, Neide, Roger, Sonia e Thalita pelo carinho, apoio, compreensão e diversão constantes.

À Célia, minha amiga e companheira de Pós-Graduação. A luta diária e nossos esforços valeram a pena.

Ao Prof. Marcos Egydio da Silva, diretor do Instituto de Geociências e constante apoiador deste trabalho e dos projetos para tornar nossa biblioteca um verdadeiro centro de apoio aos pesquisadores.

Aos docentes entrevistados por apoiarem esta pesquisa e torná-la um rico objeto de estudo.

Àquela que me deu a vida, minha mãe Conceição. Esteja onde estiver tudo isso só foi possível por seu carinho e apoio ao longo dessa vida em que tive a honra de ser cuidado por ti.

E agradeço principalmente aos meus dois amores, Ana Lucia minha companheira para a vida e meu lindo, forte e apaixonado Gabriel. A vocês agradeço por me apoiarem e serem tudo o que mais desejei em minha vida. Amo vocês. 

"Para pequenas criaturas como nós, a vastidão é suportável apenas por meic do amor." Carl Edward Sagan 



\section{RESUMO}

SANTANA, Anderson. Avaliação bibliométrica individual: internacionalização e perfis contextualizados nas Geociências. 2018. 289 p. Dissertação (Mestrado Profissional) Escola de Comunicações e Artes, Universidade de São Paulo, São Paulo, 2018.

Os processos de avaliação empreendidos por agências governamentais e instituições de ensino vêm crescentemente se pautando em parâmetros mensuráveis (quantitativos), incluindo os indicadores bibliométricos. Almejando análises em nível Macro, se baseiam em indicadores de periódicos em nível Meso (Fator de Impacto do Journal Citation Reports). Nesse sentido, a pesquisa realizada vislumbrou a proposição de um modelo de avaliação bibliométrica em nível individual (Micro), que abarcou um conjunto de variáveis e de contextos dos docentes do Instituto de Geociências da Universidade de São Paulo (IGc/USP). Pautou-se em aspectos quantitativos, mas também qualitativos, oferecendo um diagnóstico da produção científica, buscando propiciar uma visão mais estratégica do processo de comunicação científica. Objetivo: Analisar a produção científica de pesquisadores com vistas à adaptação de um modelo de avaliação bibliométrica em nível individual, que forneça subsídios para o planejamento de uma avaliação institucional. Procedimentos Metodológicos: Trata-se de uma pesquisa qualitativa e quantitativa, com finalidade exploratório-descritiva, utilizando-se de levantamento de dados e análise bibliométrica baseada no método desenvolvido por Gorraiz; Wieland e Gumpenberger (2016) e adaptada à realidade do IGc/USP. Os métodos foram divididos em três partes: (1) Análise Geral, em que se realizou: (a) o mapeamento da inserção da comunidade de docentes do IGc/USP em plataformas de identificação de autores e registro da produtividade científica, e; (b) um diagnóstico da produção científica do IGc/USP, agregando dados de diversas fontes, tanto institucionais (Banco de Dados Bibliográfico da USP - Dedalus; sistemas corporativos; CAPES etc.) quanto comerciais (ResearchGate, Scopus e WoS) para o desenvolvimento de uma base de dados da produção da instituição; (2) Análise Amostral que, utilizando-se da base de dados desenvolvida, estabeleceu critérios para a seleção de uma amostra de docentes, definida com base em diferentes perfis de publicação identificados, considerando níveis de internacionalização de sua produção científica; (3) Adaptação do Método de Gorraiz, Wieland e Gumpenberger, que se baseou em: (a) entrevista estruturada com os docentes da amostra, com o objetivo de prover suporte à identificação, desambiguação, coleta e análise dos dados a serem utilizados, e; (b) desenvolvimento do perfil bibliométrico individual da produção científica desses docentes, analisando-se: atividade de publicação, coautorias; colaboração (institucional, nacional, internacional); afiliação empregada e financiamentos de pesquisa recebidos; visibilidade e impacto da produção científica; referências utilizadas em seus artigos; e informações adicionais. 
Resultados: (1) A Análise Geral permitiu traçar o perfil da comunidade estudada, totalizando 88 docentes (Ativos, Sêniores e Aposentados em atividade) e gerar uma base de produção científica com mais de 10 mil documentos das mais diversas tipologias; para a (2) A Análise Amostral, considerou somente os docentes Ativos e sua produção em periódicos (domésticos e estrangeiros) e possibilitou a identificação de nove diferentes perfis de publicação, dos quais selecionou-se um docente por perfil; (3) As entrevistas com os docentes propiciaram o desenvolvimento dos relatórios/perfis bibliométricos de cada um. Observou-se que, dos nove docentes, apenas dois não tiveram evolução de sua produção rumo à internacionalização; em termos de visibilidade, constatou-se que a mediana do percentual de artigos publicados em periódicos indexados na WoS foi de $68,75 \%$; quanto à colaboração internacional, a mediana foi de 56,10\%; e a mediana de artigos publicados no 10 Quartil de periódicos do JCR foi de $41,18 \%$. O método adaptado nesta pesquisa mostrou-se funcional e atento às melhores práticas de comunicação científica, apresentando-se como uma ferramenta promissora a ser utilizada em avaliações institucionais. Considerações Finais: $O$ estudo constatou a aplicabilidade, reprodutibilidade e adaptabilidade do método analisado e concluiu que a utilização do método como um todo pode trazer benefícios, pelo fato de permitir uma análise detalhada da produção e impacto da pesquisa realizada, com o adicional de não o fazer de maneira estática, mas considerando aspectos contextuais, além de evoluções ao longo do tempo.

Palavras-chave: Avaliação bibliométrica individual. Bibliometria. Nível Micro. Comunicação científica. Avaliação institucional. Internacionalização. 


\begin{tabular}{|c|}
\hline 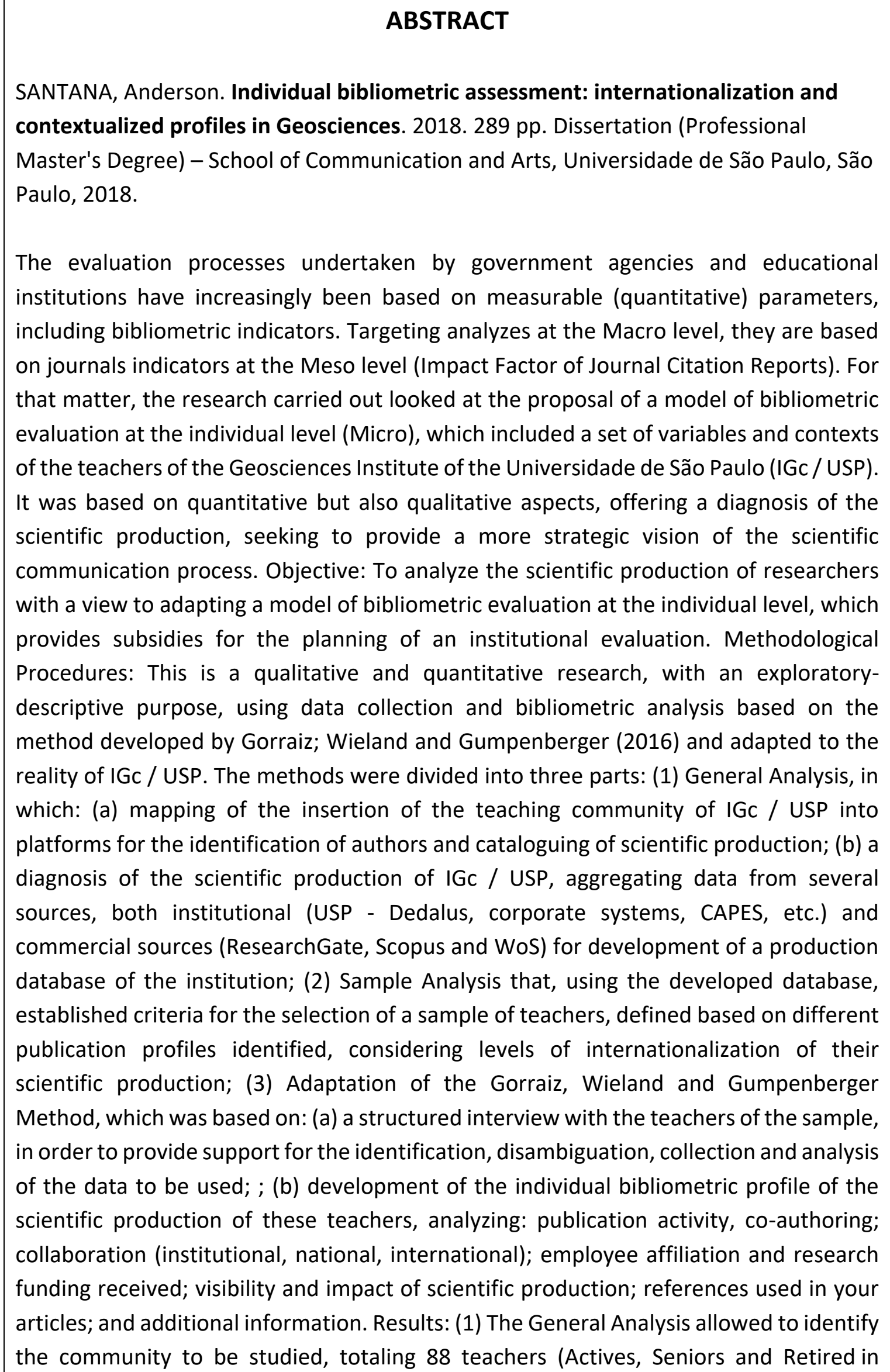 \\
\hline
\end{tabular}


activity) which allowed to generate a scientific production base with more than 10 thousand documents of the most diverse types; for the (2) Sampling Analysis, only Active teachers and their production in journals (domestic and foreign) were considered, allowing the identification of nine different publication profiles, from which one teacher was selected by profile; (3) finally, the interviews with the teachers were carried out, and later the development of the reports / bibliometric profiles of each one. It was observed that, of the nine teachers, only two did not have an evolution of their production towards internationalization; in terms of visibility, it was found that the median percentage of articles published in journals indexed in WoS was 68.75\%; as for international collaboration, the median was $56.10 \%$; and the median of articles published in the 1 st Quartile of JCR journals was $41.18 \%$. The method adapted in this research proved to be functional and attentive to the best practices of scientific communication, presenting itself as a promising tool to be used in institutional evaluations. Final Considerations: The study verified the applicability, reproducibility and adaptability of the analyzed method and concludes that the use of the method as a whole can bring benefits, as it allows a detailed analysis of the production and impact of the research performed, with the additional to not do it in a static way, but considering contextual aspects, besides evolutions over time.

Keywords: Individual bibliometric assessment. Bibliometrics. Micro Level. Scientific communication. Institutional evaluation. Internationalization. 


\section{LISTA DE FIGURAS}

Figura 1 - Fluxograma de desenvolvimento da Base de Dados da Produção Intelectual do IGc/USP.

Figura 2 - Distribuição percentual de produções do tipo Eventos e Periódicos com nacionalidade Doméstica por Departamento

Figura 3 - Fluxograma para criação de perfil de publicação dos Docentes do IGc/USP 84 



\section{LISTA DE TABELAS}

Tabela 1 - Distribuição da Produção Intelectual do IGc/USP indexada no Banco Dedalus por tipo de publicação 80

Tabela 2 - Distribuição da Produção Intelectual do IGc/USP indexada no Banco Dedalus distribuída por Nacionalidade 80

Tabela 3 - Distribuição dos docentes analisados do IGC/USP por categoria. 81

Tabela 4 - Distribuição dos Docentes Ativos por Departamentos do IGc/USP e Função

Tabela 5 - Distribuição da Produção de Artigos de Periódicos do IGc/USP indexada no Banco Dedalus distribuída por Nacionalidade 95

Tabela 6 - Produção de Artigos de Periódicos do IGc/USP indexada no Banco Dedalus distribuída pelas Avaliações da CAPES e por Nacionalidade compreendendo todas as categorias de docentes (Ativos, Aposentados e Sêniores) credenciados na Pós-Graduação 96

Tabela 7 - Produção de Artigos de Periódicos do IGc/USP indexada no Banco Dedalus distribuída pelas Avaliações da CAPES e por Nacionalidade compreendendo somente docentes Ativos credenciados na Pós-Graduação em ao menos um período de Avaliação

Tabela 8 - Produção de Artigos de Periódicos do IGc/USP indexada no Banco Dedalus distribuída pelas Avaliações da CAPES e por Nacionalidade compreendendo somente docentes Ativos credenciados na Pós-Graduação em dois ou mais períodos de Avaliação.

Tabela 9 - Produção de Artigos de Periódicos do IGc/USP indexada no Banco Dedalus distribuída pelos Departamentos, Avaliações da CAPES e por Nacionalidade compreendendo somente docentes Ativos credenciados na Pós-Graduação em dois ou mais períodos de Avaliação 98

Tabela 10 - Distribuição da Amostra Docente por Departamentos e Função na Carreira USP. 99

Tabela 11 - Produção Intelectual do Docente 01 registrada no Dedalus distribuída por tipo de publicação 101

Tabela 12 - Artigos do Docente 01 indexados na WoS Core Collection distribuídos por título de periódico.

Tabela 13 - Quantidade de autores nos artigos com participação do Docente 01 ..... 103

Tabela 14 - Artigos distribuídos por quantidade de autores e posição na autoria do Docente 01 nos artigos em que participa. 103

Tabela 15 - Quantidade de países dos autores que publicaram nos artigos com

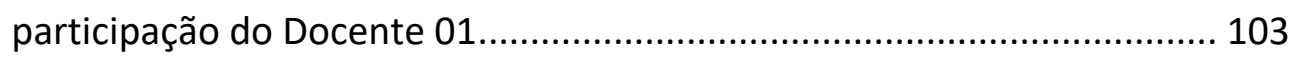

Tabela 16 - Países dos autores que publicaram nos artigos com participação do Docente 01 104 
Tabela 17 - Quantidade de instituições dos autores que publicaram nos artigos com participação do Docente 01

Tabela 18 - Distribuição das Instituições por países dos autores que publicaram com o Docente 01 105

Tabela 19 - Agências de Fomento que apoiaram as pesquisas que geraram as publicações com participação do Docente 01, distribuídas por ano ........ 106

Tabela 20 - Artigos publicados pelo Docente 01 distribuídos por Ciclos de Avaliação da CAPES e indexados em periódicos do 10 Quartil do FI/JCR 107

Tabela 21 - Artigos publicados pelo Docente 01 distribuídos por Ciclos de Avaliação da CAPES e classificação do periódico nos estratos Qualis da área de avaliação das Geociências 109

Tabela 22 - Artigos publicados pelo Docente 01 distribuídos segundo instituições que colaboraram duas ou mais vezes e Ciclos de Avaliação da CAPES, com indicação do percentual de artigos no 1 o Quartil do JCR. 109

Tabela 23 - Impacto dos artigos do Docente 01 distribuídos por ano de publicação. 111 Tabela 24 - Lista de Referências utilizadas nos artigos do Docente 01 distribuídas pelas Zonas 1 e 2 de Bradford

Tabela 25 - Quantidade de publicações citadas pelo Docente 01 distribuídas pelas Zonas de Bradford.

Tabela 26 - Lista de periódicos nos quais o Docente 01 publicou seus artigos com indicação das Zonas de Bradford.

Tabela 27 - Idade das Referências citadas nos artigos do Docente 01 114

Tabela 28 - Produção Intelectual do Docente 04 registrada no Dedalus distribuída por tipo de publicação 116

Tabela 29 - Artigos do Docente 04 indexados na WoS Core Collection distribuídos por título de periódico 117

Tabela 30 - Quantidade de autores nos artigos com participação do Docente 04 ..... 118 Tabela 31 - Artigos distribuídos por quantidade de autores e posição na autoria do Docente 04 nos artigos em que participa.

Tabela 32 - Quantidade de países dos autores que publicaram nos artigos com participação do Docente 04 . 119

Tabela 33 - Países dos autores que publicaram nos artigos com participação do Docente 04.

Tabela 34 - Quantidade de instituições dos autores que publicaram nos artigos com participação do Docente 04

Tabela 35 - Distribuição das Instituições por países dos autores que publicaram com o Docente 04 120

Tabela 36 - Agências de Fomento que apoiaram as pesquisas que geraram as publicações com participação do Docente 04, distribuídas por ano

Tabela 37 - Artigos publicados pelo Docente 04 distribuídos por Ciclos de Avaliação da CAPES e indexados em periódicos do 10 Quartil do Fl/JCR 
Tabela 38 - Artigos publicados pelo Docente 04 distribuídos por Ciclos de Avaliação da CAPES e classificação do periódico nos estratos Qualis da área de avaliação das Geociências

Tabela 39 - Artigos publicados pelo Docente 04 distribuídos segundo instituições que colaboraram duas ou mais vezes e Ciclos de Avaliação da CAPES, com indicação do percentual de artigos no 1으 Quartil do JCR

Tabela 40 - Impacto dos artigos do Docente 04 distribuídos por ano de publicação. 125 Tabela 41 - Lista de Referências utilizadas nos artigos do Docente 04 distribuídas pelas Zonas 1 e 2 de Bradford.

Tabela 42 - Quantidade de publicações citadas pelo Docente 04 distribuídas pelas Zonas de Bradford.

Tabela 43 - Lista de periódicos nos quais o Docente 04 publicou seus artigos com indicação das Zonas de Bradford.............................................................. 128

Tabela 44 - Idade das Referências citadas nos artigos do Docente 04 ....................... 129

Tabela 45 - Produção Intelectual do Docente 05 registrada no Dedalus distribuída por tipo de publicação

Tabela 46 - Artigos do Docente 05 indexados na WoS Core Collection distribuídos por título de periódico

Tabela 47 - Quantidade de autores nos artigos com participação do Docente 05 ..... 132

Tabela 48 - Artigos distribuídos por quantidade de autores e posição na autoria do Docente 05 nos artigos em que participa.

Tabela 49 - Quantidade de países dos autores que publicaram nos artigos com participação do Docente 05

Tabela 50 - Países dos autores que publicaram nos artigos com participação do Docente 05.

Tabela 51 - Quantidade de instituições dos autores que publicaram nos artigos com participação do Docente 05 .

Tabela 52 - Distribuição das Instituições por países dos autores que publicaram com o Docente 05

Tabela 53 - Agências de Fomento que apoiaram as pesquisas que geraram as publicações com participação do Docente 05 , distribuídas por ano

Tabela 54 - Artigos publicados pelo Docente 05 distribuídos por Ciclos de Avaliação da CAPES e indexados em periódicos do 10 Quartil do FI/JCR 139

Tabela 55 - Artigos publicados pelo Docente 05 distribuídos por Ciclos de Avaliação da CAPES e classificação do periódico nos estratos Qualis da área de avaliação das Geociências 140

Tabela 56 - Artigos publicados pelo Docente 05 distribuídos segundo instituições que colaboraram duas ou mais vezes e Ciclos de Avaliação da CAPES, com indicação do percentual de artigos no 10 Quartil do JCR. 142

Tabela 57 - Impacto dos artigos do Docente 05 distribuídos por ano de publicação. 143 
Tabela 58 - Lista de Referências utilizadas nos artigos do Docente 05 distribuídas pelas Zonas 1 e 2 de Bradford.

Tabela 59 - Quantidade de publicações citadas pelo Docente 05 distribuídas pelas Zonas de Bradford.

Tabela 60 - Lista de periódicos nos quais o Docente 05 publicou seus artigos com indicação das Zonas de Bradford............................................................. 148

Tabela 61 - Idade das Referências citadas nos artigos do Docente 05 ....................... 149

Tabela 62 - Produção Intelectual do Docente 06 registrada no Dedalus distribuída por tipo de publicação

Tabela 63 - Artigos do Docente 06 indexados na WoS Core Collection distribuídos por título de periódico

Tabela 64 - Quantidade de autores nos artigos com participação do Docente 06 ..... 152

Tabela 65 - Artigos distribuídos por quantidade de autores e posição na autoria do Docente 06 nos artigos em que participa.

Tabela 66 - Quantidade de países dos autores que publicaram nos artigos com participação do Docente 06

Tabela 67 - Países dos autores que publicaram nos artigos com participação do Docente 06.

Tabela 68 - Quantidade de instituições dos autores que publicaram nos artigos com participação do Docente 06

Tabela 69 - Distribuição das Instituições por países dos autores que publicaram com o Docente 06 154

Tabela 70 - Agências de Fomento que apoiaram as pesquisas que geraram as publicações com participação do Docente 06, distribuídas por ano ........ 155

Tabela 71 - Artigos publicados pelo Docente 06 distribuídos por Ciclos de Avaliação da CAPES e indexados em periódicos do 10 Quartil do Fl/JCR 156

Tabela 72 - Artigos publicados pelo Docente 06 distribuídos por Ciclos de Avaliação da CAPES e classificação do periódico nos estratos Qualis da área de avaliação das Geociências

Tabela 73 - Artigos publicados pelo Docente 06 distribuídos segundo instituições que colaboraram duas ou mais vezes e Ciclos de Avaliação da CAPES, com indicação do percentual de artigos no 10 Quartil do JCR. 158

Tabela 74 - Impacto dos artigos do Docente 06 distribuídos por ano de publicação. 159 Tabela 75 - Lista de Referências utilizadas nos artigos do Docente 06 distribuídas pelas Zonas 1 e 2 de Bradford 160

Tabela 76 - Quantidade de publicações citadas pelo Docente 06 distribuídas pelas Zonas de Bradford. 160

Tabela 77 - Lista de periódicos nos quais o Docente 06 publicou seus artigos com indicação das Zonas de Bradford. 161

Tabela 78 - Idade das Referências citadas nos artigos do Docente 06 162 
Tabela 79 - Produção Intelectual do Docente 08 registrada no Dedalus distribuída por tipo de publicação

Tabela 80 - Artigos do Docente 08 indexados na WoS Core Collection distribuídos por título de periódico. 164

Tabela 81 - Quantidade de autores nos artigos com participação do Docente 08..... 164

Tabela 82 - Artigos distribuídos por quantidade de autores e posição na autoria do Docente 08 nos artigos em que participa. 165

Tabela 83 - Quantidade de países dos autores que publicaram nos artigos com participação do Docente 08................................................................... 165

Tabela 84 - Países dos autores que publicaram nos artigos com participação do Docente 08.

Tabela 85 - Quantidade de instituições dos autores que publicaram nos artigos com participação do Docente 08 . 166

Tabela 86 - Distribuição das Instituições por países dos autores que publicaram com o Docente 08 166

Tabela 87 - Agências de Fomento que apoiaram as pesquisas que geraram as publicações com participação do Docente 08, distribuídas por ano 167

Tabela 88 - Artigos publicados pelo Docente 08 distribuídos por Ciclos de Avaliação da CAPES e indexados em periódicos do 10 Quartil do FI/JCR 168

Tabela 89 - Artigos publicados pelo Docente 08 distribuídos por Ciclos de Avaliação da CAPES e classificação do periódico nos estratos Qualis da área de avaliação das Geociências 168

Tabela 90 - Artigos publicados pelo Docente 08 distribuídos segundo instituições que colaboraram duas ou mais vezes e Ciclos de Avaliação da CAPES, com indicação do percentual de artigos no 1 ㅇ Quartil do JCR.

Tabela 91 - Impacto dos artigos do Docente 08 distribuídos por ano de publicação. 170 Tabela 92 - Lista de Referências utilizadas nos artigos do Docente 08 distribuídas pelas Zonas 1 e 2 de Bradford..

Tabela 93 - Quantidade de publicações citadas pelo Docente 08 distribuídas pelas Zonas de Bradford.

Tabela 94 - Lista de periódicos nos quais o Docente 08 publicou seus artigos com indicação das Zonas de Bradford.

Tabela 95 - Idade das Referências citadas nos artigos do Docente 08 173

Tabela 96 - Produção Intelectual do Docente 12 registrada no Dedalus distribuída por tipo de publicação 175

Tabela 97 - Artigos do Docente 12 indexados na WoS Core Collection distribuídos por título de periódico 176

Tabela 98 - Quantidade de autores nos artigos com participação do Docente 12 ..... 177 Tabela 99 - Artigos distribuídos por quantidade de autores e posição na autoria do Docente 12 nos artigos em que participa. 177 
Tabela 100 - Quantidade de países dos autores que publicaram nos artigos com

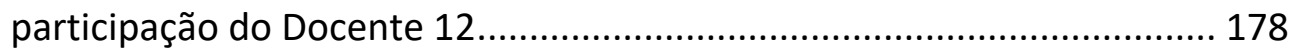

Tabela 101 - Países dos autores que publicaram nos artigos com participação do

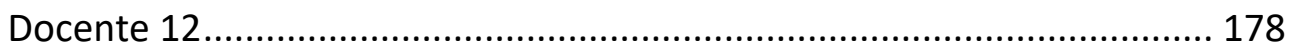

Tabela 102 - Quantidade de instituições dos autores que publicaram nos artigos com participação do Docente 12 179

Tabela 103 - Distribuição das Instituições por países dos autores que publicaram com o Docente 12

Tabela 104 - Agências de Fomento que apoiaram as pesquisas que geraram as publicações com participação do Docente 12 , distribuídas por ano 181

Tabela 105 - Artigos publicados pelo Docente 12 distribuídos por Ciclos de Avaliação da CAPES e indexados em periódicos do 1ㅇ Quartil do FI/JCR.

Tabela 106 - Artigos publicados pelo Docente 12 distribuídos por Ciclos de Avaliação da CAPES e classificação do periódico nos estratos Qualis da área de avaliação das Geociências 183

Tabela 107 - Artigos publicados pelo Docente 12 distribuídos segundo instituições que colaboraram duas ou mais vezes e Ciclos de Avaliação da CAPES, com indicação do percentual de artigos no 10 Quartil do JCR. 185

Tabela 108 - Impacto dos artigos do Docente 12 distribuídos por ano de publicação 186 Tabela 109 - Lista de Referências utilizadas nos artigos do Docente 12 distribuídas pelas Zonas 1 e 2 de Bradford 187

Tabela 110 - Quantidade de publicações citadas pelo Docente 12 distribuídas pelas Zonas de Bradford 189

Tabela 111 - Lista de periódicos nos quais o Docente 12 publicou seus artigos com indicação das Zonas de Bradford.............................................................. 190

Tabela 112 - Idade das Referências citadas nos artigos do Docente 12 ..................... 191 Tabela 113 - Produção Intelectual do Docente 14 registrada no Dedalus distribuída por tipo de publicação 192

Tabela 114 - Artigos do Docente 14 indexados na WoS Core Collection distribuídos por título de periódico 193

Tabela 115 - Quantidade de autores nos artigos com participação do Docente 14 ... 193 Tabela 116 - Artigos distribuídos por quantidade de autores e posição na autoria do Docente 14 nos artigos em que participa............................................... 194

Tabela 117 - Quantidade de países dos autores que publicaram nos artigos com

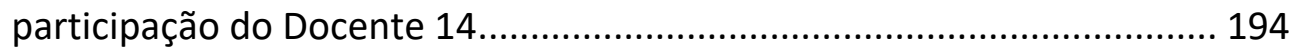

Tabela 118 - Países dos autores que publicaram nos artigos com participação do Docente 14 194

Tabela 119 - Quantidade de instituições dos autores que publicaram nos artigos com participação do Docente 14 195

Tabela 120 - Distribuição das Instituições por países dos autores que publicaram com o Docente 14 195 
Tabela 121 - Agências de Fomento que apoiaram as pesquisas que geraram as publicações com participação do Docente 14, distribuídas por ano ........ 196

Tabela 122 - Artigos publicados pelo Docente 14 distribuídos por Ciclos de Avaliação da CAPES e indexados em periódicos do 10 Quartil do FI/JCR.

Tabela 123 - Artigos publicados pelo Docente 14 distribuídos por Ciclos de Avaliação da CAPES e classificação do periódico nos estratos Qualis da área de avaliação das Geociências 197

Tabela 124 - Artigos publicados pelo Docente 14 distribuídos segundo instituições que colaboraram duas ou mais vezes e Ciclos de Avaliação da CAPES, com indicação do percentual de artigos no 10 Quartil do JCR. 198

Tabela 125 - Impacto dos artigos do Docente 14 distribuídos por ano de publicação 199 Tabela 126 - Lista de Referências utilizadas nos artigos do Docente 14 distribuídas pelas Zonas 1 e 2 de Bradford. 200

Tabela 127 - Quantidade de publicações citadas pelo Docente 14 distribuídas pelas Zonas de Bradford 201

Tabela 128 - Lista de periódicos nos quais o Docente 14 publicou seus artigos com indicação das Zonas de Bradford. 202

Tabela 129 - Idade das Referências citadas nos artigos do Docente 14 202

Tabela 130 - Produção Intelectual do Docente 15 registrada no Dedalus distribuída por tipo de publicação 204

Tabela 131 - Artigos do Docente 15 indexados na WoS Core Collection distribuídos por título de periódico 205

Tabela 132 - Quantidade de autores nos artigos com participação do Docente 15 ... 206 Tabela 133 - Artigos distribuídos por quantidade de autores e posição na autoria do Docente 15 nos artigos em que participa.................................................. 206

Tabela 134 - Quantidade de países dos autores que publicaram nos artigos com

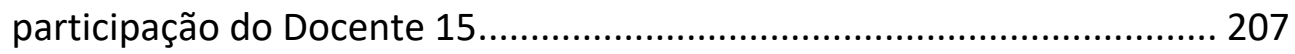

Tabela 135 - Países dos autores que publicaram nos artigos com participação do Docente 15. 207

Tabela 136 - Quantidade de instituições dos autores que publicaram nos artigos com participação do Docente 15 . 208

Tabela 137 - Distribuição das Instituições por países dos autores que publicaram com o Docente 15 208

Tabela 138 - Agências de Fomento que apoiaram as pesquisas que geraram as publicações com participação do Docente 15 , distribuídas por ano 211

Tabela 139 - Artigos publicados pelo Docente 15 distribuídos por Ciclos de Avaliação da CAPES e indexados em periódicos do 10 Quartil do FI/JCR

Tabela 140 - Artigos publicados pelo Docente 15 distribuídos por Ciclos de Avaliação da CAPES e classificação do periódico nos estratos Qualis da área de avaliação das Geociências 213 
Tabela 141 - Artigos publicados pelo Docente 15 distribuídos segundo instituições que colaboraram duas ou mais vezes e Ciclos de Avaliação da CAPES, com indicação do percentual de artigos no 1 으 Quartil do JCR.

Tabela 142 - Impacto dos artigos do Docente 15 distribuídos por ano de publicação 215

Tabela 143 - Lista de Referências utilizadas nos artigos do Docente 15 distribuídas pelas

Zonas 1 e 2 de Bradford.

Tabela 144 - Quantidade de publicações citadas pelo Docente 15 distribuídas pelas Zonas de Bradford 219

Tabela 145 - Lista de periódicos nos quais o Docente 15 publicou seus artigos com indicação das Zonas de Bradford. 219

Tabela 146 - Idade das Referências citadas nos artigos do Docente 15 220

Tabela 147 - Produção Intelectual do Docente 25 registrada no Dedalus distribuída por tipo de publicação

Tabela 148 - Artigos do Docente 25 indexados na WoS Core Collection distribuídos por título de periódico

Tabela 149 - Quantidade de autores nos artigos com participação do Docente 25 ... 224 Tabela 150 - Artigos distribuídos por quantidade de autores e posição na autoria do Docente 25 nos artigos em que participa.

Tabela 151 - Quantidade de países dos autores que publicaram nos artigos com participação do Docente 25 . 224

Tabela 152 - Países dos autores que publicaram nos artigos com participação do Docente 25 225

Tabela 153 - Quantidade de instituições dos autores que publicaram nos artigos com participação do Docente 25 . 225

Tabela 154 - Distribuição das Instituições por países dos autores que publicaram com o Docente 25 226

Tabela 155 - Agências de Fomento que apoiaram as pesquisas que geraram as publicações com participação do Docente 25 , distribuídas por ano 227

Tabela 156 - Artigos publicados pelo Docente 25 distribuídos por Ciclos de Avaliação da CAPES e indexados em periódicos do 1 o Quartil do $\mathrm{Fl} / \mathrm{JCR}$

Tabela 157 - Artigos publicados pelo Docente 25 distribuídos por Ciclos de Avaliação da CAPES e classificação do periódico nos estratos Qualis da área de avaliação das Geociências 228

Tabela 158 - Artigos publicados pelo Docente 25 distribuídos segundo instituições que colaboraram duas ou mais vezes e Ciclos de Avaliação da CAPES, com indicação do percentual de artigos no 10 Quartil do JCR.

Tabela 159 - Impacto dos artigos do Docente 25 distribuídos por ano de publicação 229

Tabela 160 - Lista de Referências utilizadas nos artigos do Docente 25 distribuídas pelas Zonas 1 e 2 de Bradford. 230

Tabela 161 - Quantidade de publicações citadas pelo Docente 25 distribuídas pelas Zonas de Bradford 
Tabela 162 - Lista de periódicos nos quais o Docente 25 publicou seus artigos com indicação das Zonas de Bradford........................................................... 233

Tabela 163 - Idade das Referências citadas nos artigos do Docente 25 ..................... 233 



\section{LISTA DE QUADROS}

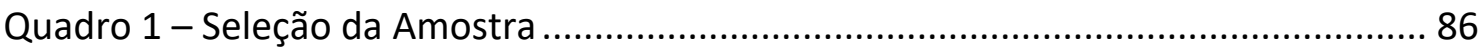

Quadro 2-Comparativo analítico do perfil bibliométrico dos docentes da amostra. 236 



\section{LISTA DE SIGLAS E ABREVIATURAS}

$\mathrm{A} \& \mathrm{HCl}$

CAA

CAPES

CEE

CERT

CNPq

CPA

CPCI-S

$\mathrm{CPCl}-\mathrm{SSH}$

CRUESP

CT\&।

CTC-ES

DOAJ

$\mathrm{ESCl}$

FAPESP

$\mathrm{FI}$

GMG

GSA

IES

IGc

INEP

ISSN

JCR

JIF

LDB

PPGGG

PPGMP

PPGRMH

Q1

RDIDP
Arts \& Humanities Citation Index

Comissão de Assuntos Acadêmicos

Coordenação de Aperfeiçoamento de Pessoal de Nível Superior

Conselho Estadual de Educação

Comissão Especial de Regimes de Trabalho

Conselho Nacional de Desenvolvimento Científico e Tecnológico

Comissão Permanente de Avaliação

Conference Proceedings Citation Index - Science

Conference Proceedings Citation Index - Social Science \& Humanities

Conselho de Reitores das Universidades Estaduais de Paulistas

Ciência, Tecnologia \& Inovação

Conselho Técnico-Científico da Educação Superior

Directory of Open Access Journals

Emerging Sources Citation Index

Fundação de Amparo à Pesquisa do Estado de São Paulo

Fator de Impacto

Departamento de Mineralogia e Geotectônica

Departamento de Geologia Sedimentar e Ambiental

Instituições de Ensino Superior

Instituto de Geociências

Instituto Nacional de Estudos e Pesquisas Educacionais Anísio Teixeira

International Standard Serial Numbers

Journal Citation Reports

Journal Impact Factor

Lei das Diretrizes e Bases da Educação Nacional

Programa de Pós-Graduação em Geoquímica e Geotectônica

Programa de Pós-Graduação em Mineralogia e Petrologia

Programa de Pós-Graduação em Recursos Minerais e Hidrogeologia

Ciclo de Avaliação Quadrienal de 2017

Regime de Dedicação Integral à Docência e à Pesquisa 


$\begin{array}{ll}\text { SCl } & \text { Science Citation Index } \\ \text { SCI-EXPANDED } & \text { Science Citation Index Expanded } \\ \text { SNPG } & \text { Sistema Nacional de Pós-Graduação } \\ \text { SSCI } & \text { Social Sciences Citation Index } \\ \text { T1 } & \text { Ciclo de Avaliação Trienal de } 2004 \\ \text { T2 } & \text { Ciclo de Avaliação Trienal de } 2007 \\ \text { T3 } & \text { Ciclo de Avaliação Trienal de } 2010 \\ \text { T4 } & \text { Ciclo de Avaliação Trienal de } 2013 \\ \text { UNESP } & \text { Universidade Estadual Paulista } \\ \text { UNICAMP } & \text { Universidade Estadual de Campinas } \\ \text { USP } & \text { Universidade de São Paulo } \\ \text { WoS } & \text { Web of Science Core Collection }\end{array}$




\section{SUMÁRIO}

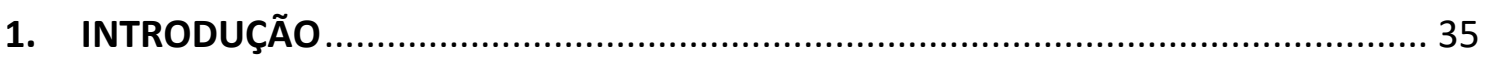

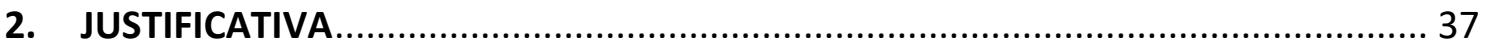

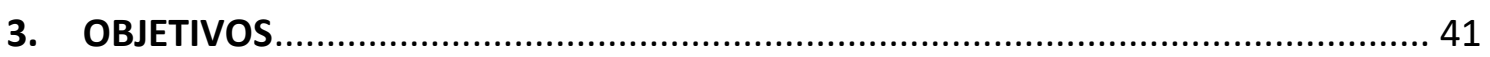

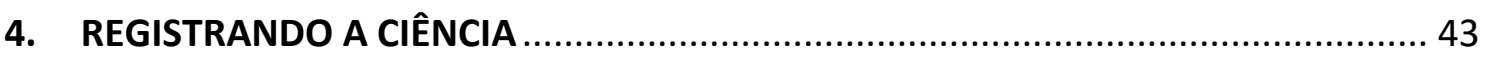

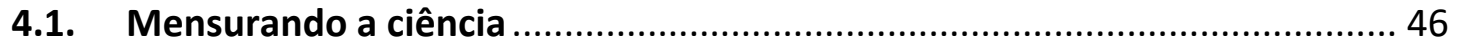

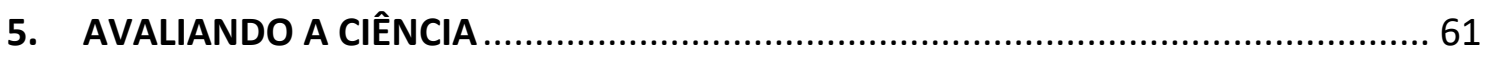

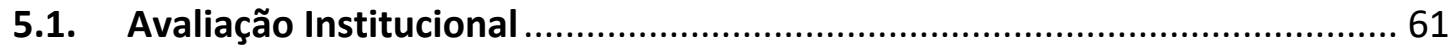

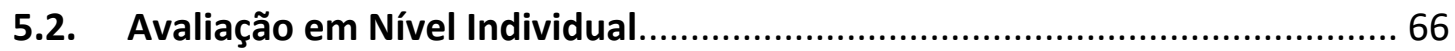

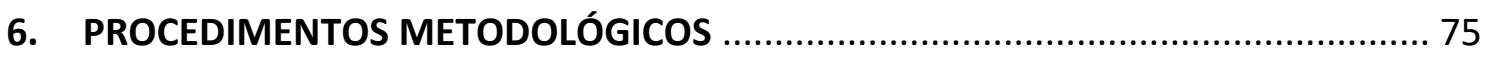

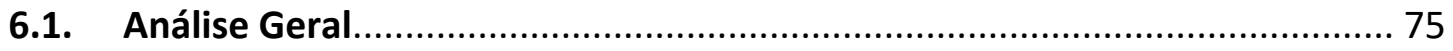

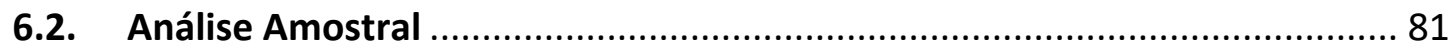

6.3. Adaptação do Método de Gorraiz, Wieland e Gumpenberger ..................... 86

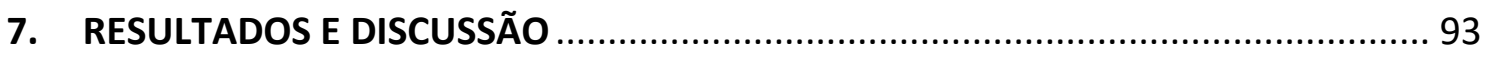

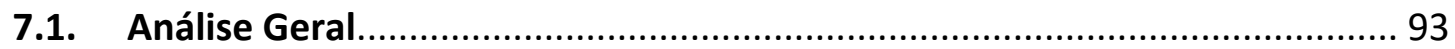

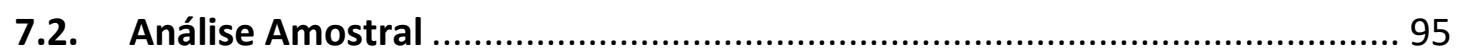

7.3. Adaptação do Método de Gorraiz, Wieland e Gumpenberger .................... 99

7.3.1 Entrevista com os docentes e Relatório/Perfil Bibliométrico individual . 100

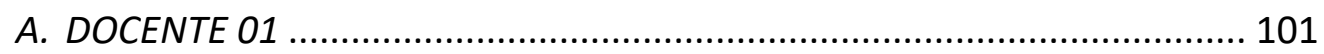

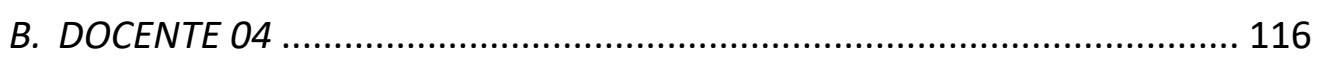

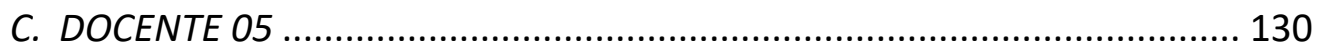

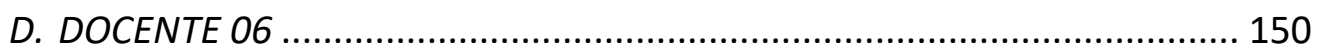

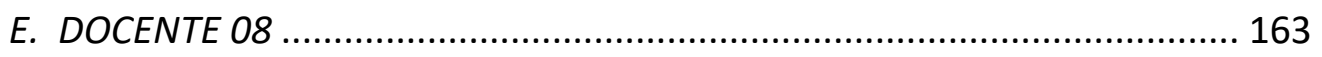

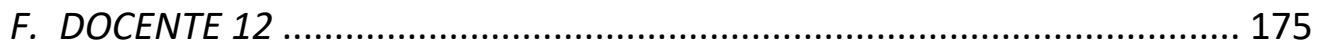

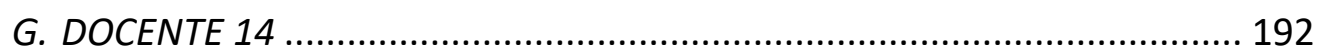

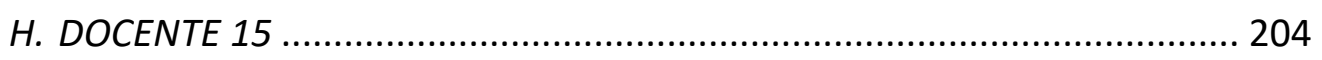

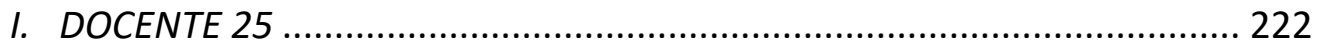

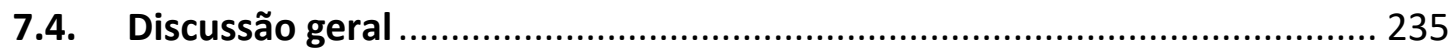

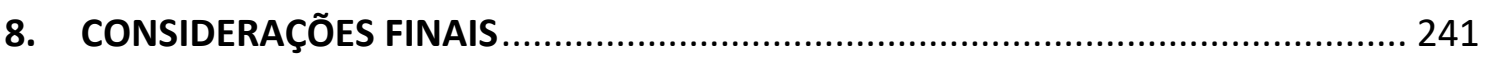

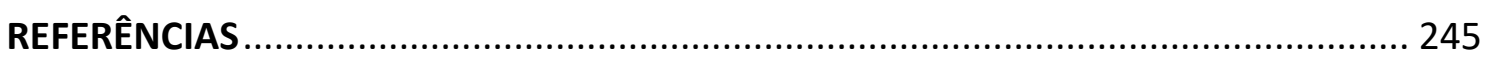

Apêndice A - Questionário para elaboração do Relatório/Perfil Bibliométrico........... 255 
Apêndice B - Adaptação do questionário para elaboração do Relatório/Perfil Bibliométrico de Gorraiz; Wieland; Gumpenberger (2016)

Apêndice C - Carta convite para participação em entrevista para pesquisa de

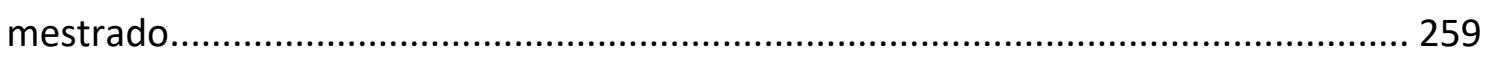

Apêndice D - Termo de Consentimento Livre e Esclarecido ....................................... 261

Apêndice E - Síntese das entrevistas realizadas com os Docentes da amostra .......... 263

Apêndice F - Mapeamento da inserção da comunidade de docentes do IGc/USP em plataformas de identificação de autores e registro da produtividade científica .......... 283

Apêndice G - Credenciamento dos docentes da amostra nos ciclos de Avaliação da CAPES 


\section{INTRODUÇÃO}

O processo de comunicação dos resultados de pesquisa tem evoluído ao longo do tempo e se constituído como um dos principais capitais tanto intelectual quanto financeiro da ciência. Nesse panorama, a necessidade de se avaliar a ciência tem se tornado temática recorrente nas esferas governamentais em níveis internacional e nacional, bem como nas instituições de fomento à pesquisa.

Políticas de incentivo e de avaliação da ciência têm sido pauta estratégica há mais de meio século no Brasil, culminando com o surgimento de órgãos de reconhecida importância, como a Coordenação de Aperfeiçoamento de Pessoal de Nível Superior (CAPES) responsável pelo credenciamento e avaliação dos cursos de Pós-Graduação. Seu processo de avaliação também tem se aperfeiçoado e fomentado uma forte internacionalização da ciência brasileira.

Por outro lado, as Instituições de Ensino Superior também têm se organizado e estimulado processos avaliativos institucionais, com vistas a uma reflexão sobre o papel da Universidade e os rumos a serem seguidos no sentido de internacionalizarem o conhecimento gerado em suas unidades de ensino e pesquisa.

Nesse sentido, a bibliometria tem proposto instrumentos de apoio na avaliação institucional, possibilitando, por meio de sua longa carta de indicadores e métricas, a obtenção de resultados que permitem gerar um quadro de avaliação quantitativo e, dependendo do nível de análise empreendido, qualitativo. No entanto, quando se trata de avaliação na perspectiva de micro de análise, ou seja, no nível do docente/pesquisador, o terreno começa a se tornar mais pantanoso e desconhecido, pois não são muitos os estudos que tratam da avaliação bibliométrica em nível individual com uma visão holística e contextualizada da carreira do avaliado.

Assim, propõe-se uma análise da adaptação de um modelo de avaliação bibliométrica individual (pesquisador/docente) que considere a diversidade da cultura de pesquisa da área a ser analisada e a pertinência dos estudos regionais. Tal avaliação terá como objeto de análise a produção científica dos docentes do Instituto de Geociências da Universidade de São Paulo (IGc/USP). 
A Universidade de São Paulo ${ }^{1}$ possui em seu quadro funcional mais de seis mil docentes distribuídos em mais de 50 unidades e órgãos de ensino e pesquisa, institutos especializados e museus. No final do ano de $2016^{2}$ foi publicado o novo estatuto docente que prevê a realização de avaliações tanto institucionais como individuais. Tal mudança corrobora a necessidade de se criar parâmetros e critérios de avaliação que sejam replicáveis e passíveis de simples validação. Logo, acreditamos que a proposta ora apresentada se insere plenamente na agenda da Universidade, bem como apresenta uma possibilidade de estabelecimento de parâmetros mínimos à avaliação citada.

As bibliotecas da USP são responsáveis, desde a década de 1980, pela coleta e registro da produção intelectual dos docentes da Universidade. Dessa forma, esses órgãos possuem experiência no tratamento e análise desses dados, possibilitando a geração de informações qualificadas e de indicadores bibliométricos validados; além disso, são as bibliotecas, por meio do Sistema Integrado de Bibliotecas, as responsáveis pelos processos de assinatura, capacitação e uso das bases de dados bibliométricas da USP.

Assim, o problema a ser abordado na presente pesquisa se insere na necessidade de se vislumbrar a proposição de um modelo de avaliação bibliométrica individual, que abarque o máximo de variáveis e de contextos dos docentes da Universidade de São Paulo no que tange os aspectos quantitativos e qualitativos de suas carreiras, apresentando-Ihes um diagnóstico de suas produções científicas que lhes propicie uma visão mais estratégica do processo de comunicação científica.

\footnotetext{
${ }^{1}$ USP em Número 2015 (com dados de 2014): https://uspdigital.usp.br/anuario/AnuarioControle

${ }^{2}$ Estatuto do Docente USP: http://sites.usp.br/cert/estatuto-docente/
} 


\section{JUSTIFICATIVA}

Os processos de avaliação empreendidos por agências governamentais e instituições de ensino vêm crescentemente se pautando em parâmetros mensuráveis (quantitativos), incluindo os indicadores bibliométricos.

A Pós-Graduação no Brasil, por exemplo, leva em consideração como critério de maior peso na avaliação dos programas a produção de artigos científicos e, em face da quantidade imensurável de periódicos existentes, acaba por utilizar indicadores bibliométricos e listas seletivas de títulos como o Fator de Impacto (FI) do Journal Citation Reports (JCR) (MUGNAINI, 2015).

De fato, o ato de avaliar é dificultoso, principalmente em escalas continentais como é o caso do Brasil; portanto, o uso de métricas capazes de medir e de apresentar os dados de forma simples e objetiva acaba por ser preferido em detrimento do uso de critérios de ordem qualitativa, geralmente difíceis de serem obtidos e analisados.

Deve-se observar o nível de agregação dos dados utilizados: micro, meso ou macro. No nível Micro encontram-se os dados sobre publicações ou citações referentes a um artigo, um projeto, uma pessoa ou um grupo de pessoas. No nível Meso os dados de um grupo de publicações, um subcampo de pesquisa ou um departamento/instituição. E no nível Macro, trataria dos dados de todas as publicações existentes acerca de uma disciplina científica em seu conjunto ou num grupo de países/instituições (VINKLER, 1988).

Quanto à questão dos públicos-alvo no uso das pesquisas bibliométricas, estes são definidos por Glänzel (2003) como: (i) Bibliometria para pesquisadores desta especialidade (trata-se do domínio da pesquisa metodológica - bibliometria básica); (ii) Bibliometria para disciplinas científicas (trata-se do maior e mais diversificado grupo de interesse, uma vez que são pesquisadores em busca de análises para suas áreas de domínio - Informação Científica); (iii) Bibliometria para política e gestão científica (tratase do domínio da avaliação da pesquisa nas estruturas nacionais, regionais e institucionais da ciência - Política Científica).

No entanto, pesquisadores alertam para uso exacerbado da bibliometria e destacam que sua aplicação não deveria se refletir na avaliação de resultados de pesquisa, tampouco poderia ser encarada de forma isolada (um único indicador 
embasando uma decisão) ou como verdade absoluta, dado que as questões de contexto, cultura e regionalismo das áreas deveriam ser trabalhadas em conjunto (GLÄNZEL; DEBACKERE, 2003; HAUSTEIN; LARIVIÈRE, 2015; RAFOLS et al., 2016).

Dessa forma, duas abordagens podem ser aplicadas à bibliometria: a avaliativa, que procura analisar o impacto da pesquisa, com vistas a comparar as contribuições científicas relativas de dois ou mais indivíduos ou grupos, em geral subsidiando o desenvolvimento de políticas; e a relacional, que procura iluminar relacionamentos dentro da pesquisa, como a estrutura cognitiva dos campos de pesquisa, o surgimento de novas frentes de pesquisa ou de padrões de coautoria nacionais e internacionais (THELWALL, 2008). Assim, o ideal seria que bibliometria avaliativa, que tem sido utilizada por órgãos decisórios em escala mundial há tanto tempo, lograsse a inclusão de aspectos relacionados à avaliação qualitativa da ciência.

Nesse sentido, um grupo de pesquisadores da bibliometria lançou o "Manifesto de Leiden", um documento estabelecendo princípios norteadores para avaliação da pesquisa bibliométrica, refletindo sobre questões como fortalecimento da pesquisa regional, transparência e abertura de dados coletados e sua subsequente análise, considerações quanto às diferentes práticas de publicação, critério no uso dos indicadores, foco nos aspectos qualitativos da carreira em análises individuais de pesquisadores, dentre outros (HICKS et al., 2015).

Entrementes, as instituições de ensino em suas avaliações institucionais, acabam por decorrer dos mesmos modelos utilizados em âmbito governamental para avaliar seu desempenho, e assim melhorar as avaliações de seus programas de pósgraduação.

Além disso, outra questão tem tomado conta das agendas das principais universidades brasileiras: os rankings universitários. Eles têm influenciado muitas instituições, homogeneizando suas políticas e criando uma cultura de avaliação baseada meramente em indicadores (FAUSTO; MUGNAINI, 2013). Tal questão é delicada e deveria ser tratada com cautela e método pelas universidades, pois estas não devem moldar sua política institucional para o atendimento de critérios tão díspares e, por vezes, aquém de seus perfis e objetivos.

Ademais, uma avaliação institucional coerente que vise efetivamente o mapeamento de seus potenciais deve levar em conta os aspectos de nível micro, seus 
docentes e pesquisadores. Esses indivíduos são um dos principais componentes de uma universidade, são aqueles que se encarregam de manter os principais vínculos nas cooperações internacionais e que produzem e fomentam a ciência, além de assumirem os principais postos da gestão da instituição.

Muitos autores têm desenvolvido métodos de avaliação bibliométrica individual, focando em dados passíveis de extração das bases de dados e mensuração por meio de medidas bibliométricas (COSTAS; VAN LEEUWEN; BORDONS, 2010; ABRAMO; CICERO; D'ANGELO, 2013; GLÄNZEL, 2014; WILDGAARD, 2016). Entrementes, uma iniciativa já aplicada e com resultados positivos é apresentada por Gorraiz; Wieland e Gumpenberger (2016), pesquisadores do Departamento de Estratégias Bibliométricas e de Publicação dos Serviços de Arquivo e Biblioteca da Universidade de Viena, Áustria. Os autores propõem uma série de critérios para o estabelecimento de relatórios bibliométricos individualizados, pesando especificidades das áreas de conhecimento, entrevistas, além de uso de indicadores alternativos, dentre outros.

Dessa forma, a presente pesquisa pretende analisar tal iniciativa e aplicá-la no âmbito da USP, especificamente no IGc, em virtude de ser este o local no qual o mestrando desenvolve suas atividades profissionais.

A se considerar que as próximas avaliações da Universidade contemplarão os três níveis de análise, Macro (USP), Meso (IGc) e Micro (Docentes), torna-se premente a proposição de modelos de avaliação que apreciem critérios qualitativos e que respeitem as diferenças entre áreas e carreiras, como o proposto pelos vienenses.

Por este motivo, decidiu-se avaliar a adoção de tal método no IGc/USP, adaptando-o à realidade desta instituição. O IGc/USP foi fundado no ano de 1969 sob o nome de Instituto de Geociências e Astronomia e em 1972 passa a se denominar Instituto de Geociências, enquanto as áreas de Astronomia e Geofísica formam o Instituto Astronômico e Geofísico - atualmente denominado Instituto de Astronomia, Geofísica e Ciências Atmosféricas. No entanto, o curso de Geociências existe desde a fundação da USP em 1934. O IGc possui dois Departamentos: Mineralogia e Geotectônica (GMG) e Geologia Sedimentar e Ambiental (GSA) (UNIVERSIDADE DE SÃO PAULO. INSTITUTO DE GEOCIÊNCIAS, 2017).

O IGc não possui ainda uma cultura de uso de indicadores e avaliações de pesquisa, porém, seu Serviço de Biblioteca e Documentação é responsável pela coleta, 
registro, preservação e acesso à produção intelectual gerada pelos docentes conforme estabelecido na Resolução USP no 2858 de 1985 (UNIVERSIDADE DE SÃO PAULO, 1985).

A Biblioteca do Instituto, além de desenvolver as atividades anteriormente expostas acerca da produção intelectual do IGc, gera anualmente relatórios de produção para a Diretoria. Atende ainda demandas dos docentes quanto à geração esporádica de dados bibliométricos de citação. O papel da biblioteca tem se modificado e tais questões estão sendo inseridas mais corriqueiramente na agenda do Instituto. 


\section{OBJETIVOS}

\section{Objetivo geral}

Analisar a produção científica de pesquisadores com base em um modelo de avaliação bibliométrica individual adaptado, visando obter subsídios para o planejamento de uma avaliação institucional.

\section{Objetivos específicos}

1. Mapear a inserção da comunidade de docentes do IGc/USP em plataformas de identificação de autores e registro da produção científica;

2. Desenvolver um diagnóstico da produção científica do IGc/USP verificando seu nível de publicação internacional;

3. Adaptar e aplicar o método de Gorraiz; Wieland e Gumpenberger (2016) para o delineamento do perfil da produção científica em Geociências da USP. 


\title{
4. REGISTRANDO A CIÊNCIA
}

O processo de fazer e comunicar a ciência tem sofrido constantes evoluções, mais tecnológicas que formais, afinal desde os primeiros registros em paredes de cavernas, perpassando pelos pergaminhos, pelo advento da imprensa no século XV e por seu derradeiro desfecho no século XX, com o surgimento dos computadores e da Internet - a maior revolução informacional da história, o modo de disseminar os resultados das pesquisas continuou praticamente o mesmo: escrita (periódicos e livros) ou oral (reuniões científicas e eventos).

No entanto, qual é o objetivo da ciência? Para Mueller e Passos, (2000, p. 14) seu objetivo não é tão somente "acumular informações nem expressar toda noção nãocontraditória; [...] é atingir um consenso no julgamento racional sobre o maior número de áreas e tão extensas quanto possível". O objetivo da ciência é avançar no sentido de desenvolver um conhecimento novo e os pesquisadores do passado sabiam que tal avanço somente seria possível se o processo fosse desenvolvido de forma coletiva, com a participação de sua comunidade.

\begin{abstract}
A literatura de um assunto científico é tão importante para ele quanto a própria pesquisa, pois esta não estaria completa se seus resultados não fossem divulgados. A publicação em periódicos científicos possibilita a disseminação ampla e relativamente rápida dos resultados de pesquisa, permitindo que sejam lidos, criticados e talvez utilizados (e então citados) por outrem. Os resultados de uma pesquisa são assim absorvidos por gerações subsequentes de pesquisadores. (MUELLER, 1995, p. 63)
\end{abstract}

Portanto, cabe aqui registrar o surgimento do principal meio que impulsionou tanto o desenvolvimento da ciência quanto a sua comunicação, os periódicos científicos. Até metade do século XVII os resultados de pesquisa eram compartilhados por meio de livros ou correspondências entre pesquisadores, ou ainda por intermédio dos encontros e eventos de renomadas autoridades das sociedades acadêmica e civil. E então, há aproximadamente 350 anos, surgiram os dois primeiros periódicos científicos, publicados com poucos meses de diferença no ano de 1665, o "Journal des Sçavans" (lançado na França) e o "Philosophical Transactions" (lançado na Inglaterra). Tais publicações tinham o intuito de estimular o avanço do conhecimento científico aproveitando os resultados dos demais colegas pesquisadores, evitando a duplicação de 
resultados, e estabelecendo os princípios de prioridade científica e revisão por pares. Além disso, tais veículos de publicação proporcionavam uma rápida distribuição e traziam relatos objetivos dos resultados das principais pesquisas (MEADOWS, 1999; LARIVIÈRE; HAUSTEIN; MONGEON, 2015).

Meadows (1999, p. 7) complementa destacando as razões para a criação dos periódicos:

Algumas eram específicas (como a expectativa de seus editores de que teriam lucro); algumas, gerais (como a crença de que para fazer novos descobrimentos era preciso que houvesse um debate coletivo). 0 motivo principal, contudo, encontra-se nessa necessidade de comunicação, do modo mais eficiente possível, com uma clientela crescente interessada em novas realizações. Ainda que a introdução do periódico fosse um passo lógico, suscitava implicações notáveis para a comunicação científica. Em particular, significava uma formalização do processo de comunicação.

Garvey (1979, p. ix) entende a comunicação científica como o processo das

atividades de troca de informações que ocorrem principalmente entre cientistas envolvidos ativamente na frente de pesquisa. Abrange a comunicação científica desde a discussão mais informal entre dois cientistas, até os aspectos formais da comunicação científica, tais como revistas, revisões, livros, etc.

Mueller (1995, p. 54) acrescenta ainda que "a comunicação científica, no entanto, não é necessária apenas para os cientistas que estão na fronteira da ciência: ela é uma atividade vital para todos os cientistas, em todos os estágios de suas carreiras". De fato, fazer ciência é a constante atividade de todo o cientista, porque todos buscam inovação, avanço, desenvolvimento de novos e melhores processos e técnicas. Isso é corroborado por Mugnaini (2006, p. 51)

O trabalho científico é um elemento universal e vital para o avanço da ciência, na qual 'nada se cria, nada se perde'. Diante de toda a literatura disponível, cabe ao cientista explorá-la e conhecer as conquistas nela já alçadas, para que possa dar continuidade ao desenvolvimento do objeto de sua área.

Retomando o ponto relativo à formalização da ciência, por meio da comunicação científica, destacada anteriormente por Meadows (1999), pode-se constatar que tal questão fundamenta-se também no modelo de avaliação do material a ser publicado, uma vez que a revisão por pares foi crucial para o desenvolvimento da comunicação científica. Davyt e Velho (2000) destacam que 
A avaliação é mais que uma ação cotidiana na ciência; ela é parte integrante do processo de construção do conhecimento científico. É através da avaliação - seja de artigos para publicação, seja do currículo de um pesquisador para contratação, seja de um projeto de pesquisa submetido para financiamento, seja de outras várias situações e atores - que se definem os rumos, tanto do próprio conteúdo da ciência quanto das instituições a ela vinculadas.

O primeiro registro documentado, identificado até o momento, contendo a descrição do processo de revisão por pares (peer review) é a obra intitulada "Ethics of the Physician" de autoria de Ishaq bin Ali al-Rohawi (854-931 AC) (SPIER, 2002, p. 357). No entanto, a forma estruturada como conhecemos hoje começa a se moldar com a criação dos dois primeiros periódicos, uma vez que somente os resultados de pesquisas que fossem corretamente descritos, analisados e com sua veracidade validada pelos demais pesquisadores eram reconhecidos como científicos. Assim, para que as pesquisas científicas pudessem ser publicadas, estas deveriam ser chanceladas por seus pares (DAVYT; VELHO, 2000).

Tal afirmação é corroborada por Meadows (1999, p. vii) ao analisar o processo de comunicação científica:

A comunicação situa-se no próprio coração da ciência. É para ela tão vital quanto a própria pesquisa, pois a esta não cabe reivindicar com legitimidade este nome enquanto não houver sido analisada e aceita pelos pares. Isso exige, necessariamente, que seja comunicada. Ademais, o apoio às atividades científicas é dispendioso, e os recursos financeiros que lhes são alocados serão desperdiçados a menos que os resultados das pesquisas sejam mostrados aos públicos pertinentes. Qualquer que seja o ângulo pelo qual examinemos, a comunicação eficiente e eficaz constitui parte essencial do processo de investigação científica.

Assim, toda a formalização, padronização e validação das publicações dos resultados das pesquisas científicas pavimentou a base para o desenvolvimento da literatura científica como conhecemos hoje, possibilitando a geração de análises e indicadores capazes de mensurar os mais diversos aspectos da comunicação científica. 


\subsection{Mensurando a ciência}

O desenvolvimento das Tecnologias de Informação \& Comunicação (TICs) ao longo da história facilitou o processo de comunicação da ciência, gerando atualmente uma colossal massa documental. Estima-se, de acordo com o estudo de Van Raan (2000), que o crescimento da produção científica esteja em um percentual aproximado de crescimento anual de 10\%; e em um estudo mais recente de Bornmann e Mutz (2015) identifica-se que esse número estaria entre 8 e $9 \%$ ao ano, todavia eles ressaltam que como as bases de dados cobrem uma pequena parcela dos trabalhos mais antigos publicados esse percentual pode ser superestimado. No entanto, considerando estes dados como "aproximados" e estimando um percentual de crescimento de $9 \%$ ao ano, teríamos uma duplicação dessa massa documental em cerca de 9 anos. Nesse sentido, manter-se atualizado é uma árdua tarefa para os pesquisadores.

$\mathrm{Na}$ tentativa de criar métodos para estabelecer suas prioridades de leitura, os pesquisadores definem quais veículos de publicação são os mais pertinentes para sua área de pesquisa.

Na década de 1950, o cientista estadunidense Eugene Garfield apresenta em seu célebre artigo "Citation Indexes for Science: a new dimension in documentation through association of ideas - Índices de citação para a Ciência: uma nova dimensão em documentação por meio da associação de ideias" uma sugestão de criação de índices de citação com vistas a desenvolver:

[...] um sistema bibliográfico para a literatura científica que pode eliminar a citação acrítica de dados fraudulentos, incompletos ou obsoletos, permitindo que o estudioso consciencioso esteja atento às críticas de documentos anteriores. É demais esperar que um pesquisador gaste uma quantidade excessiva de tempo buscando os descendentes bibliográficos de documentos antecedentes. Não seria excessivo exigir que os estudiosos completos verifiquem todos os trabalhos que tenham citado ou criticado esses papéis, se pudessem localizar-se rapidamente. O índice de citação faz esta verificação praticável. Mesmo que não houvesse outro uso para um índice de citações do que o de minimizar a citação de dados ruins, o índice valeria o esforço necessário para compilá-lo.(GARFIELD, 1955, p. 108)

A proposta de Garfield era a criação de um sistema de registro de citações, uma nova abordagem para o controle de assunto da literatura científica por meio de citações 
e organizá-las de forma estruturada facilitando a recuperação e possíveis análises. Tal proposta foi inovadora, uma vez que propiciou a criação dos estudos de impacto dos resultados de pesquisa.

Em 1961 Garfield publica a primeira edição do "Science Citation Index" (SCI), que resulta do mapeamento de um núcleo de periódicos determinado pelas referências bibliográficas de artigos científicos. Tal proposta tem origem em um trabalho publicado 28 anos antes por Gross e Gross (1927) no qual realizaram uma análise das referências bibliográficas citadas em um volume do "The Journal of the American Chemical Society" com vistas a definir uma lista dos principais periódicos da área de química a terem suas assinaturas mantidas na biblioteca de sua instituição de ensino (Pomona College), uma pequena Universidade na Califórnia, EUA. O estudo em si não era inovador, visto que vários pesquisadores no passado utilizaram as "estatísticas bibliográficas" para análises comparativas e de crescimento das áreas de conhecimento, e inclusive citação (HOOD; WILSON, 2001, p. 292).

No entanto, esse estudo da área de química, de uma pequena instituição de ensino, gera impactos até hoje, na medida em que na década de 1970 o SCl passa a publicar um relatório de citações de periódicos, o JCR, que trazia consigo o FI de cada periódico.(GARFIELD, 2006; MUGNAINI, 2016). O FI é explicado por Garfield (1972, p. 537) como sendo a divisão do número de vezes que um periódico foi citado pelo número de artigos que publicou durante algum período de tempo específico, portanto, o fator de impacto do periódico refletiria uma taxa média de citação por artigo publicado.

Com isso Garfield afirma ter transformado a "Lei de Dispersão de Bradford" (a qual estabelece que os artigos de interesse de uma determinada área não ocorrem somente em seus periódicos especializados, mas também em periódicos de outras áreas em uma constante crescente) na "Lei de Concentração de Garfield" que, em oposição à dispersão, estabelece uma concentração básica de revistas como núcleo (ou núcleo comum), de todos os campos (GARFIELD, 1971):

Nossos estudos no ISI [N.A.: Institute for Scientific Information] mostraram que uma lista de 1000 periódicos conterá todas as revistas líderes em qualquer lista de especialidades, bem como uma grande porcentagem de todos os artigos publicados nesse campo, em outras palavras, o que a Lei de Bradford postula para disciplinas únicas, a Lei de Garfield postula para a ciência como um todo. 
Nesse sentido, o uso de uma métrica de cálculo simples, como a do FI, para estabelecer o ranqueamento de periódicos científicos das mais diversas áreas (JCR), favoreceu a adoção generalizada desses instrumentos pela comunidade científica e também pelas bibliotecas, tornando o Fl uma das principais medidas para os estudos de impacto da ciência e abriu as portas para uma série de outros indicadores "bibliométricos".

O termo Bibliometria foi definido por Pritchard (1969, p. 349) como "a aplicação de métodos matemáticos e estatísticos a livros e outros meios de comunicação". Mesmo após tantas décadas, evolução dos métodos e medidas e novas descobertas da origem do termo "Bibliometria" a definição de Pritchard é ainda uma das mais populares.

Mugnaini (2013) faz uma retrospectiva histórica dos principais atores e momentos relacionados a esta especialidade de análise da área em nível mundial e uma importante lembrança é o uso do termo "Bibliométrie" por Paul Otlet (1934, p. 12) no seu célebre livro "Traité de Documentation" em uma seção intitulada "Le Livre et la Mesure. Bibliométrie", a qual encontra-se traduzida ${ }^{3}$ a seguir:

1. Em qualquer ordem de conhecimento, a medida é uma forma mais elevada que leva conhecimento. Ele deve constituir uma série de medidas coordenadas para o livro e o documento, a Bibliometria.

2. As medidas são aquelas relativas aos objetos, aos fenômenos ou fatos, às relações ou leis. Ela diz respeito ao indivíduo (métrica adequada) ou ao conjunto (estatística); que diz respeito ao que é ou o que deveria ser (unidade e padronização).

Medições de relatórios-chave considerados pela ciência sob a forma de índices (Por exemplo, os geógrafos considerando as relações da água da chuva e dos territórios criaram o índice de aridez).

3. Os dados adquiridos das métricas em geral, e a sociometria em particular, devem ser levados em consideração para realizar a Bibliometria.

Otlet vislumbrava em seu texto de 1934 a Bibliometria como uma especialidade multidisciplinar, compreensiva e integradora, fundamentando as áreas de

\footnotetext{
${ }^{3}$ Texto original em francês: 1 . En tout ordre de connaissance, la mesure est une forme supérieure que prend la connaissance. Il y a lieu de constituer en un ensemble coordonné les mesures relatives au livre et au document, la Bibliométrie. 2. Le mesures son celles relatives aux objets, aux phénomènes ou faits, aux relations ou lois. Elle concerne le particulier (métrie proprement dite) ou les ensembles (statistique); elle concerne ce qui est ou ce qui devrait être (unité et standardisation). Les mesures des rapports principaux considérées par un science prennent la forme d'indices. (Par exemple les géographes considérant les rapports de l'eau pluviale et des territoires ont créé l'indice d'aridité). 3. Les données acquises de la métrie en général, de la Sociométrie en particulier sont à prendre en considération pour réaliser la Bibliométrie.
} 
conhecimento, fornecendo métodos e estratégias para sua mensuração e análises tanto quantitativas como qualitativas. Tal visão é compartilhada por Glänzel (2003, p. 5):

Atualmente, a bibliometria é um dos raros campos de pesquisa verdadeiramente interdisciplinares por se estender a quase todos os campos científicos. A metodologia bibliométrica compreende componentes de matemática, ciências sociais, ciências naturais, engenharia e até mesmo ciências da vida.

Dessa forma, podemos verificar que a bibliometria está imbricada nas mais diversas áreas do conhecimento, propiciando estudos de medição da ciência, de impacto da produção científica e dos autores/pesquisadores. Nesse sentido, torna-se importante identificar os principais grupos-alvo das pesquisas bibliométricas, tal como propôs Glänzel (2003, p. 9-10):

(i) Bibliometria para pesquisadores desta especialidade (Metodologia) Este é o domínio da pesquisa bibliométrica básica e é tradicionalmente financiado pelas bolsas usuais. A pesquisa metodológica é conduzida principalmente neste domínio.

(ii) Bibliometria para disciplinas científicas (Informação Científica) Os pesquisadores em disciplinas científicas formam o maior grupo de interesse e também o mais diversificado em bibliometria. Devido à sua principal orientação científica, os seus interesses estão fortemente relacionados com a sua especialidade. Este domínio pode ser considerado uma extensão da informação científica por meios métricos. Aqui também encontramos fronteiras conjuntas com pesquisas quantitativas na recuperação de informações.

(iii) Bibliometria para política e gestão científica (Política Científica) Este é o domínio da avaliação da pesquisa, atualmente o tópico mais importante no campo. Aqui, as estruturas nacionais, regionais e institucionais da ciência e sua apresentação comparativa estão em primeiro plano.

Podemos considerar que os grupos-alvo (ii) e (iii) possuem muita aderência em seus estudos, devido a muitas das pesquisas desenvolvidas pelo grupo ii, com enfoque prioritariamente metodológico, serem utilizadas como base das análises do grupo iii, no intuito de compreender o desenvolvimento da literatura nas diversas áreas.

Entrementes, para se compreender o uso dos indicadores em processos de avaliação faz-se necessário identificar os níveis nos quais eles se distribuem. Segundo Vinkler (1988, p.242) os indicadores podem se referir a níveis micro, meso ou macro, dependendo do seu escopo. No nível Micro dizem respeito a dados sobre publicações ou citações referentes a um artigo, um projeto, uma pessoa ou um grupo de pessoas; 
no nível Meso, para um grupo de publicações, um subcampo de pesquisa ou um departamento/instituição; e no nível Macro, todas as publicações existentes acerca de uma disciplina científica em seu conjunto ou num grupo de países/instituições.

Dessa forma, considerando os diferentes níveis de agregação dos dados utilizados é fundamental que os indicadores sejam empregados de maneira coerente e balizada. No entanto, o que se verifica é o uso de métricas de forma a subsidiar o desenvolvimento de políticas científicas para avaliações institucionais, para ranqueamento de cursos de pós-graduação ou para distribuição de financiamentos tem sido cada vez mais matéria de preocupação e muita discussão (GARFIELD, 1999; WEINGART, 2005; ARCHAMBAULT; LARIVIÈRE, 2009; MUGNAINI, 2015). Dessa forma, cabe ressaltar o alerta de Glänzel e Debackere (2003, p. 225-226):

\begin{abstract}
A bibliometria pode ser usada para desenvolver e fornecer ferramentas a serem aplicadas na avaliação da pesquisa, mas não é projetada para avaliar os resultados da pesquisa. Além disso, a bibliometria não visa a substituição de métodos qualitativos por abordagens quantitativas. Consequentemente, a bibliometria não foi projetada para corrigir ou mesmo substituir avaliações por pares ou avaliação por especialistas; métodos qualitativos e quantitativos em estudos científicos devem ser complementares.
\end{abstract}

Nesse sentido, nenhum indicador bibliométrico deve ser utilizado de forma isolada, deve-se observar as diferenças culturais de pesquisa, por exemplo aquelas relativas à tipologia da produção mais publicada (livros, artigos, anais de eventos etc), à abrangência da temática (internacional, regional ou local) ou ao nível de imediatismo do uso (tempo médio de vida do documento) (HICKS, 1999; ARCHAMBAULT; LARIVIÈRE, 2010). Assim, estudiosos da bibliometria vêm definindo uma abordagem muito mais qualitativa desse ramo, apresentando-a com duas distintas aplicações, a avaliativa e a relacional:

A bibliometria avaliativa procura avaliar o impacto do trabalho acadêmico, geralmente para comparar as contribuições científicas relativas de dois ou mais indivíduos ou grupos. Essas avaliações às vezes são usadas para subsidiar políticas de pesquisa e para ajudar diretamente o financiamento de pesquisa. Em contraste, a bibliometria relacional busca iluminar relacionamentos dentro da pesquisa, como a estrutura cognitiva dos campos de pesquisa, o surgimento de novas frentes de pesquisa ou padrões de coautoria nacionais e internacionais (THELWALL, 2008, p. 606). 
No Brasil, a Coordenação de Aperfeiçoamento de Pessoal de Nível Superior (CAPES) vem utilizando indicadores bibliométricos no âmbito da bibliometria avaliativa há anos na Avaliação do Sistema Nacional de Pós-Graduação (SNPG) (MINISTÉRIO DA EDUCAÇÃO. CAPES, 2017a).

Fundada no ano de 1951, a CAPES surge "com o objetivo de estimular a qualificação do corpo docente das Universidades Públicas do país"; seis meses antes havia sido criado o Conselho Nacional de Desenvolvimento Científico e Tecnológico (CNPq) "com o objetivo de financiar a pesquisa científica e tecnológica no país". Ambas iniciativas faziam parte da institucionalização de uma política de incentivo à ciência brasileira iniciada nos anos cinquenta, que teve como objetivo maior capacitar minimamente o país para que pudéssemos ter acesso à tecnologia nuclear. No entanto, tanto os recursos investidos quanto os resultados obtidos foram bastantes modestos (BALBACHEVSKY, 2010, p. 3-4). No início da década seguinte surge uma das principais iniciativas de fomento à pesquisa fora da esfera federal, o Governo do Estado de São Paulo cria a Fundação de Amparo à Pesquisa do Estado de São Paulo (FAPESP), com um diferencial em termos de investimentos (a ela seria concedido $0,5 \%$ de toda a arrecadação ordinária do Estado), no entanto, em 1989 com a nova constituição estadual, o índice passa para 1\% tornando o estado de São Paulo uma superpotência em termos de produção científica (FAPESP, 1999; BALBACHEVSKY, 2010).

Ao longo de sua existência, as agências financiadoras de pesquisa em Ciência, Tecnologia \& Inovação (CT\&l) tiveram seus altos e baixos em termos de orçamento, ora com parcos investimentos, ora com orçamentos altamente expressivos e inúmeros editais de investimento. Em um momento dessa história, mais especificamente no ano de 1976, a CAPES desenvolve seu sistema de avaliação da pós-graduação e passa a avaliar as publicações dos pesquisadores que formavam os grupos de pesquisas vinculados aos programas de pós. Tais procedimentos avaliativos foram se consolidando ao longo dos próximos anos, se "configurando numa política relevante que conectava desempenho e apoio, além de constituir um importante sinal de qualidade reconhecido como tal por todos os atores relevantes para essa área" (BALBACHEVSKY, 2010, p. 6).

No entanto, o "tamanho diminuto da comunidade científica brasileira e a grande exposição e visibilidade desses comitês tornava-os especialmente vulneráveis a pressões de ordem paroquial" (BALBACHEVSKY, 2010, p. 11), apresentando um 
aumento do número de programas de pós-graduação com conceitos de excelência (A e B). Diante de tal situação a CAPES, em 1998, decide reformar totalmente seu sistema de avaliação, com um novo e rígido modelo, que apesar de manter a autoridade dos comitês de avaliação dos programas, dotava-os de regras mais claras direcionadas ao estabelecimento de padrões de qualidade aceitos internacionalmente, parâmetros para avaliação de desempenho dos professores, com foco em sua produção acadêmica utilizando-se para tanto de um novo conjunto de indicadores. No modelo anterior, a escala de avaliação tinha cinco pontos, no novo modelo passa a ter sete, no qual os dois níveis mais altos (seis e sete) são atribuídos somente a programas que oferecem doutorado e que são qualificados como bons ou excelentes, de acordo com os padrões internacionais de qualidade. Por outro lado, a nota três é o mínimo exigido para que um programa seja reconhecido. Além disso, a periodicidade da avaliação também foi alterada, passando de dois para três anos (BALBACHEVSKY, 2005, p. 283).

Os objetivos estabelecidos pela CAPES para a avaliação da pós-graduação são, de forma sucinta, contribuir para a garantia de sua qualidade; apresentar sua situação de forma clara e efetiva; contribuir para o desenvolvimento de cada programa e área em particular e da pós-graduação brasileira em geral ao fornecer, a cada programa avaliado, as apreciações criteriosas sobre os pontos fortes e os pontos fracos de seu desempenho, no contexto do conjunto dos programas da área, e antepor-lhes desafios e metas para o futuro; fornecer subsídios para a definição de planos e programas de desenvolvimento e a realização de investimentos no SNPG (MINISTÉRIO DA EDUCAÇÃO. CAPES, 2017a).

Dentre estes desafios podemos destacar a questão da internacionalização, que a CAPES toma como critério de excelência para os Programas de Pós-Graduação (PPG's), concedendo àqueles que atingem os critérios estabelecidos pelas áreas as notas mais altas (seis e sete). Marrara (2007) comenta que:

\footnotetext{
"A obtenção dessas notas, por sua vez, amplia o reconhecimento das IES e do programa bem avaliado, além de lhes permitir o acesso a certos recursos financeiros, tais como os provenientes do Programa de Excelência Acadêmica (PROEX), exclusivos para programas com reconhecido nível de excelência."
}

No entanto, a exigência dessa internacionalização gera reflexos diretos no processo de comunicação científica, bem como na gestão e direcionamento dos 
periódicos científicos brasileiros que se veem compelidos a buscar cada vez mais padrões de excelência internacionais para se manterem pertinentes às suas áreas de conhecimento (SANTOS; MUGNAINI, 2018).

A definição da internacionalidade dos periódicos científicos não é simples e tampouco consensual, como bem apontado por Zitt e Bassecoulard (1998), vários autores já propuseram inúmeras dimensões de análises para o estabelecimento do nível de internacionalidade, dos quais destacaram: a distribuição nacional dos autores (quantidade de autores do país de publicação do periódico); distribuição nacional dos usuários (incluindo leitores, assinantes e citadores); vinculação dos coautores (proporção de coautorias nacionais e internacionais); idioma e publicação por editoras comerciais; e nacionalidade dos conselhos editoriais.

Buela-Casal et al. (2006) comentam que análises de internacionalidade dos periódicos científicos têm recebido cada vez mais atenção, em especial pela globalização mundial e consideram que uma medida quantitativa na forma de um índice seria indispensável para a comunidade científica. E nesse sentido, propõem um conjunto diversificado de critérios para o desenvolvimento de tal índice, ressaltando que alguns deles não desempenham um papel importante na avaliação da internacionalidade. Os critérios propostos são:

- idioma da publicação;

- país de publicação;

- inclusão do termo "internacional" no título;

- inclusão em bases de dados internacionais;

- Fator de Impacto;

- afiliação a uma instituição ou associação internacional;

- distribuição multinacional dos membros do conselho editorial;

- distribuição multinacional dos editores associados;

- distribuição multinacional de autores;

- distribuição multinacional de usuários;

- padrões de colaboração internacional;

- acesso on-line. 
Tais critérios foram testados pelos autores em um conjunto de periódicos da área de psicologia e puderam identificar que “...mesmo os critérios bem definidos quantitativamente produzem uma medida ambígua de internacionalidade quando considerados individualmente" e "...qualidade e internacionalidade não estão necessariamente correlacionadas", destacam ainda que "...percepções limitadas baseadas em um ou outro critério único podem penetrar na área de avaliação de periódicos distorcendo a imagem de alguns e afetando a avaliação da qualidade acadêmica" (BUELA-CASAL et al, 2006).

De fato, a internacionalidade dos veículos de publicação dos pesquisadores é um dos principais critérios no processo de avaliação empreendido pela CAPES, como veremos mais a frente.

Mugnaini $(2015$, p. 3) comenta que uma questão central a se analisar sobre o processo de avaliação da CAPES seria:

a diferenciação de programas, o que permite depreender que devem ser estabelecidos critérios de qualidade específicos de cada área, que estabeleçam objetivos, metas, que os pesquisadores devam alcançar para melhor desempenho de seu programa. Obviamente tais critérios abrangerão cada aspecto da vida acadêmica de um professor atuante na pós-graduação, distinguindo: veículos de publicação dos resultados de sua pesquisa; formação de mestres e doutores; atuação em diversos âmbitos da vida acadêmica (como emitir parecer sobre manuscritos, projetos, disciplinas, relatórios científicos e técnicos, compor comitês científicos e administrativos no âmbito da universidade ou agências de fomento, organizar eventos científicos); além de realizar ações de extensão que transbordem o fazer científico para a sociedade, e a outras áreas do conhecimento.

Ao todo são 49 áreas avaliadas, com quesitos e uma sistemática básicos. A avaliação é realizada pelos comitês de área, formados por consultores acadêmicos com reconhecida experiência em ensino e orientação de pós-graduação, pesquisa e inovação. Os comitês devem instituir suas comissões de áreas que serão responsáveis pelo processo de avaliação. A avaliação em sua análise levava em conta, até 2013 , os três anos anteriores a sua realização, no entanto as avaliações a partir de 2017 passam a ser quadrienais, analisando os dados de 2013-2016. As comissões são responsáveis pela avaliação dos programas, utilizando-se dos documentos de áreas preparados pelos comitês. Tais documentos apresentam uma análise geral da área, fazem recomendações 
e estabelecem os critérios para estabelecimento dos pesos a serem utilizados nas fichas de avaliação dos programas (MINISTÉRIO DA EDUCAÇÃO. CAPES, 2017b).

A título de exemplo, para que um programa de pós-graduação seja selecionado para obter as notas mais altas (seis e sete) nas Geociências existe um conjunto de 20 indicadores a serem considerados, dos quais destacam-se em relação à produtividade $e$ internacionalização:

- as publicações dos docentes permanentes devem se dar dominantemente em periódicos internacionais dos estratos mais elevados do Qualis (A1, A2 e B1), livros e capítulos publicados no exterior em editoras qualificadas e livros nacionais de alta qualidade;

- projetos com financiamento internacional e participação em editais internacionais;

- produção intelectual em cooperação com pesquisadores estrangeiros;

- participação qualificada (palestrante ou conferencista convidado) e apresentação de trabalhos em eventos científicos internacionais de alto nível acadêmico. (MINISTÉRIO DA EDUCAÇÃO. CAPES, 2016)

Ou seja, a importância da internacionalização tanto da produção intelectual, quanto da colaboração internacional são critérios preponderantes para que os programas atinjam a excelência.

Nesse sentido, os comitês de áreas são responsáveis também por realizarem a classificação do Qualis-Periódicos (e suas duas outras edições: Livros e Artístico). O Qualis-Periódicos é um índice utilizado para classificar a produção científica dos programas de pós-graduação, no que tange os artigos científicos publicados em periódicos. Sua classificação é realizada enquadrando os títulos de periódicos em estratos indicativos de qualidade: $\mathrm{A} 1$ (o mais alto), A2, B1, B2, B3, B4, B5 e C (peso zero). Sua classificação é baseada nas definições apresentadas pelas áreas em seus comitês e são classificados no Qualis somente aqueles periódicos nos quais os docentes e discentes dos programas de pós-graduação brasileiros tiveram publicação e, dessa forma, um mesmo periódico pode ser avaliado em várias áreas de conhecimento e em cada uma figurar em um estrato diferente (MINISTÉRIO DA EDUCAÇÃO. CAPES, 2017b). Dentre os critérios considerados na classificação do Qualis-Periódicos estão o FI e sua indexação no JCR (MUGNAINI, 2006, p. 27). 
No entanto, devido às diferentes culturas de pesquisa das áreas de conhecimento, o Qualis-Periódicos não poderia ser utilizado por todas como instrumento equalizador. Dessa forma, em 2007 é implementado o Qualis-Artístico para as áreas de Artes/Música levando em consideração a produção artística dos programas. Em 2009, o Conselho Técnico-Científico da Educação Superior (CTC-ES) da CAPES aprova o Roteiro para Classificação de Livros (Qualis-Livros), trazendo conceitos e definições comuns e uma sugestão de folha de avaliação, permitindo assim uma melhor adequação da avaliação aos programas de pós-graduação das áreas de humanidades (MINISTÉRIO DA EDUCAÇÃO. CAPES, 2017b).

Apesar desses avanços e adequações realizadas, a produção científica publicada em periódicos ainda possui um peso maior que outros tipos de documentos/produtos na grande maioria das áreas, mantendo, dessa forma, o status de supremacia do Qualis-Periódicos para os programas de pós-graduação.

Assim, ao avaliar os Programas de Pós-Graduação a CAPES o faz em nível Macro, no entanto se baseia em indicadores de nível Meso, uma vez que o QualisPeriódicos leva em consideração os dados bibliométricos de bases como a WoS e JCR.

Tal questão gera uma discrepância em termos de análise da produção científica brasileira, na medida em que apenas uma pequena parcela dos periódicos nacionais é indexada e que tais veículos são fundamentais para a comunicação de pesquisas de ordem regional ou local. A $\mathrm{WOS}^{4}$ é a base de dados originária do $\mathrm{SCl}$ do Institute for Scientific Information (ISI), organização criada por Eugene Garfield na década de 1960 e comprada pela Thomson Corporation (atual Thomson Reuters). Em 2016 o braço corporativo da Thomson Reuters responsável pela WoS e outros produtos de informação, como o JCR foi adquirido por uma joint venture formando-se a Clarivate Analytics. A WoS Core Collection possui uma cobertura temporal iniciada em 1900 e é formada por mais de 12 mil títulos de periódicos ranqueados pelo JCR, além das bases adicionais: Science Citation Index Expanded (SCI-EXPANDED), Social Sciences Citation Index (SSCl), Arts \& Humanities Citation Index (A\&HCI), Conference Proceedings Citation Index - Science (CPCI-S), Conference Proceedings Citation Index - Social Science \& Humanities ( $\mathrm{CPCl}-\mathrm{SSH})$ e Emerging Sources Citation Index (ESCl). A base possui

\footnotetext{
${ }^{4}$ Web of Science Core Collection: www.webofknowledge.com
} 
indicadores relacionados às citações recebidas pelos documentos indexados, além de estatísticas de uso. É considerada a base de dados mais utilizada para estudos cientométricos e possui indicadores bibliométricos (CLARIVATE ANALYTICS, 2017a, 2017b; COSTAS, 2017).

Em 2004, a Elsevier lança a principal concorrente da WoS, a base de dados Scopus ${ }^{5}$, com um número maior de títulos indexados, mais de 22 mil, no entanto com uma cobertura temporal que se inicia somente em 1960. Todavia, a Elsevier tem trabalhado na indexação retrospectiva dos conteúdos e, em breve, essa janela temporal será ampliada. Ademais, a Scopus tem incluído ao longo dos anos várias métricas tradicionais e mais recentemente as alternativas (altmetrics) como citações em redes sociais como o Twitter e Facebook, em blogs, nas mídias de massa (jornais e mídias especializados), dentre outras (COSTAS, 2017; ELSEVIER, 2017).

Apesar de ambas as bases terem aumentado os conteúdos regionais ao longo da última década há ainda um grande abismo separando, especialmente, os países da América Latina. Segundo o estudo de Santa e Herrero-Solana (2010) o Brasil era o país com mais periódicos indexados no JCR edição 2008, 31, no total a América Latina tinha 79 títulos, correspondendo respectivamente a $0,36 \%$ e $0,92 \%$ do total de 8.605 títulos analisados nessa edição do JCR. Na edição 2018 do JCR ${ }^{6}$, o Brasil conta com 129 títulos e a América Latina com 252, denotando um aumento de $416 \%$ na quantidade dos periódicos brasileiros e 319\% para os da América Latina como um todo. E em termos de representatividade os periódicos brasileiros correspondem na edição 2018 do JCR a 1,05\% do total de 12.298 títulos analisados e a América Latina a 2,05\%. Apenas a título comparativo, no Directory of Open Access Journals ${ }^{7}$ (DOAJ) o Brasil é o terceiro país com mais títulos indexados, $1.280^{8}$ no total. Além disso, o país ocupa a 13a posição em quantidade de artigos publicados no ano de 2017 e indexados na WoS Core Collection.

Nesse sentido, há que se verificar se as bases de dados utilizadas para gerar indicadores com vistas à análise de impacto da produção científica dos programas de pós-graduação brasileiros realmente evidenciam a completeza e/ou o real impacto do que se produz.

\footnotetext{
${ }^{5}$ Scopus: www.scopus.com

${ }^{6}$ Journal Citation Reports: https://icr.incites.thomsonreuters.com

${ }^{7}$ Directory of Open Access Journals: https://doaj.org

${ }^{8}$ Dado coletado em agosto de 2018.
} 
Um outro ponto a se destacar sobre a cobertura das bases de dados diz respeito às áreas de conhecimento indexadas. É senso comum entre os pesquisadores que as humanidades são consideradas como o calcanhar de Aquiles para uma aplicação bemsucedida de métodos cientométricos e bibliométricos em exercícios de avaliação de pesquisa (GUMPENBERGER et al., 2016).

Como já mencionado anteriormente, a cultura de pesquisa das áreas de humanidades difere do padrão das áreas de exatas e biológicas, as quais acabam sendo representadas a contento nas principais bases de dados. No entanto, o grande problema para as humanidades é que os índices de citação como WoS e Scopus concentram sua cobertura principalmente em revistas e menos em outros veículos de divulgação de conhecimento científico, como os livros, anais de eventos e relatórios (MONGEON; PAUL-HUS, 2016, p. 2).

Archambault e Larivière (2010) acrescentam que há três razões principais que dificultam as análises bibliométricas e, por conseguinte, a geração de indicadores consistentes nas áreas de Ciências Sociais e Humanidades (SSH - sigla para a expressão em inglês Social Science and Humanities): [1] menor proporção de artigos de revistas de SSH; [2] taxas de envelhecimento da literatura sobre SSH inversamente proporcional às taxas comuns de citação de pós-publicação (os documentos da SSH são mais citados com o passar do tempo); [3] relevância local do conhecimento em SSH.

De fato, estudos comprovam que o uso de artigos científicos nas áreas de humanidades em geral corresponde a $50 \%$ ou menos e que o principal canal são os livros (HICKS, 1999; LARIVIÈRE et al., 2006). A obsolescência de um artigo em humanidades é maior e sua janela de citação é praticamente o dobro das áreas de Ciências Naturais e Engenharias, e em Ciências Sociais um artigo atinge seu pico de citação em aproximadamente 10 anos (ARCHAMBAULT; LARIVIÈRE, 2010). Quanto à questão da internacionalização das pesquisas dessa área, um fator a se destacar é o maior uso da língua pátria, dado que, em geral, os objetos e o ambiente de estudo são especificamente regionais e seus resultados tendem a ser comunicados para os pares da sua própria região.

Assim, apesar da crescente indexação dos periódicos regionais nas bases de dados de citações isso não completa o ciclo da produção intelectual de todas áreas e de todas as regiões. Há que se levar em conta que livros e anais de eventos precisam de 
premente atenção, bem como maior abertura para conteúdos exclusivamente regionalizados.

Retomando a questão do uso de indicadores bibliométricos para avaliação de CT\&I e ligando-a ao exposto anteriormente, acerca da cobertura das bases em termos de áreas de conhecimento e conteúdos regionais, há que considerar que o uso de dados quantitativos para análises qualitativas deve ser realizado com planejamento, conhecimento e critério.

Nesse sentido, um grupo de pesquisadores reunidos na 20ạ Conferência Internacional sobre Indicadores em Ciência e Tecnologia (STI - em inglês: Science and Technology Indicators) de 2014 em Leiden na Holanda, redigiram um documento com vistas ao estabelecimento de princípios norteadores para avaliação de pesquisa. 0 "Manifesto de Leiden", como foi intitulado, apresenta dez princípios:

1. A avaliação quantitativa deve dar suporte à avaliação qualitativa especializada.

2. Medir o desempenho de acordo com a missão da instituição, do grupo ou do pesquisador.

3. Proteger a excelência da pesquisa localmente relevante.

4. Manter a coleta de dados e os processos analíticos abertos, transparentes e simples.

5. Permitir que os avaliados verifiquem os dados e as análises.

6. Considerar as diferenças entre áreas nas práticas de publicação e citação.

7. Basear a avaliação de pesquisadores individuais no juízo qualitativo da sua carreira.

8. Evite solidez mal colocada e falsa precisão.

9. Reconhecer os efeitos sistêmicos da avaliação e dos indicadores.

10. Examinar e atualizar os indicadores regularmente (HICKS et al., 2015).

Os autores comentam no início do Manifesto que:

A questão é que agora a avaliação é majoritariamente dependente de dados, ao invés de juízos de valor. As métricas proliferaram: em geral bem-intencionadas, nem sempre bem informadas, e frequentemente mal aplicadas. Corremos o risco de prejudicar o sistema da ciência com as próprias ferramentas projetadas para melhorá-lo, uma vez que a avaliação é cada vez mais realizada por instituições sem o devido conhecimento sobre as boas práticas e sobre a interpretação adequada de indicadores (HICKS et al., 2015).

O Manifesto lança luz sobre os equívocos e incoerências que porventura possam ser constatadas nas avaliações, sem que haja a devida análise e manipulação correta dos dados, trazendo uma abordagem qualitativa para a bibliometria avaliativa 
focando principalmente na segurança e confiabilidade do que se está objetivando com os processos de avaliação de pesquisa.

Rafols et al.(2016) em uma análise acerca da avaliação da pesquisa em países periféricos comentam que:

Nas duas últimas décadas, muitos países na periferia do sistema
científico desenvolveram políticas para melhorar a "qualidade" de sua
ciência. Essas políticas para "recuperar o atraso" com os países
desenvolvidos incluem instrumentos políticos baseados em noções de
"qualidade" ou "excelência" - explícita ou implícita. Uma análise desses
instrumentos de política revela duas observações. Em primeiro lugar,
eles são baseados em métodos de avaliação quantitativa que são
implementados de forma fórmica e rígida. Em segundo lugar, os
critérios implícitos nessas avaliações quantitativas visam a excelência
internacional e, portanto, muitas vezes são tendenciosos contra
pesquisas relacionadas a perspectivas ou tópicos locais.

Como países periféricos os autores entendem aqueles que são liderados e não líderes na maioria dos campos científicos e que por isso não recebem muitas citações, não são membros de corpos editoriais e que precisam estudar ou receber treinamento em países mais centrais.

Para os autores, as avaliações de pesquisa, nos moldes empreendidos pela CAPES com o Qualis, tem como objetivo em primeiro lugar o controle sobre o que se produz, e em segundo para distribuição de recursos, com muito pouco espaço para aprender/aprimorar a avaliação (RAFOLS et al., 2016).

De fato, apesar de o processo de avaliação dos programas de pós-graduação brasileros ter evoluído ao longo dessas décadas e continuar sendo aprimorado, seu objetivo tem sido muito mais quantitativo que qualitativo.

E seguindo nessa mesma linha de desenvolvimento da ciência, as instituições de ensino também têm tentado criar mecanismos para avaliar tanto suas unidades/institutos de ensino como seus docentes. Tais atividades carecem também de maior transparência e de métodos que levem em consideração, por exemplo, princípios qualitativos como sugere o Manifesto de Leiden.

Nesse sentido, evidencia-se a necessidade emergente de estudos que analisem métodos e modelos de avaliação da ciência no nível Micro, ou seja, do pesquisador (indivíduo) em relação à sua contribuição à instituição. 


\section{AVALIANDO A CIÊNCIA}

Como comentam Bornmann \& Leydesdorff (2014) as "avaliações de qualidade permeiam todo o empreendimento científico, de pedidos de financiamento à promoções, prêmios e concursos para docentes". A Ciência como um todo em algum momento é avaliada e como pudemos ver nos capítulos anteriores os processos para isso são diversos e nem sempre utilizados da melhor forma.

Nesse sentido, apresentam-se a seguir os processos de avaliação da ciência em dois níveis específicos, o Institucional e o Individual.

\subsection{Avaliação Institucional}

Assim como avaliar a produção intelectual de um país e seus programas de pósgraduação se tornou uma necessidade comum para as instituições governamentais, para as Instituições de Ensino Superior (IES) essa atividade também tem se tornado cada vez mais necessária e exigida, à medida que analisar a eficiência dos planos de gestão educacional se tornam prementes em tempos de escassez de financiamentos

Oliveira e Agopyan, 2017, p. 111) comentam que o processo de avaliar consiste em:

empreender um diagnóstico a partir da comparação entre as metas que se pretendem alcançar, confrontando-se os objetivos estabelecidos previamente com os efeitos obtidos, em um decurso de tempo, a fim de perceber as potencialidades e os pontos críticos. É uma atividade que possibilita a formação de um vínculo de caráter histórico, pelo qual se pretende a análise do momento presente da entidade - o qual é reflexo das escolhas e práticas passadas - a fim de possibilitar a programação relativamente a momentos posteriores e a possíveis mudanças.

De fato, o processo de avaliação de uma universidade além de ser enriquecedor em termos de autoconhecimento, permite um registro da evolução histórica da instituição, bem como seu planejamento futuro.

Mais recentemente as universidades brasileiras têm tido que lidar com mais um desafio em suas avaliações institucionais, os chamados rankings universitários. Fausto e Mugnaini (2013, p.2) apontam que os rankings "induzem, de forma prescritiva, uma 
homogeneização de políticas e desempenho institucionais e nesse contexto, inserem-se numa cultura de avaliação baseada em indicadores".

No entanto é importante levar em conta que deve haver cuidado no uso dos termos avaliação e ranqueamento. A avaliação estabelece uma referência em relação à qual a performance universitária pode, em certos momentos, ser avaliada. O objetivo é determinar se uma universidade passa no processo de avaliação, o que significa que alcançou ou superou um nível básico de requisitos. Os resultados da avaliação não precisam ser quantitativos. A avaliação descritiva é suficiente em alguns contextos de avaliação, e alguns resultados de avaliação indicam simplesmente decisões finais, como passar ou não. Por outro lado, o ranking classifica um grupo de universidades por meio de indicadores numéricos. O ranking apresenta a força e a fraqueza relativa da universidade comparada às suas instituições pares nas áreas representadas pelos indicadores. Indica claramente a posição relativa de uma universidade em uma escala que representa sua força no aspecto medido. A natureza numérica do ranking também simplifica as comparações. O ranking é um método de avaliação eficiente, conveniente e facilmente compreensível, embora alguns tenham discutido sobre a equidade das comparações quantitativas de universidades onde cada universidade é única e difere das outras em alguns aspectos. O ranking que emprega medidas compostas por múltiplos indicadores pode, em certa medida, superar os possíveis problemas de equidade (HUANG, 2011, p. 5).

Tanto a avaliação quanto o ranqueamento têm sido tomados como mecanismos para a análise de desempenho das universidades, todavia, há que se levar em conta as controvérsias sobre os rankings, como destacado pelo autor.

Para Marginson e Van der Wende (2007, p. 308) os rankings universitários "cimentaram a noção de uma competição ou mercado universitário mundial arranjado em uma única tabela de classificação para fins comparativos, dando um poderoso impulso às pressões competitivas intranacionais e internacionais no setor".

Rauhvargers (2013, p. 26) analisa em seu segundo relatório sobre rankings universitários produzido para a Associação Universitária Europeia que estes continuam focando somente em pesquisa e não incluem os resultados e impactos obtidos em áreas como as Artes, Humanidades e Ciências Sociais, e que mesmo os indicadores bibliométricos utilizados têm fortes distorções e falhas. No entanto, ele finaliza sua 
análise destacando que os rankings vieram para ficar e que para as universidades uma boa posição neles significa financiamentos adicionais, todavia, alerta que se deve ter em mente que nem toda a produção intelectual consiste em artigos científicos e muitas questões relevantes para a qualidade acadêmica não podem ser mensuradas de forma quantitativa.

Santos (2015, p. 322) corrobora tal constatação:

O aperfeiçoamento das universidades não está em modificar o valor de um indicador, e sim em modificar condições, práticas e culturas institucionais que aumentem as possibilidades de melhores respostas frente à sua missão institucional. Assim, sistemas de classificação não são instrumentos de melhoria das universidades, eles podem servir ao debate político macro em algumas áreas específicas, mas não são suficientes para o desenvolvimento das universidades.

Em 2017, uma iniciativa capitaneada pelo Conselho de Reitores das Universidades Estaduais de Paulistas (CRUESP) e apoiada pela FAPESP ${ }^{9}$ institui o Projeto "Indicadores de Desempenho nas Universidades Estaduais Paulistas" com o objetivo de "estudar indicadores de desempenho institucional e acadêmico e os mecanismos de governança relacionados com acompanhamento de performance acadêmica e impacto social das Universidades Paulistas vinculadas" (MÉTRICAS, 2018).

O projeto, coordenado pelo Professor Jacques Marcovitch da USP, estabelece a criação em cada uma das três universidades (USP, UNESP e UNICAMP) de Unidades de Inteligência, que serão responsáveis pelo monitoramento, verificação e disponibilização em tempo real das métricas de desempenho institucional, "cuja eficácia depende da sua capacidade em garimpar informações, de modo a retratar competências, resultados e limitações na formulação de políticas universitárias baseadas em métricas" (MARCOVITCH, 2018).

Os resultados esperados com esse projeto e que dependerão da atividade direta das Unidades de Inteligência são em linhas gerais: o lançamento de uma plataforma digital para a disponibilização de dados e relatórios; relatórios institucionais que diferentemente dos anuários estatísticos das universidades, conterá resumos curtos do desempenho institucional baseado em indicadores-chave; avaliação comparativa dos dados apresentados com os de instituições internacionais com perfis similares;

\footnotetext{
${ }^{9}$ Processo FAPESP N ${ }^{\circ} .17 / 50046-8$ - Indicadores de desempenho nas universidades estaduais paulistas. URL: https://bv.fapesp.br/pt/auxilios/97010/
} 
monitoramento de indicadores-chave de desempenho; monitoramento de rankings nacionais e globais; cursos de extensão para dirigentes e profissionais dedicados ao tema (MARCOVITCH, 2018).

Como se pode perceber, em tempos atuais, torna-se praticamente impraticável pensar em avaliação institucional, sem considerar os indicadores, os resultados e as análises dos rankings universitários.

O processo de avaliação institucional é uma exigência do estado brasileiro e está amparado na Lei Federal no 9.394, de 20 de dezembro de 1996 conhecida como Lei das Diretrizes e Bases da Educação Nacional (LDB). Em seu artigo 9, incisos VI e IX, estabelecem-se as regras dirigidas à avaliação das universidades:

$\mathrm{VI}$ - assegurar processo nacional de avaliação do rendimento escolar no ensino fundamental, médio e superior, em colaboração com os sistemas de ensino, objetivando a definição de prioridades e a melhoria da qualidade do ensino;

IX - autorizar, reconhecer, credenciar, supervisionar e avaliar, respectivamente, os cursos das instituições de educação superior e os estabelecimentos do seu sistema de ensino (BRASIL, 1996).

Do ponto de vista da avaliação educacional o Governo Federal brasileiro institui no ano de 2003 o Instituto Nacional de Estudos e Pesquisas Educacionais Anísio Teixeira (INEP) tendo dentre seu conjunto de finalidades desenvolver sistemas e projetos de avaliação educacional e coordenar o processo de avaliação dos cursos de graduação (MINISTÉRIO DA EDUCAÇÃO. INEP, 2017).

Todavia, considerando-se a USP, uma autarquia da esfera pública estadual, esta encontra-se sob as regras de avaliação instituídas pelo Conselho Estadual de Educação do Estado de São Paulo, por meio da deliberação CEE 04/2000 (SÃO PAULO. CONSELHO ESTADUAL DE EDUCAÇÃO, 2000), a qual estabelece como finalidades para o processo de avaliação:

\footnotetext{
I - orientar, acompanhar e fiscalizar o desenvolvimento das instituições;

II - analisar periodicamente o nível de desempenho e atualização institucional, principalmente quanto aos seguintes aspectos:

a) eficácia e eficiência do seu ensino;

b) importância dos seus programas de pesquisa;

c) relevância de sua produção cultural e científica;

d) eficácia da formação profissional;

e) significado da importância das ações comunitárias;

f) condições gerais e específicas dos cursos de graduação e pósgraduação;
} 
g) qualidade da gestão administrativa e financeira.

A USP iniciou seu processo de avaliação institucional, de maneira sistematizada, no ano de 1992 (antes da deliberação do CEE) com a constituição da Comissão Permanente de Avaliação (CPA), uma proposição de duas Comissões: Comissão de Assuntos Acadêmicos (CAA) e Comissão Especial de Regimes de Trabalho (CERT). Desde então foram realizados quatro ciclos de avaliação de 1992-1998 (1‥), 2000-2004 (2‥), 2005-2009 (3․). e 2010-2014 (4․).) (OLIVEIRA; AGOPYAN, 2017, p. 116-117).

Atentando-se mais especificamente para o quarto e mais recente ciclo de avaliação da USP, há que se destacar que em relação aos anteriores este utilizou um instrumento de avaliação aperfeiçoado intitulado de "Formulário de Avaliação". Tal documento possuía dois níveis institucionais de auto avaliação, um para a unidade de ensino e outro para seus departamentos. Especificamente no que tange à produção intelectual (aqui compreendida como: científica, acadêmica, tecnológica e artística), esta encontrava-se representada em três âmbitos, o da Pós-Graduação, o da Pesquisa e o da Cultura e Extensão, tanto para as Unidades como para os Departamentos. Para a Pós-Graduação as perguntas estavam voltadas para o impacto nacional e internacional do conhecimento científico e tecnológico gerado pelas teses e dissertações, além do desempenho dos Programas de Pós-Graduação, considerando as duas últimas avaliações da CAPES. No que diz respeito à Pesquisa as perguntas se centravam na evolução da produção (artigos, livros, patentes, curadorias, exposições e outras) nos últimos cinco anos, os indicadores utilizados para avaliação da relevância da produção científica e tecnológica (número de citações no ISI, SCImago, Scopus, impacto das revistas e outros, patentes depositadas e licenciadas), nível de colaboração internacional, política de apoio à publicação (editoração de livros ou capítulos, artigos, patentes, outras publicações de pesquisa e criação de políticas públicas) e impacto da produção científica dos pós-doutorandos. E quanto à Cultura e Extensão o foco era direcionado à contabilização e ao impacto da produção docente no tocante às atividades de educação e divulgação científica, artística, cultural, técnica ou tecnológica (curso de difusão, programa de atualização, projetos dirigidos à educação básica, exposições e feiras, textos, material didático ou outros produtos voltados para a comunidade externa à Universidade) (COMISSÃO PERMANENTE DE AVALIAÇÃO, 2014a, 2014b, 2016; OLIVEIRA; AGOPYAN, 2017). 
Como pudemos verificar no quarto ciclo de avaliação institucional da USP, apesar de não analisar o docente individualmente (nível Micro) de forma explícita, acaba por gerar nas Unidades e Departamentos, um primeiro esboço de um relatório individual dos pesquisadores, na medida em que para se preencher o formulário de departamento havia a necessidade de obter dados do corpo docente vinculado.

É possível verificar uma visão mais compreensiva da produção intelectual, uma vez que não somente artigos e patentes estavam sendo analisados, mas inclusive áreas pouco valorizadas em avaliações de produtividade, como por exemplo atividades de cultura e extensão e concepção de políticas públicas.

Em novembro de 2016 a USP publica seu novo Estatuto Docente, que dentre os inúmeros objetivos elencados destaca-se a vinculação a um único processo, tanto para a avaliação periódica a qual o docente será submetido, quanto para a avaliação de progressão na carreira. Os critérios para essa avaliação serão definidos pela CPA, que teve seu regimento atualizado também em novembro de 2016 e que estabelece que os ciclos de avaliação serão de cinco anos, tanto para docentes, quanto para departamentos e Unidades de Ensino (UNIVERSIDADE DE SÃO PAULO, 2016a, 2016b).

\subsection{Avaliação em Nível Individual}

A demanda por análises de performance em nível individual pelas administrações universitárias e instituições de pesquisa tem crescido, especialmente a partir do começo dos anos 2000 (WOUTERS, 2013). Tem sido considerada uma ferramenta fundamental para a gestão, auxiliando a tomada de decisões em áreas como contratação de pesquisadores, avanço na carreira, sistemas de recompensa, concessão de prêmios e financiamento de projetos (ABRAMO; CICERO; D'ANGELO, 2013, p. 528).

No entanto, são muitos os senões para o uso da bibliometria na avaliação em nível individual. Glänzel \& Wouters (2013) alertam para as 10 ações que não devem ser empreendidas ao se produzir uma análise bibliométrica individual:

1. Não reduza o desempenho individual para um único número: o desempenho de pesquisa pode ser influenciado por diversos fatores, um único/indicador mesmo que baseado em dados e métodos corretos não é suficiente para refletir a 
complexidade da atividade de pesquisa e o contexto de trabalho do pesquisador deve ser levado em consideração.

2. Não use o Fator de Impacto como medida de qualidade: desde sua criação pelo ISI o FI evoluiu para uma ferramenta de avaliação que se tornou moeda comum para avaliação da qualidade de pesquisa influenciando carreiras e financiamentos dos pesquisadores, no entanto o $\mathrm{Fl}$ não é de forma alguma uma medida de desempenho de artigos individuais, nem dos autores desses documentos.

3. Não aplique "filtros bibliométricos" (secretos) para seleção: pesos, limites ou filtros são definidos para avaliações internas ou para pré-seleção de material para uso externo. Esta é uma prática questionável, pois se os filtros estiverem configurados, eles devem sempre apoiar o julgamento humano e não prejulgálo.

4. Não aplique pesos arbitrários à coautoria: um problema conhecido na bibliometria é como creditar adequadamente autores por sua contribuição para papers em que são coautores. A questão é que somente os próprios autores podem avaliar sua contribuição. A sequência dos coautores não é uma ciência exata, cada área de conhecimento, instituição, grupos de pesquisa possuem regras próprias quanto a isso.

5. Não classifique os cientistas de acordo com um único indicador: classificar os candidatos que foram selecionados, por exemplo, para um cargo, de acordo com os critérios relevantes é legítimo, todavia, o ranking não deve ser meramente baseado em bibliometria. A classificação interna ou pública do desempenho da pesquisa sem qualquer objetivo prático específico (como uma candidatura) é problemática e um outro efeito negativo das listas de classificação (como dados de fácil acesso e prontos para uso) é que eles poderiam ser usados na tomada de decisões em outros contextos diversos daqueles para os quais foram preparados.

6. Não combine medidas incomensuráveis: prática problemática que geralmente se inicia com relatórios produzidos pelos próprios cientistas, por exemplo as contagens de citações que aparecem em currículos ou aplicativos e que às vezes 
são baseadas em diferentes fontes (WoS, Scopus, Google Scholar ${ }^{10}$ ). No entanto, essa combinação de fontes incomensuráveis mescladas com padrões de referência inadequados tornam os indicadores bibliométricos praticamente inúteis. Não se deve permitir que os usuários juntem resultados bibliométricos de diferentes fontes sem que tenha sido verificada sua compatibilidade.

7. Não use estatísticas defeituosas: Os limites e os indicadores para atribuição de níveis de desempenho são ferramentas comprovadas em bibliometria (por exemplo, para identificar artigos de autores que publicam com a indústria, nunca citados ou altamente citados). No entanto, olhando para a literatura recente, encontramos uma infinidade de fórmulas para medidas "melhoradas" ou indicadores compostos que não possuem nenhum fundo matemático sério. Os conjuntos de dados pequenos são típicos deste nível de agregação: isso pode aumentar o viés ou resultar em erros sérios e os métodos estatísticos padrão (matemáticos) estão no limite ou além do limite aqui.

8. Não acredite cegamente nos "one-hit wonders" (um único hit de sucesso): não se deve avaliar um cientista com base em um artigo top. As descobertas em geral são baseadas em um único conceito teórico ou visão de mundo e publicados em um artigo que atraia a atenção de estrelas da área. Deve-sempre pesar a importância dos artigos altamente citados com o valor de uma série publicações consistentes. É importante considerar o trabalho completo de uma vida ou aqueles criados em janela temporal de análise.

9. Não compare maçãs e laranjas: a pesquisa e sua comunicação diferem estruturalmente nos diversos domínios de conhecimento. Dessa forma, não se devem avaliar áreas distintas com a mesma régua.

10. Não permita que prazos e carga de trabalho obriguem você a descartar boas práticas: a sobrecarga de demandas pode forçar que o analista por vezes utilize os dados pré-prontos das fontes de dados, no entanto, deve-se levar em consideração que as vidas de cientistas / pesquisadores / grupos de pesquisa durante uma avaliação estão em jogo e, portanto, dependem de uma análise validada para ascender na carreira, obter um financiamento etc. Não se deve

\footnotetext{
${ }^{10}$ Google Scholar: http://scholar.google.com
} 
jamais prescindir das boas práticas e recomendações de uso dos indicadores e análise de dados.

De fato, essas questões devem pautar os profissionais responsáveis por análises bibliométricas de forma geral em todos os tipos de estudos. Especialmente em nível individual a recomendação dos principais pesquisadores é a realização de um estudo multidimensional, que leve em consideração vários indicadores tanto quantitativos, quanto qualitativos. O assunto é tão pertinente que a Académie des Sciences do Institut de France (INSTITUT DE FRANCE; ACADÉMIE DES SCIENCES, 2011) publicou um relatório acerca do uso adequado da bibliometria para a avaliação individual de pesquisadores. O documento compreendeu questões sobre revisão por pares, o uso e as armadilhas da bibliometria como instrumento de avaliação, diversidade e costumes das áreas de conhecimento, a questão da quantidade e ordem das autorias nos papers - trazendo inclusive uma análise apontando as médias e estruturas das principais áreas na França, seleção de índices e bases de dados e por fim recomendações para a realização das avaliações que se alinham plenamente com as propostas apresentadas por Glänzel e Wouters (2013).

Nesse sentido, alguns pesquisadores têm tentado desenvolver modelos replicáveis para atender essa demanda emergente de avaliação. Abramo, Cicero e D’angelo (2013), por exemplo, apresentam o indicador chamado de "Fractional Scientific Strength" (FSS - em português: Força Científica Fracionada) que consiste em medir as citações normalizadas por campo de estudo das publicações de um pesquisador durante um período de observação, ao mesmo tempo em que contabiliza partes fracionárias sobre a autoria conjunta das publicações. Isso significa que são imputados pesos distintos para a ordem de apresentação dos autores nos artigos, tal peso varia de acordo com o campo de estudo, sendo que em algumas áreas o autor principal nem sempre aparece como primeiro da lista.

Há também a proposta de Wildgaard (2016), que sugere uma análise crítica do desempenho de autores baseada em um cluster de 44 indicadores. $O$ objetivo é agrupar os elementos de uma coleção para que eles sejam congregados em "Clusters". Cada cluster possui elementos muito semelhantes e, de preferência, altamente heterogêneo a partir dos elementos agrupados nos outros clusters. A partir desse agrupamento, a estrutura interna de um conjunto de dados de acordo com alguns atributos escolhidos 
pode ser interpretada. Trata-se de uma ferramenta para os pesquisadores compreenderem agrupamentos de dados e obter conhecimento de como classificar elementos em conjuntos de dados multidimensionais, interpretando suas semelhanças e desigualdades.

Temos ainda a proposta de Costas; Van Leeuwen e Bordons (2010) que tem como objetivo desenvolver um esquema classificatório que permita (a) caracterizar e descrever diferentes perfis ou classes (níveis de carreira) de cientistas, com ênfase especial na identificação de "pesquisadores top" como uma classe específica, e (b) explorar diferentes aspectos do processo de pesquisa e se eles podem diferir entre cientistas de acordo com sua classe. Tal estudo é utilizado ainda para avaliar a produtividade e impacto do pesquisador com relação à sua idade.

No entanto, o modelo de avaliação bibliométrica individual que demostrou ter maior aderência com as recomendações de boas práticas para esse tipo de análise foi apresentado pela equipe de pesquisadores do Department for bibliometrics and Publication Strategies (conhecido como Departamento de Bibliometria) da Biblioteca da Universidade de Viena. O Departamento tem como função atender as demandas da alta gestão da Universidade (apoiando iniciativas de avaliação da pesquisa) e dos pesquisadores individualmente. A equipe do Departamento, tem como principal preocupação a prevenção de estudos bibliométricos "rápidos e sujos" (inconsistentes) e, consequentemente suas interpretações incorretas e prejudiciais, alcançando uma situação com uma administração bem informada, por um lado, e cientistas bem preparados que possam lidar com todas essas práticas de avaliação por outro. Assim, desenvolveram desde sua fundação em 200833 relatórios de pesquisadores da Universidade, que objetivaram apresentar aos cientistas os aspectos quantitativos dos resultados de suas pesquisas e servir de base para uma discussão futura sobre as estratégias de publicação. Com base nesse serviço, o escopo foi ampliado para uma avaliação em nível individual do corpo docente. Importante destacar que na Universidade de Viena alguns docentes precisam ser avaliados cinco anos após a sua nomeação, devido aos critérios estabelecidos em seus termos contratuais (GORRAIZ; WIELAND; GUMPENBERGER, 2016).

A característica mais importante do relatório bibliométrico é o seu caráter multidimensional e individual. Para cada indivíduo, um relatório é pessoalmente elaborado de acordo com o(s) campo(s) de 
pesquisa correspondente(s). Este processo inclui a seleção e uso de fontes de dados adequadas, a consideração de diferentes culturas de publicação e veículos de publicação, e o uso apropriado das ferramentas disponíveis para análise e apresentação (GORRAIZ; WIELAND; GUMPENBERGER, 2016, p. 903).

Este pode ser considerado o principal ponto que diferencia o modelo proposto pelos autores: a personalização da avaliação. Se por um lado ela demanda muito mais tempo para ser gerada, por outro ela permite uma visão mais qualitativa e adaptada às diferenças entre as áreas de conhecimento, os níveis de carreira e o perfil pessoal do indivíduo analisado: "[...] a avaliação individual requer tratamento personalizado e não pode ser alcançada através de relatórios de avaliação automatizados no estilo "aperte o botão" (GORRAIZ; WIELAND; GUMPENBERGER, 2016).

O método consiste nos seguintes passos:

i. Entrevista com o pesquisador avaliado: este passo é fundamental para conhecer o trabalho do pesquisador avaliado e as peculiaridades de seu campo de investigação, além de propiciar-lhe um melhor entendimento das ferramentas e métodos de avaliação que estão sendo aplicados. A entrevista consiste em perguntas sobre as fontes de dados utilizados pelo avaliado para busca de literatura na sua área, se utiliza identificadores únicos de pesquisador, se utiliza repositórios e sistemas de registro de pesquisa da Universidade, os principais veículos de publicação da sua área, se a ordem dos autores (primeiro, último ou autor para correspondência) desempenha um papel no seu campo de pesquisa, o critério principal da sua estratégia de publicação, se publica em Acesso Aberto, se participa de conferências, se é revisor de algum veículo de publicação, se possui um website ou entrada na Wikipédia ou perfil no Google Scholar, se utiliza sistemas de gerenciamento de referências, se participa de listas de discussão ou blogs, se utiliza mídias sociais, sua opinião sobre métricas de uso (downloads) e altimetria (métricas alternativas), se gera dados de pesquisa e sua estratégia para selecionar colaboradores.

ii. Relatório ou "perfil bibliométrico" das publicações do pesquisador: o pesquisador na entrevista entrega uma lista de suas publicações e esta é comparada com as fontes de dados bibliométricos pela equipe do Departamento de Bibliometria. É produzido um relatório bibliométrico customizado com o perfil 
de publicação do avaliado. O relatório é formado pelas seguintes seções: metodologia, cobertura em bases de dados, análise de atividades para publicação, análise de afiliação e financiamento, análise de coautoria, análise de visibilidade, análise de impacto, análise de citações, análise de rede e cooperação, análise de referência, foco de pesquisa, sumário/síntese e anexos.

iii. Discussão e validação dos resultados com o pesquisador avaliado: todos os relatórios são discutidos pela equipe do Departamento com o pesquisador avaliado. Esse encontro é utilizado para dirimir possíveis dúvidas e esclarecer questões por exemplo sobre a seleção dos veículos de publicação, ou períodos de baixa produtividade.

iv. Análises opcionais: são oferecidas ao avaliado três análises opcionais, a primeira diz respeito ao foco de sua pesquisa. Com a ajuda do pesquisador seu campo de pesquisa é delineado em uma base de dados (WoS e Scopus preferencialmente) e a estratégia de busca é salva, para que seja utilizada no serviço de alerta e assim ser notificado sobre novas e relevantes publicações no seu tópico. Com base nos resultados da pesquisa, os atores-chave mais importantes dos últimos dez anos são identificados: autores e instituições mais ativos, bem como agências de financiamento. Em seguida, as publicações mais citadas e os primeiros autores mais citados são recuperados e/ou plotados em um mapa. Finalmente, as principais publicações citadas (Top 10\% e Top 1\%) são identificadas. A segunda análise aborda a exploração de referências. Solicita-se ao pesquisador que escolha três pares líderes em seu campo de pesquisa. O resultado do pesquisador será então comparado com o resultado desses pares selecionados nos últimos 10 anos, incluindo visibilidade, impacto, cooperação e análise de foco como já foi referido anteriormente. O valor adicional é criado fazendo uma análise de referência. As referências mais citadas são identificadas para os pares selecionados e, em seguida, comparadas com as mais citadas do pesquisador em avaliação. O pesquisador pode então decidir se essas fontes são ou não relevantes para ele, e se os desvios são intencionais ou não. Este tipo de análise fornece informações valiosas sobre como melhorar a base de conhecimento. A terceira análise está relacionada à avaliação do impacto societal ou do impacto 
na web. Para este propósito são utilizadas duas ferramentas, altmetric.com ${ }^{11} \mathrm{e}$ Plum $X^{12}$, às vezes até complementadas por dados recuperados da Scopus. As publicações são analisadas principalmente usando o DOI de cada publicação, mas também por meio de outras opções como URL, ISBN, número de patente, etc., dependendo da ferramenta selecionada. A maioria de nossas análises foram realizadas até agora com o PlumX. Permite uma diferenciação entre citações (em Pubmed ${ }^{13}$ e Scopus), dados de uso (Ebsco ${ }^{14}$, etc.), capturas e menções (GORRAIZ; WIELAND; GUMPENBERGER, 2016).

Como pudemos ver o modelo adotado na Universidade de Viena utiliza uma análise multidimensional para avaliação dos seus pesquisadores/docentes, levando em conta as particularidades e questões imensuráveis, concatenando-as com dados e indicadores quantitativos, evidenciando todo o espectro da carreira do indivíduo analisado.

Sobre o papel da Biblioteca nesse processo, Gorraiz; Wieland e Gumpenberger (2016, p. 912) comentam sobre sua experiência na Universidade de Viena:

\begin{abstract}
nossa experiência ilustra o papel crucial que as bibliotecas científicas modernas estão predestinadas a desempenhar em exercícios de avaliação de pesquisa. O campo da bibliometria é ideal para bibliotecários acadêmicos para fortalecer sua postura no campus. A bibliometria oferece uma grande quantidade de oportunidades para fornecer serviços inovadores tanto para a universidade como para a universidade administradora. Ao fazê-lo, os bibliotecários podem contribuir ativamente para o desenvolvimento de novas estratégias de publicação e o avanço da inovação.
\end{abstract}

As bibliotecas da Universidade de São Paulo possuem plena capacidade de fornecerem respostas qualificadas e auxiliar na agenda estratégica das suas unidades de ensino, bem como a equipe da Universidade de Viena tem demonstrado ao longo desses anos de existência.

\footnotetext{
${ }^{11}$ Altmetric.com: https://www.altmetric.com

12 PlumX: http://plumanalytics.com

${ }_{13}$ PubMed: https://www.ncbi.nlm.nih.gov/pubmed

${ }^{14}$ Ebsco: https://www.ebsco.com
} 


\section{PROCEDIMENTOS METODOLÓGICOS}

Foi aplicada para o desenvolvimento do presente estudo uma pesquisa qualitativa e quantitativa, com finalidade exploratório-descritiva, utilizando-se de levantamento de dados e análise bibliométrica baseada no método desenvolvido por Gorraiz; Wieland e Gumpenberger (2016) e adaptada à realidade do IGc/USP, bem como às necessidades surgidas ao longo de aplicação.

A seguir apresentam-se os procedimentos metodológicos adotados:

\subsection{Análise Geral}

Para a primeira parte do estudo, identificada como Análise Geral, foram realizados o mapeamento e o diagnóstico da produção intelectual do IGc/USP, conforme descrito a seguir:

I. Mapeamento da inserção da comunidade de docentes do IGc/USP em plataformas de identificação de autores e registro da produção científica.

a. Obtenção da listagem oficial de docentes ativos, sêniores ${ }^{15}$ e aposentados junto ao Departamento Pessoal e Assistência Acadêmica do IGc/USP;

b. Levantamento dos currículos dos docentes no Currículo Lattes;

c. Levantamento dos perfis dos docentes na Biblioteca Virtual da FAPESP;

d. Levantamento dos perfis dos docentes registrados no Google Scholar;

e. Levantamento para obtenção de identificadores únicos dos docentes nos sistemas: ResearcherID e ORCID;

f. Levantamento dos identificadores da base Scopus (Scopus ID) da Elsevier B.V. dos docentes que possuem trabalhos nela indexados;

g. Levantamento dos perfis dos docentes que se registraram no ResearchGate.

\footnotetext{
${ }^{15}$ De acordo com a Resolução no 6073, de 10 de março de 2012 que dispõe sobre a criação do Programa de "Professor Sênior" na USP, o indivíduo para se enquadrar nessa situação precisa estar aposentado de forma compulsória ou por tempo de serviço, ter ao menos o título de doutor e ter comprovada atuação na Universidade. Tal atividade é voluntária e não gera vínculo empregatício. Endereço eletrônico: http://www.leginf.usp.br/?resolucao=resolucao-no-6073-de-1o-de-marco-de-2012
} 
Com base nos dados obtidos por meio deste mapeamento foi possível proceder um levantamento mais completo e inequívoco, do ponto de vista da autoria dos trabalhos, propiciando assim o desenvolvimento do Diagnóstico apresentado a seguir:

II. Diagnóstico da produção científica do IGc/USP

Sistemas informacionais utilizados:

a. WeR_USP (fonte dos dados: DataUSP): trata-se de uma interface de visualização e análise de dados acerca de informações estratégicas para a USP. Desenvolvido no âmbito da Pró-reitora de Pesquisa e Superintendência de Tecnologia de Informação, o WeR_USP integra dados do Currículo Lattes e informações de citações oriundas das bases de dados WoS, Scopus e Google Scholar Citations. Tais informações encontram-se registradas em um banco de dados informacionais da USP intitulado DataUSP e tem como objetivo principal "fornecer aos gestores e dirigentes da universidade uma ferramenta computacional que proporcione análise de dados em vários contextos institucionais em que a USP está envolvida" (UNIVERSIDADE DE SÃO PAULO, 2017). Por meio dessa interface é possível analisar a produção científica da Universidade em nível global, por unidades de ensino, por departamentos e por docente.

b. Banco de Dados Bibliográfico da USP - Dedalus ${ }^{16}$ (Base de Produção Científica): de acordo com a Resolução no 2858, de 1을 de fevereiro de 1985, "as Bibliotecas das Unidades [USP] constituem órgão centralizador e depositário da produção científica, técnica e artística gerada em suas instituições a fim de salvaguardar a memória das Unidades e facilitar o acesso ao objeto físico da informação"(UNIVERSIDADE DE SÃO PAULO, 1985). Nesse sentido, as bibliotecas têm trabalhado no registro e armazenamento de toda a produção da universidade, o que resultou em um banco de dados com mais de 745 mil registros de produção científica

\footnotetext{
${ }^{16}$ Banco de Dados Bibliográfico da USP - Dedalus (Base de Produção Científica). Disponível em duas interfaces: http://www.dedalus.usp.br (catálogo bibliográfico) e http://www.bdpi.usp.br/ (plataforma analítica)
} 
(artigos, livros, anais de eventos etc.) e mais de 148 mil produções acadêmicas (teses e dissertações), tornando-se a maior fonte de dados para visualização e análise da produção da universidade. Todos os trabalhos são identificados utilizando-se o número USP do docente, que é uma chave única e o acompanha durante toda sua carreira.

c. Janus $^{17}$ (fonte dos dados: banco de dados corporativo da USP): plataforma de suporte à Pró-Reitoria de Pós-Graduação com vistas a automatizar os processos inerentes à gestão dos Programas de PósGraduação da USP, com informações para todos os níveis de usuários: gestores, programas de pós e estudantes. Por meio desta plataforma é possível consultar e matricular-se nas disciplinas oferecidas, obter informações sobre orientadores e acompanhar seu desempenho durante o curso. Além disso, do ponto de vista gerencial, é possível identificar os docentes ativos por programas de pós-graduação em períodos específicos.

d. Marte $^{18}$ (fonte dos dados: banco de dados corporativo da USP): é o sistema de gerenciamento dos Recursos Humanos da USP incluindo todas as informações sobre os funcionários e docentes ativos e aposentados. Por meio da interface de acesso dos setores de pessoal das unidades/institutos de ensino e pesquisa é possível obter informações sobre data de nascimento, data de contratação, nível na carreira, dentre outras sobre os docentes.

e. CAPES $^{19}$ (fonte dos dados: Avaliações dos Programas de Pós-Graduação brasileiros): como já mencionado anteriormente a CAPES é responsável pela avaliação dos programas de pós-graduação brasileiros por meio das coordenações de áreas, sendo possível, assim, obter notas e desempenho dos programas avaliados.

f. Scopus $\left(\right.$ Elsevier B.V. ${ }^{20}$ (fonte dos dados: própria): Scopus@ é um banco de dados bibliográfico, com dados de citação, responsável pela indexação

\footnotetext{
${ }^{17}$ Janus: https://uspdigital.usp.br/janus/comum/apresentacao.jsf

${ }^{18}$ Marte: https://uspdigital.usp.br/marteweb

${ }^{19}$ CAPES - Avaliação: http://www.capes.gov.br/avaliacao

${ }^{20}$ Scopus@ Elsevier B.V.: https://www.elsevier.com/solutions/scopus/content
} 
de mais de 22,8 mil títulos de periódicos e mais de 150 mil livros, somando mais de 70 milhões de itens indexados de todas as áreas do conhecimento. Por meio deste banco é possível realizar levantamentos de dados e citações de países e universidades, bem como de pesquisadores individualmente, utilizando-se para isso o seu identificador de autor, o ScopusID.

A Figura 1 apresenta o fluxograma para o desenvolvimento da base de dados gerada para a realização do diagnóstico da produção científica do IGc/USP.

Utilizando-se o Banco Bibliográfico Dedalus foram obtidos os registros da produção intelectual indexada do IGc/USP até novembro de 2017, totalizando 10.072 itens.

Com vistas à padronização dos dados foram realizadas correções dos títulos, dos Números Internacionais Normalizados para Publicações Seriadas (International Standard Serial Numbers - ISSN's ${ }^{21}$ ) e da nacionalidade dos periódicos (Domésticos ou Estrangeiros), a fim de proporcionar confiabilidade à análise.

A título de esclarecimento cabe aqui apresentar o critério de internacionalidade definido para a produção intelectual do IGc/USP nesta pesquisa. Como já apresentado, foram muitas as fontes dos dados utilizadas, no entanto a principal foi o Banco Dedalus, que utiliza como critério para estabelecimento da origem do item catalogado seu local de publicação: caso o item (artigo, livro, evento etc.) tenha sido publicado/realizado no Brasil este é catalogado como Nacional, ou como adotamos nesta pesquisa, Doméstico; no entanto se o item foi publicado/realizado fora do Brasil este é catalogado como Internacional (Estrangeiro).

Apesar de haver concordância com o conjunto de critérios de internacionalidade propostos por Buela-Casal (2006), optou-se, por motivo do tempo reduzido para a execução da pesquisa, manter o critério utilizado na fonte principal dos dados, e apenas executar a correção dos eventuais erros de catalogação identificados no momento da padronização.

\footnotetext{
${ }^{21}$ ISSN - https://issn.org/
} 
Figura 1 - Fluxograma de desenvolvimento da Base de Dados da Produção Intelectual do IGc/USP

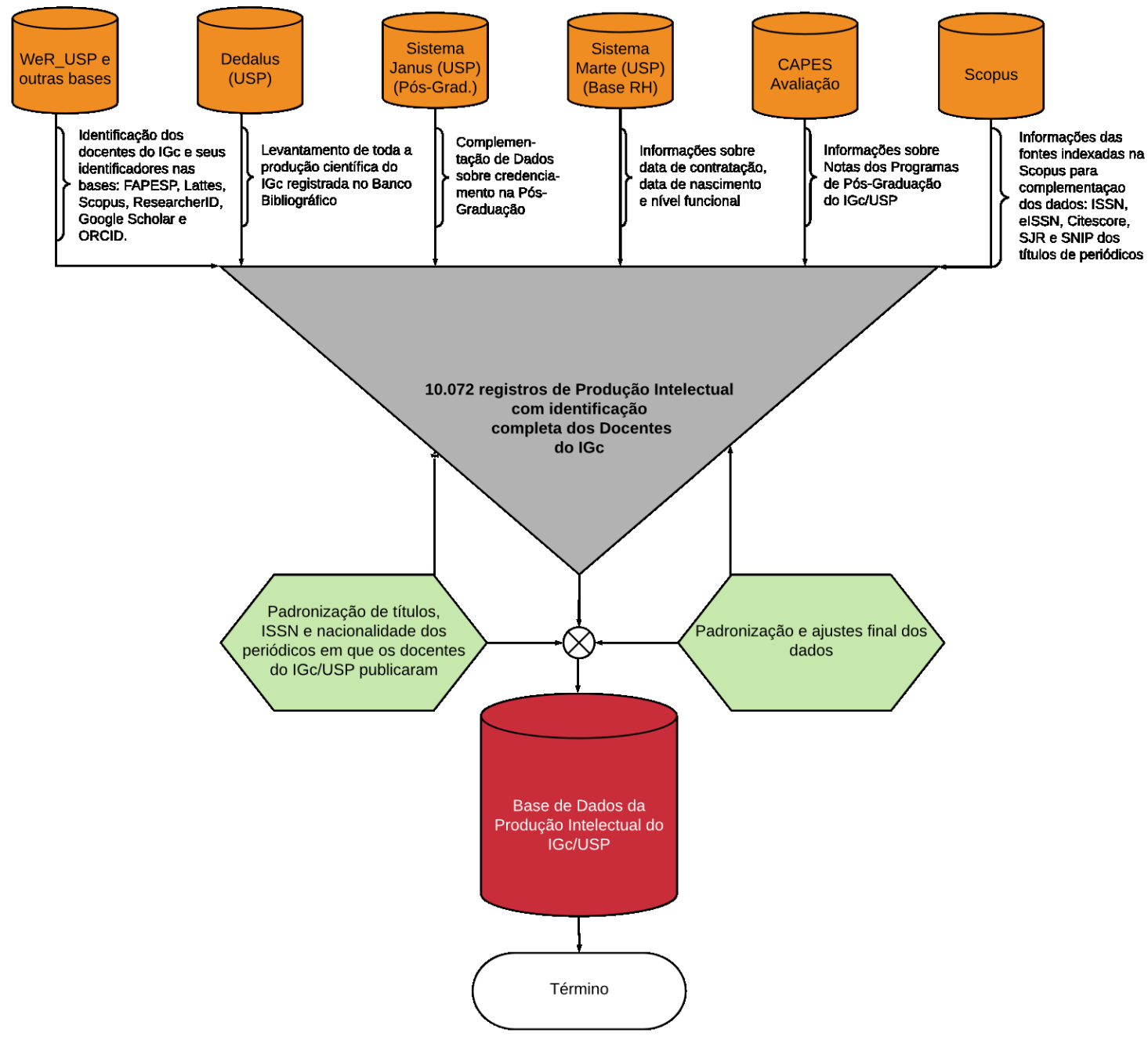

Fonte: Elaborada pelo autor.

A Tabela 1 apresenta a produção intelectual do IGc/USP, excluindo-se Teses e Dissertações, distribuída por tipo publicação, compreendendo o período de 1945 a 2017.

Artigos de periódicos compreendem 31,25\% do total de produções registradas, nos diversos veículos, no Banco Dedalus, sendo os anais de evento (TRABALHO DE EVENTO-RESUMO, TRABALHO DE EVENTO e TRABALHO DE EVENTO-RESUMO PERIODICO) o principal veículo de publicação representando $60,82 \%$ do total geral. 
Tabela 1 - Distribuição da Produção Intelectual do IGc/USP indexada no Banco Dedalus por tipo de publicação

\begin{tabular}{lrr}
\hline TIPO DE PUBLICAÇÃO & REGISTROS & \% REGISTROS \\
\hline TRABALHO DE EVENTO-RESUMO & $\mathbf{3 . 2 9 6}$ & $\mathbf{3 2 , 7 2 \%}$ \\
\hline ARTIGO DE PERIODICO & $\mathbf{3 . 1 4 7}$ & $\mathbf{3 1 , 2 5 \%}$ \\
\hline TRABALHO DE EVENTO & $\mathbf{2 . 5 6 2}$ & $\mathbf{2 5 , 4 4 \%}$ \\
\hline PARTE DE MONOGRAFIA/LIVRO & $\mathbf{4 6 9}$ & $\mathbf{4 , 6 6 \%}$ \\
\hline TRABALHO DE EVENTO-RESUMO PERIODICO & $\mathbf{2 6 8}$ & $\mathbf{2 , 6 6 \%}$ \\
\hline MONOGRAFIA/LIVRO & $\mathbf{8 5}$ & $\mathbf{0 , 8 4 \%}$ \\
\hline TRABALHO DE EVENTO-ANAIS PERIODICO & $\mathbf{3 8}$ & $\mathbf{0 , 3 8 \%}$ \\
\hline ARTIGO DE JORNAL-DEPOIMENTO/ENTREVISTA & $\mathbf{3 2}$ & $\mathbf{0 , 3 2 \%}$ \\
\hline ARTIGO DE JORNAL & $\mathbf{2 6}$ & $\mathbf{0 , 2 6 \%}$ \\
\hline ARTIGO DE PERIODICO-DEPOIMENTO/ENTREVISTA & $\mathbf{2 3}$ & $\mathbf{0 , 2 3 \%}$ \\
\hline ARTIGO DE PERIODICO-CARTA/EDITORIAL & $\mathbf{1 7}$ & $\mathbf{0 , 1 7 \%}$ \\
\hline RELATORIO TECNICO & $\mathbf{1 6}$ & $\mathbf{0 , 1 6 \%}$ \\
\hline FOLHETO & $\mathbf{1 6}$ & $\mathbf{0 , 1 6 \%}$ \\
MONOGRAFIA/LIVRO-EDITOR/ORGANIZADOR & $\mathbf{1 4}$ & $\mathbf{0 , 1 4 \%}$ \\
ARTIGO DE PERIODICO-APRESENTAÇÃO/INTRODUÇÃO & $\mathbf{9}$ & $\mathbf{0 , 0 9 \%}$ \\
\hline TEXTO NA WEB & $\mathbf{6}$ & $\mathbf{0 , 0 6 \%}$ \\
\hline MONOGRAFIA/LIVRO-TRADUCAO & $\mathbf{5}$ & $\mathbf{0 , 0 5 \%}$ \\
\hline PARTE DE MONOGRAFIA/LIVRO- & & $\mathbf{0 , 0 5 \%}$ \\
APRESENTAÇÃO/PREFÁCIO/POSFÁCIO & $\mathbf{5}$ & $\mathbf{0 , 0 5 \%}$ \\
\hline ARTIGO DE PERIODICO-DIVULGACAO & $\mathbf{5}$ & $\mathbf{0 , 0 5 \%}$ \\
\hline ARTIGO DE PERIODICO-TRADUCAO & $\mathbf{5}$ & $\mathbf{0 , 0 5 \%}$ \\
\hline ARTIGO DE PERIODICO-RESENHA & $\mathbf{5}$ & $\mathbf{0 , 0 4 \%}$ \\
\hline PATENTE & $\mathbf{4}$ & $\mathbf{0 , 1 9 \%}$ \\
\hline OUTROS & $\mathbf{1 9}$ & $\mathbf{1 0 0 , 0 0 \%}$ \\
\hline \hline TOTAL & &
\end{tabular}

Fonte: Preparada pelo autor com dados do Banco Dedalus.

No que diz respeito à Internacionalização da produção analisada do IGc/USP apenas $25,51 \%$ é estrangeira, tendo como veículos domésticos seu principal meio de publicação, conforme Tabela 2.

Tabela 2 - Distribuição da Produção Intelectual do IGc/USP indexada no Banco Dedalus distribuída por Nacionalidade

\begin{tabular}{lrr}
\hline Nacionalidade & Registros & \% Registros \\
\hline Doméstico & 7.503 & $\mathbf{7 4 , 4 9 \%}$ \\
Estrangeiro & 2.569 & $\mathbf{2 5 , 5 1 \%}$ \\
\hline \hline TOTAL & 10.072 & $100,00 \%$ \\
\hline
\end{tabular}

Fonte: Elaborada pelo autor com dados do Banco Dedalus. 
De acordo com a Tabela 3 ao todo foram analisadas as produções de 88 docentes correspondentes a três categorias, sendo 49 destes Ativos, e o restante Aposentados (somente aqueles com ao menos uma produção intelectual no período entre 2001-2016) e Sêniores. Para fins desta pesquisa, somente os docentes Ativos foram considerados.

Tabela 3 - Distribuição dos docentes analisados do IGC/USP por categoria

\begin{tabular}{lcc}
\hline Categoria & Docentes & \%Docentes \\
\hline Ativo & 49 & $55,68 \%$ \\
Aposentado & 12 & $13,64 \%$ \\
Sênior & 27 & $30,68 \%$ \\
\hline \hline Total & 88 & $100,00 \%$ \\
\hline
\end{tabular}

Fonte: Elaborada pelo autor com dados dos sistemas corporativos da USP.

\subsection{Análise Amostral}

Ao todo o IGc/USP conta com 49 docentes ativos divididos em dois Departamentos: Mineralogia e Geotectônica (GMG - 25 docentes) e Geologia Sedimentar e Ambiental (GSA - 24 docentes).

Como etapa final do diagnóstico delineado na Análise Geral, o próximo passo se direcionou aos diversos veículos de publicação utilizados pelos docentes do IGc/USP. Ao mesmo tempo a internacionalização foi um elemento importante a se considerar e levando-se em conta que a nacionalidade dos veículos (domésticos ou estrangeiros) era uma informação relevante para os periódicos e anais de evento, foi realizada uma análise do perfil dos docentes nestes dois veículos.

A Figura 2 apresenta o percentual de publicações em veículos domésticos (em contraposição ao estrangeiro), tanto em periódicos (eixo horizontal) como em anais (eixo vertical), para cada docente, de cada um dos departamentos do IGc/USP. A nuvem de pontos de ambos os gráficos permite observar que o percentual de publicação em periódicos domésticos é mais heterogêneo do que em anais de eventos.

A faixa que delimita os $70 \%$ de publicação em anais de eventos domésticos (verde) permite observar que, em ambos os departamentos, os eventos estrangeiros não respondem por um percentual significativo da produção da maioria dos docentes. Por outro lado, a produção em periódicos revela uma distribuição ao longo de toda 
extensão horizontal dos gráficos, só que revelando concentração abaixo da faixa dos 70\% (vermelha), o que denota maior percentual de publicação em periódicos domésticos (se comparado com os anais). Pode-se observar ainda que para o GMG mais docentes apresentam perfil tendendo aos periódicos estrangeiros, haja vista a quantidade de pontos abaixo dos $50 \%$.

Figura 2 - Distribuição percentual de produções do tipo Eventos e Periódicos com nacionalidade Doméstica por Departamento

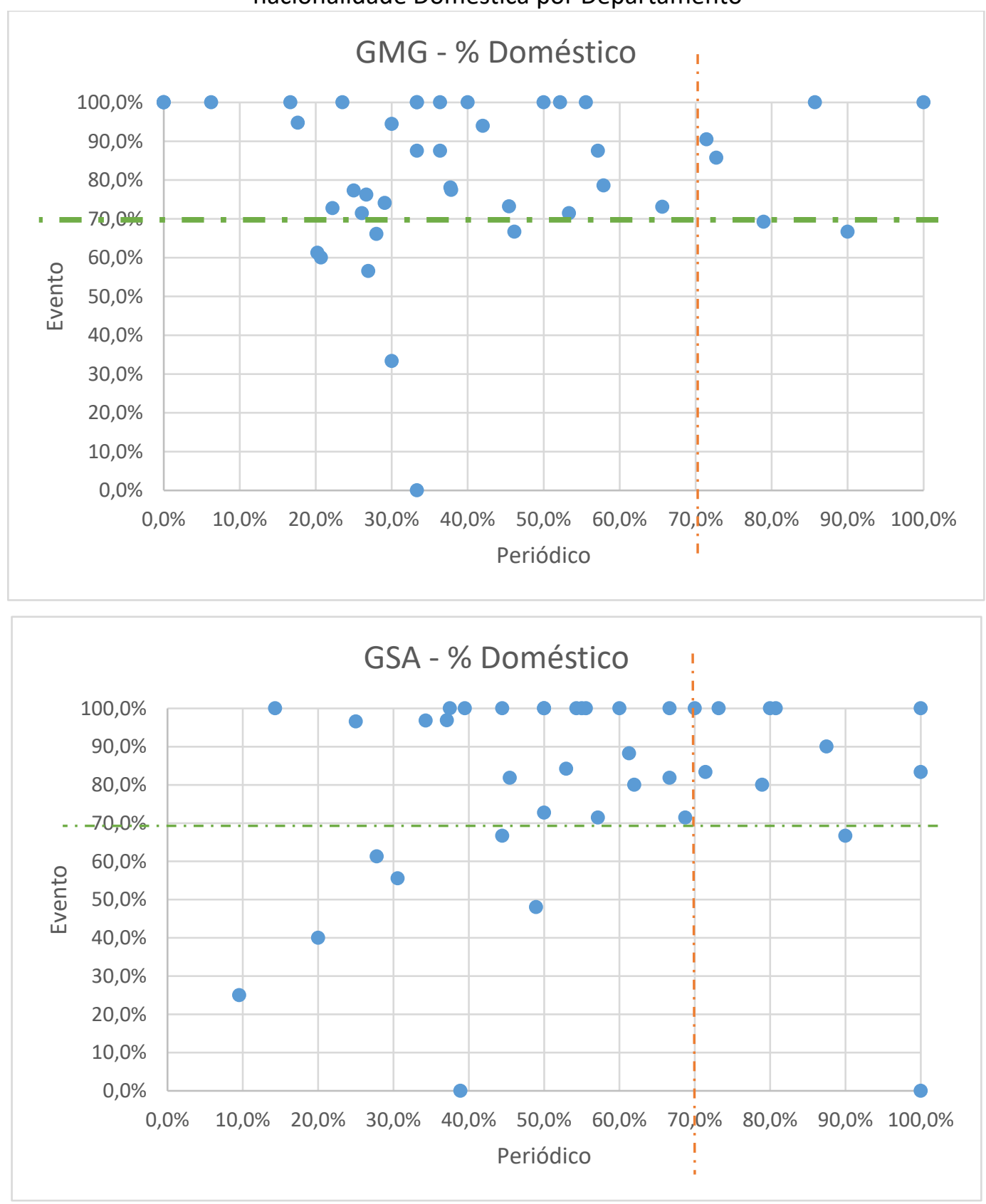

Fonte: Elaborada pelo autor com dados do Bando Dedalus. 
Devido à relevância do aspecto "internacionalização" para esta pesquisa e diante do que se observou na Figura 2 considerou-se que a produção em anais de eventos seria de menor utilidade para diferenciar os docentes segundo o nível de internacionalização, indicando que as análises deveriam se restringir à publicação em periódicos.

A amostra da população docente do IGc/USP para aplicação da pesquisa foi definida pela estratificação segundo perfil de publicação e baseada na evolução da carreira docente ${ }^{22}$ na USP. Foram analisados somente docentes em Regime de Dedicação Integral à Docência e à Pesquisa (RDIDP) e de três categorias: Professor Doutor, Professor Associado e Professor Titular (mais alto nível na carreira).

Conforme pode-se verificar no fluxograma, o filtro de seleção amostral (SANTANA; MUGNAINI, 2018) usou como critério primordial a participação dos docentes na Pós-Graduação. O IGc/USP possui três Programas de Pós-Graduação: Geoquímica e Geotectônica (PPGGG), Mineralogia e Petrologia (PPGMP) e Recursos Minerais e Hidrogeologia (PPGRMH).

Com a população a ser estudada definida passou-se para os passos seguintes:

i. Definição da tipologia material: Artigos de Periódicos (conforme explicitado na seção anterior);

ii. Identificação dos docentes que participaram de duas ou mais Avaliações da CAPES (uma vez que se pretendia comparar a evolução):

a. T1-Trienal 2004, artigos publicados em 2001-2003;

b. T2-Trienal 2007, artigos publicados em 2004-2006;

c. T3-Trienal 2010, artigos publicados em 2007-2009;

d. T4-Trienal 2013, artigos publicados em 2010-2012, e;

e. Q1-Quadrienal 2017, artigos publicados em 2013-2016.

iii. Subdivisão do período completo (2001-2016) em dois subperíodos

a. Subperíodo 1 (T1-T3), e;

b. Subperíodo 2 (T4-Q1).

iv. Cálculo dos percentuais da nacionalidade (doméstico ou estrangeiro) dos artigos publicados, em cada subperíodo.

22 Carreira docente - Departamento de Recursos Humanos: http://www.usp.br/drh/trabalhe-nausp/carreiras-usp/carreira-docente/ 
Figura 3 - Fluxograma para criação de perfil de publicação dos Docentes do IGc/USP

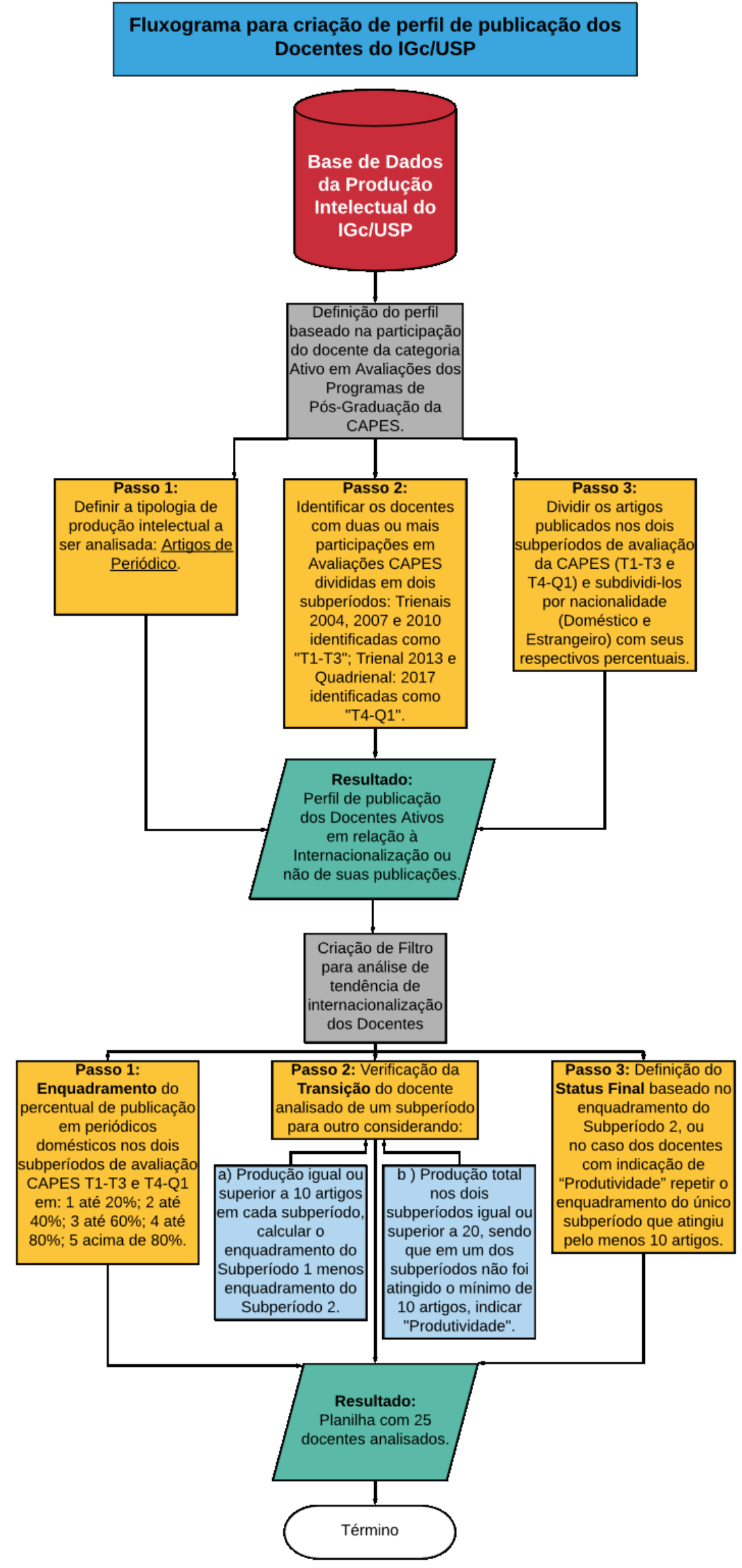

Fonte: Elaborada pelo autor. 
De posse de tais informações realizou-se o enquadramento dos docentes em níveis de publicação nacional (doméstica): se publicou até $20 \%$ em periódicos nacionais, seu nível de publicação nacional é [1]; até 40\%, [2]; até 60\% [3], até $80 \%$ [4] e acima de $80 \%$ [5]. Determinado esse nível para cada um dos subperíodos, pôde-se compará-los, a fim de verificar se houve diminuição do nível de publicação nacional - ou seja, se ocorreu internacionalização. Tais procedimentos visaram diferenciar docentes segundo os seguintes perfis, que apresentaram: (1) diferentes níveis extremos de produção (nacional ou internacional), ou; (2) mudança de nível significativa (transição) entre os subperíodos.

Então, considerou-se primeiramente sua produtividade: o docente deveria ter em cada subperíodo ao menos 10 artigos ou pelo menos 20 artigos nos dois subperíodos somados. Em caso positivo seria identificada sua transição considerando a subtração: Subperíodo 1 e Subperíodo 2. O resultado era a magnitude de sua "Transição". Por exemplo, se um docente no primeiro subperíodo (T1-T3) teve um nível de publicação nacional 4 e no segundo subperíodo 1 sua transição foi 3 (significando que o mesmo evoluiu 3 níveis rumo à internacionalização da sua produção).

Nos casos em que um docente não atingiu o mínimo de 10 artigos em um dos dois subperíodos, porém a soma de ambos era igual o superior a 20, este recebeu a indicação de "Produtividade" no lugar do cálculo. Estes critérios de produtividade visaram garantir uma maior quantidade de dados e consistência nas análises - sendo, portanto, um critério de exclusão.

Finalmente, o nível do docente no segundo subperíodo foi denominado "Status Final", sendo que no caso dos docentes com indicação de "Produtividade" não houve cálculo da Transição e o Status Final consistiu no nível identificado no único subperíodo em que haviam pelo menos 10 artigos.

Dessa forma, partindo-se do total de 49 docentes ativos, 29 encontravam-se credenciados em pelo menos dois dos ciclos avaliativos da Capes (T1, T2, T3, T4 e Q1). Com a aplicação dos critérios do filtro, estes determinaram uma amostra total 25 docentes.

Por fim esses docentes foram organizados em estratos, considerando-se a Transição e o Status Final, além do departamento e função, resultando num total de 9 estratos, dos quais foi selecionado um docente como amostra para aplicação do método 
de Gorraiz; Wieland; Gumpenberger (2016), conforme apresentado no Quadro 1, a seguir.

Quadro 1 - Seleção da Amostra

\begin{tabular}{|c|c|c|c|c|c|c|c|c|}
\hline Docente & Depto. & Função & $\begin{array}{l}\text { T1- } \\
\text { T3 } \\
\end{array}$ & $\begin{array}{l}\text { T4- } \\
\text { Q1 } \\
\end{array}$ & Transição & $\begin{array}{c}\text { Status } \\
\text { Final } \\
\end{array}$ & Estrato & Amostra \\
\hline Docente 01 & GMG & Prof. Titular & 3 & 1 & 2 & 1 & 1 & $x$ \\
\hline Docente 02 & GSA & Prof. Titular & 4 & 2 & 2 & 2 & 2 & \\
\hline Docente 03 & GMG & Prof. Titular & 4 & 2 & 2 & 2 & 2 & \\
\hline Docente 04 & GMG & Prof. Titular & 4 & 2 & 2 & 2 & 2 & $x$ \\
\hline Docente 05 & GMG & Prof. Titular & 2 & 1 & 1 & 1 & 3 & $x$ \\
\hline Docente 06 & GMG & Prof. Associado & 3 & 2 & 1 & 2 & 4 & $x$ \\
\hline Docente 07 & GSA & Prof. Titular & 3 & 2 & 1 & 2 & 4 & \\
\hline Docente 08 & GSA & Prof. Titular & 5 & 4 & 1 & 4 & 5 & $x$ \\
\hline Docente 09 & GSA & Prof. Titular & 2 & 2 & 0 & 2 & 6 & \\
\hline Docente 10 & GMG & Prof. Titular & 2 & 2 & 0 & 2 & 6 & \\
\hline Docente 11 & GSA & Prof. Associado & 2 & 2 & 0 & 2 & 6 & \\
\hline Docente 12 & GMG & Prof. Associado & 2 & 2 & 0 & 2 & 6 & $x$ \\
\hline Docente 13 & GSA & Prof. Titular & 3 & 3 & 0 & 3 & 6 & \\
\hline Docente 14 & GSA & Prof. Titular & 4 & 5 & -1 & 5 & 7 & $x$ \\
\hline Docente 15 & GSA & Prof. Associado & 4 & 1 & Produtividade & 1 & 8 & $x$ \\
\hline Docente 16 & GSA & Prof. Associado & 5 & 1 & Produtividade & 1 & 8 & \\
\hline Docente 17 & GMG & Prof. Associado & 3 & 1 & Produtividade & 1 & 8 & \\
\hline Docente 18 & GMG & Prof. Associado & 3 & 2 & Produtividade & 2 & 9 & \\
\hline Docente 19 & GMG & Prof. Titular & 1 & 2 & Produtividade & 2 & 9 & \\
\hline Docente 20 & GMG & Prof. Associado & 1 & 2 & Produtividade & 2 & 9 & \\
\hline Docente 21 & GSA & Prof. Associado & 5 & 2 & Produtividade & 2 & 9 & \\
\hline Docente 22 & GMG & Prof. Associado & 2 & 3 & Produtividade & 3 & 9 & \\
\hline Docente 23 & GSA & Prof. Associado & 2 & 3 & Produtividade & 3 & 9 & \\
\hline Docente 24 & GMG & Prof. Associado & 4 & 4 & Produtividade & 4 & 9 & \\
\hline Docente 25 & GSA & Prof. Doutor & 1 & 4 & Produtividade & 4 & 9 & $\mathrm{x}$ \\
\hline
\end{tabular}

Fonte: Elaborada pelo autor com dados dos sistemas corporativos da USP e Banco Dedalus.

\subsection{Adaptação do Método de Gorraiz, Wieland e Gumpenberger}

De acordo com os objetivos desta pesquisa, procedeu-se aplicação da adaptação do método de Gorraiz; Wieland; Gumpenberger (2016), que se baseou em:

I. Entrevista com os docentes do IGc/USP por meio do questionário disponível no Apêndice B (no Apêndice A encontra-se a versão traduzida livremente do original).

Os autores do método afirmam que a entrevista é uma parte altamente relevante para a avaliação individual pois 


\begin{abstract}
"por um lado, os bibliométricos e os avaliadores obtêm informações valiosas sobre o trabalho do pesquisador e as peculiaridades do campo de pesquisa correspondente. Por outro lado, o pesquisador tem a oportunidade de entender os métodos e ferramentas de avaliação aplicados e discutir adequação e restrições." (GORRAIZ; WIELAND; GUMPENBERGER, 2016)
\end{abstract}

Ou seja, o questionário/entrevista tem como objetivo servir de suporte à identificação, desambiguação, coleta e análise dos dados a serem utilizados no desenvolvimento do perfil bibliométrico.

O questionário possui uma sequência estruturada e fundamentada de aplicação:

- Questões 1 e 6 dizem respeito às fontes de dados a serem utilizadas nas análises bibliométricas;

- Questão 2 é importante para ser utilizada em uma possível desambiguação de dados;

- Questão 3 foi adaptada do original, uma vez que a USP não possui um Sistema de Informação de Pesquisa Corrente (CRIS - Current Research Information System), todavia o banco Dedalus assume esse papel, e a questão se apresenta pertinente porque tal banco também pode ser um suporte na desambiguação de dados;

- Questões 4 (adaptada pois a USP não possui um Repositório Institucional), 5 (adaptada para facilitar a compreensão), 8 e 9 (adaptada pois a USP não possui uma política de Acesso Aberto) são relevantes para a análise de visibilidade;

- Questão 7 permite compreender como os papéis dos pesquisadores são representados nos artigos científicos, bem como identificar e compreender a cultura de publicação da área;

- Questões 10 (adaptada para identificação dos eventos pertinentes para o docente), 11 e 12 (adaptada com vistas a obter a visão do docente em caso negativo) permitem verificar a experiência e a reputação do docente no seu campo de atuação; 
- Questões 13 a 17 permitem compreender a visão do docente sobre as novas métricas e mídias sociais, e a adaptação na questão 17 permite verificar sua visão sobre as métricas já estabelecidas;

- Questão 18 permite verificar qual o conhecimento do docente acerca da temática de gerenciamento de dados, bem como identificar as plataformas de depósito desse conteúdo;

- Questão 19 permite conhecer os critérios e instrumentos utilizados pelo docente na seleção de potenciais colegas/colaboradores;

- Questões 20 e 21 foram acrescentadas ao questionário com o intuito de conhecer a visão do docente sobre os processos avaliativos existentes e assim compreender melhor seu perfil de publicação. Além disso, tais questões foram relevantes para a elaboração das análises e discussão dos resultados obtidos nesta pesquisa;

- Questão 22 visa atender alguma expectativa específica do docente que porventura não tenha sido atendida nas demais questões.

Para aplicação do questionário foi redigida uma carta (Apêndice C) apresentando os objetivos da pesquisa e convidando o docente a agendar uma data e horário que melhor Ihe conviesse para a realização da entrevista de forma pessoal.

Dos nove (9) docentes da amostra oito (8) responderam positivamente ao convite e apenas um (1) docente (Docente 08) por motivo de força maior não pôde participar da entrevista, mesmo tendo Ihe sido ofertada, em caráter excepcional, a possibilidade de responder o questionário por e-mail.

As entrevistas tiveram seus áudios gravados eletronicamente com a autorização expressa dos docentes por meio de um Termo de Consentimento Livre e Esclarecido (Apêndice D) o qual preservava e assegurava o anonimato dos docentes, por conta disto não foram incluídas as transcrições dos áudios neste estudo.

Nesse sentido, para fins de análise, foi realizada uma síntese de cada uma das entrevistas as quais se encontram registradas no Apêndice $E$. 


\section{Relatório/Perfil Bibliométrico individual da produção dos docentes.}

Após as entrevistas e de posse da síntese de cada docente procedeu-se com o próximo estágio do método, a confecção do relatório/perfil bibliométrico individual dos docentes. O relatório, assim como o questionário foi adaptado e contemplou as seguintes seções:

\section{- Definição temporal dos dados a serem utilizados no relatório/perfil bibliométrico.}

O tempo de cobertura definido para análise compreendeu o mesmo utilizado para definição da amostra, 2001 a 2016.

\section{- Definição de uso e cobertura das fontes de dados.}

Para fins desta pesquisa foram definidas como fontes de dados o Banco Dedalus, a WoS Core Collection, não sendo contempladas outras fontes que porventura tenham sido indicadas pelos docentes nas entrevistas.

\section{- Análise da atividade de publicação do docente.}

A análise tem o intuito de identificar o perfil de publicação do docente, verificando quais os principais tipos de publicação. Todavia, para esta pesquisa a análise mais depurada foi realizada às publicações efetuadas em periódicos indexados na base de dado WoS Core Collection e analisados pelo InCites ${ }^{23}$, por serem fontes e ferramentas que permitem analisar as citações.

\section{- Análise de coautorias.}

Para a análise de coautorias foram identificados o número de coautores e a posição dos docentes da amostra nos artigos (dividida entre: primeiro autor, meio posição intermediária - e último).

\footnotetext{
${ }^{23} \mathrm{O}$ InCites é uma ferramenta para análise de produção científica, que permite personalização de visualizações e apresentação de dados. Sua interface é web e permite analisar a produtividade institucional, monitorar a atividade de colaboração, identificar pesquisadores influentes e áreas de destaque. Sua fonte de dados é a Web of Science. $O$ acesso está disponível pelo endereço: 
- Análise da cooperação do docente (institucional, nacional, internacional).

Tal análise se baseia nas informações advindas dos coautores dos artigos publicados pelos docentes. Com base nos dados extraídos da WoS Core Collection foram analisadas as instituições e países colaboradores de cada docente.

\section{- Análise da afiliação empregada e financiamentos de pesquisa recebidos.}

Apesar de a USP não possuir uma formalização acerca da afiliação a ser empregada por seu corpo docente em publicações científicas, foram verificadas as afiliações dos docentes da amostra na WoS Core Collection, na qual as afiliações relacionadas à Universidade de São Paulo foram padronizadas. Dessa forma, todos os artigos recuperados encontravam-se com a afiliação correta.

Quanto às informações de financiamento de pesquisa estas foram obtidas também com dados da WoS e analisada pela ferramenta InCites, também da Clarivate Analytics. Importante destacar que a WoS garante a padronização dos dados de Agências de Fomento a partir do ano de 2008 e, assim, parte dos dados de cada docente da amostra não puderam ser analisados, pois, como já informado, a cobertura temporal foi de 2001 a 2016.

Foram incorporadas à análise os nomes das agências de fomento, quantidade de artigos das pesquisas financiadas indexados na WoS, quantidade de citações recebidas, índice de citações por artigo e Impacto de Citação Normalizado pela Categoria (Category Normalized Citation Impact) - que é calculado dividindo a contagem real de itens citados pela taxa de citações esperada para documentos com a mesma tipologia, ano de publicação e área de assunto (THOMSON REUTERS, 2014, p. 11-12).

\section{- Análise de visibilidade da produção científica do docente.}

A visibilidade da produção científica é compreendida pelos autores do método como tendo duas partes, sendo uma delas referente ao percentual da produção dos docentes indexada internacionalmente e a outra o número e o percentual dos artigos presentes em periódicos de impacto.

Assim, foi identificado o total de artigos publicados pelos docentes da amostra tomando como base o banco Dedalus e suas produções indexadas na WoS Core Collection. 
Para fins de análises complementares foram adicionados os estratos de classificação do Qualis Periódicos específicos dos anos compreendidos pelas avaliações trienais e quadrienal da CAPES e quantidade de artigos publicados em periódicos do 1은 Quartil do Fator de Impacto (Journal Impact Factor do Journal Citation Reports $\mathrm{JIF} / \mathrm{JCR}^{24}$ ) na área em que esse melhor se posiciona.

\section{- Análise de impacto da produção científica do docente.}

O impacto da produção científica foi medido pelo total de artigos indexados na WoS Core Collection, percentual de artigos citados, citações recebidas, citações por artigo, quantidade de artigos presentes nos Top $10 \%{ }^{25}$ - que compreende os $10 \%$ dos artigos mais citados na WoS Core Collection - e o Impacto de Citação Normalizado pela Categoria.

\section{- Análise das referências utilizadas pelo docente em sua produção científica.}

A análise se baseou nos dados obtidos com as referências citadas nos artigos publicados e indexados pela WoS Core Collection dos docentes da amostra. Para cada docente foi gerada uma lista com os títulos das publicações e a quantidade de vezes que estas foram citadas.

Utilizou-se o método de Zonas de Bradford (BRADFORD, 1934), para analisar a frequência de citações por periódicos afim de determinar quão pertinentes ao escopo destes elas são. Assim, foram separados os conjuntos de referências citadas de cada docente da amostra e o total foi dividido por três zonas - partindo daquela de maior frequência para aquela com menor - possibilitando verificar quais as publicações mais pertinentes para a área de atuação do docente.

Assim, foi possível comparar o que o docente utiliza como base referencial de citação, com os canais em que publica seus resultados de pesquisa. Além disso, permitiu

\footnotetext{
${ }^{24}$ Journal Impact Factor / Journal Citation Reports: http://jcr.incites.thomsonreuters.com

${ }^{25}$ A WoS Core Collection possui dentre sua gama de indicadores dois que dizem respeito ao percentual de alto impacto dos artigos de sua base levando em conta o total de citações recebidas, são eles o Top 1\% e o Top 10\%. Artigos no Top 1\% representam o 1\% mais citado da base (THOMSON REUTERS, 2014, p. 15). Todavia nenhum dos docentes da amostra possuía artigos com essas características e portanto manteve-se somente o Top $10 \%$.
} 
verificar ainda se as publicações citadas pelo docente na entrevista como sendo as mais importantes do seu campo são aquelas que ele efetivamente utiliza.

Importante ressaltar que não foram executadas ações de padronização das listas de referências obtidas pela WoS e isso possibilitou verificarmos a deficiência da base quanto à parametrização desses dados, como por exemplo falhas de marcações, títulos iguais com abreviações diferentes, gerando, assim, possíveis inconsistências em citações dentre, outras.

Por fim, analisou-se a idade das referências utilizadas pelos docentes dividindoas em faixas de anos: $0-5,6-10,11-20,21-30,31-40 ; 41-50$ e maior que 50 . Permitindo verificar se há uma média equilibrada entre as publicações mais recentes e as com maior idade.

- Informações adicionais.

O item foi desenvolvido com o objetivo de apresentar fatos adicionais constatados durante as entrevistas e que porventura não tenham sido identificados ao longo do relatório/perfil bibliométrico do docente.

Os Perfis Bibliométricos foram desenvolvidos para os nove (9) docentes da amostra.

Mesmo o Docente 08 não tendo respondido o questionário considerou-se importante, para fins de análise, o desenvolvimento de seu perfil bibliométrico. 


\section{RESULTADOS E DISCUSSÃO}

Os resultados e suas respectivas discussões estão organizados na mesma ordem estabelecida nos Procedimentos Metodológicos com vistas a facilitar as análises.

\subsection{Análise Geral}

O primeiro passo da Análise Geral foi o mapeamento da inserção da comunidade de docentes do IGc/USP em plataformas de identificação de autores e registro da produção científica.

A primeira ação foi a obtenção da listagem oficial de docentes ativos, aposentados e sêniores. Tal informação foi obtida junto ao Departamento Pessoal e Assistência Acadêmica do IGc/USP, com a identificação de número USP (código único da Universidade para cada indivíduo cadastrado nos sistemas), e-mail, Departamento, Data de Nascimento, Data de Ingresso como docente USP, Dados de Carreira (Classe, Mérito, Nível e Função) e Gênero.

De posse tais informações foram realizadas buscas nos sistemas de registro de pesquisadores e identificadores únicos de autor (que também possuem função de curriculum vitae): Currículo Lattes; Biblioteca Virtual da FAPESP; perfil do Google Scholar Citations; identificadores únicos do ResearcherID e ORCID; identificadores da base Scopus (Scopus ID) da Elsevier B.V.; registro no ResearchGate; além de perfil na Biblioteca Digital de Produção Intelectual da USP26.

Assim, pudemos identificar, de acordo com o quadro disponível no Apêndice $F$, que o IGc/USP possuía, até novembro de 2017, 49 docentes ativos, 27 sêniores e 12 aposentados.

Na Tabela 4 pode-se observar que a distribuição dos Docentes por Departamento (Mineralogia e Geotectônica - GMG e Geologia Sedimentar e Ambiental - GSA) e Função é equitativa. Quanto aos docentes ativos ao todo o IGc/USP possuía 22 Professores Doutores, 14 Professores Associados e 13 Professores Titulares.

Tabela 4 - Distribuição dos Docentes Ativos por Departamentos do IGc/USP e Função

\footnotetext{
${ }^{26}$ Biblioteca Digital de Produção Intelectual da USP (BDPI): $\underline{\text { http://bdpi.usp.br/ }}$
} 


\begin{tabular}{lcc}
\hline Departamentos/Função & Docentes & \% Docentes \\
\hline GMG & $\mathbf{4 4}$ & $\mathbf{5 0 , 0 0 \%}$ \\
Prof. Associado & 7 & $15,91 \%$ \\
Prof. Doutor & 11 & $25,00 \%$ \\
Prof. Titular & 7 & $15,91 \%$ \\
Aposentado & 6 & $13,64 \%$ \\
Sênior & 13 & $29,55 \%$ \\
GSA & $\mathbf{4 4}$ & $\mathbf{5 0 , 0 0 \%}$ \\
Prof. Associado & 7 & $15,91 \%$ \\
Prof. Doutor & 11 & $25,00 \%$ \\
Prof. Titular & 6 & $13,64 \%$ \\
Aposentado & 6 & $13,64 \%$ \\
Sênior & 14 & $31,82 \%$ \\
\hline \hline Total Geral & $\mathbf{8 8}$ & $\mathbf{1 0 0 , 0 0 \%}$ \\
\hline
\end{tabular}

Fonte: Elaborada pelo autor com dados dos sistemas corporativos da USP.

Desses 88 docentes Ativos (A), Sêniores (S) e Aposentados (Ap), 87 possuíam perfis no Currículo Lattes (somente 1 Ap não possuía), 79 na Biblioteca Virtual FAPESP (47A, 23S e 9Ap), 51 no Google Scholar Citations (35A, 14S e 2Ap), 84 no Scopus ID (48A, $26 \mathrm{~S}$ e 10Ap), 30 no ResearcherID (30A, 7S e 2Ap), 62 no ResearchGate (43A, 16S e 3Ap) e 34 no ORCID (27A, 6S e 1Ap).

Com base nesses dados é possível constatar que os docentes do IGc/USP entendem a necessidade de se projetar nos mais diversos espaços acadêmico-científicos na Internet, além daqueles exigidos pelos vínculos institucionais como o Currículo Lattes e BV FAPESP, ou daqueles gerados automaticamente como o ScopusID. Quanto a este último, foi realizado um trabalho de verificação dos dados dos docentes na base Scopus de fevereiro a maio de 2017 com vistas a padronizar e unificar perfis duplicados e até triplicados dos docentes do IGc/USP. Assim, os dados aqui apresentados possuem alto grau de consistência.

Retomando a questão da inserção dos docentes em bases de currículos, o ResearchGate teve um grande destaque com $70 \%$ dos docentes utilizando-o, demonstrando que este tem sido um importante canal de divulgação das pesquisas do IGc/USP.

De posse de tais informações os dados da produção intelectual do IGc/USP foram coletados, conforme apresentado no Capítulo 7.1, gerando uma base de dados com mais de 10 mil registros. Por meio desses dados verificamos que $74,49 \%$ da produção total é 
predominantemente doméstica e que em termos de Artigos de Periódicos, que é a tipologia de produção analisada nesta pesquisa, a Tabela 5 apresenta que somente 40,96\% é estrangeira, confirmando esta característica de maior concentração da produção em veículos de publicação nacionais.

Tabela 5 - Distribuição da Produção de Artigos de Periódicos do IGc/USP indexada no Banco Dedalus distribuída por Nacionalidade

\begin{tabular}{lrr}
\hline Nacionalidade & Registros & \% Registros \\
\hline Doméstico & 1.858 & $59,04 \%$ \\
Estrangeiro & 1.289 & $40,96 \%$ \\
\hline \hline Total & 3.147 & $100,00 \%$ \\
\hline
\end{tabular}

Fonte: Elaborada pelo autor com dados do Banco Dedalus.

Tal constatação auxiliou, como já apresentado, na operacionalização e definição da Análise Amostral.

\subsection{Análise Amostral}

Como já explicitado o fator Internacionalização foi preponderante para definição da Análise Amostral, de modo a permitir uma melhor avaliação do método de Gorraiz, Wieland \& Gumpenberger (2016).

Nesse sentido, foi pertinente utilizar a Avaliação da CAPES como instrumento fundamental de comparação, visto que os Programas de Pós-Graduação são incentivados a se internacionalizarem. A Tabela 6 nos apresenta a produção do IGc/USP em artigos publicada nos períodos cobertos pelas Avaliações Trienais da CAPES de 2004, 2007, 2010 e 2013 e Quadrienal de 2017.

É possível verificar que houve um crescimento do percentual de artigos estrangeiros nas Avaliações da CAPES, tendo passado de 45,41\% na Trienal de 2004 para 69,19\% na Quadrienal de 2017, resultando em um aumento de $23,78 \%$. Verifica-se, também, um aumento dos artigos publicados entre as avaliações. 
Tabela 6 - Produção de Artigos de Periódicos do IGc/USP indexada no Banco Dedalus distribuída pelas Avaliações da CAPES e por Nacionalidade compreendendo todas as categorias de docentes (Ativos, Aposentados e Sêniores) credenciados na Pós-Graduação

\begin{tabular}{|c|c|c|c|c|c|}
\hline \multirow{2}{*}{ Avaliações CAPES } & \multicolumn{2}{|c|}{ Doméstico } & \multicolumn{2}{|c|}{ Estrangeiro } & \multirow{2}{*}{$\begin{array}{l}\text { Total de } \\
\text { Artigos }\end{array}$} \\
\hline & Artigos & $\%$ Artigos & Artigos & \%Artigos & \\
\hline Trienal 2004 & 125 & $54,59 \%$ & 104 & $45,41 \%$ & 229 \\
\hline Aposentados & 10 & $71,43 \%$ & 4 & $28,57 \%$ & 14 \\
\hline Ativos & 56 & $50,00 \%$ & 56 & $50,00 \%$ & 112 \\
\hline Sêniores & 59 & $57,28 \%$ & 44 & $42,72 \%$ & 103 \\
\hline Trienal 2007 & 101 & $50,75 \%$ & 98 & $49,25 \%$ & 199 \\
\hline Aposentados & 10 & $58,82 \%$ & 7 & $41,18 \%$ & 17 \\
\hline Ativos & 48 & $48,00 \%$ & 52 & $52,00 \%$ & 100 \\
\hline Sêniores & 43 & $52,44 \%$ & 39 & $47,56 \%$ & 82 \\
\hline Trienal 2010 & 122 & $52,14 \%$ & 112 & $47,86 \%$ & 234 \\
\hline Aposentados & 1 & $33,33 \%$ & 2 & $66,67 \%$ & 3 \\
\hline Ativos & 73 & $51,41 \%$ & 69 & $48,59 \%$ & 142 \\
\hline Sêniores & 48 & $53,93 \%$ & 41 & $46,07 \%$ & 89 \\
\hline Trienal 2013 & 140 & $47,30 \%$ & 156 & $52,70 \%$ & 296 \\
\hline Aposentados & 3 & $30,00 \%$ & 7 & $70,00 \%$ & 10 \\
\hline Ativos & 67 & $41,36 \%$ & 95 & $58,64 \%$ & 162 \\
\hline Sêniores & 70 & $56,45 \%$ & 54 & $43,55 \%$ & 124 \\
\hline Quadrienal 2017 & 122 & $30,81 \%$ & 274 & $69,19 \%$ & 396 \\
\hline Aposentados & 4 & $26,67 \%$ & 11 & $73,33 \%$ & 15 \\
\hline Ativos & 80 & $28,57 \%$ & 200 & $71,43 \%$ & 280 \\
\hline Sêniores & 38 & $37,62 \%$ & 63 & $62,38 \%$ & 101 \\
\hline Total & 610 & $45,05 \%$ & 744 & $54,95 \%$ & 1.354 \\
\hline
\end{tabular}

Fonte: Elaborada pelo autor com dados do Banco Dedalus.

Considerando-se somente os Docentes Ativos do IGc/USP, as Tabelas 7 e 8, corroboram o crescimento da publicação dessa produção em veículos estrangeiros, atingindo na última Avaliação de 2017 71,43\% e 72,65\% respectivamente, demonstrando que os docentes estão atentos aos critérios de publicação exigidos pela Pós-Graduação.

Destaca-se ainda que na Tabela 7 temos a produção de 38 docentes que corresponde a 796 artigos, enquanto que na Tabela 8 temos 29 docentes com 718 artigos. 
Tabela 7 - Produção de Artigos de Periódicos do IGc/USP indexada no Banco Dedalus distribuída pelas Avaliações da CAPES e por Nacionalidade compreendendo somente docentes Ativos credenciados na Pós-Graduação em ao menos um período de Avaliação

\begin{tabular}{lccccc}
\hline \multirow{2}{*}{ Avaliações CAPES } & \multicolumn{2}{c}{ Doméstico } & \multicolumn{2}{c}{ Estrangeiro } & Total de \\
& Registros & \%Registros & Registros & \%Registros & Registros \\
\hline Trienal 2004 & 56 & $50,00 \%$ & 56 & $50,00 \%$ & 112 \\
\hline Trienal 2007 & 48 & $48,00 \%$ & 52 & $52,00 \%$ & 100 \\
\hline Trienal 2010 & 73 & $51,41 \%$ & 69 & $48,59 \%$ & 142 \\
Trienal 2013 & 67 & $41,36 \%$ & 95 & $58,64 \%$ & 162 \\
Quadrienal 2017 & 80 & $\mathbf{2 8 , 5 7 \%}$ & 200 & $\mathbf{7 1 , 4 3 \%}$ & 280 \\
\hline \hline Total & $\mathbf{3 2 4}$ & $\mathbf{4 0 , 7 0 \%}$ & $\mathbf{4 7 2}$ & $\mathbf{5 9 , 3 0 \%}$ & $\mathbf{7 9 6}$ \\
\hline
\end{tabular}

Fonte: Elaborada pelo autor com dados do Banco Dedalus.

Tabela 8 - Produção de Artigos de Periódicos do IGc/USP indexada no Banco Dedalus distribuída pelas Avaliações da CAPES e por Nacionalidade compreendendo somente docentes Ativos credenciados na Pós-Graduação em dois ou mais períodos de Avaliação

\begin{tabular}{lccccc}
\hline \multirow{2}{*}{ Avaliações CAPES } & \multicolumn{2}{c}{ Doméstico } & \multicolumn{2}{c}{ Estrangeiro } & Total de \\
& Registros & \%Registros & Registros & \%Registros & Registros \\
\hline Trienal 2004 & 49 & $48,51 \%$ & 52 & $51,49 \%$ & 101 \\
Trienal 2007 & 45 & $47,37 \%$ & 50 & $52,63 \%$ & 95 \\
Trienal 2010 & 67 & $51,15 \%$ & 64 & $48,85 \%$ & 131 \\
Trienal 2013 & 58 & $39,73 \%$ & 88 & $60,27 \%$ & 146 \\
Quadrienal 2017 & 67 & $27,35 \%$ & 178 & $72,65 \%$ & 245 \\
\hline \hline Total & $\mathbf{2 8 6}$ & $\mathbf{3 9 , 8 3 \%}$ & $\mathbf{4 3 2}$ & $\mathbf{6 0 , 1 7 \%}$ & $\mathbf{7 1 8}$ \\
\hline
\end{tabular}

Fonte: Elaborada pelo autor com dados do Banco Dedalus.

A Tabela 9 nos apresenta a distribuição da produção pelos Departamentos do IGc/USP (GMG e GSA) nas avaliações da CAPES. É possível verificar uma predominância da produção estrangeira para o GMG até a Trienal de 2013. Em termos de produtividade o desempenho de ambos os departamentos é bastante próximo, com uma leve vantagem para o GSA.

Cabe destacar que o IGc/USP possui três Programas de Pós-Graduação credenciados na CAPES: Geoquímica e Geotectônica (Nota 7); Mineralogia e Petrologia (Nota 4) e Recursos Minerais e Hidrogeologia (Nota 4). Os docentes dos dois Departamentos, bem como sua produção científica, se dividem entre os programas e, portanto, os dados aqui apresentados não têm o intuito de uma análise do desempenho desses programas. 
Tabela 9 - Produção de Artigos de Periódicos do IGc/USP indexada no Banco Dedalus distribuída pelos Departamentos, Avaliações da CAPES e por Nacionalidade compreendendo somente docentes Ativos credenciados na Pós-Graduação em dois ou mais períodos de Avaliação

\begin{tabular}{cccccc}
\hline \multirow{2}{*}{ Avaliações CAPES } & \multicolumn{2}{c}{ GMG } & \multicolumn{2}{c}{ GSA } & Total de \\
& Artigos & \%Artigos & Artigos & \%Artigos & Artigos \\
\hline Trienal 2004 & $\mathbf{5 0}$ & $\mathbf{4 9 , 5 0 \%}$ & $\mathbf{5 1}$ & $\mathbf{5 0 , 5 0 \%}$ & $\mathbf{1 0 1}$ \\
Doméstico & 15 & $30,61 \%$ & 34 & $69,39 \%$ & 49 \\
Estrangeiro & 35 & $\mathbf{6 7 , 3 1 \%}$ & 17 & $32,69 \%$ & 52 \\
\hline Trienal 2007 & $\mathbf{4 4}$ & $\mathbf{4 6 , 3 2 \%}$ & $\mathbf{5 1}$ & $\mathbf{5 3 , 6 8 \%}$ & $\mathbf{9 5}$ \\
\hline Doméstico & 19 & $42,22 \%$ & 26 & $57,78 \%$ & 45 \\
\hline Estrangeiro & 25 & $50,00 \%$ & 25 & $50,00 \%$ & 50 \\
\hline Trienal 2010 & $\mathbf{7 3}$ & $\mathbf{5 5 , 7 3 \%}$ & $\mathbf{5 8}$ & $\mathbf{4 4 , 2 7 \%}$ & $\mathbf{1 3 1}$ \\
Doméstico & 30 & $44,78 \%$ & 37 & $55,22 \%$ & 67 \\
Estrangeiro & 43 & $\mathbf{6 7 , 1 9 \%}$ & 21 & $32,81 \%$ & 64 \\
\hline Trienal 2013 & $\mathbf{7 6}$ & $\mathbf{5 2 , 0 5 \%}$ & $\mathbf{7 0}$ & $\mathbf{4 7 , 9 5 \%}$ & $\mathbf{1 4 6}$ \\
\hline Doméstico & 24 & $41,38 \%$ & 34 & $58,62 \%$ & 58 \\
\hline Estrangeiro & 52 & $59,09 \%$ & 36 & $40,91 \%$ & 88 \\
\hline Quadrienal 2017 & $\mathbf{1 1 1}$ & $\mathbf{4 5 , 3 1 \%}$ & $\mathbf{1 3 4}$ & $\mathbf{5 4 , 6 9 \%}$ & $\mathbf{2 4 5}$ \\
Doméstico & 31 & $46,27 \%$ & 36 & $53,73 \%$ & 67 \\
Estrangeiro & 80 & $44,94 \%$ & 98 & $55,06 \%$ & 178 \\
\hline Total & $\mathbf{3 5 4}$ & $\mathbf{4 9 , 3 0 \%}$ & $\mathbf{3 6 4}$ & $\mathbf{5 0 , 7 0 \%}$ & $\mathbf{7 1 8}$ \\
\hline
\end{tabular}

Fonte: Elaborada pelo autor.

Com a massa de dados obtida e com a aplicação do filtro de seleção da amostra (SANTANA; MUGNAINI, 2018) sobre os 29 docentes que participaram de duas ou mais avaliações da CAPES, foram selecionados 25 docentes (conforme apresentado no Quadro 1) e dentre estes foram identificados 9 diferentes perfis de publicação, aqui chamados de estratos.

A seleção dos nove docentes da amostra levou em consideração: o estrato; a carreira docente da USP do RDIDP compreendendo especificamente as categorias de Professor Doutor, Professor Associado e Professor Titular (não foram considerados os níveis dentro de cada categoria); e distribuição equitativa entre os departamentos (GMG e GSA). Assim, conforme apresentado na Tabela 10 a distribuição dos docentes da amostra por Departamento e Função foi a mais equitativa possível dentro das especificidades de cada estrato. Foram selecionados um Professor Doutor (havia apenas um dentre os 25 pré-selecionados), três Professores Associados e cinco Professores Titulares. 
Tabela 10 - Distribuição da Amostra Docente por Departamentos e Função na Carreira USP

\begin{tabular}{|c|c|c|c|c|}
\hline \multirow{2}{*}{ Departamento/Docente } & \multicolumn{3}{|c|}{ Função } & \multirow{2}{*}{$\begin{array}{l}\text { Total de } \\
\text { Docentes }\end{array}$} \\
\hline & Prof. Doutor & Prof. Associado & Prof. Titular & \\
\hline GMG & & 2 & 3 & 5 \\
\hline Docente 01 & & & $\sqrt{ }$ & \\
\hline Docente 04 & & & $V$ & \\
\hline Docente 05 & & & $\sqrt{ }$ & \\
\hline Docente 06 & & $V$ & & \\
\hline Docente 12 & & $\sqrt{ }$ & & \\
\hline GSA & 1 & 1 & 2 & 4 \\
\hline Docente 08 & & & $\sqrt{ }$ & \\
\hline Docente 14 & & & $\sqrt{ }$ & \\
\hline Docente 15 & & $\sqrt{ }$ & & \\
\hline Docente 25 & $\sqrt{ }$ & & & \\
\hline Total & 1 & 3 & 5 & 9 \\
\hline
\end{tabular}

Fonte: Elaborada pelo autor.

Com a amostra selecionada passou-se para o próximo passo metodológico, a aplicação da adaptação do método de Gorraiz, Wieland \& Gumpenberger (2016).

\subsection{Adaptação do Método de Gorraiz, Wieland e Gumpenberger}

O método de avaliação individual de Gorraiz, Wieland \& Gumpenberger (2016) compreende quatro passos, a saber: (I) entrevista com pesquisador em avaliação; (II) relatório ou "perfil bibliométrico" da produção científica do pesquisador; (III) discussão e validação dos resultados com pesquisador em avaliação; e (IV) análises opcionais. Para fins desta pesquisa, a adaptação realizada levou em consideração somente os dois primeiros itens, por se tratar de uma pesquisa de mestrado profissional com período restrito para a realização dos diversos procedimentos metodológicos detalhados até aqui. Além disso, optou-se por não recorrer aos pesquisadores em mais de uma etapa, sendo mantidos os dois primeiros passos, apresentados a seguir. 


\subsubsection{Entrevista com os docentes e Relatório/Perfil Bibliométrico individual}

A amostra para a aplicação da adaptação do método é formada por nove docentes, baseada em nove estratos/perfis diferentes de publicação. Destes, apenas um docente não pôde participar da entrevista.

A síntese dessas entrevistas encontra-se disponível no Apêndice E. Os dados obtidos foram substanciosos e altamente pertinentes para a análise dos resultados dos Perfis Bibliométricos dos docentes.

Por ser a entrevista um instrumento complementar ao perfil bibliométrico, ela será apresentada de forma integrada à análise dos resultados contidos nos itens do perfil.

Por se tratar de um método de avaliação individual os perfis bibliométricos foram organizados e separados por docente.

Os três primeiros itens do Perfil Bibliométrico já foram predefinidos nos Procedimentos Metodológicos e são comuns a todos os docentes. Dessa forma, não farão parte dos relatórios individuais, porém os apresentamos a seguir:

- Definição temporal dos dados: 2001-2016.

- Definição de uso e cobertura das fontes de dados: Banco Dedalus (USP) e WoS Core Collection (Clarivate Analytics).

- Análise da atividade de publicação: exclusivamente artigos, focando principalmente em periódicos, com ênfase naqueles indexados na WoS.

A fim de complementar as informações do Perfil Bibliométrico, o Apêndice G apresenta em quais ciclos de Avaliação da CAPES os nove docentes da amostra estavam credenciados. 


\section{A. DOCENTE 01}

O Docente 01, conforme apresentado no Quadro 1, obteve um nível de publicação 3 no primeiro subperíodo de ciclos de avaliação da CAPES (2001-2009), com um percentual de publicação em periódicos domésticos de 52,94\%. No segundo subperíodo (2010-2016) ocorreu uma alteração acentuada em seu nível de publicação passando para 1, com um percentual de 19,05\% de publicação em periódicos domésticos, apresentando, assim, uma transição de dois níveis rumo à internacionalização, resultando num Status Final claramente internacionalizado.

Com base nos dados coletados no Banco Dedalus, a Tabela 11 apresenta a distribuição da produção intelectual do Docente 01 por tipo de publicação.

Observa-se que o Docente 01 possui 69,91\% da produção registrada publicada em eventos, fato que chama a atenção considerando que na entrevista ele afirma não ter muito interesse por eventos. Todavia, os eventos são um importante canal de troca de experiências, e por conta disso, muitos orientandos (graduandos e pós-graduandos) tendem a ter uma participação mais ativa, situação esta que pode justificar tal índice de publicação em eventos.

Quanto à publicação em artigos de periódicos, verifica-se o já mencionado perfil internacionalizado do docente, com 65,63\% em periódicos estrangeiros.

Tabela 11 - Produção Intelectual do Docente 01 registrada no Dedalus distribuída por tipo de publicação

\begin{tabular}{lccccc}
\hline \multirow{2}{*}{ Tipo de Publicação / Ciclo de Avaliação } & \multicolumn{2}{c}{ Doméstico } & \multicolumn{2}{c}{ Estrangeiro } & \multirow{2}{*}{ Total } \\
& Docs & \% Docs & Docs & \% Docs & \\
\hline ARTIGO DE PERIODICO & 11 & $34,38 \%$ & 21 & $65,63 \%$ & 32 \\
\hline PARTE DE MONOGRAFIA/LIVRO & 2 & $100,00 \%$ & 0 & $0,00 \%$ & 2 \\
\hline TRABALHO DE EVENTO & 17 & $94,44 \%$ & 1 & $5,56 \%$ & 18 \\
TRABALHO DE EVENTO-RESUMO & 53 & $88,33 \%$ & 7 & $11,67 \%$ & 60 \\
\hline TRABALHO DE EVENTO-RESUMO PERIODICO & 0 & $0,00 \%$ & 1 & $100,00 \%$ & 1 \\
\hline \hline Total & $\mathbf{8 3}$ & $\mathbf{7 3 , 4 5 \%}$ & $\mathbf{3 0}$ & $\mathbf{2 6 , 5 5 \%}$ & $\mathbf{1 1 3}$ \\
\hline
\end{tabular}

Fonte: Elaborada pelo autor com dados do Dedalus.

Em relação à produção científica do Docente 01 indexada na WoS Core Collection, a Tabela 12 traz os dados referentes aos artigos publicados, distribuídos por periódico. Os periódicos com maior número de publicação foram o Journal of South 
American Earth Sciences (Categoria do JCR: Geoscience e Multidisciplinary; FI de 1,639; Categoria SJR: Earth and Planetary Sciences; SJR de 0,82) com 8 artigos e o Precambrian Research (Categoria do JCR: Geoscience e Multidisciplinary; FI de 3,907; Categoria SJR: Earth and Planetary Sciences; SJR de 2,769) com 6, juntos correspondendo a 63,64\% do total de artigos publicados.

Tabela 12 - Artigos do Docente 01 indexados na WoS Core Collection distribuídos por título de periódico

\begin{tabular}{lcc}
\hline Periódicos & Artigos & \%Artigos \\
\hline JOURNAL OF SOUTH AMERICAN EARTH SCIENCES & 8 & $36,36 \%$ \\
\hline PRECAMBRIAN RESEARCH & 6 & $\mathbf{2 7 , 2 7 \%}$ \\
\hline INTERNATIONAL JOURNAL OF EARTH SCIENCES & 3 & $13,64 \%$ \\
\hline GONDWANA RESEARCH & 2 & $9,09 \%$ \\
ANDEAN GEOLOGY & 1 & $4,55 \%$ \\
BRAZILIAN JOURNAL OF GEOLOGY & 1 & $4,55 \%$ \\
CANADIAN MINERALOGIST & 1 & $\mathbf{4 , 5 5 \%}$ \\
\hline \hline Total & $\mathbf{2 2}$ & $\mathbf{1 0 0 , 0 0 \%}$ \\
\hline
\end{tabular}

Fonte: Elaborada pelo autor com dados da WoS Core Collection.

A seguir apresentam-se os dados de acordo com o Perfil Bibliométrico adaptado da proposta de Gorraiz, Wieland \& Gumpenberger (2016).

\section{- Análise de coautorias}

A Tabela 13 apresenta os dados de coautoria do Docente 01, nos quais é possível identificar que a maior concentração de publicações encontra-se em artigos com 4 a 5 autores. A informação é complementada pela Tabela 14 que apresenta a posição do docente nos artigos, demonstrando uma maior quantidade de artigos em posição central, e corroborando a informação fornecida pelo docente na entrevista, na qual indica a tendência de colocar os pós-graduandos como primeiro autor de suas pesquisas.

Ademais, ficou constatado de maneira geral nas entrevistas com os docentes da amostra que é uma praxe que aos alunos de pós-graduação sejam dadas as primeiras posições na sequência autoral. 
Tabela 13 - Quantidade de autores nos artigos com participação do Docente 01

\begin{tabular}{cccc}
\hline Quantidade de Autores & Total de Artigos & \% Artigos \\
\hline 2 & 1 & $4,55 \%$ \\
3 & 3 & $13,64 \%$ \\
4 & 5 & $22,73 \%$ \\
5 & 5 & $22,73 \%$ \\
6 & 3 & $13,64 \%$ \\
& 3 & 1 & $4,55 \%$ \\
& 9 & 2 & $9,09 \%$ \\
& 10 & 2 & $9,09 \%$ \\
\hline \hline Total & & $\mathbf{2 2}$ & $\mathbf{1 0 0 , 0 0 \%}$ \\
\hline
\end{tabular}

Fonte: Elaborada pelo autor com dados da WoS Core Collection.

Tabela 14 - Artigos distribuídos por quantidade de autores e posição na autoria do Docente 01 nos artigos em que participa

\begin{tabular}{|c|c|c|c|c|}
\hline \multirow{2}{*}{ Quantidade de autores } & \multicolumn{3}{|c|}{ Posição na Autoria } & \multirow{2}{*}{ Total } \\
\hline & Primeiro & Meio & Último & \\
\hline 2 & & & 1 & 1 \\
\hline 3 & & 3 & & 3 \\
\hline 4 & 1 & 3 & 1 & 5 \\
\hline 5 & & 3 & 2 & 5 \\
\hline 6 ou mais & 1 & 6 & 1 & 8 \\
\hline Total & 2 & 15 & 5 & 22 \\
\hline
\end{tabular}

Fonte: Elaborada pelo autor com dados da WoS Core Collection.

- Análise da colaboração

A colaboração internacional na produção científica tem se tornado um elemento importante, como destacado pelos docentes nas entrevistas realizadas, e a Tabela 15 confirma esse fato, uma vez que mais da metade dos artigos do Docente 01 foram publicados com coautores de mais de 2 países.

Tabela 15 - Quantidade de países dos autores que publicaram nos artigos com participação do Docente 01

\begin{tabular}{cccc}
\hline Quantidade de Países & Total de Artigos & \% Artigos \\
\hline 1 & 10 & $45,45 \%$ \\
& 2 & 7 & $31,82 \%$ \\
& 3 & 3 & $13,64 \%$ \\
\hline \hline Total & 2 & $9,09 \%$ \\
\hline
\end{tabular}

Fonte: Elaborada pelo autor com dados da WoS Core Collection. 
Já a Tabela 16 apresenta os países colaboradores, com destaque para Argentina e Austrália com maior participação em artigos. Vale destacar ainda que 10 artigos foram produzidos exclusivamente com a colaboração de instituições nacionais.

E a Tabela 17 traz a quantidade de instituições dos autores desses artigos destacando-se uma maior concentração naqueles com apenas uma instituição (USP) com $36,36 \%$; e com duas com $27,27 \%$.

Tabela 16 - Países dos autores que publicaram nos artigos com participação do Docente 01

\begin{tabular}{lcc}
\hline Países & Total de Artigos & $\%$ Artigos \\
\hline Brasil & 10 & $45,45 \%$ \\
\hline Argentina & 4 & $18,18 \%$ \\
\hline Austrália & 3 & $13,64 \%$ \\
\hline Inglaterra & 2 & $9,09 \%$ \\
\hline Alemanha & 2 & $9,09 \%$ \\
\hline China & 2 & $9,09 \%$ \\
Escócia & 2 & $9,09 \%$ \\
Estados Unidos & 2 & $9,09 \%$ \\
Canadá & 1 & $4,55 \%$ \\
Espanha & 1 & $4,55 \%$ \\
\hline \hline Total & $\mathbf{2 2}$ & $\mathbf{1 0 0 , 0 0 \%}$ \\
\hline
\end{tabular}

Fonte: Elaborada pelo autor com dados da WoS Core Collection.

Tabela 17 - Quantidade de instituições dos autores que publicaram nos artigos com participação do Docente 01

\begin{tabular}{cccc}
\hline Quantidade de Instituições & Total de Artigos & \% Artigos \\
\hline 1 & 8 & $36,36 \%$ \\
2 & 6 & $27,27 \%$ \\
3 & 3 & $13,64 \%$ \\
4 & 2 & $9,09 \%$ \\
5 & 1 & $4,55 \%$ \\
& 6 & 1 & $4,55 \%$ \\
& 7 & 1 & $4,55 \%$ \\
\hline \hline Total & $\mathbf{2 2}$ & $\mathbf{1 0 0 , 0 0 \%}$ \\
\hline
\end{tabular}

Fonte: Elaborada pelo autor com dados da WoS Core Collection apresentados via Incites.

Para completar a análise, a Tabela 18 apresenta as instituições e seus respectivos países, permitindo observar que a colaboração se distribui em um conjunto significativo de instituições, com redundância apenas com instituições alemãs, argentinas, australianas, brasileiras e norte-americanas. 
Tabela 18 - Distribuição das Instituições por países dos autores que publicaram com o Docente 01

\section{País/Instituição}

Artigos

\section{Alemanha}

University of Gottingen

2

\section{Argentina}

Consejo Nac. de Inv. Cient. y Tecnicas (CONICET) 4

National University of Cordoba $\quad 2$

National University of La Plata 4

University of Buenos Aires 1

\begin{tabular}{ll} 
Austrália & \\
Australian National University & 1 \\
University of Wollongong & 3 \\
Brasil & \\
Universidade do Estado do Rio de Janeiro & 1 \\
Universidade Federal de Sao Paulo (UNIFESP) & 1 \\
Universidade Federal do Ceara & 2 \\
Canadá & \\
$\quad$ University of Alberta & 1 \\
China & \\
Chinese Academy of Geological Sciences & 1 \\
Chinese Academy of Sciences & 1 \\
Escócia & \\
Scottish Universities Research \& Reactor Center & 1 \\
University of St Andrews & 1 \\
Espanha & \\
Consejo Nac. de Inv. Cient. y Tecnicas (CONICET) & 1 \\
CSIC - Inst. de Rec. Natur. y Agrobiologia de Salamanca (IRNASA) & 1 \\
Estados Unidos & 2 \\
University of Kansas & 1 \\
\hline Inglaterra & 1 \\
NERC British Geological Survey & 1 \\
NERC Natural Environment Research Council & \\
University of Bristol & \\
\hline
\end{tabular}

Fonte: Incites com dados da WoS Core Collection.

- Análise dos financiamentos de pesquisa recebidos

A presente análise verifica quais foram as Agências de Fomento que apoiaram as pesquisas realizadas pelo Docente 01 . Cabe destacar que a WoS somente padronizou os dados de Agências de Fomento de 2008 para frente e, portanto, dos 22 artigos do Docente 01 indexados na WoS somente 17 puderam ser analisados, uma vez que os outros 5 são anteriores a esse período. 
A Tabela 19 apresenta as informações das agências de fomento que apoiaram as pesquisas publicadas pelo Docente 01, com destaque para o ano de 2016 com participação de 7 agências e concentrando altos índices de Impacto Normalizado.

$\mathrm{Na}$ entrevista o docente destacou a importância da participação em redes/grupos de pesquisa internacionais e isso se evidencia no ano de 2016 no qual é possível identificar 4 agências internacionais.

Cabe aqui destacar ainda que não se pode comparar o número absoluto de citações recebidas por artigos de anos diferentes porque artigos publicados em 2008 e 2015, por exemplo, apresentarão tempo de exposição significativamente diferentes, tendendo a favorecer o mais antigo. Entretanto optou-se por apresentá-las aqui a título de complementação das informações, já que o indicador ideal para este fim é o Impacto Normalizado.

Com base nos dados apresentados é possível constatar que no ano de 2016 todos os artigos publicados com financiamento de agências de fomento estrangeiras tiveram um impacto acima da média esperada para a área $(1,0)$.

Tabela 19 - Agências de Fomento que apoiaram as pesquisas que geraram as publicações com participação do Docente 01, distribuídas por ano

(continua)

\begin{tabular}{lcccc}
\hline Agências de Fomento por Ano & Artigos & Citações & Citações/Artigo & $\begin{array}{c}\text { Impacto } \\
\text { Normalizado }\end{array}$ \\
\hline 2009 & $\mathbf{1}$ & --- & --- & --- \\
FAPESP & 1 & 18 & 18 & 0,99 \\
2010 & $\mathbf{1}$ & --- & --- & --- \\
\hline FAPESP & 1 & 18 & 18 & 0,93 \\
$\mathbf{2 0 1 1}$ & $\mathbf{6}$ & --- & --- & --- \\
CONICET & 1 & 20 & 20 & 0,37 \\
FAPESP & 4 & 62 & 15,5 & 0,7 \\
Nat. University of La Plata & 1 & 20 & 20 & 0,37 \\
$\mathbf{2 0 1 2}$ & $\mathbf{3}$ & --- & --- & --- \\
\hline CAPES & 1 & 4 & 4 & 0,26 \\
FAPESP & 2 & 6 & 3 & 0,2 \\
$\mathbf{2 0 1 3}$ & $\mathbf{3}$ & --- & --- & --- \\
CAPES & 1 & 15 & 15 & 1,23 \\
FAPESP & 2 & 24 & 12 & 0,98 \\
$\mathbf{2 0 1 4}$ & $\mathbf{2}$ & --- & --- & --- \\
CNPq & 1 & 8 & 8 & 0,85 \\
FAPESP & 1 & 8 & 8 & 0,85 \\
\hline
\end{tabular}


Tabela 19 - Agências de Fomento que apoiaram as pesquisas que geraram as publicações com participação do Docente 01, distribuídas por ano

(conclusão)

\begin{tabular}{lcccc}
\hline Agências de Fomento por Ano & Artigos & Citações & Citações/Artigo & $\begin{array}{c}\text { Impacto } \\
\text { Normalizado }\end{array}$ \\
2016 & 13 & --- & --- & --- \\
CAPES & 3 & 9 & 3 & 0,91 \\
CNPq & 1 & 4 & 4 & 1,21 \\
CONICET & 2 & 7 & 3,5 & 1,25 \\
European Union (EU) & 1 & 4 & 4 & 1,21 \\
FAPESP & 4 & 13 & 3,25 & 0,98 \\
FONCyT & 1 & 3 & 3 & 1,29 \\
NERC Nat. Envir. Res. Council & 1 & 4 & 4 & 1,21 \\
\hline
\end{tabular}

Fonte: Incites com dados da WoS Core Collection

\section{- Análise de visibilidade da produção científica}

No que diz respeito à visibilidade da produção científica do docente, esta é medida levando em conta a quantidade de artigos registrada no Dedalus (32) e quantidade de artigos indexada na WoS (22), assim o percentual do Docente 01 é de $68,75 \%$.

Outro fator proposto é o percentual de artigos presentes em periódicos de impacto. A Tabela 20 apresenta os artigos do docente publicados em periódicos indexados na WoS Core Collection, distribuídos segundo Ciclos de Avaliação da CAPES e percentual publicado em periódicos do 10 Quartil do FI/JCR. Dos 22 artigos do Docente 01 indexados na WoS Core Collection 45,45\% estão presentes no 1ㅇ Quartil - vale ressaltar que nos últimos ciclos se intensifica a publicação em periódicos de maior impacto na área.

Tabela 20 - Artigos publicados pelo Docente 01 distribuídos por Ciclos de Avaliação da CAPES e indexados em periódicos do 10 Quartil do $\mathrm{Fl} / \mathrm{JCR}$

\begin{tabular}{lcc}
\hline Ciclos de Avaliação CAPES & Total de Artigos & \% Artigos no 10 Quartil \\
\hline 2001-2003 - Trienal 2004 & 1 & $0,00 \%$ \\
2004-2006 - Trienal 2007 & 1 & $0,00 \%$ \\
2007-2009 - Trienal 2010 & 1 & $0,00 \%$ \\
$2010-2012$ - Trienal 2013 & 9 & $44,44 \%$ \\
\hline 2013-2016 - Quadrienal 2017 & 10 & $60,00 \%$ \\
\hline \hline Total & $\mathbf{2 2}$ & $\mathbf{4 5 , 4 5 \%}$ \\
\hline
\end{tabular}

Fonte: Incites com dados da WoS Core Collection 
Analisando-se a publicação científica mais fortemente relacionada aos instrumentos de Avaliação da CAPES, a Tabela 21 apresenta a quantidade de artigos publicados distribuídos pelos Ciclos de Avaliação e classificação nos estratos Qualis da área de avaliação das Geociências.

Verifica-se que $68,18 \%$ dos artigos do Docente 01 encontram-se nos estratos mais altos ( $A, A 1$ e $A 2)$ e os demais em periódicos $B 1$. Além disso, verifica-se na Trienal de 2013 que 100\% (9) dos artigos publicados pelo docente foram em periódicos dos estratos A1 e A2 e na Quadrienal de 2017 apenas 50\%. Isso se explica talvez pela transição dos periódicos International Journal of Earth Sciences e Journal of South American Earth Sciences do estrato A2 na Trienal de 2013 para B1 na Quadrienal de 2017.

Esse ponto pode ter relação com a regra da CAPES em que apenas $25 \%$ dos periódicos nos quais a área publicou possam estar nos estratos A1 e A2.

Adicionalmente, é possível notar que houve um aumento do número de artigos do docente no estrato A1 entre as avaliações Trienal de 2013 e Quadrienal de 2017, de dois para cinco, respectivamente. Aparentemente o docente deu preferência no período coberto pela Quadrienal de 2017 à publicação em um periódico com maior impacto (Precambrian Research) em detrimento do que tinha maior produção no período coberto pela Trienal de 2013 (Journal of South American Earth Sciences).

De forma a aprofundar a análise sobre as colaborações e a visibilidade das publicações, a Tabela 22 apresenta as instituições que colaboraram com o Docente 01 em dois ou mais artigos, distribuídas entre os Ciclos de Avaliação da CAPES, com a indicação do percentual dos artigos no 10 Quartil do JCR.

Ao todo são 7 instituições com a característica exigida, e destas, o destaque foi a University of Kansas, presente no período da Avaliação Quadrienal de 2017, que dos dois artigos em colaboração $100 \%$ deles foram publicados em periódicos do 10 Quartil. Entretanto, nesse mesmo ciclo foram publicados outros 6 artigos e nenhum deles em periódicos do 1으 Quartil. 
Tabela 21 - Artigos publicados pelo Docente 01 distribuídos por Ciclos de Avaliação da CAPES e classificação do periódico nos estratos Qualis da área de avaliação das Geociências

\begin{tabular}{|c|c|c|c|c|c|}
\hline \multirow{2}{*}{ Periódicos e Ciclo de Avaliação } & \multicolumn{4}{|c|}{ Estratos Qualis ${ }^{27}$} & \multirow{2}{*}{ Tota } \\
\hline & A & A1 & A2 & B1 & \\
\hline 2001-2003 - TRIENAL 2004 & 1 & & & & 1 \\
\hline JOURNAL OF SOUTH AMERICAN EARTH SCIENCES & 1 & & & & 1 \\
\hline 2004-2006 - TRIENAL 2007 & & & & 1 & 1 \\
\hline GONDWANA RESEARCH & & & & 1 & 1 \\
\hline 2007-2009 - TRIENAL 2010 & & & & 1 & 1 \\
\hline CANADIAN MINERALOGIST & & & & 1 & 1 \\
\hline 2010-2012 - TRIENAL 2013 & & 2 & 7 & & 9 \\
\hline GONDWANA RESEARCH & & 1 & & & 1 \\
\hline INTERNATIONAL JOURNAL OF EARTH SCIENCES & & & 2 & & 2 \\
\hline JOURNAL OF SOUTH AMERICAN EARTH SCIENCES & & & 5 & & 5 \\
\hline PRECAMBRIAN RESEARCH & & 1 & & & 1 \\
\hline 2013-2016 - QUADRIENAL 2017 & & 5 & & 5 & 10 \\
\hline ANDEAN GEOLOGY & & & & 1 & 1 \\
\hline BRAZILIAN JOURNAL OF GEOLOGY & & & & 1 & 1 \\
\hline INTERNATIONAL JOURNAL OF EARTH SCIENCES & & & & 1 & 1 \\
\hline JOURNAL OF SOUTH AMERICAN EARTH SCIENCES & & & & 2 & 2 \\
\hline PRECAMBRIAN RESEARCH & & 5 & & & 5 \\
\hline Total & 1 & 7 & 7 & 7 & 22 \\
\hline
\end{tabular}

Fonte: Elaborada pelo autor com dados da WoS Core Collection e Qualis/CAPES.

Entretanto no ciclo Trienal de 2013 dos 6 artigos publicados em colaboração com 3 instituições, 50\% deles foram em periódicos do 1으 Quartil.

Tabela 22 - Artigos publicados pelo Docente 01 distribuídos segundo instituições que colaboraram duas ou mais vezes e Ciclos de Avaliação da CAPES, com indicação do percentual de artigos no 1으 Quartil do JCR

(continua)

\begin{tabular}{lccc}
\hline Instituição Colaboradora & $\begin{array}{c}\text { 2010-2012 - } \\
\text { TRIENAL 2013 }\end{array}$ & $\begin{array}{c}\text { 2013-2016 - } \\
\text { QUADRIENAL 2017 }\end{array}$ & Total \\
\hline CONICET & & 2 \\
$\quad$ Total de artigos & 2 & 2 \\
\% Arts. no 10 Quartil & $0,00 \%$ & $0,00 \%$ \\
National University of Cordoba & & \\
$\quad$ Total de artigos & 2 & 2 \\
\% Arts. no 10 Quartil & $0,00 \%$ & $0,00 \%$
\end{tabular}

\footnotetext{
${ }^{27}$ Os Ciclos de Avaliação da CAPES utilizavam até a Trienal de 2004 um sistema alfabético para o Qualis Periódicos (A, B e C) e com indicação de circulação (Internacional e Nacional). A partir da Trienal de 2007 o Qualis Periódicos passou a ser alfanumérico (A1, A2, B1, B2, B3, B4, B5 e C).
} 
Tabela 22 - Artigos publicados pelo Docente 01 distribuídos segundo instituições que colaboraram duas ou mais vezes e Ciclos de Avaliação da CAPES, com indicação do percentual de artigos no 1 ㅇ Quartil do JCR

Fonte: Elaborada pelo autor com dados da WoS Core Collection e Qualis/CAPES.

\section{- Análise de impacto da produção científica}

Nenhum os artigos do Docente 01 se encontrava presente no Top 10\%, portanto decidiu-se basear a análise exclusivamente no Impacto Normalizado. A Tabela 23 traz os dados de total de artigos, percentual de artigos citados, total de citações, citações por artigo e o Impacto Normalizado. Verifica-se que somente no ano de 2016 o Docente 01 esteve acima da média esperada $(1,0)$ no impacto normalizado. Quanto às citações por artigo os destaques ficaram para os anos de 2009 e 2010 . 
Tabela 23 - Impacto dos artigos do Docente 01 distribuídos por ano de publicação

\begin{tabular}{cccccc}
\hline $\begin{array}{c}\text { Ano de } \\
\text { Publicação }\end{array}$ & $\begin{array}{c}\text { Total de } \\
\text { Artigos }\end{array}$ & $\begin{array}{c}\text { \% Artigos } \\
\text { Citados }\end{array}$ & $\begin{array}{c}\text { Total de } \\
\text { Citações }\end{array}$ & $\begin{array}{c}\text { Citações/ } \\
\text { Artigo }\end{array}$ & $\begin{array}{c}\text { Impacto } \\
\text { Normalizado }\end{array}$ \\
\hline 2003 & 1 & $100,00 \%$ & 3 & 3,0 & 0,1 \\
2004 & 1 & $100,00 \%$ & 14 & 14,0 & 0,5 \\
2009 & 1 & $100,00 \%$ & 18 & 18,0 & 1,0 \\
2010 & 2 & $100,00 \%$ & 36 & 18,0 & 0,6 \\
2011 & 5 & $100,00 \%$ & 66 & 13,2 & 0,6 \\
2012 & 2 & $100,00 \%$ & 6 & 3,0 & 0,2 \\
2013 & 3 & $100,00 \%$ & 34 & 11,3 & 1,0 \\
\hline 2014 & 1 & $100,00 \%$ & 8 & 8,0 & 0,9 \\
\hline 2016 & 6 & $100,00 \%$ & 20 & 3,3 & 1,1 \\
\hline \hline Total & $\mathbf{2 2}$ & $\mathbf{1 0 0 , 0 0 \%}$ & $\mathbf{2 0 5}$ & -- & -- \\
\hline
\end{tabular}

Fonte: Incites com dados da WoS Core Collection

Em termos de impacto da sua produção científica, o Docente 01, mesmo publicando em periódicos estrangeiros, de alto Fator de Impacto ou Estrato JCR, obteve apenas em 3 anos a média normalizada esperada para sua área (2009, 2013 e 2016) - o que permite confirmar críticas anteriores de que a avaliação de pesquisadores por meio do impacto do periódico onde publica é uma forma indireta, e consequentemente parcial, de avaliação.

\section{- Análise das referências utilizadas}

O último item a se analisar são as referências utilizadas pelo Docente na redação de seus artigos. Ao todo o Docente 01 utilizou 395 fontes bibliográficas diferentes, citando-as 1.547 vezes em seus 22 artigos, gerando uma média de 70,32 referências por trabalho.

Utilizando-se as Zonas de Bradford para analisar as principais publicações citadas nos artigos, pôde-se verificar pelas Tabelas 24 e 25 que, das 1.547 referências utilizadas, o primeiro terço delas (Zona 1 - com 530 referências) estão concentradas em apenas 9 periódicos que correspondem à $2,28 \%$ das publicações; já no segundo terço (Zona 2 com 516 referências) em 36 publicações, já possuindo uma maior variedade de tipologias de documentos e correspondendo à 9,11\%. O terceiro terço é a zona de maior dispersão com um total de 350 publicações, sendo a maioria delas com baixa frequência de citação (não sendo, portanto, apresentadas na tabela). 
Essas 45 publicações somadas correspondem a 11,39\% das publicações, que por conseguinte, correspondem a $67,61 \%$ de todas as referências citadas.

Tabela 24 - Lista de Referências utilizadas nos artigos do Docente 01 distribuídas pelas Zonas 1 e 2 de Bradford

(continua)

\begin{tabular}{|c|c|c|c|c|}
\hline$\#$ & Publicações & Citações & \% Citações & Zona de Bradford \\
\hline 1 & PRECAMBRIAN RES & 119 & $7,69 \%$ & \multirow{9}{*}{ Zona 1} \\
\hline 2 & J S AM EARTH SCI & 92 & $5,95 \%$ & \\
\hline 3 & GONDWANA RES & 61 & $3,94 \%$ & \\
\hline 4 & EARTH PLANET SC LETT & 51 & $3,30 \%$ & \\
\hline 5 & LITHOS & 47 & $3,04 \%$ & \\
\hline 6 & CONTRIB MINERAL PETR & 41 & $2,65 \%$ & \\
\hline 7 & REV BRASILEIRA GEOCI & 41 & $2,65 \%$ & \\
\hline 8 & GEOLOGY & 39 & $2,52 \%$ & \\
\hline 9 & J PETROL & 39 & $2,52 \%$ & \\
\hline 1 & TECTONIC EVOLUTION S & 36 & $2,33 \%$ & \multirow{25}{*}{ Zona 2} \\
\hline 2 & J METAMORPH GEOL & 32 & $2,07 \%$ & \\
\hline 3 & GEOL SOC SPEC PUBL & 31 & $2,00 \%$ & \\
\hline 4 & CHEM GEOL & 29 & $1,87 \%$ & \\
\hline 5 & J STRUCT GEOL & 28 & $1,81 \%$ & \\
\hline 6 & GEOCHIM COSMOCHIM AC & 27 & $1,75 \%$ & \\
\hline 7 & THESIS U SAO PAULO & 26 & $1,68 \%$ & \\
\hline 8 & TECTONICS & 23 & $1,49 \%$ & \\
\hline 9 & TECTONOPHYSICS & 21 & $1,36 \%$ & \\
\hline 10 & AM MINERAL & 16 & $1,03 \%$ & \\
\hline 11 & ANAIS ACAD BRASILEIR & 16 & $1,03 \%$ & \\
\hline 12 & GEOL SOC AM BULL & 14 & $0,90 \%$ & \\
\hline 13 & REV ASOC GEOL ARGENT & 13 & $0,84 \%$ & \\
\hline 14 & AN ACAD BRAS CIENC & 13 & $0,84 \%$ & \\
\hline 15 & REV BRAS GEOC & 13 & $0,84 \%$ & \\
\hline 16 & EPISODES & 13 & $0,84 \%$ & \\
\hline 17 & INT J EARTH SCI & 12 & $0,78 \%$ & \\
\hline 18 & NATURE & 12 & $0,78 \%$ & \\
\hline 19 & EARTH-SCI REV & 12 & $0,78 \%$ & \\
\hline 20 & J GEOL SOC LONDON & 11 & $0,71 \%$ & \\
\hline 21 & GEOLOGIA USP C & 10 & $0,65 \%$ & \\
\hline 22 & SCIENCE & 9 & $0,58 \%$ & \\
\hline 23 & REV. ASOC. GEOL. ARGENT. & 9 & $0,58 \%$ & \\
\hline 24 & GEOLOGIA USP SERIE C & 9 & $0,58 \%$ & \\
\hline 25 & B RESUMOS EXPANDIDOS & 8 & $0,52 \%$ & \\
\hline
\end{tabular}


Tabela 24 - Lista de Referências utilizadas nos artigos do Docente 01 distribuídas pelas Zonas 1 e 2 de Bradford

(conclusão)

\begin{tabular}{clccc}
\hline$\#$ & Publicações & Citações & \% Citações & Zona de Bradford \\
\hline 26 & 3 S AM S IS GEOL & 8 & $0,52 \%$ & \\
27 & GEOSTAND GEOANAL RES & 7 & $0,45 \%$ & \\
28 & CAN MINERAL & 7 & $0,45 \%$ & \\
29 & CONTINENTAL CRUST IT & 7 & $0,45 \%$ & \\
30 & J GEOL & 7 & $0,45 \%$ & \\
31 & J GEOPHYS RES & 7 & $0,45 \%$ & \\
32 & REV ASOCIACION GEOLO & 6 & $0,39 \%$ & \multirow{2}{*}{ Zona 2 } \\
33 & CAN J EARTH SCI & 6 & $0,39 \%$ & \\
34 & MAPA GEOLOGICO FOLHA & 6 & $0,39 \%$ & \\
35 & SPECIAL PUBLICATION & 6 & $0,39 \%$ & \\
36 & GONDWANA & 6 & $0,39 \%$ & \\
\hline \hline Total & 45 Títulos & $\mathbf{1 . 0 4 6}$ & $\mathbf{6 7 , 6 1 \%}$ & \\
\hline
\end{tabular}

Fonte: Elaborada pelo autor com dados da WoS Core Collection.

Tabela 25 - Quantidade de publicações citadas pelo Docente 01 distribuídas pelas Zonas de Bradford

Zonas de Bradford Total de Publicações \% Publicações Total de Citações \% Citações

\begin{tabular}{lcccc}
\hline Zona 1 & 9 & $2,28 \%$ & 530 & $34,26 \%$ \\
Zona 2 & 36 & $9,11 \%$ & 516 & $33,35 \%$ \\
Zona 3 & 350 & $88,61 \%$ & 501 & $32,39 \%$ \\
\hline \hline Total & $\mathbf{3 9 5}$ & $\mathbf{1 0 0 , 0 0 \%}$ & $\mathbf{1 . 5 4 7}$ & $\mathbf{1 0 0 , 0 0 \%}$ \\
\hline
\end{tabular}

Fonte: Elaborada pelo autor com dados da WoS Core Collection.

Tais dados permitem ainda analisar a relação de onde se publica com o que se cita. A Tabela 26 nos apresenta que dos sete periódicos nos quais foram publicados os 22 artigos do Docente 01 os dois primeiros com maior número de publicações estão presentes na Zona 01, sendo que o primeiro corresponde à segunda publicação mais referenciada e o segundo, à primeira. Dos cinco restantes, um pertence à Zona 1 , dois à Zona 2 e os outros dois à Zona 3.

Durante a entrevista quando perguntado sobre às publicações mais importantes do seu campo de atuação o Docente 01 citou apenas um periódico, justamente o que ele mais referencia, o Precrambrian Research. 
Tabela 26 - Lista de periódicos nos quais o Docente 01 publicou seus artigos com indicação das Zonas de Bradford

\begin{tabular}{lccc}
\hline Título dos Periódico & $\begin{array}{c}\text { Total de } \\
\text { Artigos }\end{array}$ & $\begin{array}{c}\text { \% Total de } \\
\text { Artigos }\end{array}$ & $\begin{array}{c}\text { Zonas de } \\
\text { Bradford }\end{array}$ \\
\hline JOURNAL OF SOUTH AMERICAN EARTH SCIENCES & 8 & $36,36 \%$ & 1 \\
\hline PRECAMBRIAN RESEARCH & 6 & $\mathbf{2 7 , 2 7 \%}$ & 1 \\
\hline INTERNATIONAL JOURNAL OF EARTH SCIENCES & 3 & $13,64 \%$ & 2 \\
\hline GONDWANA RESEARCH & 2 & $9,09 \%$ & 1 \\
\hline BRAZILIAN JOURNAL OF GEOLOGY & 1 & $4,55 \%$ & 3 \\
ANDEAN GEOLOGY & 1 & $4,55 \%$ & 3 \\
\hline CANADIAN MINERALOGIST & 1 & $\mathbf{4 , 5 5 \%}$ & 2 \\
\hline \hline Total & $\mathbf{2 2}$ & $\mathbf{1 0 0 , 0 0 \%}$ & -- \\
\hline
\end{tabular}

Fonte: Elaborada pelo autor com dados da WoS Core Collection.

A Tabela 27 apresenta a idade das referências citadas pelo Docente 01 de acordo com o ano de publicação de cada um de seus artigos. A maior concentração encontrase em referências de 11 a 20 anos, com 34,32\% e das faixas de 0 a 5 e 6 a 10 anos, que somadas correspondem a $45,83 \%$. Somando essas três faixas tem-se $80,16 \%$ do total geral de citações de referências com até 20 anos.

Tabela 27 - Idade das Referências citadas nos artigos do Docente 01

\begin{tabular}{|c|c|c|}
\hline Idade das Referências & Total de Citações & \% Citações \\
\hline $0-5$ & 335 & $21,65 \%$ \\
\hline $6-10$ & 374 & $24,18 \%$ \\
\hline $11-20$ & 531 & $34,32 \%$ \\
\hline $21-30$ & 167 & $10,80 \%$ \\
\hline $31-40$ & 98 & $6,33 \%$ \\
\hline $41-50$ & 32 & $2,07 \%$ \\
\hline+50 & 10 & $0,65 \%$ \\
\hline Total & 1.547 & $100,00 \%$ \\
\hline
\end{tabular}

Fonte: Elaborada pelo autor com dados da WoS Core Collection.

- Informações adicionais

De forma a complementar os dados e análises apresentados neste relatório/perfil bibliométrico, apresentam-se algumas análises baseadas nas informações obtidas com a entrevista realizada com o Docente 01

$\mathrm{Na}$ entrevista o docente comenta que não possui estratégia de publicação científica e que seleciona a revista com base na qualidade do artigo que escreveu e sua abrangência, priorizando periódicos com maior impacto. 
Obviamente este planejamento utilizado é uma estratégia de publicação científica e, baseado em seu perfil de publicação, fica evidente que, a despeito de não entendê-la como tal, ela tem sido bem positiva para o docente.

Quando questionado sobre os processos de avaliação o docente considera que avaliação das agências de fomento é fundamental para se conseguir apoio financeiro e que a internacionalização de sua produção apesar de não ser critério inerente ao seu campo de atuação propicia maior visibilidade. Ressalta, também, que o fato de participar de redes e grupos de pesquisa internacionais torna praticamente obrigatória a publicação em periódicos estrangeiros.

De fato, fica clara a evolução do pesquisador no que tange a colaboração internacional em seus artigos analisados, especialmente no período coberto pela Avaliação Quadrienal de 2017 da CAPES. Outra ação que corrobora esse perfil internacionalizado do docente é também notada na Quadrienal 2017, que foi a priorização da publicação em periódicos com maior Fato de Impacto.

O Docente 01 apesar de possuir um perfil internacionalizado também mantém sua produção regional, contribuindo para o desenvolvimento da área no Brasil por meio de suas publicações em anais de eventos e em periódicos domésticos. Esse balanceamento alcançado pelo docente tem Ihe propiciado bons resultados. 


\section{B. DOCENTE 04}

O Docente 04, conforme apresentado no Quadro 1, obteve um nível de publicação 4 no primeiro subperíodo de ciclos de avaliação da CAPES (2001-2009), com um percentual de publicação em periódicos domésticos de $75 \%$. No segundo subperíodo (2010-2016) ocorreu uma alteração em seu nível de publicação passando para 2, com um percentual de 35,71\% de publicação em periódicos domésticos, apresentando, assim, uma transição de dois níveis rumo à internacionalização, refletindo num Status Final que se encontra em processo de internacionalização.

Baseada nos dados coletados no Banco Dedalus, a Tabela 28 apresenta a distribuição da produção intelectual do Docente 04 por tipo de publicação.

Nota-se que a maior concentração da produção total do Docente 04 está registrada em eventos, totalizando $69,79 \%$, o fato corrobora a informação fornecida em sua entrevista na qual ele informa participar ativamente de eventos, tanto nacionais quanto internacionais. Dos 134 documentos relacionados a trabalhos de eventos, $94,03 \%$ deles foram publicados nacionalmente. E a despeito do fato de eventos nacionais praticamente não serem passíveis de mensuração e, de acordo com o Documento de Área das Geociências (MINISTÉRIO DA EDUCAÇÃO. CAPES, 2016), não gerarem pontuação para os Programas de Pós-Graduação, tais publicações são um importante canal para troca de experiências e promoção de avanços regionais.

Considerando-se somente a publicação em artigos de periódicos, verifica-se que o Docente 04 possui um índice de 56,60\% em periódicos estrangeiros.

Tabela 28 - Produção Intelectual do Docente 04 registrada no Dedalus distribuída por tipo de publicação

\begin{tabular}{lcccccc}
\hline \multirow{2}{*}{ Tipo de Publicação / Ciclo de Avaliação } & \multicolumn{2}{c}{$\begin{array}{c}\text { Doméstico } \\
\text { Docs }\end{array}$} & $\begin{array}{c}\text { Estrangeiro } \\
\text { \%ocs }\end{array}$ & Docs & Total Docs & \\
\hline ARTIGO DE PERIODICO & 23 & $43,40 \%$ & 30 & $56,60 \%$ & 53 \\
ARTIGO DE PERIODICO-APRES/INTR & 0 & $0,00 \%$ & 1 & $100,00 \%$ & 1 \\
\hline PARTE DE MONOGRAFIA/LIVRO & 3 & $100,00 \%$ & 0 & $0,00 \%$ & 3 \\
PARTE DE MONOGRAFIA/LIVRO-APRES/PREF/POSF & 1 & $100,00 \%$ & 0 & $0,00 \%$ & 1 \\
\hline TRABALHO DE EVENTO & 31 & $93,94 \%$ & 2 & $6,06 \%$ & 33 \\
TRABALHO DE EVENTO-RESUMO & 95 & $95,96 \%$ & 4 & $4,04 \%$ & 99 \\
\hline TRABALHO DE EVENTO-RESUMO PERIODICO & 0 & $0,00 \%$ & 2 & $100,00 \%$ & 2 \\
\hline \hline Total & $\mathbf{1 5 3}$ & $\mathbf{7 9 , 6 9 \%}$ & $\mathbf{3 9}$ & $\mathbf{2 0 , 3 1 \%}$ & $\mathbf{1 9 2}$ \\
\hline
\end{tabular}

Fonte: Elaborada pelo autor com dados do Dedalus. 
Em relação à produção científica do Docente 04 indexada na WoS Core Collection, a Tabela 29 traz os dados referentes aos artigos publicados, distribuídos por periódico. Os periódicos com maior número de publicação foram o Journal of South American Earth Sciences (Categoria do JCR: Geoscience e Multidisciplinary; FI de 1,639; Categoria SJR: Earth and Planetary Sciences; SJR de 0,82) com 8 artigos, Lithos (Categoria do JCR: Geochemistry \& Geophysics e Mineralogy; FI de 3,857; Categoria SJR: Earth and Planetary Sciences: Geochemistry and Petrology; SJR de 2,67) com 4, o Precambrian Research (Categoria do JCR: Geoscience e Multidisciplinary; FI de 3,907; Categoria SJR: Earth and Planetary Sciences; SJR de 2,769) também com 4 e os Anais da Academia Brasileira de Ciências (Categoria do JCR: Multidisciplinary Sciences; FI de 0,956; Categoria SJR: Multidisciplinary; SJR de 0,418) com 3. Os quatro periódicos juntos correspondem a $57,58 \%$ do total de artigos publicados.

Tabela 29 - Artigos do Docente 04 indexados na WoS Core Collection distribuídos por título de periódico

\begin{tabular}{lcc}
\hline Periódicos & Artigos & \%Artigos \\
\hline JOURNAL OF SOUTH AMERICAN EARTH SCIENCES & 8 & $24,24 \%$ \\
\hline LITHOS & 4 & $12,12 \%$ \\
\hline PRECAMBRIAN RESEARCH & 4 & $12,12 \%$ \\
\hline ANAIS DA ACADEMIA BRASILEIRA DE CIENCIAS & 3 & $9,09 \%$ \\
\hline ARABIAN JOURNAL OF GEOSCIENCES & 1 & $3,03 \%$ \\
\hline CANADIAN MINERALOGIST & 1 & $3,03 \%$ \\
CENTRAL EUROPEAN JOURNAL OF GEOSCIENCES & 1 & $3,03 \%$ \\
\hline CHEMICAL GEOLOGY & 1 & $3,03 \%$ \\
\hline EARTH AND PLANETARY SCIENCE LETTERS & 1 & $3,03 \%$ \\
\hline ENVIRONMENTAL EARTH SCIENCES & 1 & $3,03 \%$ \\
\hline GEOSTANDARDS AND GEOANALYTICAL RESEARCH & 1 & $3,03 \%$ \\
\hline INTERNATIONAL JOURNAL OF EARTH SCIENCES & 1 & $3,03 \%$ \\
\hline JOURNAL OF ALLOYS AND COMPOUNDS & 1 & $3,03 \%$ \\
\hline JOURNAL OF MAPS & 1 & $3,03 \%$ \\
\hline JOURNAL OF METAMORPHIC GEOLOGY & 1 & $3,03 \%$ \\
\hline JOURNAL OF PETROLOGY & 1 & $3,03 \%$ \\
\hline JOURNAL OF VOLCANOLOGY AND GEOTHERMAL RESEARCH & 1 & $3,03 \%$ \\
\hline QUIMICA NOVA & 1 & $3,03 \%$ \\
\hline \hline Total & $\mathbf{3 3}$ & $\mathbf{1 0 0 , 0 0 \%}$ \\
\hline
\end{tabular}

Fonte: Elaborada pelo autor com dados da WoS Core Collection.

A seguir apresentam-se os dados de acordo com o Perfil Bibliométrico adaptado da proposta de Gorraiz, Wieland \& Gumpenberger (2016). 
- Análise de coautorias

A Tabela 30 apresenta os dados de coautoria do Docente 04, nos quais é possível identificar que a maior concentração de publicações encontra-se em artigos com 3, 4 e 5 autores, totalizando $78.79 \%$.

Tabela 30 - Quantidade de autores nos artigos com participação do Docente 04

\begin{tabular}{cccc}
\hline Quantidade de Autores & Total de Artigos & $\%$ Artigos \\
\hline 1 & 1 & $3,03 \%$ \\
& 2 & 1 & $3,03 \%$ \\
& 3 & 8 & $24,24 \%$ \\
& 4 & 10 & $30,30 \%$ \\
& 5 & 8 & $24,24 \%$ \\
& 6 & 3 & $9,09 \%$ \\
\hline \hline Total & 2 & $6,06 \%$ \\
\hline Fonte: Elaborada pelo & $\mathbf{3 3}$ & $\mathbf{1 0 0} \%$ \\
\hline
\end{tabular}

Fonte: Elaborada pelo autor com dados da WoS Core Collection.

A Tabela 31 apresenta que em $69,70 \%$ dos artigos publicados o docente ocupa a posição central, confirmando a informação fornecida em sua entrevista que aos orientandos é dada a primeira autoria, ficando ele com a segunda ou terceira posição nos artigos. Esta é uma prática comum no IGc/USP e foi confirmada pela maioria dos docentes entrevistados.

Tabela 31 - Artigos distribuídos por quantidade de autores e posição na autoria do Docente 04 nos artigos em que participa

\begin{tabular}{|c|c|c|c|c|c|}
\hline \multirow{2}{*}{ Quantidade de Autores } & \multicolumn{4}{|c|}{ Posição na Autoria } & \multirow{2}{*}{ Total } \\
\hline & Primeiro & Meio & Último & Único & \\
\hline 1 & & & & 1 & 1 \\
\hline 2 & & & 1 & & 1 \\
\hline 3 & 1 & 4 & 3 & & 8 \\
\hline 4 & 1 & 7 & 2 & & 10 \\
\hline 5 & 1 & 7 & & & 8 \\
\hline 6 ou mais & & 5 & & & 5 \\
\hline Total & 3 & 23 & 6 & 1 & 33 \\
\hline
\end{tabular}

Fonte: Elaborada pelo autor com dados da WoS Core Collection.

- Análise da colaboração

Colaborar internacionalmente tem se tornado um elemento fundamental para a produção da ciência e obtenção de financiamento para pesquisa. A Tabela 32 informa 
que o Docente 04 durante o período analisado produziu quase metade dos seus artigos somente com coautores brasileiros e a outra metade apenas com coautores de dois países (Brasil e outro).

Tabela 32 - Quantidade de países dos autores que publicaram nos artigos com participação do Docente 04

\begin{tabular}{lccc}
\hline Quantidade de Países & Total de Artigos & \% Artigos \\
\hline & 1 & 15 & $45,45 \%$ \\
& 2 & 18 & $54,55 \%$ \\
\hline \hline Total Geral & $\mathbf{3 3}$ & $\mathbf{1 0 0 , 0 0 \%}$ \\
\hline
\end{tabular}

Fonte: Elaborada pelo autor com dados da WoS Core Collection.

Com a Tabela 33 é possível verificar que o docente realizou colaboração com apenas dois países estrangeiros, sendo que no caso do Senegal apenas um artigo. Os coautores canadenses são seus principais colaboradores internacionais, tendo participado de $51,52 \%$ de seus artigos.

Tabela 33 - Países dos autores que publicaram nos artigos com participação do Docente 04

\begin{tabular}{lcc}
\hline Países & Total de Artigos & \% Artigos \\
\hline Canadá & 17 & $51,52 \%$ \\
Brasil & 15 & $45,45 \%$ \\
Senegal & 1 & $3,03 \%$ \\
\hline \hline Total & $\mathbf{3 3}$ & $\mathbf{1 0 0 , 0 0 \%}$ \\
\hline
\end{tabular}

Fonte: Elaborada pelo autor com dados da WoS Core Collection.

Em termos de instituições parceiras as Tabelas 34 e 35 trazem dados mais granulares dessas colaborações. Pode-se verificar que $42,42 \%$ dos seus artigos foram produzidos no máximo com duas instituições e apenas $24,24 \%$ com três. Ao todo ele colaborou com apenas cinco instituições, sendo a principal parceira a University of Alberta do Canadá com 10 artigos em conjunto.

Tabela 34 - Quantidade de instituições dos autores que publicaram nos artigos com participação do Docente 04

\begin{tabular}{lccc}
\hline Quantidade de Instituições & Total de Artigos & \% Artigos \\
\hline 1 & 11 & $33,33 \%$ \\
& 2 & 14 & $42,42 \%$ \\
& 3 & 8 & $24,24 \%$ \\
\hline \hline Total & $\mathbf{3 3}$ & $\mathbf{1 0 0 , 0 0 \%}$ \\
\hline
\end{tabular}

Fonte: Elaborada pelo autor com dados da WoS Core Collection apresentados via Incites. 
Tabela 35 - Distribuição das Instituições por países dos autores que publicaram com o Docente 04

\begin{tabular}{lc}
\hline País/Instituição & Artigos \\
\hline Brasil & 2 \\
$\quad$ Universidade Federal de Sao Paulo (UNIFESP) & 5 \\
Universidade Federal do Rio Grande do Sul & \\
Canadá & 10 \\
University of Alberta & 7 \\
University of Quebec & 7 \\
University of Quebec Chicoutimi & \\
Senegal & 1 \\
$\quad$ University Cheikh Anta Diop Dakar & \\
\hline \hline
\end{tabular}

Fonte: Incites com dados da WoS Core Collection.

- Análise dos financiamentos de pesquisa recebidos

A presente análise verifica quais foram as Agências de Fomento que apoiaram as pesquisas realizadas pelo Docente 04 . Cabe destacar que a WoS somente padronizou os dados de Agências de Fomento de 2008 para frente e, portanto, dos 33 artigos do Docente 04 indexados na WoS somente 24 puderam ser analisados, uma vez que os outros 9 são anteriores a esse período.

A Tabela 36 apresenta as informações das agências de fomento que apoiaram as pesquisas publicadas pelo Docente 04, com destaque para o ano de 2011 no qual todos os artigos obtiveram um Impacto Normalizado acima da média para a área (maior que $1,0)$ e os mais altos índices de citações por artigo. Destaque especial para o artigo financiado pelo CNPq que obteve um índice de 3,13 e uma média de citações por artigo de 56.

Nos anos de 2013 e 2016, a maioria dos artigos também obteve um impacto normalizado acima da média, com destaque para o artigo produzido no ano de 2016 com financiamento do Natural Sciences and Engineering Research Council of Canada (NSERC) com um impacto normalizado de 4,29, ou seja, 3 vezes acima do esperado. 
Tabela 36 - Agências de Fomento que apoiaram as pesquisas que geraram as publicações com participação do Docente 04, distribuídas por ano

\begin{tabular}{|c|c|c|c|c|}
\hline Agências de Fomento por Ano & Artigos & Citações & Citações/Artigo & Impacto Normalizado \\
\hline 2008 & 3 & --- & --- & --- \\
\hline FINEP & 1 & 8 & 8 & 0,32 \\
\hline FAPERGS & 1 & 8 & 8 & 0,32 \\
\hline CNPq & 1 & 8 & 8 & 0,32 \\
\hline 2009 & 3 & --- & --- & --- \\
\hline FAPESP & 3 & 36 & 12 & 0,6 \\
\hline 2010 & 1 & --- & --- & --- \\
\hline FAPESP & 1 & 2 & 2 & 0,1 \\
\hline 2011 & 6 & --- & --- & --- \\
\hline FAPESP & 3 & 83 & 27,67 & 1,57 \\
\hline CNPq & 1 & 56 & 56 & 3,13 \\
\hline $\begin{array}{l}\text { Nat. Sci. and Eng. Res. Coun. } \\
\text { of Canada (NSERC) }\end{array}$ & 2 & 61 & 30,5 & 1,71 \\
\hline 2012 & 8 & --- & --- & --- \\
\hline FAPESP & 6 & 41 & 6,83 & 0,46 \\
\hline CNPq & 2 & 9 & 4,5 & 0,31 \\
\hline 2013 & 2 & --- & --- & --- \\
\hline CAPES & 1 & 15 & 15 & 1,23 \\
\hline FAPESP & 1 & 15 & 15 & 1,23 \\
\hline 2014 & 7 & --- & --- & --- \\
\hline CAPES & 1 & 3 & 3 & 0,34 \\
\hline FAPESP & 3 & 13 & 4,33 & 0,47 \\
\hline FAPERGS & 1 & 10 & 10 & 1,06 \\
\hline $\mathrm{CNPq}$ & 1 & 0 & 0 & 0 \\
\hline $\begin{array}{l}\text { Nat. Sci. and Eng. Res. Coun. } \\
\text { of Canada (NSERC) }\end{array}$ & 1 & 10 & 10 & 1,06 \\
\hline 2015 & 5 & --- & --- & --- \\
\hline FAPESP & 3 & 14 & 4,67 & 0,73 \\
\hline CNPq & 2 & 12 & 6 & 0,94 \\
\hline 2016 & 5 & --- & --- & --- \\
\hline CAPES & 1 & 2 & 2 & 0,6 \\
\hline FAPESP & 3 & 13 & 4,33 & 1,73 \\
\hline $\begin{array}{l}\text { Nat. Sci. and Eng. Res. Coun. } \\
\text { of Canada (NSERC) }\end{array}$ & 1 & 10 & 10 & 4,29 \\
\hline
\end{tabular}

Fonte: Incites com dados da WoS Core Collection

Outro fato relevante a se considerar é que todos os artigos financiados pela NSERC obtiveram índices de impacto normalizado acima da média, demonstrando que a colaboração com os canadenses tem sido bastante vantajosa para o Docente 04. 
- $\quad$ Análise de visibilidade da produção científica

No que diz respeito à visibilidade da produção científica do docente, esta é medida levando em conta a quantidade de artigos registrada no Dedalus (53) e quantidade de artigos indexada na WoS (33), assim o percentual do Docente 04 é de $62,26 \%$.

Outro fator considerado é o percentual de artigos presentes em periódicos de impacto. A Tabela 37 apresenta os artigos do docente publicados em periódicos indexados na WoS Core Collection, distribuídos segundo os Ciclos de Avaliação da CAPES e percentual publicado em periódicos do 10 Quartil do FI/JCR. Dos 33 artigos do Docente 04 indexados na WoS Core Collection 30,30\% estão presentes no 10 Quartil - vale ressaltar que nos últimos ciclos se intensifica a publicação em periódicos de maior impacto na área.

Tabela 37 - Artigos publicados pelo Docente 04 distribuídos por Ciclos de Avaliação da CAPES e indexados em periódicos do 10 Quartil do Fl/JCR

\begin{tabular}{lcc}
\hline Ciclos de Avaliação CAPES & Total de Artigos & \% Artigos no 10. Quartil \\
\hline Trienal 2004 & 3 & $66,67 \%$ \\
\hline Trienal 2007 & 1 & $0,00 \%$ \\
Trienal 2010 & 8 & $37,50 \%$ \\
Trienal 2013 & 10 & $40,00 \%$ \\
Quadrienal 2017 & 11 & $45,45 \%$ \\
\hline \hline Total & $\mathbf{3 3}$ & $\mathbf{3 0 , 3 0 \%}$ \\
\hline
\end{tabular}

Fonte: Incites com dados da WoS Core Collection

Analisando-se a publicação científica mais fortemente relacionada aos instrumentos de Avaliação da CAPES, a Tabela 38 apresenta a quantidade de artigos publicados distribuídos pelos Ciclos de Avaliação e classificação nos estratos Qualis da área de avaliação das Geociências.

Verifica-se que $57,57 \%$ dos artigos do Docente 04 encontram-se nos estratos mais altos ( $A, A 1$ e $A 2)$ e 33,33\% em periódicos $B 1$. É possível notar um aumento da produção do docente nos dois últimos ciclos de avaliação da CAPES, o Trienal de 2013 (com 10 artigos, dos quais 7 foram publicados em periódicos A1 e A2) e o Quadrienal de 2017 (com 11 artigos, dos quais 6 foram publicados nos mesmos estratos), uma vez que a soma dos 3 ciclos anteriores (Trienais de 2004, 2007 e 2010) juntos somavam 6 artigos nos mais altos estratos ( $A, A 1$ e $A 2)$. Ou seja, é notório o engajamento do docente na 
publicação em periódicos que resultem em maior impacto da sua pesquisa. Isso provavelmente se deva às suas colaborações internacionais.

Tabela 38 - Artigos publicados pelo Docente 04 distribuídos por Ciclos de Avaliação da CAPES e classificação do periódico nos estratos Qualis da área de avaliação das Geociências

\begin{tabular}{|c|c|c|c|c|c|c|c|}
\hline \multirow{2}{*}{ Periódicos e Ciclo de Avaliação } & \multicolumn{6}{|c|}{ Estratos Qualis } & \multirow{2}{*}{ Total } \\
\hline & A A1 & A2 & B1 & B2 & B3 & B4 & \\
\hline 2001-2003 - TRIENAL 2004 & 3 & & & & & & 3 \\
\hline JOURNAL OF ALLOYS AND COMPOUNDS & 1 & & & & & & 1 \\
\hline JOURNAL OF SOUTH AMERICAN EARTH SCIENCES & 1 & & & & & & 1 \\
\hline PRECAMBRIAN RESEARCH & 1 & & & & & & 1 \\
\hline 2004-2006 - TRIENAL 2007 & & & 1 & & & & 1 \\
\hline ANAIS DA ACADEMIA BRASILEIRA DE CIENCIAS & & & 1 & & & & 1 \\
\hline 2007-2009 - TRIENAL 2010 & 2 & 1 & 5 & & & & 8 \\
\hline ANAIS DA ACADEMIA BRASILEIRA DE CIENCIAS & & & 1 & & & & 1 \\
\hline CANADIAN MINERALOGIST & & & 1 & & & & 1 \\
\hline CHEMICAL GEOLOGY & 1 & & & & & & 1 \\
\hline GEOSTANDARDS AND GEOANALYTICAL RESEARCH & & 1 & & & & & 1 \\
\hline JOURNAL OF PETROLOGY & 1 & & & & & & 1 \\
\hline JOURNAL OF SOUTH AMERICAN EARTH SCIENCES & & & 2 & & & & 2 \\
\hline QUIMICA NOVA & & & 1 & & & & 1 \\
\hline 2010-2012 - TRIENAL 2013 & 4 & 3 & 2 & & 1 & & 10 \\
\hline ANAIS DA ACADEMIA BRASILEIRA DE CIENCIAS & & & 1 & & & & 1 \\
\hline ARABIAN JOURNAL OF GEOSCIENCES & & & & & 1 & & 1 \\
\hline EARTH AND PLANETARY SCIENCE LETTERS & 1 & & & & & & 1 \\
\hline ENVIRONMENTAL EARTH SCIENCES & & & 1 & & & & 1 \\
\hline INTERNATIONAL JOURNAL OF EARTH SCIENCES & & 1 & & & & & 1 \\
\hline JOURNAL OF SOUTH AMERICAN EARTH SCIENCES & & 2 & & & & & 2 \\
\hline LITHOS & 2 & & & & & & 2 \\
\hline PRECAMBRIAN RESEARCH & 1 & & & & & & 1 \\
\hline 2013-2016 - QUADRIENAL 2017 & 5 & 1 & 3 & 1 & & 1 & 11 \\
\hline CENTRAL EUROPEAN JOURNAL OF GEOSCIENCES & & & & & & 1 & 1 \\
\hline JOURNAL OF MAPS & & & & 1 & & & 1 \\
\hline JOURNAL OF METAMORPHIC GEOLOGY & 1 & & & & & & 1 \\
\hline JOURNAL OF SOUTH AMERICAN EARTH SCIENCES & & & 3 & & & & 3 \\
\hline JOURNAL OF VOLCANOLOGY AND GEOTHERMAL RESEARCH & & 1 & & & & & 1 \\
\hline LITHOS & 2 & & & & & & 2 \\
\hline PRECAMBRIAN RESEARCH & 2 & & & & & & 2 \\
\hline Total & 311 & 5 & 11 & 1 & 1 & 1 & 33 \\
\hline
\end{tabular}

Fonte: Elaborada pelo autor com dados da WoS Core Collection e Qualis/CAPES.

De forma a aprofundar a análise sobre as colaborações e a visibilidade das publicações, a Tabela 39 apresenta as instituições que colaboraram com o Docente 04 
em dois ou mais artigos, distribuídas entre os Ciclos de Avaliação da CAPES, com a indicação do percentual dos artigos no 10 Quartil do JCR.

Ao todo foram identificadas quatro instituições com a característica exigida e distribuídas em apenas três ciclos Trienais de 2010 e 2013 e Quadrienal de 2017, estes dois últimos com artigos publicados em periódicos do 10 Quartil, obtendo 62,50\% e $57,14 \%$ respectivamente.

Das quatro instituições, três tiveram publicações no 1 을 Quartil, a brasileira Universidade Federal do Rio Grande do Sul e as canadenses University of Quebec e University of Quebec Chicoutimi.

Tabela 39 - Artigos publicados pelo Docente 04 distribuídos segundo instituições que colaboraram duas ou mais vezes e Ciclos de Avaliação da CAPES, com indicação do percentual de artigos no 1 을 Quartil do JCR

\begin{tabular}{|c|c|c|c|c|}
\hline Instituição Colaboradora & Trienal 2010 & Trienal 2013 & Quadrienal 2017 & Total \\
\hline \multicolumn{5}{|l|}{ University of Alberta } \\
\hline Artigos & 2 & 5 & & 7 \\
\hline$\%$ Artigos no 1o. Quartil & $0,00 \%$ & $60,00 \%$ & & $42,86 \%$ \\
\hline \multicolumn{5}{|l|}{$\begin{array}{l}\text { Universidade Federal do Rio } \\
\text { Grande do Sul }\end{array}$} \\
\hline Artigos & & 3 & & 3 \\
\hline$\%$ Artigos no 1o. Quartil & & $66,67 \%$ & & $66,67 \%$ \\
\hline \multicolumn{5}{|l|}{ University of Quebec } \\
\hline Artigos & & & 7 & 7 \\
\hline$\%$ Artigos no 1o. Quartil & & & $57,14 \%$ & $57,14 \%$ \\
\hline \multicolumn{5}{|l|}{ University of Quebec Chicoutimi } \\
\hline Artigos & & & 7 & 7 \\
\hline$\%$ Artigos no 1o. Quartil & & & $57,14 \%$ & $57,14 \%$ \\
\hline Total Artigos & 2 & 8 & 14 & 24 \\
\hline Total \% Artigos no 10. Quartil & $0,00 \%$ & $62,50 \%$ & $57,14 \%$ & $54,17 \%$ \\
\hline
\end{tabular}

Fonte: Elaborada pelo autor com dados da WoS Core Collection e Qualis/CAPES.

- Análise de impacto da produção científica

Os critérios para a análise de impacto compreendem a análise das citações recebidas e, do total de artigos indexados, a quantidade destes nos Top 10\%. Dos 33 artigos do Docente 04 indexados na WoS, dois se encontram presentes no Top 10\%, correspondendo a 6,06\% da sua produção.

A Tabela 40 apresenta que em 5 dos 13 anos, com produção do Docente 04 indexada pela WoS, o índice de impacto normalizado foi igual ou superior a 1,0. Destes 
cinco, três estão presentes no período coberto pelos dois últimos ciclos de avaliação da CAPES (Trienal 2013 e Quadrienal 2017). Ou seja, nestes períodos o docente teve a maioria de suas publicações em periódicos de mais alto impacto, porém em somente 3 ocasiões esteve atingiu ou passou a média esperada. Reafirmando a premissa de que avaliar os pesquisadores levando-se em conta somente o impacto dos periódicos em que publica resulta em uma análise enviesada.

Quanto às citações por artigo, obviamente os anos mais antigos (2001 e 2002) receberam a primeira (2001) e a terceira (2002) maiores médias de citações, entretanto o ano de 2011, como já demonstrado anteriormente, obteve uma média alta de 27,7 citações por artigo, a segunda maior do docente.

Tabela 40 - Impacto dos artigos do Docente 04 distribuídos por ano de publicação

\begin{tabular}{|c|c|c|c|c|c|c|}
\hline $\begin{array}{l}\text { Ano de } \\
\text { Publicação }\end{array}$ & $\begin{array}{l}\text { Total de } \\
\text { Artigos }\end{array}$ & $\begin{array}{l}\text { \% Artigos } \\
\text { Citados }\end{array}$ & $\begin{array}{l}\text { Total de } \\
\text { Citações }\end{array}$ & $\begin{array}{l}\text { Citações/ } \\
\text { Artigo }\end{array}$ & $\begin{array}{c}\text { Art. Top } \\
10 \%\end{array}$ & $\begin{array}{l}\text { Impacto } \\
\text { Normalizado }\end{array}$ \\
\hline 2001 & 1 & $100,00 \%$ & 36 & 36,0 & $0,00 \%$ & 1,2 \\
\hline 2002 & 2 & $100,00 \%$ & 53 & 26,5 & $0,00 \%$ & 1,0 \\
\hline 2006 & 1 & $100,00 \%$ & 3 & 3,0 & $0,00 \%$ & 0,1 \\
\hline 2007 & 2 & $100,00 \%$ & 17 & 8,5 & $0,00 \%$ & 0,4 \\
\hline 2008 & 1 & $100,00 \%$ & 8 & 8,0 & $0,00 \%$ & 0,3 \\
\hline 2009 & 5 & $100,00 \%$ & 68 & 13,6 & $0,00 \%$ & 0,6 \\
\hline 2010 & 1 & $100,00 \%$ & 2 & 2,0 & $0,00 \%$ & 0,1 \\
\hline 2011 & 3 & $100,00 \%$ & 83 & 27,7 & $33,33 \%$ & 1,6 \\
\hline 2012 & 6 & $100,00 \%$ & 41 & 6,8 & $0,00 \%$ & 0,5 \\
\hline 2013 & 1 & $100,00 \%$ & 15 & 15,0 & $0,00 \%$ & 1,2 \\
\hline 2014 & 4 & $75,00 \%$ & 15 & 3,8 & $0,00 \%$ & 0,4 \\
\hline 2015 & 3 & $100,00 \%$ & 14 & 4,7 & $0,00 \%$ & 0,7 \\
\hline 2016 & 3 & $100,00 \%$ & 13 & 4,3 & $33,33 \%$ & 1,7 \\
\hline Total & 33 & $98,08 \%$ & 368 & --- & $6,06 \%$ & --- \\
\hline
\end{tabular}

Fonte: Incites com dados da WoS Core Collection

\section{- Análise das referências utilizadas}

O último item a se analisar são as referências utilizadas pelo Docente na redação de seus artigos. Ao todo o Docente 04 utilizou 391 fontes bibliográficas diferentes, citando-as 1.857 vezes em seus 33 artigos, gerando uma média de 56,27 referências por trabalho.

Utilizando-se as Zonas de Bradford para analisar as principais publicações citadas nos artigos, pôde-se verificar pelas Tabelas 41 e 42 que, das 1.857 referências utilizadas, 
no primeiro terço delas (Zona 1 - com 643 referências) concentram-se apenas 8 periódicos, os quais correspondem a 2,05\% das publicações; já no segundo terço (Zona 2 -com 618 referências) 36 publicações, já possuindo uma maior variedade de tipologias de documentos, corresponde a 9,21\%. O terceiro terço é a zona de maior dispersão com um total de 596 publicações, sendo a maioria delas com baixa frequência de citação (não sendo, portanto, apresentadas na tabela).

Essas 44 publicações somadas correspondem a 11,26\% das publicações, que, por conseguinte, correspondem a $67,91 \%$ de todas as referências citadas.

Tabela 41 - Lista de Referências utilizadas nos artigos do Docente 04 distribuídas pelas Zonas 1 e 2 de Bradford

(continua)

\begin{tabular}{|c|c|c|c|c|}
\hline$\#$ & Publicações & Citações & \% Citações & Zona de Bradford \\
\hline 1 & PRECAMBRIAN RES & 124 & $6,71 \%$ & \multirow{8}{*}{ Zona 1} \\
\hline 2 & J PETROL & 103 & $5,58 \%$ & \\
\hline 3 & LITHOS & 83 & $4,49 \%$ & \\
\hline 4 & CONTRIB MINERAL PETR & 78 & $4,22 \%$ & \\
\hline 5 & J S AM EARTH SCI & 77 & $4,17 \%$ & \\
\hline 6 & REV BRASILEIRA GEOCI & 69 & $3,74 \%$ & \\
\hline 7 & EARTH PLANET SC LETT & 56 & $3,03 \%$ & \\
\hline 8 & GEOCHIM COSMOCHIM AC & 53 & $2,87 \%$ & \\
\hline 1 & CHEM GEOL & 51 & $2,76 \%$ & \multirow{18}{*}{ Zona 2} \\
\hline 2 & THESIS U SAO PAULO & 47 & $2,54 \%$ & \\
\hline 3 & GEOLOGY & 43 & $2,33 \%$ & \\
\hline 4 & GONDWANA RES & 37 & $2,00 \%$ & \\
\hline 5 & AM MINERAL & 34 & $1,84 \%$ & \\
\hline 6 & ANAIS ACAD BRASILEIR & 25 & $1,35 \%$ & \\
\hline 7 & TECTONIC EVOLUTION S & 23 & $1,25 \%$ & \\
\hline 8 & GEOL SOC SPEC PUBL & 22 & $1,19 \%$ & \\
\hline 9 & GEOLOGIA USP C & 21 & $1,14 \%$ & \\
\hline 10 & TECTONOPHYSICS & 20 & $1,08 \%$ & \\
\hline 11 & GEOSTANDARD NEWSLETT & 17 & $0,92 \%$ & \\
\hline 12 & NATURE & 16 & $0,87 \%$ & \\
\hline 13 & EARTH-SCI REV & 16 & $0,87 \%$ & \\
\hline 14 & QUIM NOVA & 15 & $0,81 \%$ & \\
\hline 15 & J GEOL & 15 & $0,81 \%$ & \\
\hline 16 & J VOLCANOL GEOTH RES & 14 & $0,76 \%$ & \\
\hline 17 & GEOL SOC AM BULL & 14 & $0,76 \%$ & \\
\hline 18 & J METAMORPH GEOL & 14 & $0,76 \%$ & \\
\hline
\end{tabular}


Tabela 41 - Lista de Referências utilizadas nos artigos do Docente 04 distribuídas pelas Zonas 1 e 2 de Bradford

(conclusão)

\begin{tabular}{|c|c|c|c|c|c|}
\hline & $\#$ & Publicações & Citações & \% Citações & Zona de Bradford \\
\hline & 19 & J GEOL SOC LONDON & 13 & $0,70 \%$ & \multirow{18}{*}{ Zona 2} \\
\hline & 20 & TECTONICS & 13 & $0,70 \%$ & \\
\hline & 21 & EPISODES & 13 & $0,70 \%$ & \\
\hline & 22 & REV BRAS GEOCIENC & 12 & $0,65 \%$ & \\
\hline & 23 & CAN MINERAL & 11 & $0,60 \%$ & \\
\hline & 24 & AN ACAD BRAS CIENC & 11 & $0,60 \%$ & \\
\hline & 25 & REV BRAS GEOC & 11 & $0,60 \%$ & \\
\hline & 26 & J STRUCT GEOL & 9 & $0,49 \%$ & \\
\hline & 27 & RARE EARTH ELEMENT G & 9 & $0,49 \%$ & \\
\hline & 28 & J GEOPHYS RES & 9 & $0,49 \%$ & \\
\hline & 29 & THESIS U FEDERAL RIO & 9 & $0,49 \%$ & \\
\hline & 30 & MINER PETROL & 8 & $0,43 \%$ & \\
\hline & 31 & REV MINERALOGY GEOCH & 8 & $0,43 \%$ & \\
\hline & 32 & J GEOPHYS RES-SOL EA & 8 & $0,43 \%$ & \\
\hline & 33 & J COLLOID INTERF SCI & 8 & $0,43 \%$ & \\
\hline & 34 & GEOL J & 8 & $0,43 \%$ & \\
\hline & 35 & 3 S AM S IS GEOL PUC & 7 & $0,38 \%$ & \\
\hline & 36 & B VOLCANOL & 7 & $0,38 \%$ & \\
\hline Total & & 44 Títulos & 1.261 & $68,27 \%$ & \\
\hline
\end{tabular}

Fonte: Elaborada pelo autor com dados da WoS Core Collection.

Tabela 42 - Quantidade de publicações citadas pelo Docente 04 distribuídas pelas Zonas de Bradford

\begin{tabular}{lcccc}
\hline Zonas de Bradford & Total de Publicações & \% Publicações & Total de Citações & \% Citações \\
\hline Zona 1 & 8 & $2,05 \%$ & 643 & $34,63 \%$ \\
\hline Zona 2 & 36 & $9,21 \%$ & 618 & $33,28 \%$ \\
\hline Zona 3 & 347 & $88,75 \%$ & 596 & $32,09 \%$ \\
\hline \hline Total & $\mathbf{3 9 1}$ & $\mathbf{1 0 0 , 0 0 \%}$ & $\mathbf{1 . 8 5 7}$ & $\mathbf{1 0 0 , 0 0 \%}$ \\
\hline
\end{tabular}

Fonte: Elaborada pelo autor com dados da WoS Core Collection.

Tais dados permitem ainda analisar a relação de onde se publica com o que se cita. A Tabela 43 nos apresenta que dos 18 periódicos nos quais foram publicados os 33 artigos do Docente 04 os três primeiros com maior número de publicações estão presentes na Zona 01, sendo que o segundo corresponde à terceira publicação mais referenciada, o terceiro à primeira e o primeiro à quinta. Dos 13 restantes, dois 
pertencem à Zona 1, seis à Zona 2, três à Zona 3 e quatro não se encontram citados nas referências utilizadas.

Durante a entrevista quando perguntado sobre as publicações mais importantes do seu campo de atuação o Docente 04 citou os periódicos: Journal of Petrology; Lithos; Chemical Geology; Journal of Volcanology and Geothermal Research; Bulletin of Volcanology; Contributions to Mineralogy and Petrology; e Precambrian Research. E a informação foi confirmada, uma vez que todos eles estão presentes ou na Zona 1 ou Zona 2.

Tabela 43 - Lista de periódicos nos quais o Docente 04 publicou seus artigos com indicação das Zonas de Bradford

\begin{tabular}{|c|c|c|c|}
\hline Título do Periódico & $\begin{array}{l}\text { Total de } \\
\text { Artigos }\end{array}$ & $\begin{array}{l}\text { \% Total de } \\
\text { Artigos }\end{array}$ & $\begin{array}{l}\text { Zonas de } \\
\text { Bradford }\end{array}$ \\
\hline $\begin{array}{l}\text { JOURNAL OF SOUTH AMERICAN EARTH } \\
\text { SCIENCES }\end{array}$ & 8 & $24,24 \%$ & 1 \\
\hline LITHOS & 4 & $12,12 \%$ & 1 \\
\hline PRECAMBRIAN RESEARCH & 4 & $12,12 \%$ & 1 \\
\hline ANAIS DA ACADEMIA BRASILEIRA DE CIENCIAS & 3 & $9,09 \%$ & 2 \\
\hline $\begin{array}{l}\text { GEOSTANDARDS AND GEOANALYTICAL } \\
\text { RESEARCH }\end{array}$ & 1 & $3,03 \%$ & 3 \\
\hline JOURNAL OF METAMORPHIC GEOLOGY & 1 & $3,03 \%$ & 2 \\
\hline ARABIAN JOURNAL OF GEOSCIENCES & 1 & $3,03 \%$ & Não citado \\
\hline CANADIAN MINERALOGIST & 1 & $3,03 \%$ & 2 \\
\hline JOURNAL OF ALLOYS AND COMPOUNDS & 1 & $3,03 \%$ & 3 \\
\hline $\begin{array}{l}\text { CENTRAL EUROPEAN JOURNAL OF } \\
\text { GEOSCIENCES }\end{array}$ & 1 & $3,03 \%$ & Não citado \\
\hline JOURNAL OF PETROLOGY & 1 & $3,03 \%$ & 1 \\
\hline QUIMICA NOVA & 1 & $3,03 \%$ & 2 \\
\hline $\begin{array}{l}\text { JOURNAL OF VOLCANOLOGY AND } \\
\text { GEOTHERMAL RESEARCH }\end{array}$ & 1 & $3,03 \%$ & 2 \\
\hline JOURNAL OF MAPS & 1 & $3,03 \%$ & 3 \\
\hline ENVIRONMENTAL EARTH SCIENCES & 1 & $3,03 \%$ & Não citado \\
\hline CHEMICAL GEOLOGY & 1 & $3,03 \%$ & 2 \\
\hline $\begin{array}{l}\text { INTERNATIONAL JOURNAL OF EARTH } \\
\text { SCIENCES }\end{array}$ & 1 & $3,03 \%$ & Não citado \\
\hline EARTH AND PLANETARY SCIENCE LETTERS & 1 & $3,03 \%$ & 1 \\
\hline Total & 33 & $100,00 \%$ & --- \\
\hline
\end{tabular}

Fonte: Elaborada pelo autor com dados da WoS Core Collection.

A Tabela 44 apresenta a idade das referências citadas pelo Docente 04 de acordo com o ano de publicação de cada um de seus artigos. A maior concentração encontrase em referências de 11 a 20 anos, com 30,69\% e nas faixas de 0 a 5 e 6 a 10 anos, que 
somadas correspondem a $48,79 \%$. Somando essas três faixas tem-se $79,48 \%$ do total geral de citações de referências com até 20 anos.

Tabela 44 - Idade das Referências citadas nos artigos do Docente 04

\begin{tabular}{|c|c|c|}
\hline Idade das Referências & Total de Citações & \% Citações \\
\hline $0-5$ & 437 & $23,53 \%$ \\
\hline $6-10$ & 469 & $25,26 \%$ \\
\hline $11-20$ & 570 & $30,69 \%$ \\
\hline $21-30$ & 246 & $13,25 \%$ \\
\hline $31-40$ & 108 & $5,82 \%$ \\
\hline $41-50$ & 13 & $0,70 \%$ \\
\hline+50 & 14 & $0,75 \%$ \\
\hline Total & 1.857 & $100,00 \%$ \\
\hline
\end{tabular}

Fonte: Elaborada pelo autor com dados da WoS Core Collection.

- Informações adicionais

Com o objetivo de cruzar as informações obtidas pela entrevista e pelo perfil bibliométrico do docente apresentam-se algumas considerações.

O Docente 04 comenta que sua área de atuação é a da Ciência Pura, a Geologia enquanto ciência e, portanto, naturalmente internacional. Todavia, sua produção geral, registrada no Dedalus, é altamente doméstica $(79,69 \%)$, conforme apresentado, sua produção em artigos de periódicos estrangeiros é de $56,60 \%$.

Suas colaborações internacionais, apesar de poucas, são consistentes e resultam no aumento do impacto da sua produção.

Nos últimos anos o docente tem direcionado suas publicações a periódicos de mais alto impacto e isso também tem trazido bons resultados em termos de impacto na sua área de pesquisa.

$\mathrm{Na}$ entrevista ficou evidente o conhecimento do docente sobre o fluxo da produção científica e sua relação com os processos avaliativos, compreendendo que para o bem e para o mal as avaliações e os indicadores bibliométricos são parte do jogo da ciência. 


\section{DOCENTE 05}

O Docente 05, conforme apresentado no Quadro 1, obteve um nível de publicação 2 no primeiro subperíodo de ciclos de avaliação da CAPES (2001-2009), com um percentual de publicação em periódicos domésticos de 36,84\%, apresentando um perfil internacionalizado. No segundo subperíodo (2010-2016) o docente alterou seu nível de publicação para 1, com um percentual de 15,94\% de publicação em periódicos domésticos, evidenciando ainda mais seu perfil já internacionalizado.

Baseada nos dados coletados no Banco Dedalus, a Tabela 45 apresenta a distribuição da produção intelectual do Docente 05 por tipo de publicação.

Nota-se que a maior concentração da produção do Docente 05 está registrada em eventos, totalizando $61,27 \%$, todavia possui também um bom índice de produção em artigos de periódicos de 33,45\%, tendo $80 \%$ sido publicados em periódicos estrangeiros.

Tabela 45 - Produção Intelectual do Docente 05 registrada no Dedalus distribuída por tipo de publicação

\begin{tabular}{lccccc}
\hline \multirow{2}{*}{ Tipo de Publicação / Ciclo de Avaliação } & \multicolumn{2}{c}{$\begin{array}{c}\text { Doméstico } \\
\text { \% Docs }\end{array}$} & $\begin{array}{c}\text { Estrangeiro } \\
\text { Docs }\end{array}$ & $\begin{array}{c}\text { \% Docs } \\
\text { Total }\end{array}$ \\
\hline ARTIGO DE JORNAL-DEP/ENTR & 1 & $100,00 \%$ & 0 & $0,00 \%$ & 1 \\
\hline ARTIGO DE PERIODICO & 19 & $20,00 \%$ & 76 & $80,00 \%$ & 95 \\
\hline ARTIGO DE PERIODICO-DEP/ENTR & 1 & $100,00 \%$ & 0 & $0,00 \%$ & 1 \\
\hline MONOGRAFIA/LIVRO & 0 & $0,00 \%$ & 1 & $100,00 \%$ & 1 \\
\hline PARTE DE MONOGRAFIA/LIVRO & 9 & $75,00 \%$ & 3 & $25,00 \%$ & 12 \\
\hline TRABALHO DE EVENTO & 30 & $58,82 \%$ & 21 & $41,18 \%$ & 51 \\
\hline TRABALHO DE EVENTO-ANAIS PERIODICO & 0 & $0,00 \%$ & 1 & $100,00 \%$ & 1 \\
\hline TRABALHO DE EVENTO-RESUMO & 70 & $60,87 \%$ & 45 & $39,13 \%$ & 115 \\
\hline TRABALHO DE EVENTO-RESUMO PERIODICO & 1 & $14,29 \%$ & 6 & $85,71 \%$ & 7 \\
\hline \hline Total & $\mathbf{1 3 1}$ & $\mathbf{4 6 , 1 3 \%}$ & $\mathbf{1 5 3}$ & $\mathbf{5 3 , 8 7 \%}$ & $\mathbf{2 8 4}$ \\
\hline
\end{tabular}

Fonte: Elaborada pelo autor com dados do Dedalus.

Em relação à produção científica do Docente 05 indexada na WoS Core Collection, a Tabela 46 traz os dados referentes aos artigos publicados, distribuídos por periódico. Os periódicos com maior número de publicação foram o Journal of South American Earth Sciences (Categoria do JCR: Geoscience e Multidisciplinary; FI de 1,639; Categoria SJR: Earth and Planetary Sciences; SJR de 0,82) com 13 artigos e Lithos 
(Categoria do JCR: Geochemistry \& Geophysics e Mineralogy; FI de 3,857; Categoria SJR: Earth and Planetary Sciences: Geochemistry and Petrology; SJR de 2,67) com 7, o Precambrian Research (Categoria do JCR: Geoscience e Multidisciplinary; FI de 3,907; Categoria SJR: Earth and Planetary Sciences; SJR de 2,769) com 6 e Ore Geology Reviews (Categoria do JCR: Geology; Mineralogy; e Mining \& Mineral Processing; FI de 3,993; Categoria SJR: Earth and Planetary Sciences: Economic Geology; Geochemistry and Petrology; e Geology; SJR de 1,707) com 5. Os quatro periódicos juntos correspondem a $45,59 \%$ do total de artigos publicados.

Tabela 46 - Artigos do Docente 05 indexados na WoS Core Collection distribuídos por título de periódico

\begin{tabular}{|c|c|c|}
\hline Periódicos & Artigos & \%Artigos \\
\hline JOURNAL OF SOUTH AMERICAN EARTH SCIENCES & 13 & $19,12 \%$ \\
\hline LITHOS & 7 & $10,29 \%$ \\
\hline PRECAMBRIAN RESEARCH & 6 & $8,82 \%$ \\
\hline ORE GEOLOGY REVIEWS & 5 & $7,35 \%$ \\
\hline MINERALIUM DEPOSITA & 4 & $5,88 \%$ \\
\hline GONDWANA RESEARCH & 3 & $4,41 \%$ \\
\hline EPISODES & 3 & $4,41 \%$ \\
\hline JOURNAL OF VOLCANOLOGY AND GEOTHERMAL RESEARCH & 2 & $2,94 \%$ \\
\hline ANDEAN GEOLOGY & 2 & $2,94 \%$ \\
\hline JOURNAL OF COASTAL RESEARCH & 2 & $2,94 \%$ \\
\hline TECTONOPHYSICS & 2 & $2,94 \%$ \\
\hline BRAZILIAN JOURNAL OF GEOLOGY & 2 & $2,94 \%$ \\
\hline GEOCHEMICAL JOURNAL & 1 & $1,47 \%$ \\
\hline OFIOLITI & 1 & $1,47 \%$ \\
\hline MINERALOGY AND PETROLOGY & 1 & $1,47 \%$ \\
\hline AUSTRALIAN JOURNAL OF EARTH SCIENCES & 1 & $1,47 \%$ \\
\hline HOLOCENE & 1 & $1,47 \%$ \\
\hline GEOSCIENCES JOURNAL & 1 & $1,47 \%$ \\
\hline CHEMICAL GEOLOGY & 1 & $1,47 \%$ \\
\hline OPEN GEOSCIENCES & 1 & $1,47 \%$ \\
\hline INTERNATIONAL GEOLOGY REVIEW & 1 & $1,47 \%$ \\
\hline MARINE GEOLOGY & 1 & $1,47 \%$ \\
\hline INTERNATIONAL JOURNAL OF EARTH SCIENCES & 1 & $1,47 \%$ \\
\hline CONTINENTAL SHELF RESEARCH & 1 & $1,47 \%$ \\
\hline GEOCHEMISTRY-EXPLORATION ENVIRONMENT ANALYSIS & 1 & $1,47 \%$ \\
\hline ECONOMIC GEOLOGY & 1 & $1,47 \%$ \\
\hline AMERICAN JOURNAL OF SCIENCE & 1 & $1,47 \%$ \\
\hline GEODINAMICA ACTA & 1 & $1,47 \%$ \\
\hline TECTONICS & 1 & $1,47 \%$ \\
\hline Total Geral & 68 & $100,00 \%$ \\
\hline
\end{tabular}

Fonte: Elaborada pelo autor com dados da WoS Core Collection. 
A seguir apresentam-se os dados de acordo com o Perfil Bibliométrico adaptado da proposta de Gorraiz, Wieland \& Gumpenberger (2016).

\section{- $\quad$ Análise de coautorias}

A Tabela 47 apresenta os dados de coautoria do Docente 05, nos quais é possível identificar que a maior concentração de publicações encontra-se em artigos com 5 e 6 autores. A informação é complementada pela Tabela 48 que apresenta a posição do docente nos artigos, demonstrando uma maior quantidade de artigos (70,59\%) no qual assume uma posição central. Como primeiro autor, o docente publicou apenas seis artigos, correspondendo a $8,82 \%$ do total.

Em sua entrevista o docente comentou que em trabalhos baseados em teses o primeiro autor sempre é o orientando e ele como segundo, portanto isso explica a alta concentração de artigos na posição central.

Tabela 47 - Quantidade de autores nos artigos com participação do Docente 05

\begin{tabular}{cccc}
\hline Quantidade de Autores & Total de Artigos & \% Artigos \\
\hline 2 & 1 & $1,47 \%$ \\
3 & 9 & $13,24 \%$ \\
4 & 9 & $13,24 \%$ \\
5 & 12 & $17,65 \%$ \\
6 & 14 & $20,59 \%$ \\
7 & 4 & $5,88 \%$ \\
& 8 & 9 & $13,24 \%$ \\
9 & 7 & $10,29 \%$ \\
\hline 10 & 2 & $2,94 \%$ \\
\hline \hline Total Geral & 15 & 1 & $1,47 \%$ \\
\hline Fonte: Elaborada & 68 & $100,00 \%$ \\
\hline
\end{tabular}

Fonte: Elaborada pelo autor com dados da WoS Core Collection.

Tabela 48 - Artigos distribuídos por quantidade de autores e posição na autoria do Docente 05 nos artigos em que participa

\begin{tabular}{lcccc}
\hline \multirow{2}{*}{ Quantidade de Autores } & \multicolumn{3}{c}{ Posição na Autoria } & Total \\
\hline 2 & Primeiro & Meio & Último & \\
\hline 3 & 2 & & 1 & 1 \\
4 & 1 & 5 & 2 & 9 \\
5 & 1 & 3 & 5 & 9 \\
6 ou mais & 2 & 9 & 2 & 12 \\
\hline \hline Total Geral & 6 & 31 & 4 & 37 \\
\hline Fon & 48 & 14 & 68 \\
\hline
\end{tabular}

Fonte: Elaborada pelo autor com dados da WoS Core Collection. 
- Análise da colaboração

A colaboração internacional na produção científica tem se tornado um elemento importante, como destacado pelos docentes nas entrevistas realizadas, e a Tabela 49 confirma esse fato, uma vez que $89,71 \%$ dos artigos do Docente 05 foram publicados com coautores de 2 ou mais países.

Tabela 49 - Quantidade de países dos autores que publicaram nos artigos com participação do Docente 05

\begin{tabular}{cccc}
\hline Quantidade de Países & Total de Artigos & \% Artigos \\
\hline 1 & 7 & $10,29 \%$ \\
& 2 & 41 & $60,29 \%$ \\
& 3 & 16 & $23,53 \%$ \\
& 4 & 2 & $2,94 \%$ \\
\hline \hline Total & 2 & $2,94 \%$ \\
\hline Fonte: Elabo & $\mathbf{6 8}$ & $\mathbf{1 0 0 , 0 0 \%}$ \\
\hline
\end{tabular}

Fonte: Elaborada pelo autor com dados da WoS Core Collection.

Já a Tabela 50 apresenta a diversidade dos países colaboradores, contendo 13 países, além do Brasil, com destaque para Portugal e Itália com maior participação em artigos. Artigos com participação apenas brasileira corresponderam a 39,71\%

Tabela 50 - Países dos autores que publicaram nos artigos com participação do Docente 05

\begin{tabular}{lcc}
\hline Países & Total de Artigos & $\%$ Artigos \\
\hline Alemanha & 3 & $4,41 \%$ \\
\hline Argentina & 11 & $16,18 \%$ \\
Austrália & 13 & $19,12 \%$ \\
Áustria & 1 & $1,47 \%$ \\
Brasil & 27 & $39,71 \%$ \\
Canadá & 10 & $14,71 \%$ \\
Chile & 4 & $5,88 \%$ \\
China & 4 & $5,88 \%$ \\
Espanha & 6 & $8,82 \%$ \\
\hline Estados Unidos & 2 & $2,94 \%$ \\
França & 5 & $7,35 \%$ \\
Inglaterra & 1 & $1,47 \%$ \\
Itália & 39 & $57,35 \%$ \\
\hline Portugal & 41 & $60,29 \%$ \\
\hline \hline Total & 68 & --- \\
\hline Fonte: & 5 & \\
\hline
\end{tabular}

Fonte: Elaborada pelo autor com dados da WoS Core Collection. 
E em quantidade de instituições colaboradoras a Tabela 51 informa que 82,35\% dos artigos foram publicados com a participação de 2 a 4 diferentes instituições. Artigos com apenas uma instituição (USP) corresponderam a apenas $2,94 \%$.

Tabela 51 - Quantidade de instituições dos autores que publicaram nos artigos com participação do Docente 05

\begin{tabular}{cccc}
\hline Quantidade de Instituições & Total de Artigos & \% Artigos \\
\hline 1 & 2 & $2,94 \%$ \\
& 2 & 14 & $20,59 \%$ \\
& 3 & 23 & $33,82 \%$ \\
& 4 & 19 & $27,94 \%$ \\
& 5 & 5 & $7,35 \%$ \\
& 6 & 2 & $2,94 \%$ \\
& 8 & 2 & $2,94 \%$ \\
\hline \hline Total & 1 & $1,47 \%$ \\
\hline
\end{tabular}

Fonte: Elaborada pelo autor com dados da WoS Core Collection apresentados via Incites.

Para completar a análise, a Tabela 52 apresenta as instituições e seus respectivos países, permitindo observar que a colaboração se distribui em um alto conjunto de instituições (69 no total). E apresenta como principais coautores os portugueses da Universidade de Lisboa, com 21 artigos e do Laboratório Nacional de Energia e Geologia IP (LNEG) com 10 artigos; além do italiano Consiglio Nazionale delle Ricerche (CNR) com 8 artigos.

Tabela 52 - Distribuição das Instituições por países dos autores que publicaram com o Docente 05

(continua)

\begin{tabular}{lc}
\hline País/Instituição & Artigos \\
\hline Alemanha & \\
Ruhr University Bochum & 1 \\
University of Munich & 1 \\
University of Stuttgart & 1
\end{tabular}

\section{Argentina}

Consejo Nacional de Investigaciones Cientificas y Tecnicas (CONICET) 6

Museo La Plata 1

National University of Cordoba 1

National University of La Plata $\quad 2$

Universidad Nacional del Comahue 1 
Tabela 52 - Distribuição das Instituições por países dos autores que publicaram com o Docente 05

\begin{tabular}{lc} 
& (continuação) \\
\hline País/Instituição & Artigos \\
\hline Austrália & \\
Australian National University & 6 \\
Curtin University & 1 \\
University of Queensland & 2 \\
University of Western Australia & 2 \\
University of Wollongong & 2
\end{tabular}

$\begin{array}{ll}\text { Áustria } & \\ \text { University of Vienna } & 1 \\ \text { Brasil } & 1 \\ \text { Centro Brasileiro de Pesquisas Fisicas } & 1 \\ \text { Centro de Desenvolvimento da Tecnologia Nuclear (CDTN) } & 1 \\ \text { Petrobras SA } & 2 \\ \text { Universidade Cruzeiro do Sul } & 4 \\ \text { Universidade de Brasilia } & 2 \\ \text { Universidade do Estado do Rio de Janeiro } & 2 \\ \text { Universidade Estadual de Campinas } & 1 \\ \text { Universidade Estadual de Feira de Santana } & 1 \\ \text { Universidade Estadual Paulista } & 1 \\ \text { Universidade Federal da Bahia } & 1 \\ \text { Universidade Federal de Amazonas } & 2 \\ \text { Universidade Federal de Mato Grosso do Sul } & 2 \\ \text { Universidade Federal de Minas Gerais } & 3 \\ \text { Universidade Federal de Ouro Preto } & 1 \\ \text { Universidade Federal de Sergipe } & 1 \\ \text { Universidade Federal do Para } & 1 \\ \text { Universidade Federal do Rio de Janeiro } & 1 \\ \text { Universidade Federal do Rio Grande do Sul } & 1\end{array}$

Canadá

Carleton University

1

University of Alberta

2

University of Calgary

2

University of Quebec

2

University of Quebec Chicoutimi

2

University of Toronto

1

Chile

Universidad Andres Bello

1

Universidad de Chile

3

\section{China}

Chinese Academy of Geological Sciences

Chinese Academy of Sciences

Institute of Geology \& Geophysics; CAS 
Tabela 52 - Distribuição das Instituições por países dos autores que publicaram com o Docente 05

(conclusão)

\section{País/Instituição}

\section{Artigos}

Espanha

Complutense University of Madrid 1

Consejo Superior de Investigaciones Cientificas (CSIC)

2

Polytechnic University of Madrid

2

Universidad de Castilla-La Mancha

\section{Estados Unidos}

Brigham Young University

1

Southern Methodist University

1

\section{França}

Centre National de la Recherche Scientifique (CNRS)

Communaute d'Universites et Etablissements d'Aquitaine (ComUE)

1

Universite de Bordeaux

University of Rennes 1

2

1

1

1

\section{Inglaterra}

University of London

1

\begin{tabular}{lc} 
Itália & \\
Consiglio Nazionale delle Ricerche (CNR) & 8 \\
Istituto di Geologia Ambientale e Geoingegneria (IGAG-CNR) & 6 \\
Istituto di Geoscienze e Georisorse (IGG-CNR) & 2 \\
Sapienza University Rome & 6 \\
Universita di Modena e Reggio Emilia & 5 \\
University of Naples Federico II & 6 \\
University of Pavia & 3 \\
University of Trieste & 3 \\
Portugal & \\
Laboratorio Nacional de Energia e Geologia IP (LNEG) & 10 \\
Universidade de Aveiro & 4 \\
Universidade de Coimbra & 2 \\
Universidade de Lisboa & 21 \\
Universidade do Porto & 2 \\
Universidade dos Acores & 1 \\
University of Evora & 1 \\
\hline \hline
\end{tabular}

Fonte: Incites com dados da WoS Core Collection.

O perfil internacionalizado do Docente 05 apresentado anteriormente se confirma também em termos de seus coautores, dada a diversidade tanto de países quanto de instituições colaboradoras. 
- Análise dos financiamentos de pesquisa recebidos

A presente análise verifica quais foram as Agências de Fomento que apoiaram as pesquisas realizadas pelo Docente 05 . Cabe destacar que a WoS somente padronizou os dados de Agências de Fomento de 2008 para frente e, portanto, dos 68 artigos do Docente 05 indexados na WoS, menos da metade (33), puderam ser analisados, uma vez que os demais são anteriores a esse período.

A Tabela 53 apresenta as informações das agências de fomento que apoiaram as pesquisas publicadas pelo Docente 05 , com destaque para o ano de 2014, no qual os artigos apoiados por três das quatro agências obtiveram um Impacto Normalizado acima da média esperada de 1,0 .

Na entrevista o docente destacou a importância da participação em grupos de pesquisa multidisciplinares internacionais e isso se evidencia tanto no item analisado anteriormente quanto neste de Agências de Fomento.

Quanto aos dados de citação, em especial seu impacto (Citações / Artigo), os artigos com maior idade tendem a concentrar os maiores índices, por exemplo, o ano de 2010.

Tabela 53 - Agências de Fomento que apoiaram as pesquisas que geraram as publicações com participação do Docente 05, distribuídas por ano

(continua)

\begin{tabular}{lcccc}
\hline Agências de Fomento por Ano & Artigos & Citações & Citações/Artigo & $\begin{array}{c}\text { Impacto } \\
\text { Normalizado }\end{array}$ \\
\hline $\mathbf{2 0 0 8}$ & $\mathbf{1}$ & --- & --- & --- \\
Portuguese Found. for Scie. and & 1 & 17 & 17 & 0,68 \\
Tec. & $\mathbf{1}$ & --- & --- & --- \\
$\mathbf{2 0 0 9}$ & 1 & 8 & 8 & 0,38 \\
\hline ANPCyT & $\mathbf{9}$ & --- & --- & --- \\
\hline $\mathbf{2 0 1 0}$ & 2 & 35 & 17,5 & 0,78 \\
CNPq & 1 & 13 & 13 & 0,67 \\
European Union (EU) & 3 & 53 & 17,67 & 0,92 \\
FAPESP & 1 & 21 & 21 & 1,11 \\
Italian National Research Council & 1 & 21 & 21 & 1,11 \\
Minist. of Edu.; Univers. and Res. & 1 & & 13 & 0,67 \\
(MIUR) & & 13 & & \\
Portuguese Found. for Scie. and & 1 & & 13 & \\
Tec. & & & &
\end{tabular}


Tabela 53 - Agências de Fomento que apoiaram as pesquisas que geraram as publicações com participação do Docente 05 , distribuídas por ano

\begin{tabular}{|c|c|c|c|c|}
\hline Agências de Fomento por Ano & Artigos & Citações & Citações/Artigo & $\begin{array}{c}\text { Impacto } \\
\text { Normalizado } \\
\end{array}$ \\
\hline 2011 & 11 & --- & --- & --- \\
\hline CNPq & 1 & 6 & 6 & 0,35 \\
\hline European Union (EU) & 3 & 24 & 8 & 0,46 \\
\hline FAPESP & 3 & 24 & 8 & 0,46 \\
\hline $\begin{array}{l}\text { Portuguese Found. for Scie. and } \\
\text { Tec. }\end{array}$ & 4 & 24 & 6 & 0,35 \\
\hline 2012 & 4 & --- & --- & --- \\
\hline CNPq & 1 & 15 & 15 & 1,08 \\
\hline FAPESP & 1 & 15 & 15 & 1,08 \\
\hline $\begin{array}{l}\text { Minist. of Edu.; Univers. and Res. } \\
\text { (MIUR) }\end{array}$ & 1 & 13 & 13 & 0,93 \\
\hline $\begin{array}{l}\text { Portuguese Found. for Scie. and } \\
\text { Tec. }\end{array}$ & 1 & 2 & 2 & 0,13 \\
\hline 2013 & 2 & --- & --- & --- \\
\hline FAPESP & 1 & 19 & 19 & 1,49 \\
\hline $\begin{array}{l}\text { Portuguese Found. for Scie. and } \\
\text { Tec. }\end{array}$ & 1 & 2 & 2 & 0,16 \\
\hline 2014 & 5 & --- & --- & --- \\
\hline Austrian Science Fund (FWF) & 1 & 18 & 18 & 2,07 \\
\hline CNPq & 2 & 21 & 10,5 & 1,19 \\
\hline $\begin{array}{l}\text { Com. Nac. de Inv. Cient. y Tec. } \\
\text { (CONICYT) }\end{array}$ & 1 & 17 & 17 & 2,77 \\
\hline $\begin{array}{l}\text { Portuguese Found. for Scie. and } \\
\text { Tec. }\end{array}$ & 1 & 2 & 2 & 0,21 \\
\hline 2015 & 17 & --- & --- & --- \\
\hline CNPq & 6 & 37 & 6,17 & 0,97 \\
\hline $\begin{array}{l}\text { Com. Nac. de Inv. Cient. y Tec. } \\
\text { (CONICYT) }\end{array}$ & 1 & 1 & 1 & 0,21 \\
\hline $\begin{array}{l}\text { Cons. Nac. de Inv. Cient. y Tec. } \\
\text { (CONICET) }\end{array}$ & 1 & 6 & 6 & 0,94 \\
\hline FAPESP & 7 & 42 & 6 & 0,94 \\
\hline National University of La Plata & 1 & 6 & 6 & 0,94 \\
\hline $\begin{array}{l}\text { Portuguese Found. for Scie. and } \\
\text { Tec. }\end{array}$ & 1 & 11 & 11 & 1,72 \\
\hline 2016 & 4 & --- & --- & --- \\
\hline CNPq & 1 & 1 & 1 & 0,29 \\
\hline FAPESP & 1 & 1 & 1 & 0,29 \\
\hline $\begin{array}{l}\text { Portuguese Found. for Scie. and } \\
\text { Tec. }\end{array}$ & 2 & 3 & 1,5 & 0,45 \\
\hline
\end{tabular}

Fonte: Incites com dados da WoS Core Collection 
- Análise de visibilidade da produção científica

No que diz respeito à visibilidade da produção científica do docente, esta é medida levando em conta a quantidade de artigos registrada no Dedalus (95) e quantidade de artigos indexada na WoS (68), assim o percentual do Docente 05 é de $71,58 \%$.

Complementarmente a Tabela 54 apresenta os artigos do docente publicados em periódicos indexados na WoS Core Collection, distribuídos segundo Ciclos de Avaliação da CAPES e o percentual publicado em periódicos do 1으 Quartil do Fl/JCR. Dos 68 artigos do Docente 05 indexados na WoS Core Collection 41,18\% estão presentes no 1으artil.

Tabela 54 - Artigos publicados pelo Docente 05 distribuídos por Ciclos de Avaliação da CAPES e indexados em periódicos do 1 을 Quartil do $\mathrm{Fl} / \mathrm{JCR}$

\begin{tabular}{lcc}
\hline Ciclos de Avaliação CAPES & Total de Artigos & \% Artigos no 10. Quartil \\
\hline Trienal 2004 & 6 & $16,67 \%$ \\
Trienal 2007 & 7 & $42,86 \%$ \\
Trienal 2010 & 13 & $53,85 \%$ \\
Trienal 2013 & 19 & $36,84 \%$ \\
Quadrienal 2017 & 23 & $43,48 \%$ \\
\hline \hline Total & $\mathbf{6 8}$ & $\mathbf{4 1 , 1 8 \%}$ \\
\hline
\end{tabular}

Fonte: Incites com dados da WoS Core Collection

Analisando-se a publicação científica mais fortemente relacionada aos instrumentos de Avaliação da CAPES, a Tabela 55 apresenta a quantidade de artigos publicados distribuídos pelos Ciclos de Avaliação e classificação nos estratos Qualis da área de avaliação das Geociências.

Verifica-se que $48,53 \%$ dos artigos do Docente 05 encontram-se nos estratos mais altos ( $A, A 1$ e $A 2)$ e 39,71\% em periódicos B e B1. Além disso, verifica-se que o docente tem aumentado ciclo após ciclo sua produção em periódicos do estrato $A 1$, no entanto na Quadrienal de 2017 o número de artigos no estrato B1 superou a quantidade daqueles no $\mathrm{A} 1$.

Outro ponto a destacar é alta produção de artigos no Journal of South American Earth Sciences, o qual já esteve no estrato A2 na Trienal de 2013 e passou para B1 na Quadrienal de 2017. Este é um título importante para a publicação de estudos mais regionalizados e, portanto, não obtém um SJR ou FI altos. 
Esse ponto pode ter relação com a regra da CAPES em que apenas $25 \%$ dos periódicos nos quais a área publicou possam estar nos estratos A1 e A2.

Tabela 55 - Artigos publicados pelo Docente 05 distribuídos por Ciclos de Avaliação da CAPES e classificação do periódico nos estratos Qualis da área de avaliação das Geociências

(continua)

\begin{tabular}{|c|c|c|c|c|c|c|}
\hline \multirow{2}{*}{ Periódicos e Ciclo de Avaliação } & \multicolumn{5}{|c|}{ Estratos Qualis } & \multirow{2}{*}{ Total } \\
\hline & A $\mathbf{A 1}$ & A2 & B B1 & B3 & -- & \\
\hline 2001-2003 - TRIENAL 2004 & 2 & & 3 & & 1 & 6 \\
\hline EPISODES & & & 2 & & & 2 \\
\hline GONDWANA RESEARCH & & & 1 & & & 1 \\
\hline HOLOCENE & & & & & 1 & 1 \\
\hline MINERALIUM DEPOSITA & 1 & & & & & 1 \\
\hline TECTONOPHYSICS & 1 & & & & & 1 \\
\hline 2004-2006 - TRIENAL 2007 & 1 & 1 & 3 & 1 & 1 & 7 \\
\hline CONTINENTAL SHELF RESEARCH & & 1 & & & & 1 \\
\hline EPISODES & & & 1 & & & 1 \\
\hline JOURNAL OF COASTAL RESEARCH & & & & 1 & & 1 \\
\hline JOURNAL OF VOLCANOLOGY AND GEOTHERMAL RESEARCH & & & & & 1 & 1 \\
\hline LITHOS & 1 & & & & & 1 \\
\hline MINERALIUM DEPOSITA & & & 1 & & & 1 \\
\hline ORE GEOLOGY REVIEWS & & & 1 & & & 1 \\
\hline 2007-2009 - TRIENAL 2010 & 3 & 2 & 7 & 1 & & 13 \\
\hline GEODINAMICA ACTA & & & & 1 & & 1 \\
\hline GONDWANA RESEARCH & 2 & & & & & 2 \\
\hline INTERNATIONAL GEOLOGY REVIEW & & & 1 & & & 1 \\
\hline JOURNAL OF SOUTH AMERICAN EARTH SCIENCES & & & 4 & & & 4 \\
\hline LITHOS & 1 & & & & & 1 \\
\hline MARINE GEOLOGY & & 1 & & & & 1 \\
\hline ORE GEOLOGY REVIEWS & & & 2 & & & 2 \\
\hline TECTONICS & & 1 & & & & 1 \\
\hline 2010-2012 - TRIENAL 2013 & 6 & 7 & 3 & 2 & 1 & 19 \\
\hline AMERICAN JOURNAL OF SCIENCE & 1 & & & & & 1 \\
\hline GEOCHEMICAL JOURNAL & & & 1 & & & 1 \\
\hline GEOCHEMISTRY-EXPLORATION ENVIRONMENT ANALYSIS & & & 1 & & & 1 \\
\hline GEOSCIENCES JOURNAL & & & & 1 & & 1 \\
\hline JOURNAL OF COASTAL RESEARCH & & & & 1 & & 1 \\
\hline JOURNAL OF SOUTH AMERICAN EARTH SCIENCES & & 4 & & & & 4 \\
\hline JOURNAL OF VOLCANOLOGY AND GEOTHERMAL RESEARCH & & 1 & & & & 1 \\
\hline LITHOS & 3 & & & & & 3 \\
\hline MINERALIUM DEPOSITA & & 1 & & & & 1 \\
\hline MINERALOGY AND PETROLOGY & & & 1 & & & 1 \\
\hline
\end{tabular}


Tabela 55 - Artigos publicados pelo Docente 05 distribuídos por Ciclos de Avaliação da CAPES e classificação do periódico nos estratos Qualis da área de avaliação das Geociências

(conclusão)

\begin{tabular}{|c|c|c|c|c|c|c|c|}
\hline \multirow{2}{*}{ Periódicos e Ciclo de Avaliação } & \multicolumn{7}{|c|}{ Estratos Qualis } \\
\hline & & A1 & A2 & B B1 & B3 & --- & IVtal \\
\hline OFIOLITI & & & & & & 1 & 1 \\
\hline ORE GEOLOGY REVIEWS & & & 1 & & & & 1 \\
\hline PRECAMBRIAN RESEARCH & & 2 & & & & & 2 \\
\hline 2013-2016 - QUADRIENAL 2017 & 8 & 3 & & 11 & 1 & & 23 \\
\hline ANDEAN GEOLOGY & & & & 2 & & & 2 \\
\hline AUSTRALIAN JOURNAL OF EARTH SCIENCES & & & & 1 & & & 1 \\
\hline BRAZILIAN JOURNAL OF GEOLOGY & & & & 2 & & & 2 \\
\hline CHEMICAL GEOLOGY & 1 & & & & & & 1 \\
\hline ECONOMIC GEOLOGY & 1 & & & & & & 1 \\
\hline INTERNATIONAL JOURNAL OF EARTH SCIENCES & & & & 1 & & & 1 \\
\hline JOURNAL OF SOUTH AMERICAN EARTH SCIENCES & & & & 5 & & & 5 \\
\hline LITHOS & 2 & & & & & & 2 \\
\hline MINERALIUM DEPOSITA & & 1 & & & & & 1 \\
\hline OPEN GEOSCIENCES & & & & & 1 & & 1 \\
\hline ORE GEOLOGY REVIEWS & & 1 & & & & & 1 \\
\hline PRECAMBRIAN RESEARCH & 4 & & & & & & 4 \\
\hline TECTONOPHYSICS & & 1 & & & & & 1 \\
\hline Total & 18 & 13 & 3 & 24 & 5 & 3 & 68 \\
\hline
\end{tabular}

Fonte: Elaborada pelo autor com dados da WoS Core Collection e Qualis/CAPES.

De forma a aprofundar a análise sobre as colaborações e a visibilidade das publicações, a Tabela 56 apresenta as instituições que colaboraram com o Docente 05 em dois ou mais artigos, distribuídas entre os Ciclos de Avaliação da CAPES, com a indicação do percentual dos artigos no 1 을 Quartil do JCR.

Ao todo são 13 instituições com a característica exigida, e destas, pode-se destacar em termos de produtividade a Universidade de Lisboa com 13 artigos em colaboração, sendo que $30,77 \%$ eram do 1 ㅇ Quartil e em termos de mais altos percentuais têm-se a Australian National University e Universidade de Brasilia com 100\% dos artigos no 1을 Quartil. Além disso, o ciclo com maior percentual de artigos no 1은 Quartil foi o Quadrienal de 2017 , com $53,85 \%$ e com participação de cinco diferentes instituições. 
Tabela 56 - Artigos publicados pelo Docente 05 distribuídos segundo instituições que colaboraram duas ou mais vezes e Ciclos de Avaliação da CAPES, com indicação do percentual de artigos no 1 10 Quartil do JCR

\begin{tabular}{|c|c|c|c|c|c|}
\hline Instituição Colaboradora & $\begin{array}{c}\text { Trienal } \\
2004\end{array}$ & $\begin{array}{c}\text { Trienal } \\
2010\end{array}$ & $\begin{array}{c}\text { Trienal } \\
2013\end{array}$ & $\begin{array}{l}\text { Quadrie- } \\
\text { nal } 2017\end{array}$ & Total \\
\hline \multicolumn{6}{|l|}{ Australian National University } \\
\hline Artigos & & 2 & & & 2 \\
\hline$\%$ Artigos no 1o. Quartil & & $100,00 \%$ & & & $100,00 \%$ \\
\hline \multicolumn{6}{|c|}{$\begin{array}{l}\text { Consejo Nacional de Investigaciones Cientificas } \\
\text { v Tecnicas (CONICET) }\end{array}$} \\
\hline Artigos & & 2 & & & 2 \\
\hline Soma de Documents in Q1 Journals & & $0,00 \%$ & & & $0,00 \%$ \\
\hline \multicolumn{6}{|l|}{$\begin{array}{l}\text { Consiglio Nazionale delle Ricerche } \\
\text { (CNR) }\end{array}$} \\
\hline Artigos & & 2 & 4 & & 6 \\
\hline$\%$ Artigos no 1o. Quartil & & $50,00 \%$ & $50,00 \%$ & & $50,00 \%$ \\
\hline \multicolumn{6}{|l|}{$\begin{array}{l}\text { Istituto di Geologia Ambientale e } \\
\text { Geoingegneria (IGAG-CNR) }\end{array}$} \\
\hline Artigos & & & 2 & & 2 \\
\hline$\%$ Artigos no 1o. Quartil & & & $50,00 \%$ & & $50,00 \%$ \\
\hline \multicolumn{6}{|l|}{$\begin{array}{l}\text { Laboratorio Nacional de Energia e } \\
\text { Geologia IP (LNEG) }\end{array}$} \\
\hline Artigos & & & 4 & & 4 \\
\hline$\%$ Artigos no 1o. Quartil & & & $0,00 \%$ & & $0,00 \%$ \\
\hline \multicolumn{6}{|l|}{ Sapienza University Rome } \\
\hline Artigos & & & 2 & & 2 \\
\hline \% Artigos no 1o. Quartil & & & $50,00 \%$ & & $50,00 \%$ \\
\hline \multicolumn{6}{|l|}{ Universidade de Brasilia } \\
\hline Artigos & & & 2 & & 2 \\
\hline$\%$ Artigos no 1o. Quartil & & & $100,00 \%$ & & $100,00 \%$ \\
\hline \multicolumn{6}{|l|}{ Universidade de Lisboa } \\
\hline Artigos & 2 & & 6 & 5 & 13 \\
\hline$\%$ Artigos no 1o. Quartil & $0,00 \%$ & & $16,67 \%$ & $60,00 \%$ & $30,77 \%$ \\
\hline \multicolumn{6}{|l|}{ Universidade Estadual de Campinas } \\
\hline Artigos & & & & 2 & 2 \\
\hline$\%$ Artigos no 1o. Quartil & & & & $50,00 \%$ & $50,00 \%$ \\
\hline \multicolumn{6}{|l|}{ University of Alberta } \\
\hline Artigos & & & & 2 & 2 \\
\hline$\%$ Artigos no 1o. Quartil & & & & $50,00 \%$ & $50,00 \%$ \\
\hline \multicolumn{6}{|l|}{ University of Naples Federico II } \\
\hline Artigos & & & 2 & & 2 \\
\hline$\%$ Artigos no 1o. Quartil & & & $50,00 \%$ & & $50,00 \%$ \\
\hline \multicolumn{6}{|l|}{ University of Quebec } \\
\hline Artigos & & & & 2 & 2 \\
\hline$\%$ Artigos no 1o. Quartil & & & & $50,00 \%$ & $50,00 \%$ \\
\hline \multicolumn{6}{|l|}{ University of Quebec Chicoutimi } \\
\hline Artigos & & & & 2 & 2 \\
\hline$\%$ Artigos no 1o. Quartil & & & & $50,00 \%$ & $50,00 \%$ \\
\hline Total Artigos & 2 & 6 & 22 & 13 & 43 \\
\hline Total \% Arts. no 10. Quartil & $0,00 \%$ & $33,33 \%$ & $36,36 \%$ & $53,85 \%$ & 41,86\% \\
\hline
\end{tabular}

Fonte: Elaborada pelo autor com dados da WoS Core Collection e Qualis/CAPES. 
- Análise de impacto da produção científica

Os critérios para a análise de impacto compreendem a análise das citações recebidas e, do total de artigos indexados, a quantidade destes no Top $10 \%$ dos artigos mais citados. No caso do Docente 05 , dos 68 artigos indexados, quatro se encontravam presentes no Top $10 \%$.

A Tabela 57 traz os dados de total de artigos, percentual de artigos citados, total de citações, citações por artigo e o Impacto Normalizado. Verifica-se que, neste último quesito, o docente esteve na média $(1,0)$ ou acima dela em quatro anos $(2010,2013$, 2015 e 2016).

O período coberto pela Quadrienal de 2017 foi o de maior impacto, obtendo em 2013 o mais alto Impacto Normalizado, 2,6.

Tabela 57 - Impacto dos artigos do Docente 05 distribuídos por ano de publicação

\begin{tabular}{ccccccc}
\hline $\begin{array}{c}\text { Ano de } \\
\text { Publicação }\end{array}$ & $\begin{array}{c}\text { Total } \\
\text { de Art. }\end{array}$ & $\begin{array}{c}\% \text { Art. } \\
\text { Citados }\end{array}$ & Citações & $\begin{array}{c}\text { Impacto da } \\
\text { Citação }\end{array}$ & $\begin{array}{c}\text { Art. Top } \\
10 \%\end{array}$ & $\begin{array}{c}\text { Impacto } \\
\text { Normalizado }\end{array}$ \\
\hline 2001 & 3 & $100,00 \%$ & 63 & 21,0 & $0,00 \%$ & 0,7 \\
\hline 2002 & 1 & $100,00 \%$ & 25 & 25,0 & $0,00 \%$ & 0,6 \\
\hline 2003 & 2 & $100,00 \%$ & 53 & 26,5 & $0,00 \%$ & 0,9 \\
\hline 2004 & 2 & $100,00 \%$ & 46 & 23,0 & $0,00 \%$ & 0,8 \\
\hline 2005 & 3 & $100,00 \%$ & 62 & 20,7 & $0,00 \%$ & 0,7 \\
\hline 2006 & 2 & $100,00 \%$ & 26 & 13,0 & $0,00 \%$ & 0,5 \\
\hline 2007 & 4 & $100,00 \%$ & 109 & 27,3 & $0,00 \%$ & 0,8 \\
\hline 2008 & 7 & $100,00 \%$ & 120 & 17,1 & $0,00 \%$ & 0,7 \\
\hline 2009 & 2 & $100,00 \%$ & 22 & 11,0 & $0,00 \%$ & 0,5 \\
\hline 2010 & 9 & $100,00 \%$ & 152 & 16,9 & $11,10 \%$ & 1,8 \\
\hline 2011 & 6 & $83,33 \%$ & 52 & 8,7 & $0,00 \%$ & 0,5 \\
\hline 2012 & 4 & $100,00 \%$ & 38 & 9,5 & $0,00 \%$ & 0,7 \\
\hline 2013 & 3 & $100,00 \%$ & 65 & 21,7 & $33,33 \%$ & 2,6 \\
\hline 2014 & 7 & $100,00 \%$ & 47 & 6,7 & $14,29 \%$ & 0,9 \\
\hline 2015 & 10 & $100,00 \%$ & 60 & 6,0 & $0,00 \%$ & 1,0 \\
\hline 2016 & 3 & $100,00 \%$ & 14 & 4,7 & $33,33 \%$ & 1,4 \\
\hline \hline Total & $\mathbf{6 8}$ & $\mathbf{9 8 , 9 6 \%}$ & 954 & --- & $5,88 \%$ & --- \\
\hline
\end{tabular}

Fonte: Incites com dados da WoS Core Collection

- Análise das referências utilizadas

O último item a se analisar são as referências utilizadas pelo Docente na redação de seus artigos. Ao todo o Docente 05 utilizou 1.200 fontes bibliográficas diferentes, 
citando-as 4.395 vezes em seus 68 artigos, gerando uma média de 64,63 referências por trabalho.

Utilizando-se as Zonas de Bradford para analisar as principais publicações citadas nos artigos, pôde-se verificar pelas Tabelas 58 e 59 que, das 4.395 referências utilizadas, o primeiro terço delas (Zona 1 - com 1424 referências) estão concentradas em apenas 11 periódicos que correspondem a 0,92\% das publicações; já no segundo terço (Zona 2 - com 1.463 referências) em 98 publicações, já possuindo uma maior variedade de tipologias de documentos e correspondendo a 8,17\%. O terceiro terço é a zona de maior dispersão com um total de 1.091 publicações, sendo a maioria delas com baixa frequência de citação (não sendo, portanto, apresentadas na tabela).

Essas 109 publicações, das Zonas 1 e 2 somadas correspondem a 9,08\% das publicações, que, por conseguinte, correspondem a 65,69\% de todas as referências citadas.

Tabela 58 - Lista de Referências utilizadas nos artigos do Docente 05 distribuídas pelas Zonas 1 e 2 de Bradford

(continua)

\begin{tabular}{|c|c|c|c|c|}
\hline$\#$ & Publicações & Citações & \% Citações & Zona de Bradford \\
\hline 1 & PRECAMBRIAN RES & 189 & $4,30 \%$ & \multirow{11}{*}{ Zona 1} \\
\hline 2 & J PETROL & 176 & $4,00 \%$ & \\
\hline 3 & CONTRIB MINERAL PETR & 173 & $3,94 \%$ & \\
\hline 4 & EARTH PLANET SC LETT & 169 & $3,85 \%$ & \\
\hline 5 & J S AM EARTH SCI & 131 & $2,98 \%$ & \\
\hline 6 & CHEM GEOL & 112 & $2,55 \%$ & \\
\hline 7 & GEOCHIM COSMOCHIM AC & 111 & $2,53 \%$ & \\
\hline 8 & LITHOS & 95 & $2,16 \%$ & \\
\hline 9 & GONDWANA RES & 93 & $2,12 \%$ & \\
\hline 10 & TECTONOPHYSICS & 89 & $2,03 \%$ & \\
\hline 11 & GEOLOGY & 86 & $1,96 \%$ & \\
\hline 1 & REV BRASILEIRA GEOCI & 86 & $1,96 \%$ & \multirow{12}{*}{ Zona 2} \\
\hline 2 & GEOL SOC SPEC PUBL & 54 & $1,23 \%$ & \\
\hline 3 & MINER DEPOSITA & 48 & $1,09 \%$ & \\
\hline 4 & AM MINERAL & 47 & $1,07 \%$ & \\
\hline 5 & THESIS U SAO PAULO & 46 & $1,05 \%$ & \\
\hline 6 & NATURE & 43 & $0,98 \%$ & \\
\hline 7 & J GEOL & 35 & $0,80 \%$ & \\
\hline 8 & J GEOL SOC LONDON & 33 & $0,75 \%$ & \\
\hline 9 & CAN MINERAL & 32 & $0,73 \%$ & \\
\hline 10 & ANAIS ACAD BRASILEIR & 31 & $0,71 \%$ & \\
\hline 11 & EARTH-SCI REV & 30 & $0,68 \%$ & \\
\hline 12 & TECTONIC EVOLUTION S & 30 & $0,68 \%$ & \\
\hline
\end{tabular}


Tabela 58 - Lista de Referências utilizadas nos artigos do Docente 05 distribuídas pelas Zonas 1 e 2 de Bradford

(continuação)

\begin{tabular}{|c|c|c|c|}
\hline$\#$ & Publicações & Citações & \% Citações \\
\hline 13 & ECON GEOL & 28 & $0,64 \%$ \\
\hline 14 & EPISODES & 28 & $0,64 \%$ \\
\hline 15 & TECTONICS & 27 & $0,61 \%$ \\
\hline 16 & J METAMORPH GEOL & 26 & $0,59 \%$ \\
\hline 17 & ECON GEOL BULL SOC & 24 & $0,55 \%$ \\
\hline 18 & CAN J EARTH SCI & 22 & $0,50 \%$ \\
\hline 19 & GEOL SOC AM BULL & 21 & $0,48 \%$ \\
\hline 20 & J GEOPHYS RES-SOL EA & 21 & $0,48 \%$ \\
\hline 21 & REV BRAS GEOC & 21 & $0,48 \%$ \\
\hline 22 & PREMESOZOIC GEOLOGY & 20 & $0,46 \%$ \\
\hline 23 & INT J EARTH SCI & 19 & $0,43 \%$ \\
\hline 24 & J AFR EARTH SCI & 19 & $0,43 \%$ \\
\hline 25 & AN ACAD BRAS CIENC & 17 & $0,39 \%$ \\
\hline 26 & J STRUCT GEOL & 17 & $0,39 \%$ \\
\hline 27 & INT GEOL REV & 17 & $0,39 \%$ \\
\hline 28 & THESIS U LISBOA & 17 & $0,39 \%$ \\
\hline 29 & TERRA NOVA & 17 & $0,39 \%$ \\
\hline 30 & MINERAL MAG & 15 & $0,34 \%$ \\
\hline 31 & ANNU REV EARTH PL SC & 14 & $0,32 \%$ \\
\hline 32 & MINER PETROL & 14 & $0,32 \%$ \\
\hline 33 & ORE GEOL REV & 14 & $0,32 \%$ \\
\hline 34 & REV EC GEOLOGY & 14 & $0,32 \%$ \\
\hline 35 & SCIENCE & 14 & $0,32 \%$ \\
\hline 36 & GEOL MAG & 13 & $0,30 \%$ \\
\hline 37 & GEOL RUNDSCH & 13 & $0,30 \%$ \\
\hline 38 & J VOLCANOL GEOTH RES & 13 & $0,30 \%$ \\
\hline 39 & $\mathrm{AM} J \mathrm{SCl}$ & 12 & $0,27 \%$ \\
\hline 40 & GEOL MIJNBOUW & 12 & $0,27 \%$ \\
\hline 41 & GEOGACETA & 12 & $0,27 \%$ \\
\hline 42 & J ASIAN EARTH SCI & 12 & $0,27 \%$ \\
\hline 43 & MESOZOIC CENOZOIC AL & 12 & $0,27 \%$ \\
\hline 44 & SCHWEIZ MINER PETROG & 12 & $0,27 \%$ \\
\hline 45 & SPECIAL PUBLICATION & 12 & $0,27 \%$ \\
\hline 46 & BERKELEY GEOCHRONOLO & 11 & $0,25 \%$ \\
\hline 47 & GEOPHYS RES LETT & 11 & $0,25 \%$ \\
\hline 48 & J GEOPHYS RES & 11 & $0,25 \%$ \\
\hline 49 & REV ASOC GEOL ARGENT & 11 & $0,25 \%$ \\
\hline 50 & GEOL SOC AM MEM & 10 & $0,23 \%$ \\
\hline 51 & GEODIN ACTA & 10 & $0,23 \%$ \\
\hline 52 & J GEODYN & 10 & $0,23 \%$ \\
\hline 53 & REV MINERAL GEOCHEM & 10 & $0,23 \%$ \\
\hline
\end{tabular}

Zona 2 
Tabela 58 - Lista de Referências utilizadas nos artigos do Docente 05 distribuídas pelas Zonas 1 e 2 de Bradford

(continuação)

\begin{tabular}{|c|c|c|c|}
\hline$\#$ & Publicações & Citações & \% Citações \\
\hline 54 & REV. ASOC. GEOL. ARGENT. & 10 & $0,23 \%$ \\
\hline 55 & AAPG BULL & 9 & $0,20 \%$ \\
\hline 56 & 4 S AM S IS GEOL SAL & 9 & $0,20 \%$ \\
\hline 57 & GEOL SOC AM SPEC PAP & 9 & $0,20 \%$ \\
\hline 58 & GEOLOGIA USP C & 9 & $0,20 \%$ \\
\hline 59 & THESIS U BRASILIA & 9 & $0,20 \%$ \\
\hline 60 & GEOLOGIA USP SERIE C & 8 & $0,18 \%$ \\
\hline 61 & GEONOMOS & 8 & $0,18 \%$ \\
\hline 62 & COMPUT GEOSCI & 8 & $0,18 \%$ \\
\hline 63 & OFIOLITI & 8 & $0,18 \%$ \\
\hline 64 & J ANAL ATOM SPECTROM & 8 & $0,18 \%$ \\
\hline 65 & CONT SHELF RES & 7 & $0,16 \%$ \\
\hline 66 & COMUN GEOL & 7 & $0,16 \%$ \\
\hline 67 & IGNEOUS PETROGENESIS & 7 & $0,16 \%$ \\
\hline 68 & CONTINENTAL CRUST IT & 7 & $0,16 \%$ \\
\hline 69 & EUR J MINERAL & 7 & $0,16 \%$ \\
\hline 70 & J GEOPHYS RES-SOLID & 7 & $0,16 \%$ \\
\hline 71 & PERIOD MINERAL & 7 & $0,16 \%$ \\
\hline 72 & MAR GEOL & 7 & $0,16 \%$ \\
\hline 73 & REV BRAS GEOCIENC & 7 & $0,16 \%$ \\
\hline 74 & B SOC GEOL ITAL & 6 & $0,14 \%$ \\
\hline 75 & GEOLOGIA CONTINENTE & 6 & $0,14 \%$ \\
\hline 76 & COMUNICACOES SERVICO & 6 & $0,14 \%$ \\
\hline 77 & DEV PETROLO & 6 & $0,14 \%$ \\
\hline 78 & MEM SERV GEOL PORTUG & 6 & $0,14 \%$ \\
\hline 79 & PRINCIPLES ISOTOPE G & 6 & $0,14 \%$ \\
\hline 80 & PHILOS T R SOC A & 6 & $0,14 \%$ \\
\hline 81 & NEUES JB MINER ABH & 6 & $0,14 \%$ \\
\hline 82 & REV ASOCIACION GEOLO & 6 & $0,14 \%$ \\
\hline 83 & SCI TOTAL ENVIRON & 6 & $0,14 \%$ \\
\hline 84 & TREATISE GEOCHEMISTR & 6 & $0,14 \%$ \\
\hline 85 & REV GEOL CHILE & 6 & $0,14 \%$ \\
\hline 86 & AUST J EARTH SCI & 5 & $0,11 \%$ \\
\hline 87 & BRAZ J GEOL & 5 & $0,11 \%$ \\
\hline 88 & 25 C BRAS GEOL & 5 & $0,11 \%$ \\
\hline 89 & 14 SEM GEOQ 8 C GEOQ & 5 & $0,11 \%$ \\
\hline 90 & CARTA GEOLOGICA CHIL & 5 & $0,11 \%$ \\
\hline 91 & COMUN SERV GEOL PORT & 5 & $0,11 \%$ \\
\hline 92 & COMUNICACOES I GEOLO & 5 & $0,11 \%$ \\
\hline 93 & GEOPH MONOG SERIES & 5 & $0,11 \%$ \\
\hline 94 & COMPUT GEOSCI-UK & 5 & $0,11 \%$ \\
\hline
\end{tabular}

\section{Zona 2}


Tabela 58 - Lista de Referências utilizadas nos artigos do Docente 05 distribuídas pelas Zonas 1 e 2 de Bradford

(conclusão)

\begin{tabular}{cclccc}
\hline & $\#$ & Publicações & Citações & \% Citações & Zona de Bradford \\
\hline & 95 & GEOSTAND GEOANAL RES & 5 & $0,11 \%$ & \\
& 96 & GEOCHIMICA BRASILIEN & 5 & $0,11 \%$ & \multirow{2}{*}{ Zona 2} \\
& 97 & CR GEOSCI & 5 & $0,11 \%$ & \\
\hline \hline Total & MINERALOGICAL ASS CA & 5 & $0,11 \%$ & \\
\hline
\end{tabular}

Fonte: Elaborada pelo autor com dados da WoS Core Collection.

Tabela 59 - Quantidade de publicações citadas pelo Docente 05 distribuídas pelas Zonas de Bradford

\begin{tabular}{lcccc}
\hline Zonas de Bradford & Total de Publicações & \% Publicações & Total de Citações & \% Citações \\
\hline Zona 1 & 11 & $0,92 \%$ & 1424 & $32,40 \%$ \\
\hline Zona 2 & 98 & $8,17 \%$ & 1463 & $33,29 \%$ \\
Zona 3 & 1091 & $90,92 \%$ & 1508 & $34,31 \%$ \\
\hline \hline Total & $\mathbf{1 . 2 0 0}$ & $\mathbf{1 0 0 , 0 0 \%}$ & $\mathbf{4 . 3 9 5}$ & $\mathbf{1 0 0 , 0 0 \%}$ \\
\hline
\end{tabular}

Fonte: Elaborada pelo autor com dados da WoS Core Collection.

Tais dados permitem ainda analisar a relação de onde se publica com o que se cita. A Tabela 60 nos apresenta que dos 29 periódicos nos quais foram publicados os 68 artigos do Docente 05 os três primeiros com maior número de publicações estão presentes na Zona 01, sendo que o primeiro corresponde à quinta publicação mais referenciada, o segundo à oitava e o terceiro à primeira. Dos restantes, três pertencem à Zona 1,15 à Zona 2, quatro à Zona 3 e outros quatro não foram citados

Durante a entrevista quando perguntado sobre às publicações mais importantes do seu campo de atuação o Docente 05 citou três periódicos: Ore Geology Reviews, Precambrian Research e Gondwana Research. Em ambos ele possui publicações e dois deles estão na Zona 01 e um, Ore Geoloy Reviews na Zona 02. 
Tabela 60 - Lista de periódicos nos quais o Docente 05 publicou seus artigos com indicação das Zonas de Bradford

\begin{tabular}{|c|c|c|c|}
\hline Título do Periódico & $\begin{array}{l}\text { Total de } \\
\text { Artigos }\end{array}$ & $\begin{array}{l}\text { \% Total de } \\
\text { Artigos }\end{array}$ & $\begin{array}{l}\text { Zonas de } \\
\text { Bradford }\end{array}$ \\
\hline $\begin{array}{l}\text { JOURNAL OF SOUTH AMERICAN EARTH } \\
\text { SCIENCES }\end{array}$ & 13 & $19,12 \%$ & 1 \\
\hline LITHOS & 7 & $10,29 \%$ & 1 \\
\hline PRECAMBRIAN RESEARCH & 6 & $8,82 \%$ & 1 \\
\hline ORE GEOLOGY REVIEWS & 5 & $7,35 \%$ & 2 \\
\hline MINERALIUM DEPOSITA & 4 & $5,88 \%$ & 2 \\
\hline GONDWANA RESEARCH & 3 & $4,41 \%$ & 1 \\
\hline EPISODES & 3 & $4,41 \%$ & 2 \\
\hline $\begin{array}{l}\text { JOURNAL OF VOLCANOLOGY AND } \\
\text { GEOTHERMAL RESEARCH }\end{array}$ & 2 & $2,94 \%$ & 2 \\
\hline ANDEAN GEOLOGY & 2 & $2,94 \%$ & Não citado \\
\hline JOURNAL OF COASTAL RESEARCH & 2 & $2,94 \%$ & Não citado \\
\hline TECTONOPHYSICS & 2 & $2,94 \%$ & 1 \\
\hline BRAZILIAN JOURNAL OF GEOLOGY & 2 & $2,94 \%$ & 2 \\
\hline GEOCHEMICAL JOURNAL & 1 & $1,47 \%$ & 3 \\
\hline OFIOLITI & 1 & $1,47 \%$ & 2 \\
\hline MINERALOGY AND PETROLOGY & 1 & $1,47 \%$ & 2 \\
\hline AUSTRALIAN JOURNAL OF EARTH SCIENCES & 1 & $1,47 \%$ & 2 \\
\hline HOLOCENE & 1 & $1,47 \%$ & 3 \\
\hline GEOSCIENCES JOURNAL & 1 & $1,47 \%$ & 3 \\
\hline CHEMICAL GEOLOGY & 1 & $1,47 \%$ & 1 \\
\hline OPEN GEOSCIENCES & 1 & $1,47 \%$ & Não citado \\
\hline INTERNATIONAL GEOLOGY REVIEW & 1 & $1,47 \%$ & 2 \\
\hline MARINE GEOLOGY & 1 & $1,47 \%$ & 2 \\
\hline $\begin{array}{l}\text { INTERNATIONAL JOURNAL OF EARTH } \\
\text { SCIENCES }\end{array}$ & 1 & $1,47 \%$ & 2 \\
\hline CONTINENTAL SHELF RESEARCH & 1 & $1,47 \%$ & 3 \\
\hline $\begin{array}{l}\text { GEOCHEMISTRY-EXPLORATION } \\
\text { ENVIRONMENT ANALYSIS }\end{array}$ & 1 & $1,47 \%$ & Não citado \\
\hline ECONOMIC GEOLOGY & 1 & $1,47 \%$ & 2 \\
\hline AMERICAN JOURNAL OF SCIENCE & 1 & $1,47 \%$ & 2 \\
\hline GEODINAMICA ACTA & 1 & $1,47 \%$ & 2 \\
\hline TECTONICS & 1 & $1,47 \%$ & 2 \\
\hline Total & 68 & $100,00 \%$ & \\
\hline
\end{tabular}

Fonte: Elaborada pelo autor com dados da WoS Core Collection.

A Tabela 61 apresenta a idade das referências citadas pelo Docente 05 de acordo com o ano de publicação de cada um de seus artigos. A maior concentração encontrase em referências de 11 a 20 anos, com 30,28\% e das faixas de 0 a 5 e 6 a 10 anos, que somadas correspondem a $43,32 \%$. Somando essas três faixas tem-se $73,61 \%$ do total geral de citações de referências com até 20 anos. 
Tabela 61 - Idade das Referências citadas nos artigos do Docente 05

\begin{tabular}{cccc}
\hline Idade das Referências & Total de Citações & \% Citações \\
\hline $0-5$ & 935 & $21,27 \%$ \\
$6-10$ & 969 & $22,05 \%$ \\
\hline $11-20$ & 1331 & $30,28 \%$ \\
$21-30$ & 681 & $15,49 \%$ \\
& $31-40$ & 331 & $7,53 \%$ \\
& $41-50$ & 95 & $2,16 \%$ \\
& +50 & 47 & $1,07 \%$ \\
\hline \hline Total & Sem Data & 6 & $0,14 \%$ \\
\hline
\end{tabular}

Fonte: Elaborada pelo autor com dados da WoS Core Collection.

- Informações adicionais

Complementando o perfil bibliométrico apresentado pode-se analisar que o Docente 05 possui um perfil de publicação consolidado, gerando um bom impacto, especialmente nos últimos 4 anos analisados (2013-2016).

Sua rede de colaboração internacional, com destaque para Portugal e Itália, é produtiva e consistente, o que se deve ao fato de, como dito pelo próprio docente na entrevista, que sua área de pesquisa facilita a publicação por gerar muitos dados.

O docente compreende bem o fluxo da comunicação científica, especialmente por ter participado de colegiados em agências de fomento e entende também que os indicadores quantitativos apenas dão uma ideia da produtividade de um pesquisador e devem ser utilizados apenas como base, não como fator decisório.

Quanto aos processos avaliativos os considera como parte do processo, pois para se obter financiamento ou coordenador projetos é necessário ser avaliado.

Por fim, considera que a vinda de estudantes estrangeiros para a Universidade é benéfica pois propicia o desenvolvimento de novas redes colaborativas e esse é um fator evidenciado em seu perfil altamente internacionalizado. 


\section{DOCENTE 06}

O Docente 06, conforme apresentado no Quadro 1, obteve um nível de publicação 3 no primeiro subperíodo de ciclos de avaliação da CAPES (2001-2009), com um percentual de publicação em periódicos domésticos de 41,67\%. No segundo subperíodo (2010-2016) ocorreu uma alteração em seu nível de publicação passando para 2, com um percentual de $28 \%$ de publicação em periódicos domésticos, apresentando, assim, uma transição de um nível rumo à internacionalização, resultando num Status Final de quem se encontra em processo de internacionalização.

Baseada nos dados coletados no Banco Dedalus, a Tabela 62 apresenta a distribuição da produção intelectual do Docente 06 por tipo de publicação.

Nota-se que a maior concentração da produção do Docente 06 está registrada em eventos, totalizando $72,07 \%$, corroborando a informação fornecida em sua entrevista que ele participa ativamente de eventos nacionais.

Quanto à sua publicação especificamente em artigos de periódicos, verifica-se que o Docente 06 possui um índice de 73,33\% em periódicos estrangeiros.

Tabela 62 - Produção Intelectual do Docente 06 registrada no Dedalus distribuída por tipo de publicação

\begin{tabular}{lccccc}
\hline \multirow{2}{*}{ Tipo de Publicação / Ciclo de Avaliação } & \multicolumn{2}{c}{ Doméstico } & \multicolumn{2}{c}{ Estrangeiro } & \multirow{2}{*}{ Total } \\
& Docs & \% Docs & Docs & \% Docs & \\
\hline ARTIGO DE PERIODICO & 8 & $26,67 \%$ & 22 & $73,33 \%$ & 30 \\
\hline PARTE DE MONOGRAFIA/LIVRO & 0 & $0,00 \%$ & 1 & $100,00 \%$ & 1 \\
\hline TRABALHO DE EVENTO & 20 & $80,00 \%$ & 5 & $20,00 \%$ & 25 \\
TRABALHO DE EVENTO-ANAIS PERIODICO & 0 & $0,00 \%$ & 1 & $100,00 \%$ & 1 \\
\hline TRABALHO DE EVENTO-RESUMO & 53 & $98,15 \%$ & 1 & $1,85 \%$ & 54 \\
\hline \hline Total & $\mathbf{8 1}$ & $\mathbf{7 2 , 9 7 \%}$ & $\mathbf{3 0}$ & $\mathbf{2 7 , 0 3 \%}$ & $\mathbf{1 1 1}$ \\
\hline
\end{tabular}

Fonte: Elaborada pelo autor com dados do Dedalus.

Em relação à produção científica do Docente 06 indexada na WoS Core Collection, a Tabela 63 traz os dados referentes aos artigos publicados, distribuídos por periódico. Os periódicos com maior número de publicação foram o Precambrian Research (Categoria do JCR: Geosciences e Multidisciplinary; FI de 3,907; Categoria SJR: Earth and Planetary Sciences; SJR de 2,769) com 4 artigos, o Journal of South American Earth Sciences (Categoria do JCR: Geosciences e Multidisciplinary; FI de 1,639; Categoria 
SJR: Earth and Planetary Sciences; SJR de 0,82) com 3 e International Journal of Earth Sciences (Categoria do JCR: Geosciences e Multidisciplinary; FI de 2,276; Categoria SJR: Earth and Planetary Sciences; SJR de 1,125) o também com 3. Os três periódicos juntos correspondem a $43,48 \%$ do total de artigos publicados.

Tabela 63 - Artigos do Docente 06 indexados na WoS Core Collection distribuídos por título de periódico

\begin{tabular}{|c|c|c|}
\hline Periódicos & Artigos & $\%$ Artigos \\
\hline PRECAMBRIAN RESEARCH & 4 & $17,39 \%$ \\
\hline JOURNAL OF SOUTH AMERICAN EARTH SCIENCES & 3 & $13,04 \%$ \\
\hline INTERNATIONAL JOURNAL OF EARTH SCIENCES & 3 & $13,04 \%$ \\
\hline JOURNAL OF STRUCTURAL GEOLOGY & 2 & $8,70 \%$ \\
\hline LITHOS & 2 & $8,70 \%$ \\
\hline TECTONOPHYSICS & 1 & $4,35 \%$ \\
\hline JOURNAL OF GEODYNAMICS & 1 & $4,35 \%$ \\
\hline SOLID EARTH & 1 & $4,35 \%$ \\
\hline JOURNAL OF THE GEOLOGICAL SOCIETY & 1 & $4,35 \%$ \\
\hline GEOLOGICAL SOCIETY OF AMERICA BULLETIN & 1 & $4,35 \%$ \\
\hline COMPTES RENDUS GEOSCIENCE & 1 & $4,35 \%$ \\
\hline JOURNAL OF VOLCANOLOGY AND GEOTHERMAL RESEARCH & 1 & $4,35 \%$ \\
\hline JOURNAL OF GEOPHYSICAL RESEARCH-SOLID EARTH & 1 & $4,35 \%$ \\
\hline GONDWANA RESEARCH & 1 & $4,35 \%$ \\
\hline Total & 23 & $100,00 \%$ \\
\hline
\end{tabular}

Fonte: Elaborada pelo autor com dados da WoS Core Collection.

A seguir apresentam-se os dados de acordo com o Perfil Bibliométrico adaptado da proposta de Gorraiz, Wieland \& Gumpenberger (2016).

\section{- Análise de coautorias}

A Tabela 64 apresenta os dados de coautoria do Docente 06, nos quais é possível identificar que a maior concentração de publicações encontra-se em artigos com 3, 4 e 5 autores. A informação é complementada pela Tabela 65 que apresenta a posição do docente nos artigos, demonstrando uma maior quantidade de artigos em posição central $(56,52 \%)$, no entanto em $30,43 \%$ dos artigos o docente a assume a primeira autoria. Segundo informado por ele na entrevista, a única regra existente quanto à sequência autoral é que se a publicação é parte de uma pesquisa de um estudante e o conteúdo é parte da dissertação/tese este aparecerá em primeiro lugar. 
Tabela 64 - Quantidade de autores nos artigos com participação do Docente 06

\begin{tabular}{cccc}
\hline Quantidade de Autores & Total de Artigos & \% Artigos \\
\hline & 2 & 1 & $4,35 \%$ \\
& 3 & 5 & $21,74 \%$ \\
& 4 & 6 & $26,09 \%$ \\
& 5 & 8 & $34,78 \%$ \\
& 6 & 2 & $8,70 \%$ \\
& 7 & 1 & $4,35 \%$ \\
\hline \hline Total & $\mathbf{2 3}$ & $\mathbf{1 0 0 , 0 0 \%}$
\end{tabular}

Fonte: Elaborada pelo autor com dados da WoS Core Collection.

Tabela 65 - Artigos distribuídos por quantidade de autores e posição na autoria do Docente 06 nos artigos em que participa

\begin{tabular}{lccccc} 
& \multirow{2}{*}{ Quantidade de Autores } & \multicolumn{2}{c}{ Posição na Autoria } & \multirow{2}{*}{ Total } \\
\hline 2 & Primeiro & Meio & Último & \\
\hline 3 & 1 & & & 1 \\
4 & 1 & 2 & 2 & 5 \\
5 & 1 & 5 & & 6 \\
6 ou mais & 3 & 4 & 1 & 8 \\
\hline \hline Total & 1 & 2 & & 3 \\
\hline Fon & 7 & 13 & 3 & 23 \\
\hline
\end{tabular}

Fonte: Elaborada pelo autor com dados da WoS Core Collection.

- Análise da colaboração

Em relação à colaboração nos artigos publicados a Tabela 66 demonstra que $78,26 \%$ dos artigos do docente foram produzidos em colaboração com autores de 2 ou mais países e apenas $21,74 \%$ tiveram colaboração exclusivamente nacional.

Tabela 66 - Quantidade de países dos autores que publicaram nos artigos com participação do Docente 06

\begin{tabular}{llcc}
\hline Quantidade de Países & & Total de Artigos & \% Artigos \\
\hline & 1 & 5 & $21,74 \%$ \\
& 2 & 14 & $60,87 \%$ \\
& 3 & 4 & $17,39 \%$ \\
\hline \hline Total & $\mathbf{2 3}$ & $\mathbf{1 0 0 , 0 0 \%}$ \\
\hline
\end{tabular}

Fonte: Elaborada pelo autor com dados da WoS Core Collection.

Já a Tabela 67 apresenta os sete países dos coautores, com destaque para França, China e Austrália com maior participação em artigos. Vale destacar ainda que 
somente cinco artigos foram produzidos exclusivamente com a colaboração de instituições nacionais.

Tabela 67 - Países dos autores que publicaram nos artigos com participação do Docente 06

\begin{tabular}{lcc}
\hline Países & Total de Artigos & \% Artigos \\
\hline Austrália & 4 & $17,39 \%$ \\
\hline Brasil & 5 & $21,74 \%$ \\
Canadá & 1 & $4,35 \%$ \\
China & 5 & $21,74 \%$ \\
Colômbia & 1 & $4,35 \%$ \\
\hline Estados Unidos & 1 & $4,35 \%$ \\
França & 9 & $39,13 \%$ \\
\hline Inglaterra & 1 & $4,35 \%$ \\
\hline \hline Total & $\mathbf{2 3}$ & --- \\
\hline
\end{tabular}

Fonte: Elaborada pelo autor com dados da WoS Core Collection.

E a Tabela 68 traz a quantidade de instituições dos autores desses artigos destacando-se uma maior concentração naqueles com duas instituições com 47,83\% e com três e quatro, que juntas somam $39,13 \%$.

Tabela 68 - Quantidade de instituições dos autores que publicaram nos artigos com participação do Docente 06

\begin{tabular}{cccc}
\hline Quantidade de Instituições & Total de Artigos & \% Artigos \\
\hline 1 & 2 & $8,70 \%$ \\
& 2 & 11 & $47,83 \%$ \\
& 3 & 4 & $17,39 \%$ \\
& 4 & 5 & $21,74 \%$ \\
\hline \hline Total & 1 & $4,35 \%$ \\
\hline
\end{tabular}

Fonte: Elaborada pelo autor com dados da WoS Core Collection apresentados via Incites.

Complementando os dados, a Tabela 69 apresenta as instituições e seus respectivos países, permitindo observar que a colaboração se distribui em um conjunto de 22 diferentes instituições, tendo como país de maior representação de instituições a França e com maior concentração de artigos a Chinese Academy of Geological Sciences, com cinco. 
Tabela 69 - Distribuição das Instituições por países dos autores que publicaram com o Docente 06

País/Instituição

Artigos

\section{Austrália}

Australian National University 3

University of Queensland

2

\section{Brasil}

Universidade do Estado do Rio de Janeiro 1

Universidade Estadual Paulista $\quad 2$

Universidade Federal de Amazonas 3

Universidade Federal do Parana $\quad 1$

Universidade Federal do Rio Grande do Norte 3

\section{Canadá}

University of Toronto

1

China

Chinese Academy of Geological Sciences

\section{5}

Peking University

2

\section{Colômbia}

Universidad Nacional de Colombia

1

\section{Estados Unidos}

Washington State University

1

\section{França}

Centre National de la Recherche Scientifique (CNRS)

\section{2}

Institut de Recherche pour le Developpement (IRD) 1

Languedoc-Roussillon Universites (ComUE) 1

Universite de Montpellier $\quad 1$

Universite de Orleans $\quad 1$

Universite de Toulouse $\quad 1$

Universite Federale Toulouse Midi-Pyrenees (ComUE) 1

Universite Toulouse III - Paul Sabatier 1

University of Nantes 5

\begin{tabular}{ll} 
Inglaterra & \\
University of Plymouth & 1 \\
\hline \hline
\end{tabular}

Fonte: Incites com dados da WoS Core Collection.

\section{- Análise dos financiamentos de pesquisa recebidos}

O próximo item analisado diz respeito às agências de fomento que financiaram as pesquisas publicadas pelo Docente 06. Os dados aqui apresentados são oriundos da WoS e é importante lembrar que a base somente padronizou os dados de Agências de Fomento de 2008 para frente e, portanto, dos 23 artigos do Docente 06 indexados na WoS somente 14 puderam ser analisados, uma vez que os outros 9 são anteriores a esse período. 
A Tabela 70 apresenta as informações das agências de fomento que apoiaram as pesquisas publicadas pelo Docente 06. Das agências listadas somente uma é de fora do Brasil, a French National Research Agency (ANR), porém o apoio ocorreu somente no ano de 2010. Em todos os outros períodos o financiamento foi das agências nacionais (CAPES, CNPq e FAPESP).

Em termos do impacto normalizado das citações, os artigos das pesquisas financiadas pela FAPESP levam ligeira vantagem sobre o CNPq, superando a média esperada $(1,0)$ em três anos e obtendo o mais alto índice $(1,75)$ no ano de 2016 . E em nenhum ano os artigos financiados pela CAPES obtiveram a média esperada.

Quanto às citações, confirma-se o fato de que artigos com maior idade tendem a acumular mais citações. Esse é o caso do ano de 2010 cujo os artigos publicados obtiveram as maiores médias de impacto (Citações / Artigo).

Tabela 70 - Agências de Fomento que apoiaram as pesquisas que geraram as publicações com participação do Docente 06, distribuídas por ano

\begin{tabular}{lcccc}
\hline Agências de Fomento por Ano & Artigos & Citações & Citações/Artigo & Impacto Normalizado \\
\hline 2010 & $\mathbf{3}$ & --- & --- & --- \\
French Nat.Res. Agency (ANR) & 1 & 29 & 29 & 1,41 \\
FAPESP & 2 & 47 & 23,5 & 1,18 \\
2012 & $\mathbf{1}$ & --- & --- & --- \\
FAPESP & 1 & 8 & 8 & 0,54 \\
$\mathbf{2 0 1 3}$ & $\mathbf{6}$ & --- & --- & --- \\
CAPES & 1 & 6 & 6 & 0,5 \\
FAPESP & 4 & 47 & 11,75 & 0,98 \\
CNPq & 1 & 8 & 8 & 0,67 \\
2014 & $\mathbf{2}$ & --- & --- & --- \\
FAPESP & 1 & 15 & 15 & 1,63 \\
CNPq & 1 & 15 & 15 & 1,63 \\
$\mathbf{2 0 1 5}$ & $\mathbf{1}$ & --- & --- & --- \\
CNPq & 1 & 9 & 9 & 1,43 \\
2016 & $\mathbf{9}$ & --- & --- & --- \\
CAPES & 3 & 6 & 2 & 0,58 \\
FAPESP & 2 & 12 & 6 & 1,75 \\
CNPq & 4 & 9 & 2,25 & 0,67 \\
\hline \hline
\end{tabular}

Fonte: Incites com dados da WoS Core Collection

- Análise de visibilidade da produção científica

No que diz respeito à visibilidade da produção científica do docente, esta é medida levando em conta a quantidade de artigos registrada no Dedalus (30) e 
quantidade de artigos indexada na WoS (23), assim o percentual do Docente 06 é de $76,67 \%$.

Outro fator analisado é o percentual de artigos presentes em periódicos de impacto. A Tabela 71 apresenta os artigos do docente publicados em periódicos indexados na WoS Core Collection, distribuídos segundo Ciclos de Avaliação da CAPES e percentual publicado em periódicos do 1으 Quartil do FI/JCR. Dos 23 artigos do Docente 06 indexados na WoS Core Collection 52,17\% estão presentes no 1 Q Quartil - vale ressaltar que no último ciclo houve uma intensificação da publicação em periódicos de maior impacto na área.

Tabela 71 - Artigos publicados pelo Docente 06 distribuídos por Ciclos de Avaliação da CAPES e indexados em periódicos do 1 o Quartil do $\mathrm{Fl} / \mathrm{JCR}$

\begin{tabular}{lcc}
\hline Ciclos de Avaliação CAPES & Total de Artigos & \% Artigos no 10. Quartil \\
\hline Trienal 2004 & 2 & $0,00 \%$ \\
Trienal 2007 & 2 & $100,00 \%$ \\
Trienal 2010 & 3 & $33,33 \%$ \\
Trienal 2013 & 4 & $50,00 \%$ \\
Quadrienal 2017 & 12 & $58,33 \%$ \\
\hline \hline Total & $\mathbf{2 3}$ & $\mathbf{5 2 , 1 7 \%}$ \\
\hline
\end{tabular}

Fonte: Incites com dados da WoS Core Collection

Analisando-se a publicação científica mais fortemente relacionada aos instrumentos de Avaliação da CAPES, a Tabela 72 apresenta a quantidade de artigos publicados distribuídos pelos Ciclos de Avaliação e classificação nos estratos Qualis da área de avaliação das Geociências.

Verifica-se que $65,22 \%$ dos artigos do Docente 06 encontram-se nos estratos mais altos (A1 e A2), 26,09\% em periódicos B1 e dois artigos em periódicos não avaliados na Trienal de 2004.

No período coberto pela Quadrienal de 2017 o docente intensificou sua produção e dos 12 artigos publicados seis foram no estrato A1 e três no A2. Demonstrando uma busca pelo aumento do impacto de suas pesquisas. 
Tabela 72 - Artigos publicados pelo Docente 06 distribuídos por Ciclos de Avaliação da CAPES e classificação do periódico nos estratos Qualis da área de avaliação das Geociências

\begin{tabular}{|c|c|c|c|c|c|}
\hline \multirow[t]{2}{*}{ Periódicos e Ciclo de Avaliação } & \multicolumn{4}{|c|}{ Estratos Qualis } & \multirow[t]{2}{*}{ Total } \\
\hline & A1 & A2 & B1 & $--{ }^{28}$ & \\
\hline 2001-2003 - TRIENAL 2004 & & & & 2 & 2 \\
\hline COMPTES RENDUS GEOSCIENCE & & & & 1 & 1 \\
\hline $\begin{array}{l}\text { JOURNAL OF GEOPHYSICAL } \\
\text { RESEARCH-SOLID EARTH }\end{array}$ & & & & 1 & 1 \\
\hline 2004-2006 - TRIENAL 2007 & 1 & 1 & & & 2 \\
\hline $\begin{array}{l}\text { JOURNAL OF THE GEOLOGICAL } \\
\text { SOCIETY }\end{array}$ & & 1 & & & 1 \\
\hline PRECAMBRIAN RESEARCH & 1 & & & & 1 \\
\hline 2007-2009 - TRIENAL 2010 & & & 3 & & 3 \\
\hline $\begin{array}{l}\text { INTERNATIONAL JOURNAL OF } \\
\text { EARTH SCIENCES }\end{array}$ & & & 1 & & 1 \\
\hline $\begin{array}{l}\text { JOURNAL OF SOUTH AMERICAN } \\
\text { EARTH SCIENCES }\end{array}$ & & & 1 & & 1 \\
\hline $\begin{array}{l}\text { JOURNAL OF STRUCTURAL } \\
\text { GEOLOGY }\end{array}$ & & & 1 & & 1 \\
\hline 2010-2012 - TRIENAL 2013 & 1 & 3 & & & 4 \\
\hline $\begin{array}{l}\text { INTERNATIONAL JOURNAL OF } \\
\text { EARTH SCIENCES }\end{array}$ & & 1 & & & 1 \\
\hline $\begin{array}{l}\text { JOURNAL OF SOUTH AMERICAN } \\
\text { EARTH SCIENCES }\end{array}$ & & 1 & & & 1 \\
\hline PRECAMBRIAN RESEARCH & 1 & & & & 1 \\
\hline TECTONOPHYSICS & & 1 & & & 1 \\
\hline 2013-2016 - QUADRIENAL 2017 & 6 & 3 & 3 & & 12 \\
\hline $\begin{array}{l}\text { GEOLOGICAL SOCIETY OF } \\
\text { AMERICA BULLETIN }\end{array}$ & 1 & & & & 1 \\
\hline GONDWANA RESEARCH & 1 & & & & 1 \\
\hline $\begin{array}{l}\text { INTERNATIONAL JOURNAL OF } \\
\text { EARTH SCIENCES }\end{array}$ & & & 1 & & 1 \\
\hline JOURNAL OF GEODYNAMICS & & 1 & & & 1 \\
\hline $\begin{array}{l}\text { JOURNAL OF SOUTH AMERICAN } \\
\text { EARTH SCIENCES }\end{array}$ & & & 1 & & 1 \\
\hline $\begin{array}{l}\text { JOURNAL OF STRUCTURAL } \\
\text { GEOLOGY }\end{array}$ & & 1 & & & 1 \\
\hline JOURNAL OF VOLCANOLOGY AND & & 1 & & & 1 \\
\hline GEOTHERMAL RESEARCH & & & & & \\
\hline LITHOS & 2 & & & & 2 \\
\hline PRECAMBRIAN RESEARCH & 2 & & & & 2 \\
\hline SOLID EARTH & & & 1 & & 1 \\
\hline Total & 8 & 7 & 6 & 2 & 23 \\
\hline
\end{tabular}

Fonte: Elaborada pelo autor com dados da WoS Core Collection e Qualis/CAPES.

${ }^{28}$ Periódicos não avaliados na Trienal de 2004. 
Analisando-se a visibilidade da sua produção pela ótica das colaborações, a Tabela 73 objetivou apresentar as instituições que colaboraram com o Docente 06 em dois ou mais artigos, num mesmo Ciclo de Avaliação da CAPES, com a indicação do percentual dos artigos no 1으 Quartil do JCR. Entretanto, apenas uma instituição atingiu o critério, a Chinese Academy of Geological Sciences, com 50\% (um artigo) presente no 1으uartil, na Quadrienal de 2017.

Tabela 73 - Artigos publicados pelo Docente 06 distribuídos segundo instituições que colaboraram duas ou mais vezes e Ciclos de Avaliação da CAPES, com indicação do percentual de artigos no 1 은 Quartil do JCR

\begin{tabular}{lcc}
\hline Instituição Colaboradora & Quadrienal 2017 & Total \\
\hline Chinese Academy of Geological Sciences & 2 & 2 \\
Artigos & $50,00 \%$ & $50,00 \%$ \\
\% Artigos no 10. Quartil & $\mathbf{2}$ & $\mathbf{2}$ \\
\hline \hline Total Artigos & $\mathbf{5 0 , 0 0 \%}$ & $\mathbf{5 0 , 0 0 \%}$ \\
\hline \hline Total \% Arts. no 10. Quartil
\end{tabular}

Fonte: Elaborada pelo autor com dados da WoS Core Collection e Qualis/CAPES.

\section{- $\quad$ Análise de impacto da produção científica}

O impacto da produção científica do docente é medido levando em conta o percentual de artigos dele presente nos Top $10 \%$ mais citados da WoS. A Tabela 74 demonstra que dos 23 artigos indexados, dois deles encontram-se presentes nos Top $10 \%$, ambos publicados no período coberto pela Quadrienal de 2017, período este, como já visto, de alta produtividade e focada em periódicos de alto impacto.

Analisando-se as citações, a tendência de artigos com maior idade terem mais citações se confirma, tendo os anos de 2008 a 2010 os mais altos índices de citação por artigo.

Quanto ao impacto normalizado por ano e área de conhecimento, o Docente 06 atingiu ou superou a média $(1,0)$ em seis anos, quatro deles entre 2013 e 2016, coroando sua estratégia de publicação em periódicos de mais alto impacto no período coberto pela Quadrienal de 2017. 
Tabela 74 - Impacto dos artigos do Docente 06 distribuídos por ano de publicação

\begin{tabular}{ccccccc}
\hline $\begin{array}{c}\text { Ano de } \\
\text { Publicação }\end{array}$ & $\begin{array}{c}\text { Total } \\
\text { de Art. }\end{array}$ & $\begin{array}{c}\text { \% Art. } \\
\text { Citados }\end{array}$ & Citações & $\begin{array}{c}\text { Citações/ } \\
\text { Artigo }\end{array}$ & $\begin{array}{c}\text { \% Art. } \\
\text { Top 10\% }\end{array}$ & $\begin{array}{c}\text { Impacto } \\
\text { Normalizado }\end{array}$ \\
\hline 2002 & 1 & $100,00 \%$ & 14 & 14,0 & $0,00 \%$ & 0,4 \\
\hline 2003 & 1 & $100,00 \%$ & 3 & 3,0 & $0,00 \%$ & 0,1 \\
\hline 2004 & 1 & $100,00 \%$ & 20 & 20,0 & $0,00 \%$ & 0,7 \\
\hline 2006 & 1 & $100,00 \%$ & 8 & 8,0 & $0,00 \%$ & 0,3 \\
\hline 2008 & 2 & $100,00 \%$ & 52 & 26,0 & $0,00 \%$ & 1,1 \\
\hline 2009 & 1 & $100,00 \%$ & 26 & 26,0 & $0,00 \%$ & 0,5 \\
\hline 2010 & 2 & $100,00 \%$ & 48 & 24,0 & $0,00 \%$ & 1,2 \\
\hline 2011 & 1 & $100,00 \%$ & 16 & 16,0 & $0,00 \%$ & 0,9 \\
\hline 2012 & 1 & $100,00 \%$ & 8 & 8,0 & $0,00 \%$ & 0,5 \\
\hline 2013 & 4 & $100,00 \%$ & 47 & 11,8 & $25,00 \%$ & 1,0 \\
\hline 2014 & 1 & $100,00 \%$ & 15 & 15,0 & $0,00 \%$ & 1,6 \\
\hline 2015 & 2 & $100,00 \%$ & 17 & 8,5 & $0,00 \%$ & 1,3 \\
\hline 2016 & 5 & $80,00 \%$ & 18 & 3,6 & $20,00 \%$ & 1,1 \\
\hline \hline Total & $\mathbf{2 3}$ & $\mathbf{9 8 , 4 6 \%}$ & $\mathbf{2 9 2}$ & --- & --- & --- \\
\hline
\end{tabular}

Fonte: Incites com dados da WoS Core Collection

\section{- Análise das referências utilizadas}

O último item a se analisar são as referências utilizadas pelo Docente na redação de seus artigos. Ao todo o Docente 06 utilizou 238 fontes bibliográficas diferentes, citando-as 1.147 vezes em seus 23 artigos, gerando uma média de 49,87 referências por trabalho.

Utilizando-se as Zonas de Bradford para analisar as principais publicações citadas nos artigos, pôde-se verificar pelas Tabelas 75 e 76 que, das 1.147 referências utilizadas, o primeiro terço delas (Zona 1 - com 375 referências) estão concentradas em apenas seis periódicos que correspondem a 2,52\% das publicações; já no segundo terço (Zona 2 - com 386 referências) em 21 publicações, já possuindo uma maior variedade de tipologias de documentos e correspondendo a 8,82\%. O terceiro terço é a zona de maior dispersão com um total de 386 publicações, sendo a maioria delas com baixa frequência de citação (não sendo, portanto, apresentadas na tabela).

Essas 27 publicações das Zonas 1 e 2 somadas correspondem a 11,34\% das publicações, que, por conseguinte, correspondem a $66,35 \%$ de todas as referências citadas. 
Tabela 75 - Lista de Referências utilizadas nos artigos do Docente 06 distribuídas pelas Zonas 1 e 2 de Bradford

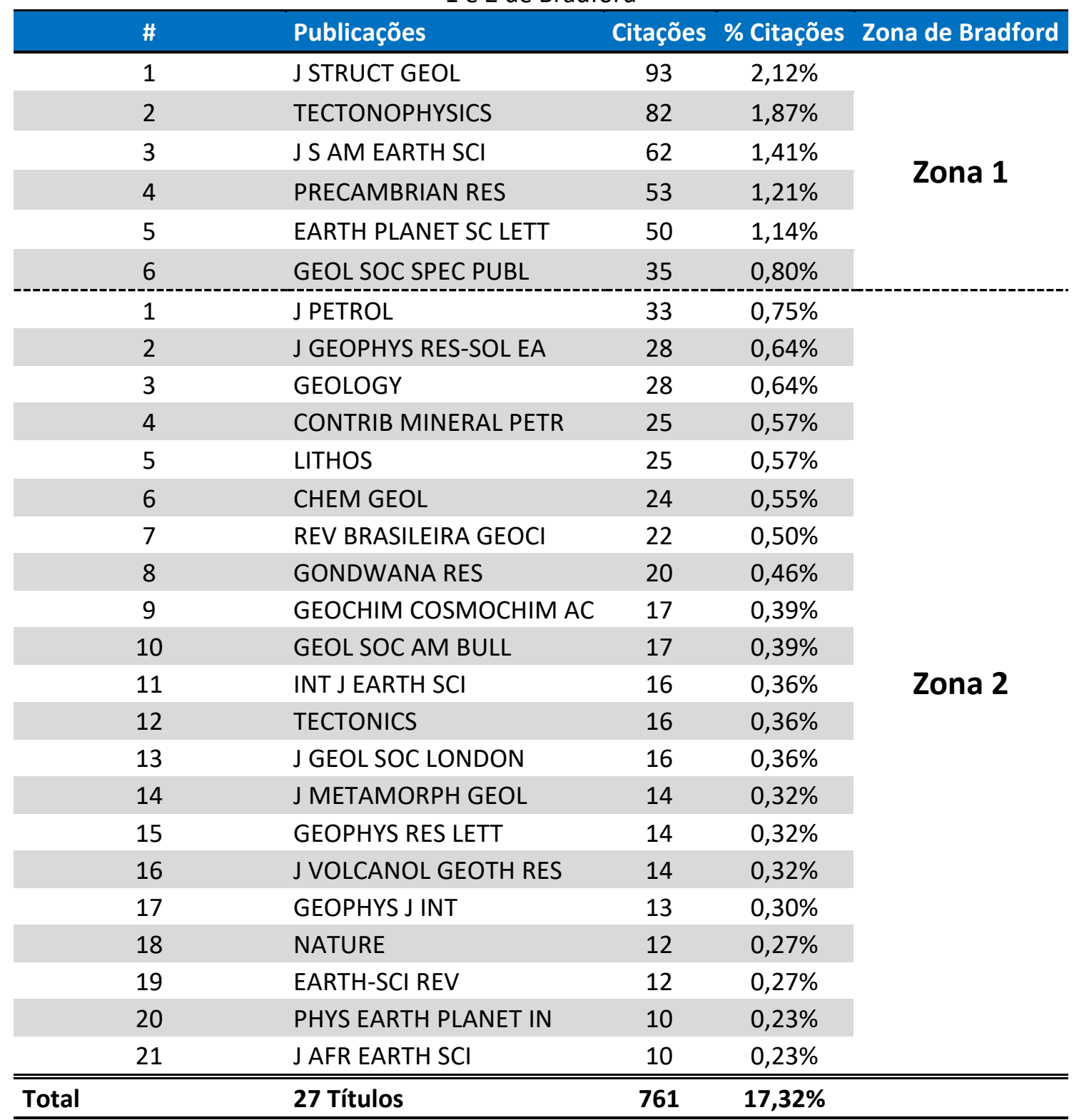

Fonte: Elaborada pelo autor com dados da WoS Core Collection.

Tabela 76 - Quantidade de publicações citadas pelo Docente 06 distribuídas pelas Zonas de Bradford

\begin{tabular}{lcccc}
\hline Zonas de Bradford & Total de Publicações & \% Publicações & Total de Citações & \% Citações \\
\hline Zona 1 & 6 & $2,52 \%$ & 375 & $32,69 \%$ \\
Zona 2 & 21 & $8,82 \%$ & 386 & $33,65 \%$ \\
Zona 3 & 211 & $88,66 \%$ & 386 & $33,65 \%$ \\
\hline \hline Total & $\mathbf{2 3 8}$ & $\mathbf{1 0 0 , 0 0 \%}$ & $\mathbf{1 . 1 4 7}$ & $\mathbf{1 0 0 , 0 0 \%}$ \\
\hline
\end{tabular}

Fonte: Elaborada pelo autor com dados da WoS Core Collection. 
A Tabela 77 nos apresenta que dos 14 periódicos nos quais foram publicados os 23 artigos do Docente 06, aquele com maior número de publicações está presente na Zona 1 e corresponde à quarta publicação mais referenciada. Do restante, três pertencem à Zona 1, oito à Zona 2 e os outros dois à Zona 3.

Durante a entrevista quando perguntado sobre as publicações mais importantes do seu campo de atuação o Docente 06 citou os periódicos Precambrian Research, Gondwana Research e Earth and Planetary Science Letters. Desses, dois encontram-se na Zona 1 e o Gondwana Research na Zona 2.

Tabela 77 - Lista de periódicos nos quais o Docente 06 publicou seus artigos com indicação das Zonas de Bradford

\begin{tabular}{|c|c|c|c|}
\hline Título do Periódico & $\begin{array}{l}\text { Total de } \\
\text { Artigos }\end{array}$ & $\begin{array}{l}\% \text { Total de } \\
\text { Artigos }\end{array}$ & $\begin{array}{l}\text { Zonas de } \\
\text { Bradford }\end{array}$ \\
\hline PRECAMBRIAN RESEARCH & 4 & $17,39 \%$ & 1 \\
\hline $\begin{array}{l}\text { JOURNAL OF SOUTH AMERICAN EARTH } \\
\text { SCIENCES }\end{array}$ & 3 & $13,04 \%$ & 1 \\
\hline $\begin{array}{l}\text { INTERNATIONAL JOURNAL OF EARTH } \\
\text { SCIENCES }\end{array}$ & 3 & $13,04 \%$ & 2 \\
\hline JOURNAL OF STRUCTURAL GEOLOGY & 2 & $8,70 \%$ & 1 \\
\hline LITHOS & 2 & $8,70 \%$ & 2 \\
\hline TECTONOPHYSICS & 1 & $4,35 \%$ & 1 \\
\hline JOURNAL OF GEODYNAMICS & 1 & $4,35 \%$ & 3 \\
\hline SOLID EARTH & 1 & $4,35 \%$ & 2 \\
\hline JOURNAL OF THE GEOLOGICAL SOCIETY & 1 & $4,35 \%$ & 2 \\
\hline GEOLOGICAL SOCIETY OF AMERICA BULLETIN & 1 & $4,35 \%$ & 2 \\
\hline COMPTES RENDUS GEOSCIENCE & 1 & $4,35 \%$ & 3 \\
\hline $\begin{array}{l}\text { JOURNAL OF VOLCANOLOGY AND } \\
\text { GEOTHERMAL RESEARCH }\end{array}$ & 1 & $4,35 \%$ & 2 \\
\hline $\begin{array}{l}\text { JOURNAL OF GEOPHYSICAL RESEARCH-SOLID } \\
\text { EARTH }\end{array}$ & 1 & $4,35 \%$ & 2 \\
\hline GONDWANA RESEARCH & 1 & $4,35 \%$ & 2 \\
\hline Total & 23 & $100,00 \%$ & \\
\hline
\end{tabular}

Fonte: Elaborada pelo autor com dados da WoS Core Collection.

A Tabela 78 apresenta a idade das referências citadas pelo Docente 06 de acordo com o ano de publicação de cada um de seus artigos. A maior concentração encontrase em referências de 11 a 20 anos, com 31,82\% e nas faixas de 0 a 5 e 6 a 10 anos, que somadas correspondem a $46,38 \%$. Somando essas três faixas tem-se $78,20 \%$ do total geral de citações de referências com até 20 anos. 
Tabela 78 - Idade das Referências citadas nos artigos do Docente 06

\begin{tabular}{|c|c|c|}
\hline Idade das Referências & Total de Citações & \% Citações \\
\hline $0-5$ & 280 & $24,41 \%$ \\
\hline $6-10$ & 252 & $21,97 \%$ \\
\hline $11-20$ & 365 & $31,82 \%$ \\
\hline $21-30$ & 160 & $13,95 \%$ \\
\hline $31-40$ & 62 & $5,41 \%$ \\
\hline $41-50$ & 20 & $1,74 \%$ \\
\hline+50 & 7 & $0,61 \%$ \\
\hline Sem Data & 1 & $0,09 \%$ \\
\hline Total & 1.147 & $100,00 \%$ \\
\hline
\end{tabular}

Fonte: Elaborada pelo autor com dados da WoS Core Collection.

- Informações adicionais

Complementarmente ao perfil bibliométrico apresentado pode-se destacar, baseando-se na entrevista com o docente, que por ser editor de periódico científico seu entendimento dos processos avaliativos dos periódicos, do fluxo da comunicação científica e foco na internacionalização da sua produção são fundamentados e têm resultado em um perfil cada vez mais internacionalizado, no que tange sua produção em periódicos científicos.

Seu alto percentual de publicação em eventos, que objetiva compartilhar com a comunidade nacional os avanços de suas pesquisas internacionais tem sido uma forma equilibrada de gerar conhecimento regional e atender, por meio dos artigos científicos, as exigências dos órgãos de avaliação de pesquisa.

O docente tem trilhado um caminho consistente e mantido sua tendência de publicação registrada na Quadrienal de 2017, é possível prever um aumento do impacto de sua produção. 


\section{E. DOCENTE 08}

O Docente 08, conforme apresentado no Quadro 1, obteve um nível de publicação 5 no primeiro subperíodo de ciclos de avaliação da CAPES (2001-2009), com um percentual de publicação em periódicos domésticos de $90 \%$. No segundo subperíodo (2010-2016) ocorreu uma alteração em seu nível de publicação passando para 4, com um percentual de $75 \%$ de publicação em periódicos domésticos, apresentando, assim, uma transição de apenas um nível mantendo um perfil voltado para os periódicos domésticos.

É importante destacar que o Docente 08 foi o único da amostra a não ser entrevistado e, portanto, comentários adicionais provenientes desse importante instrumento qualitativo não foram utilizados para complementar a análise do perfil bibliométrico.

Baseada nos dados coletados no Banco Dedalus, a Tabela 79 apresenta a distribuição da produção intelectual do Docente 08 por tipo de publicação.

É possível verificar que a produção do Docente 08 está dividida entre dois principais tipos, eventos com 52,58\% e artigos de periódicos com $43,30 \%$, este último com 19,05\% publicados em periódicos estrangeiros.

Tabela 79 - Produção Intelectual do Docente 08 registrada no Dedalus distribuída por tipo de publicação

\begin{tabular}{lccccc}
\hline \multirow{2}{*}{ Tipo de Publicação / Ciclo de Avaliação } & \multicolumn{2}{c}{ Doméstico } & \multicolumn{2}{c}{ Estrangeiro } & \multirow{2}{*}{ Total } \\
& Docs & \% Docs & Docs & \% Docs & \\
\hline ARTIGO DE PERIODICO & 34 & $80,95 \%$ & 8 & $19,05 \%$ & 42 \\
MATERIAL DIDATICO & 1 & $100,00 \%$ & 0 & $0,00 \%$ & 1 \\
\hline PARTE DE MONOGRAFIA/LIVRO & 3 & $100,00 \%$ & 0 & $0,00 \%$ & 3 \\
TRABALHO DE EVENTO & 20 & $95,24 \%$ & 1 & $4,76 \%$ & 21 \\
\hline TRABALHO DE EVENTO-RESUMO & 24 & $80,00 \%$ & 6 & $20,00 \%$ & 30 \\
\hline \hline Total & $\mathbf{8 2}$ & $\mathbf{8 4 , 5 4 \%}$ & $\mathbf{1 5}$ & $\mathbf{1 5 , 4 6 \%}$ & $\mathbf{9 7}$ \\
\hline
\end{tabular}

Fonte: Elaborada pelo autor com dados do Dedalus.

Em relação à produção científica do Docente 08 indexada na WoS Core Collection, a Tabela 80 traz os dados referentes aos artigos publicados, distribuídos por periódico. Ao todo, o docente possui nove artigos indexados e o periódico com maior número de publicações é o Journal of South American Earth Sciences (Categoria do JCR: 
Geoscience e Multidisciplinary; FI de 1,639; Categoria SJR: Earth and Planetary Sciences; SJR de 0,82 ) com 4 artigos, que correspondem a $44,44 \%$ do total

Tabela 80 - Artigos do Docente 08 indexados na WoS Core Collection distribuídos por título de periódico

\begin{tabular}{lcc}
\hline Periódicos & Artigos & \%Artigos \\
JOURNAL OF SOUTH AMERICAN EARTH SCIENCES & 4 & $44,44 \%$ \\
\hline BRAZILIAN JOURNAL OF GEOLOGY & 2 & $22,22 \%$ \\
GEOMORPHOLOGY & 1 & $11,11 \%$ \\
SEDIMENTARY GEOLOGY & 1 & $11,11 \%$ \\
JOURNAL OF STRUCTURAL GEOLOGY & 1 & $11,11 \%$ \\
\hline \hline Total & $\mathbf{9}$ & $\mathbf{1 0 0 , 0 0 \%}$ \\
\hline
\end{tabular}

Fonte: Elaborada pelo autor com dados da WoS Core Collection.

A seguir apresentam-se os dados de acordo com o Perfil Bibliométrico adaptado da proposta de Gorraiz, Wieland \& Gumpenberger (2016).

- Análise de coautorias

A Tabela 81 apresenta os dados de coautoria do Docente 08 , nos quais é possível identificar que a maior concentração de publicações encontra-se em artigos com 3 a 5 autores. A informação é complementada pela Tabela 82 que apresenta a posição do docente nos artigos, demonstrando uma maior quantidade de artigos em que assume uma posição autoral central.

Tabela 81 - Quantidade de autores nos artigos com participação do Docente 08

\begin{tabular}{lccc}
\hline Quantidade de Autores & Total de Artigos & \% Artigos \\
\hline & 2 & 1 & $11,11 \%$ \\
& 3 & 2 & $22,22 \%$ \\
& 4 & 2 & $22,22 \%$ \\
& 5 & 3 & $33,33 \%$ \\
\hline \hline Total & 6 & 1 & $11,11 \%$ \\
\hline
\end{tabular}

Fonte: Elaborada pelo autor com dados da WoS Core Collection. 
Tabela 82 - Artigos distribuídos por quantidade de autores e posição na autoria do Docente 08 nos artigos em que participa

\begin{tabular}{|c|c|c|c|c|}
\hline \multirow{2}{*}{ Quantidade de Autores } & \multicolumn{3}{|c|}{ Posição na Autoria } & \multirow{2}{*}{ Total } \\
\hline & Primeiro & Meio & Último & \\
\hline 2 & & & 1 & 1 \\
\hline 3 & & 2 & & 2 \\
\hline 4 & 1 & & 1 & 2 \\
\hline 5 & & 3 & & 3 \\
\hline 6 ou mais & & 1 & & 1 \\
\hline Total & 1 & 6 & 2 & 9 \\
\hline
\end{tabular}

Fonte: Elaborada pelo autor com dados da WoS Core Collection.

- Análise da colaboração

Em termos de colaboração internacional, o docente, dos seus nove artigos, teve colaboração com outros países somente em três deles e com no máximo um país além do Brasil.

Tabela 83 - Quantidade de países dos autores que publicaram nos artigos com participação do Docente 08

\begin{tabular}{llcc}
\hline Quantidade de Países & Total de Artigos & \% Artigos \\
\hline & 1 & 6 & $66,67 \%$ \\
& 2 & 3 & $33,33 \%$ \\
\hline \hline Total & & $\mathbf{9}$ & $\mathbf{1 0 0 , 0 0 \%}$ \\
\hline
\end{tabular}

Fonte: Elaborada pelo autor com dados da WoS Core Collection.

Na Tabela 84 podemos verificar que os países com os quais o docente colaborou foram Canadá (1 artigo) e França ( 2 artigos). O dado referente ao Brasil corrobora o perfil nacionalizado do docente, com $66,67 \%$ de artigos produzidos somente com colaboração nacional.

Tabela 84 - Países dos autores que publicaram nos artigos com participação do Docente 08

\begin{tabular}{lcc}
\hline Países & Total de Artigos & $\%$ Artigos \\
\hline Brasil & 6 & $66,67 \%$ \\
Canadá & 1 & $11,11 \%$ \\
França & 2 & $22,22 \%$ \\
\hline \hline Total & 9 & --- \\
\hline
\end{tabular}

Fonte: Elaborada pelo autor com dados da WoS Core Collection. 
A Tabela 85 traz a quantidade de instituições dos autores desses artigos demonstrando que nenhum dos artigos foi escrito somente por autores da USP e tendo uma maior concentração em artigos publicados em colaboração com três instituições (duas além da USP).

Tabela 85 - Quantidade de instituições dos autores que publicaram nos artigos com participação do Docente 08

\begin{tabular}{lccc}
\hline Quantidade de Instituições & Total de Artigos & \% Artigos \\
\hline 2 & 1 & $11,11 \%$ \\
& 3 & 5 & $55,56 \%$ \\
\hline \hline Total & 4 & 3 & $33,33 \%$ \\
\hline
\end{tabular}

Fonte: Elaborada pelo autor com dados da WoS Core Collection apresentados via Incites.

Na Tabela 86 podemos verificar quais foram as instituições e seus respectivos países, permitindo observar que a colaboração nacional ocorreu com seis diferentes instituições e a internacional com duas, uma delas - a francesa - com duas participações.

Tabela 86 - Distribuição das Instituições por países dos autores que publicaram com o Docente 08

\begin{tabular}{ll}
\hline País/Instituição & Artigos \\
\hline Brasil & 1 \\
Petrobras SA & 2 \\
Universidade Estadual Paulista & 2 \\
Universidade Federal de Ouro Preto & 2 \\
Universidade Federal do Parana & 2 \\
Universidade Federal do Rio Grande do Sul & 2 \\
$\quad$ Universidade Federal Rural do Rio de Janeiro (UFRRJ) & \\
Canadá & 1 \\
$\quad$ University of Guelph & \\
França & 2 \\
$\quad$ University of Rennes 1 & \\
\hline \hline
\end{tabular}

Fonte: Incites com dados da WoS Core Collection.

- Análise dos financiamentos de pesquisa recebidos

Quanto ao financiamento de pesquisa, a Tabela 87 apresenta as informações das agências de fomento que apoiaram as pesquisas publicadas pelo Docente 08 indexadas 
de 2008 para frente pela WoS. Dos nove artigos indexados, sete possuem dados de financiamento.

Podemos verificar que os artigos publicados pelo Docente 08 tiveram o apoio de quatro diferentes agências de fomento nacionais (CAPES, CNPq, FAPEMIG e FAPESP) e de apenas uma internacional (Canada Foundation for Innovation).

Em termos de Impacto Normalizado, nenhum dos artigos apoiados pelas agências de fomento obtiveram a média esperada $(1,0)$. $O$ índice mais alto foi obtido em 2014 e atingiu $0,67$.

Quanto às citações, o impacto (Citações / Artigo) mais expressivo foi obtido em 2014 também para duas Agências, CAPES e CNPq, com 5 e 6,5 citações por artigo, respectivamente. No entanto, a tendência é que artigos mais antigos tenham um índice de citações mais elevado, devido a idade da publicação.

Tabela 87 - Agências de Fomento que apoiaram as pesquisas que geraram as publicações com participação do Docente 08 , distribuídas por ano

\begin{tabular}{lcccc}
\hline Agências de Fomento por Ano & Artigos & Citações & Citações/Artigo & Impacto Normalizado \\
\hline 2014 & --- & --- & --- & --- \\
Canada Found for Innov. & 1 & 2 & 2 & 0,21 \\
CAPES & 3 & 15 & 5 & 0,52 \\
CNPq & 2 & 13 & 6,5 & 0,67 \\
2015 & --- & --- & --- & --- \\
CNPq & - & 5 & 2,5 & 0,53 \\
2016 & --- & --- & --- & --- \\
FAPEMIG & 1 & 2 & 2 & 0,6 \\
FAPESP & 1 & 1 & 1 & 0,3 \\
\hline \hline
\end{tabular}

Fonte: Incites com dados da WoS Core Collection

\section{- Análise de visibilidade da produção científica}

No que diz respeito à visibilidade da produção científica do docente, esta é medida levando em conta a quantidade de artigos registrada no Dedalus (42) e quantidade de artigos indexada na WoS (9), assim o percentual do Docente 08 é de $21,43 \%$.

Outra forma de medir a visibilidade é identificar o percentual de artigos presentes em periódicos de maior impacto no JCR. A Tabela 88 apresenta os artigos do docente publicados em periódicos indexados na WoS Core Collection, distribuídos segundo Ciclos de Avaliação da CAPES e percentual publicado em periódicos do 10 
Quartil do FI/JCR. Dos 9 artigos do Docente 08 indexados na WoS Core Collection 33,33\% estão presentes no 1ㅇ Quartil, todos no último ciclo de avaliação, Quadrienal de 2017.

Tabela 88 - Artigos publicados pelo Docente 08 distribuídos por Ciclos de Avaliação da CAPES e indexados em periódicos do 1으 Quartil do $\mathrm{Fl} / \mathrm{JCR}$

\begin{tabular}{lcc}
\hline Ciclos de Avaliação CAPES & Total de Artigos & \% Artigos no 10. Quartil \\
\hline Trienal 2007 & 1 & $0,00 \%$ \\
Trienal 2010 & 1 & $0,00 \%$ \\
Quadrienal 2017 & 7 & $42,86 \%$ \\
\hline \hline Total & $\mathbf{9}$ & $\mathbf{3 3 , 3 3 \%}$ \\
\hline
\end{tabular}

Fonte: Incites com dados da WoS Core Collection

Analisando-se sua publicação científica relacionada aos instrumentos de Avaliação da CAPES, a Tabela 89 apresenta a quantidade de artigos publicados, distribuídos pelos Ciclos de Avaliação e classificados nos estratos Qualis da área de avaliação das Geociências.

Verifica-se que $33,33 \%$ dos artigos do Docente 08 encontram-se no estrato A2 e $66,67 \%$ em periódicos B1. Ainda, é notório o crescimento da produção do docente na Quadrienal 2017, com sete dos nove artigos publicados nesse período, bem como uma estratégia em aumentar a publicação em um estrato mais alto.

Tabela 89 - Artigos publicados pelo Docente 08 distribuídos por Ciclos de Avaliação da CAPES e classificação do periódico nos estratos Qualis da área de avaliação das Geociências

\begin{tabular}{|c|c|c|c|}
\hline \multirow{2}{*}{ Periódicos e Ciclo de Avaliação } & \multicolumn{2}{|c|}{ Estratos Qualis } & \multirow{2}{*}{ Tota } \\
\hline & A2 & B1 & \\
\hline 2004-2006 - TRIENAL 2007 & & 1 & 1 \\
\hline JOURNAL OF SOUTH AMERICAN EARTH SCIENCES & & 1 & 1 \\
\hline 2007-2009 - TRIENAL 2010 & & 1 & 1 \\
\hline JOURNAL OF SOUTH AMERICAN EARTH SCIENCES & & 1 & 1 \\
\hline 2013-2016 - QUADRIENAL 2017 & 3 & 4 & 7 \\
\hline BRAZILIAN JOURNAL OF GEOLOGY & & 2 & 2 \\
\hline GEOMORPHOLOGY & 1 & & 1 \\
\hline JOURNAL OF SOUTH AMERICAN EARTH SCIENCES & & 2 & 2 \\
\hline JOURNAL OF STRUCTURAL GEOLOGY & 1 & & 1 \\
\hline SEDIMENTARY GEOLOGY & 1 & & 1 \\
\hline Total & 3 & 6 & 9 \\
\hline
\end{tabular}

Fonte: Elaborada pelo autor com dados da WoS Core Collection e Qualis/CAPES. 
De forma a aprofundar a análise sobre as colaborações e a visibilidade das publicações, a Tabela 90 apresenta as instituições que colaboraram com o Docente 14 em dois ou mais artigos, distribuídas entre os Ciclos de Avaliação da CAPES, com a indicação do percentual dos artigos no 1으 Quartil do JCR.

Havia somente uma instituição com a característica exigida, a Universidade Federal Rural do Rio de Janeiro (UFRRJ), presente no período da Avaliação Quadrienal de 2017. E dos dois artigos em colaboração um deles foi publicado em um periódico do 10 Quartil do JCR.

Tabela 90 - Artigos publicados pelo Docente 08 distribuídos segundo instituições que colaboraram duas ou mais vezes e Ciclos de Avaliação da CAPES, com indicação do percentual de artigos no 1 으 Quartil do JCR

\begin{tabular}{lcc}
\hline Ciclos & Quadrienal 2017 & Total Geral \\
\hline Universidade Federal Rural do Rio de Janeiro (UFRRJ) & & \\
$\quad$ Artigos & 2 & 2 \\
\% Artigos no 10. Quartil & $50,00 \%$ & $50,00 \%$ \\
\hline \hline Total Artigos & $\mathbf{2}$ & $\mathbf{2}$ \\
\hline \hline Total \% Arts. no 10. Quartil & $\mathbf{5 0 , 0 0 \%}$ & $\mathbf{5 0 , 0 0 \%}$ \\
\hline
\end{tabular}

Fonte: Elaborada pelo autor com dados da WoS Core Collection e Qualis/CAPES.

- Análise de impacto da produção científica

Para a análise de impacto da produção científica o cálculo realizado leva em consideração a quantidade de artigos do docente entre os Top $10 \%$ da WoS. Nenhum dos artigos do Docente 08 se encontrava presente no Top 10\%, portanto decidiu-se basear a análise no Impacto Normalizado e Citações por Artigo.

A Tabela 91 demonstra que apenas no ano de 2005 o docente atingiu e ultrapassou a média esperada para a área $(1,0)$. O artigo publicado no Journal of South American Earth Sciences obteve no impacto normalizado o índice de 1,8, além disso, este mesmo artigo recebeu o maior número de citações por artigo, 49,0, e a despeito do fato de artigos com maior idade receberem mais citações, este artigo em especial, baseado no seu impacto normalizado, realmente se destaca dos demais. Nos outros anos tanto o impacto normalizado obteve índices bem modestos. 
Tabela 91 - Impacto dos artigos do Docente 08 distribuídos por ano de publicação

\begin{tabular}{cccccc}
\hline $\begin{array}{c}\text { Ano de } \\
\text { Publicação }\end{array}$ & $\begin{array}{c}\text { Total } \\
\text { de Art. }\end{array}$ & \% Art. Citados & Citações & Citações/Artigo & $\begin{array}{c}\text { Impacto } \\
\text { Normalizado }\end{array}$ \\
\hline 2005 & 1 & $100,00 \%$ & 49 & 49,0 & 1,8 \\
2007 & 1 & $100,00 \%$ & 8 & 8,0 & 0,1 \\
2014 & 3 & $100,00 \%$ & 15 & 5,0 & 0,5 \\
2015 & 2 & $50,00 \%$ & 5 & 2,5 & 0,5 \\
2016 & 2 & $100,00 \%$ & 3 & 1,5 & 0,5 \\
\hline \hline Total & $\mathbf{9}$ & $\mathbf{9 0 , 0 0 \%}$ & $\mathbf{8 0}$ & --- & --- \\
\hline
\end{tabular}

Fonte: Incites com dados da WoS Core Collection

Tal fato pode ser justificado tomando como base o perfil nacionalizado de publicação do docente, que tende a publicar temas de interesse mais regionalizado.

- Análise das referências utilizadas

O último item a se analisar são as referências utilizadas pelo Docente na redação de seus artigos. Ao todo o Docente 08 utilizou 257 fontes bibliográficas diferentes, citando-as 600 vezes em seus 9 artigos, gerando uma média de $66,67 \%$ referências por trabalho.

Utilizando-se as Zonas de Bradford para analisar as principais publicações citadas nos artigos, pôde-se verificar pelas Tabelas 92 e 93 que, das 600 referências utilizadas, o primeiro terço delas (Zona 1 - com 204 referências) está concentrado em apenas 13 periódicos que correspondem à 5,06\% das publicações; já no segundo terço (Zona 2 com 201 referências) em 57 publicações, já possuindo uma maior variedade de tipologias de documentos e correspondendo à $22,18 \%$. O terceiro terço é a zona de maior dispersão com um total de 195 publicações, sendo a maioria delas com baixa frequência de citação (não sendo, portanto, apresentadas na tabela).

Essas 70 publicações da Zona 1 e 2 somadas correspondem à 27,24\% das publicações, que, por conseguinte, correspondem a $67,50 \%$ de todas as referências citadas. 
Tabela 92 - Lista de Referências utilizadas nos artigos do Docente 08 distribuídas pelas Zonas 1 e 2 de Bradford

(continua)

\begin{tabular}{|c|c|c|c|c|}
\hline$\#$ & Publicações & Citações & \% Citações & Zona de Bradford \\
\hline 1 & J S AM EARTH SCl & 34 & $5,67 \%$ & \multirow{13}{*}{ Zona 1} \\
\hline 2 & GONDWANA RES & 24 & $4,00 \%$ & \\
\hline 3 & J STRUCT GEOL & 24 & $4,00 \%$ & \\
\hline 4 & REV BRASILEIRA GEOCI & 19 & $3,17 \%$ & \\
\hline 5 & PRECAMBRIAN RES & 16 & $2,67 \%$ & \\
\hline 6 & GEOLOGY & 14 & $2,33 \%$ & \\
\hline 7 & THESIS U SAO PAULO & 14 & $2,33 \%$ & \\
\hline 8 & GEOL SOC AM BULL & 11 & $1,83 \%$ & \\
\hline 9 & AN ACAD BRAS CIENC & 11 & $1,83 \%$ & \\
\hline 10 & REV BRAS GEOCIENC & 10 & $1,67 \%$ & \\
\hline 11 & TECTONICS & 10 & $1,67 \%$ & \\
\hline 12 & SEDIMENT GEOL & 9 & $1,50 \%$ & \\
\hline 13 & EARTH-SCI REV & 8 & $1,33 \%$ & \\
\hline 1 & EPISODES & 8 & $1,33 \%$ & \multirow{29}{*}{ Zona 2} \\
\hline 2 & TECTONOPHYSICS & 8 & $1,33 \%$ & \\
\hline 3 & B RESUMOS EXPANDIDOS & 8 & $1,33 \%$ & \\
\hline 4 & COMPUT GEOSCI-UK & 7 & $1,17 \%$ & \\
\hline 5 & NATURE & 7 & $1,17 \%$ & \\
\hline 6 & TECTONIC EVOLUTION S & 6 & $1,00 \%$ & \\
\hline 7 & GEOPHYSICS & 6 & $1,00 \%$ & \\
\hline 8 & CHEM GEOL & 6 & $1,00 \%$ & \\
\hline 9 & EARTH PLANET SC LETT & 6 & $1,00 \%$ & \\
\hline 10 & CONTRIB MINERAL PETR & 5 & $0,83 \%$ & \\
\hline 11 & REV BRAS GEOC & 5 & $0,83 \%$ & \\
\hline 12 & GEOL SOC SPEC PUBL & 5 & $0,83 \%$ & \\
\hline 13 & J GEOPHYS RES & 5 & $0,83 \%$ & \\
\hline 14 & PESQUISAS & 4 & $0,67 \%$ & \\
\hline 15 & GEOCHIM COSMOCHIM AC & 4 & $0,67 \%$ & \\
\hline 16 & ANAIS & 4 & $0,67 \%$ & \\
\hline 17 & J PETROL & 4 & $0,67 \%$ & \\
\hline 18 & SCIENCE & 4 & $0,67 \%$ & \\
\hline 19 & GEOMORPHOLOGY & 4 & $0,67 \%$ & \\
\hline 20 & ANAIS ACAD BRASILEIR & 4 & $0,67 \%$ & \\
\hline 21 & GEOLOGICAL SOC LONDO & 4 & $0,67 \%$ & \\
\hline 22 & GEOCIENCIAS & 4 & $0,67 \%$ & \\
\hline 23 & SEDIMENTOLOGY & 4 & $0,67 \%$ & \\
\hline 24 & PESQUISAS GEOCIENCIA & 3 & $0,50 \%$ & \\
\hline 25 & ACTA GEOLOGICA LEOPO & 3 & $0,50 \%$ & \\
\hline 26 & CARTA GEOLOGICA BRAS & 3 & $0,50 \%$ & \\
\hline 27 & INT J EARTH SCI & 3 & $0,50 \%$ & \\
\hline 28 & DESVENDAR CONTINENTE & 3 & $0,50 \%$ & \\
\hline 29 & GONDWANA & 3 & $0,50 \%$ & \\
\hline
\end{tabular}


Tabela 92 - Lista de Referências utilizadas nos artigos do Docente 08 distribuídas pelas Zonas 1 e 2 de Bradford

(conclusão)

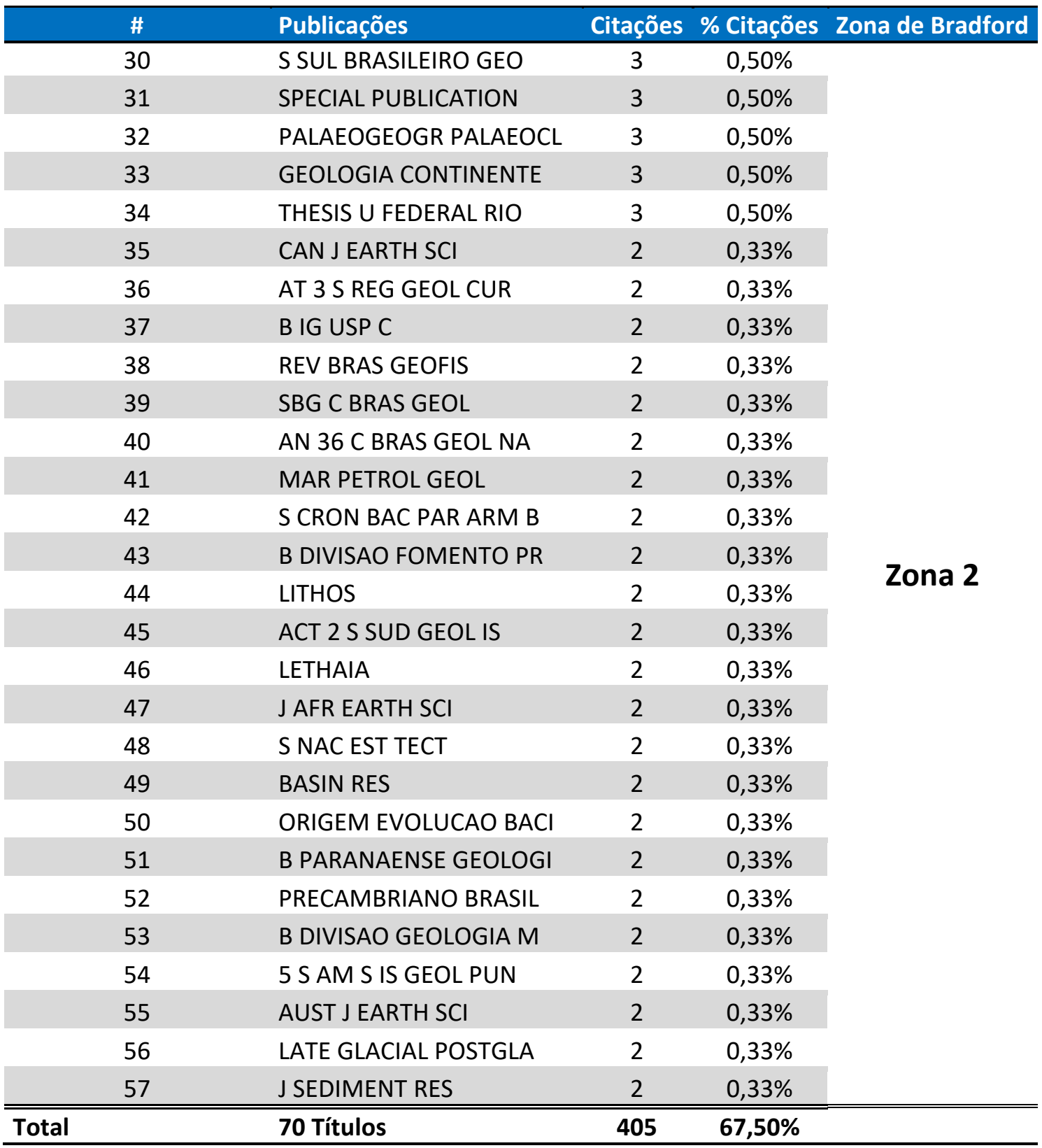

Fonte: Elaborada pelo autor com dados da WoS Core Collection.

Tabela 93 - Quantidade de publicações citadas pelo Docente 08 distribuídas pelas Zonas de Bradford

\begin{tabular}{lcccc}
\hline Zonas de Bradford & Total de Publicações & \% Publicações & Total de Citações & \% Citações \\
\hline Zona 1 & 13 & $5,06 \%$ & 204 & $34,00 \%$ \\
\hline Zona 2 & 57 & $22,18 \%$ & 201 & $33,50 \%$ \\
Zona 3 & 187 & $72,76 \%$ & 195 & $32,50 \%$ \\
\hline \hline Total & $\mathbf{2 5 7}$ & $\mathbf{1 0 0 , 0 0 \%}$ & $\mathbf{6 0 0}$ & $\mathbf{1 0 0 , 0 0 \%}$ \\
\hline
\end{tabular}

Fonte: Elaborada pelo autor com dados da WoS Core Collection. 
Tais dados permitem ainda analisar a relação de onde se publica com o que se cita. A Tabela 94 nos apresenta que dos cinco periódicos nos quais foram publicados os 9 artigos do Docente 08 o primeiro deles, com maior número de publicações (Journal of South American Earth Sciences) é justamente publicação mais referenciada na Zona 01. Dos quatro restantes, dois pertencem à Zona 1, um à Zona 2 e um à Zona 3.

Como não foi possível a realização da entrevista com o Docente 08 não se tem condições de comparar as publicações que para ele seriam as mais importantes em seu campo de atuação, com aquelas que ele citou em seus trabalhos indexados na WoS.

Tabela 94 - Lista de periódicos nos quais o Docente 08 publicou seus artigos com indicação das Zonas de Bradford

\begin{tabular}{lccc}
\hline Título do Periódico & $\begin{array}{c}\text { Total de } \\
\text { Artigos }\end{array}$ & $\begin{array}{c}\text { \% Total de } \\
\text { Artigos }\end{array}$ & $\begin{array}{c}\text { Zonas de } \\
\text { Bradford }\end{array}$ \\
\hline JOURNAL OF SOUTH AMERICAN EARTH & 4 & $44,44 \%$ & 1 \\
SCIENCES & 2 & $22,22 \%$ & 3 \\
BRAZILIAN JOURNAL OF GEOLOGY & 1 & $11,11 \%$ & 1 \\
JOURNAL OF STRUCTURAL GEOLOGY & 1 & $11,11 \%$ & 2 \\
GEOMORPHOLOGY & 1 & $11,11 \%$ & 1 \\
\hline SEDIMENTARY GEOLOGY & $\mathbf{9}$ & $\mathbf{1 0 0 , 0 0 \%}$ & \\
\hline \hline Total
\end{tabular}

Fonte: Elaborada pelo autor com dados da WoS Core Collection.

A Tabela 95 apresenta a idade das referências citadas pelo Docente 06 de acordo com o ano de publicação de cada um de seus artigos. A maior concentração encontrase em referências de 11 a 20 anos, com 32,17\% e nas faixas de 0 a 5 e 6 a 10 anos, que somadas correspondem a 35\%. Entretanto, a faixa de 31 a 40 anos também possui um alto percentual, que somada às outras três atinge $86,83 \%$ do total geral de citações de referências com até 30 anos.

Tabela 95 - Idade das Referências citadas nos artigos do Docente 08

\begin{tabular}{cccc}
\hline Idade das Referências & Total de Citações & \% Citações \\
\hline $0-5$ & 75 & $12,50 \%$ \\
& $6-10$ & 135 & $22,50 \%$ \\
& $11-20$ & 193 & $32,17 \%$ \\
& $21-30$ & 118 & $19,67 \%$ \\
& $31-40$ & 48 & $8,00 \%$ \\
& $41-50$ & 18 & $3,00 \%$ \\
& +50 & 12 & $2,00 \%$ \\
\hline \hline Total & Sem Data & 1 & $0,17 \%$ \\
\hline
\end{tabular}

Fonte: Elaborada pelo autor com dados da WoS Core Collection. 
- Informações adicionais

Em praticamente todos os itens analisados no perfil bibliométrico, o Docente 08 corroborou seu perfil de publicação nacionalizado, tendo um alto índice de colaborações nacionais e as internacionais restritas a apenas um artigo cada. Isso se reflete em seus indicadores de impacto normalizado e citações por artigo.

Todavia, é possível identificar que no período coberto pela Avaliação Quadrienal de 2017 da CAPES, o docente iniciou um processo de publicação em periódicos de maior impacto, publicando em títulos classificados no estrato A2 do Qualis.

Infelizmente pela impossibilidade do docente em realizar a entrevista, análises adicionais e complementares do ponto de vista qualitativo que enriqueceriam o estudo, não puderam ser efetivadas.

Pesquisadores como o Docente 08 precisam de estudos mais profundos (considerando índices de citação que privilegiem os periódicos domésticos, como seria o caso da SciELO, por exemplo) e que compreendam mais elementos além daqueles analisados neste perfil bibliométrico. 


\section{F. DOCENTE 12}

O Docente 12, de acordo com o apresentado no Quadro 1, obteve um nível de publicação 2 no primeiro subperíodo de ciclos de avaliação da CAPES (2001-2009), com um percentual de publicação em periódicos domésticos de $28,57 \%$. No segundo subperíodo (2010-2016) o docente permaneceu no mesmo nível, com um percentual de $36,36 \%$ de publicação em periódicos domésticos. No entanto houve um aumento de mais de $300 \%$ na sua produção de artigos, passando de 14 no primeiro subperíodo para 44 no segundo. Tal aumento talvez se deva à sua participação em apenas um ciclo de avaliação no primeiro subperíodo e em dois no segundo subperíodo. Todavia, seu perfil resultou num Status Final de "em processo de internacionalização".

Baseada nos dados coletados no Banco Dedalus, a Tabela 96 apresenta a distribuição da produção intelectual do Docente 12 por tipo de publicação. Verifica-se que a maior concentração da produção do Docente 12 está registrada em eventos, totalizando $69,23 \%$. Artigos de periódicos correspondem a $24,43 \%$, sendo que destes 62,96\% foram publicados em periódicos estrangeiros.

Tabela 96 - Produção Intelectual do Docente 12 registrada no Dedalus distribuída por tipo de publicação

\begin{tabular}{lccccc}
\hline \multirow{2}{*}{ Tipo de Publicação / Ciclo de Avaliação } & \multicolumn{2}{c}{ Doméstico } & \multicolumn{2}{c}{ Estrangeiro } & \multirow{2}{*}{ Total } \\
& Docs & \% Docs & Docs & \% Docs & \\
\hline ARTIGO DE PERIODICO & 20 & $37,04 \%$ & 34 & $62,96 \%$ & 54 \\
\hline ARTIGO DE PERIODICO-CARTA/EDITORIAL & 1 & $100,00 \%$ & 0 & $0,00 \%$ & 1 \\
\hline PARTE DE MONOGRAFIA/LIVRO & 3 & $23,08 \%$ & 10 & $76,92 \%$ & 13 \\
TRABALHO DE EVENTO & 32 & $78,05 \%$ & 9 & $21,95 \%$ & 41 \\
\hline TRABALHO DE EVENTO-ANAIS PERIODICO & 0 & $0,00 \%$ & 1 & $100,00 \%$ & 1 \\
\hline TRABALHO DE EVENTO-RESUMO & 75 & $71,43 \%$ & 30 & $\mathbf{2 8 , 5 7 \%}$ & 105 \\
\hline TRABALHO DE EVENTO-RESUMO PERIODICO & 1 & $16,67 \%$ & 5 & $83,33 \%$ & 6 \\
\hline \hline Total & $\mathbf{1 3 2}$ & $\mathbf{5 9 , 7 3 \%}$ & $\mathbf{8 9}$ & $\mathbf{4 0 , 2 7 \%}$ & $\mathbf{2 2 1}$ \\
\hline
\end{tabular}

Fonte: Elaborada pelo autor com dados do Dedalus.

Em relação à produção científica do Docente 12 indexada na WoS Core Collection, a Tabela 97 traz os dados referentes aos artigos publicados, distribuídos periódico. Os periódicos com maior número de publicação foram o Precambrian Research (Categoria do JCR: Geosciences e Multidisciplinary; FI de 3,907; Categoria SJR: Earth and Planetary Sciences; SJR de 2,769) com 6 artigos, o Journal of South American 
Earth Sciences (Categoria do JCR: Geosciences e Multidisciplinary; FI de 1,639; Categoria SJR: Earth and Planetary Sciences; SJR de 0,82) também com 6 artigos, o Brazilian Journal of Geology (Categoria do JCR: Geosciences e Multidisciplinary; FI de 1,250; Categoria SJR: Earth and Planetary Sciences; SJR de 0,608) e o Gondwana Research (Categoria do JCR: Geosciences e Multidisciplinary; FI de 5,657; Categoria SJR: Earth and Planetary Sciences: Geology; SJR de 3,424) também com 5 artigos. Estes quatro periódicos juntos correspondem a $53,66 \%$ do total de artigos publicados.

Tabela 97 - Artigos do Docente 12 indexados na WoS Core Collection distribuídos por título de periódico

\begin{tabular}{lcc}
\hline Periódicos & Artigos & $\%$ Artigos \\
\hline PRECAMBRIAN RESEARCH & 6 & $14,63 \%$ \\
\hline JOURNAL OF SOUTH AMERICAN EARTH SCIENCES & 6 & $14,63 \%$ \\
\hline BRAZILIAN JOURNAL OF GEOLOGY & 5 & $12,20 \%$ \\
\hline GONDWANA RESEARCH & 5 & $12,20 \%$ \\
\hline TERRA NOVA & 3 & $7,32 \%$ \\
\hline QUIMICA NOVA & 2 & $4,88 \%$ \\
\hline ATMOSPHERIC RESEARCH & 1 & $2,44 \%$ \\
\hline TECTONOPHYSICS & 1 & $2,44 \%$ \\
\hline LITHOS & 1 & $2,44 \%$ \\
\hline EPISODES & 1 & $2,44 \%$ \\
\hline JOURNAL DE PHYSIQUE IV & 1 & $2,44 \%$ \\
\hline ANALYTICAL CHEMISTRY & 1 & $2,44 \%$ \\
\hline CHEMICAL GEOLOGY & 1 & $2,44 \%$ \\
\hline JOURNAL OF AFRICAN EARTH SCIENCES & 1 & $2,44 \%$ \\
\hline ORE GEOLOGY REVIEWS & 1 & $2,44 \%$ \\
\hline ATMOSPHERIC CHEMISTRY AND PHYSICS & 1 & $2,44 \%$ \\
\hline EARTH AND PLANETARY SCIENCE LETTERS & 1 & $2,44 \%$ \\
\hline QUATERNARY RESEARCH & 1 & $2,44 \%$ \\
\hline INTERNATIONAL GEOLOGY REVIEW & 1 & $2,44 \%$ \\
\hline HOLOCENE & 1 & $2,44 \%$ \\
\hline \hline TOtal Geral & $\mathbf{4 1}$ & $\mathbf{1 0 0 , 0 0 \%}$ \\
\hline FOnte: ElabOrada PEO aUtOr COM dados da WOS COre COIlction & \\
\hline
\end{tabular}

Fonte: Elaborada pelo autor com dados da WoS Core Collection.

A seguir apresentam-se os dados de acordo com o Perfil Bibliométrico adaptado da proposta de Gorraiz, Wieland \& Gumpenberger (2016).

- Análise de coautorias

A Tabela 98 apresenta os dados de coautoria do Docente 12, nos quais é possível identificar que a maior concentração de publicações encontra-se em artigos com 4 a 6 
autores. A informação é complementada pela Tabela 99 que apresenta a posição do docente nos artigos, demonstrando uma maior quantidade de artigos $(68,29 \%)$ em que assumiu uma posição central.

O docente comentou na entrevista que nas Geociências o primeiro autor é quem realmente lidera/coordena e escreve mais. A ordem dos autores reflete o nível de participação naquela pesquisa, ou seja, o último autor pode não ter colaborado na pesquisa, porém contribuiu com verba ou com alguma outra forma de participação. Assim, podemos verificar que em 12,19\% dos artigos o docente assumiu a primeira posição da autoria e em $19,51 \%$ a última.

Tabela 98 - Quantidade de autores nos artigos com participação do Docente 12

\begin{tabular}{|cccc}
\hline Quantidade de Autores & Total de Artigos & $\%$ Artigos \\
\hline 3 & 3 & $7,32 \%$ \\
& 4 & 10 & $24,39 \%$ \\
& 5 & 7 & $17,07 \%$ \\
& 6 & 12 & $29,27 \%$ \\
& 7 & 1 & $2,44 \%$ \\
& 8 & 4 & $9,76 \%$ \\
& 9 & 2 & $4,88 \%$ \\
\hline \hline Total Geral & 10 & 1 & $2,44 \%$ \\
\hline Fonte: Elaborat & 1 & $\mathbf{1 0 0 , 0 0 \%}$ \\
\hline
\end{tabular}

Fonte: Elaborada pelo autor com dados da WoS Core Collection.

Tabela 99 - Artigos distribuídos por quantidade de autores e posição na autoria do Docente 12 nos artigos em que participa

\begin{tabular}{lcccc} 
& \multicolumn{3}{c}{ Posição na Autoria } & \multirow{2}{*}{ Total } \\
\hline 3 & Primeiro & Meio & Último & \\
\hline 4 & 1 & 2 & & 3 \\
5 & 2 & 6 & 2 & 10 \\
6 ou mais & 1 & 3 & 3 & 7 \\
\hline \hline Total Geral & 1 & 17 & 3 & 21 \\
\hline
\end{tabular}

Fonte: Elaborada pelo autor com dados da WoS Core Collection.

\section{- Análise da colaboração}

Em relação às colaborações nas pesquisas, a Tabela 100 demonstra que a

Docente 12 possui um equilíbrio entre publicar somente com parceiros nacionais 
$(43,90 \%)$ e internacionais $(56,10 \%)$, sendo estas últimas realizadas com um ou dois países além do Brasil.

Tabela 100 - Quantidade de países dos autores que publicaram nos artigos com participação do Docente 12

\begin{tabular}{llcc}
\hline Quantidade de Países & Total de Artigos & \% Artigos \\
\hline & 1 & 18 & $43,90 \%$ \\
& 2 & 15 & $36,59 \%$ \\
& 3 & 8 & $19,51 \%$ \\
\hline \hline Total & & $\mathbf{4 1}$ & $\mathbf{1 0 0 , 0 0 \%}$ \\
\hline
\end{tabular}

Fonte: Elaborada pelo autor com dados da WoS Core Collection.

Na Tabela 101 verifica-se quais os países dos coautores do Docente 12. Ao todo ele contou com a colaboração de 12 países, seis deles mais de uma vez. Os países com maior colaboração são Austrália (com seis), China e Estados Unidos (ambos com cinco).

Tabela 101 - Países dos autores que publicaram nos artigos com participação do Docente 12

\begin{tabular}{lcc}
\hline Países & Total de Artigos & $\%$ Artigos \\
\hline África do Sul & 1 & $2,44 \%$ \\
Austrália & 6 & $14,63 \%$ \\
Brasil & 18 & $43,90 \%$ \\
\hline Camarões & 1 & $2,44 \%$ \\
Canadá & 2 & $4,88 \%$ \\
\hline China & 5 & $12,20 \%$ \\
Dinamarca & 1 & $2,44 \%$ \\
\hline Estados Unidos & 5 & $12,20 \%$ \\
França & 4 & $9,76 \%$ \\
Inglaterra & 3 & $7,32 \%$ \\
Itália & 1 & $2,44 \%$ \\
Suiça & 1 & $2,44 \%$ \\
Uruguai & 1 & $2,44 \%$ \\
\hline \hline Total & 41 & --- \\
\hline Fonte: Elara
\end{tabular}

Fonte: Elaborada pelo autor com dados da WoS Core Collection.

Por meio da Tabela 102 pode-se verificar a quantidade de instituições dos coautores desses artigos destacando-se uma maior concentração naqueles com quatro instituições com $34,15 \%$; e com três correspondendo a $24,39 \%$. No total, $87,80 \%$ dos artigos foram produzidos com a colaboração de mais uma instituição além da USP. 
Tabela 102 - Quantidade de instituições dos autores que publicaram nos artigos com participação do Docente 12

\begin{tabular}{lccc}
\hline Quantidade de Instituições & Total de Artigos & \% Artigos \\
\hline & 1 & 5 & $12,20 \%$ \\
& 2 & 5 & $12,20 \%$ \\
& 3 & 10 & $24,39 \%$ \\
& 4 & 14 & $34,15 \%$ \\
& 5 & 6 & $14,63 \%$ \\
\hline \hline Total & 6 & 1 & $2,44 \%$ \\
\hline Fon & $\mathbf{4 1}$ & $\mathbf{1 0 0 , 0 0 \%}$ \\
\hline
\end{tabular}

Fonte: Elaborada pelo autor com dados da WoS Core Collection apresentados via Incites.

Complementando a análise, a Tabela 103 apresenta as instituições e seus respectivos países, permitindo observar que a colaboração se distribui em um conjunto significativo de 46 instituições, 22 delas com mais de um artigo produzido. A maior colaboradora foi a brasileira Universidade Federal de Minas Gerais (UFMG) com nove artigos produzidos. Das estrangeiras o destaque fica com a Australian National University, com cinco artigos e a Chinese Academy of Geological Sciences, com quatro.

Tabela 103 - Distribuição das Instituições por países dos autores que publicaram com o Docente 12

(continua)

\begin{tabular}{ll}
\hline País/Instituição & Artigos \\
\hline África do Sul & \\
University of Cape Town & 1 \\
Austrália & 5 \\
Australian National University & 1 \\
Curtin University & 1 \\
University of Western Australia & 1 \\
University of Wollongong & \\
Brasil & 1 \\
Centro Universitario Fieo & 6 \\
Comissao Nacional de Energia Nuclear (CNEN) & 5 \\
Instituto de Pesquisas Energeticas e Nucleares (IPEN) & 4 \\
Universidade de Brasilia & 1 \\
Universidade do Estado do Rio de Janeiro & 1 \\
Universidade Estadual de Campinas & 6 \\
Universidade Estadual Paulista & 2 \\
Universidade Federal da Bahia & 2 \\
Universidade Federal de Mato Grosso do Sul & 9 \\
Universidade Federal de Minas Gerais & 4 \\
Universidade Federal de Ouro Preto &
\end{tabular}


Tabela 103 - Distribuição das Instituições por países dos autores que publicaram com o Docente 12

(conclusão)

País/Instituição Artigos

Universidade Federal de Pernambuco 2

Universidade Federal de Sao Paulo (UNIFESP) 2

Universidade Federal do Para

2

Universidade Federal do Rio Grande do Norte $\quad 1$

Universidade Federal do Rio Grande do Sul 3

Universidade Federal dos Vales do Jequitinhonha e Mucuri (UFVJM) 2

Universidade Guarulhos

1

\section{Camarões}

University of Yaounde I

1

\section{Canadá}

University of Calgary

2

China

Chinese Academy of Geological Sciences

4

Peking University

1

\section{Dinamarca}

University of Copenhagen

1

\section{Estados Unidos}

New Mexico Institute of Mining Technology 1

University of Kansas 2

University of Maryland College Park 1

University System of Maryland 1

Washington State University $\quad 1$

\section{França}

Centre National de la Recherche Scientifique (CNRS) 3

Institut de Recherche pour le Developpement (IRD) 1

Languedoc-Roussillon Universites (ComUE) 2

Universite de Montpellier $\quad 2$

Universite de Toulouse 1

Universite Federale Toulouse Midi-Pyrenees (ComUE) 1

Universite Toulouse III - Paul Sabatier 1

\begin{tabular}{lc} 
Inglaterra & 2 \\
Imperial College London & 2 \\
Natural History Museum London & 1 \\
University of Surrey & 1 \\
Itália & \\
$\quad$ University of Trieste & 1 \\
Suiça & \\
$\quad$ University of Geneva & 1 \\
\hline $\begin{array}{l}\text { Uruguai } \\
\quad \text { University of the Republic - Uruguay }\end{array}$ \\
\hline \hline
\end{tabular}

Fonte: Incites com dados da WoS Core Collection. 
- Análise dos financiamentos de pesquisa recebidos

O financiamento de pesquisa é fundamental para a pesquisa e foi destacado pelo Docente 12 na entrevista. A presente análise verifica quais foram as Agências de Fomento que apoiaram suas pesquisas. Como os dados são oriundos da WoS, tem-se dados de financiamento padronizados somente a partir de 2008. Dessa forma, dos 41 artigos do docente, somente aproximadamente metade pôde ser analisada (22 artigos).

A Tabela 104 apresenta as informações das agências de fomento que apoiaram as pesquisas publicadas pelo Docente 12, com destaque para o ano de 2012 com participação de seis agências e com todos os artigos obtendo índices de impacto normalizado acima da média esperada $(1,0)$ para a área. Outros anos que merecem destaque são 2010, com todos os artigos também acima da média e 2015 com duas agências também acima da média.

Ao todo o docente obteve apoio nas pesquisas de sete diferentes agências, sendo duas delas estrangeiras, a National Science Foundation (Estados Unidos) e Swiss National Science Foundation (Suíça).

Quanto às citações, corroborando a premissa que artigos com maior idade tendem a serem mais citados, os anos de 2010 e 2012 concentram os maiores índices de citações por artigo.

Tabela 104 - Agências de Fomento que apoiaram as pesquisas que geraram as publicações com participação do Docente 12, distribuídas por ano

(continua)

\begin{tabular}{|ccccc}
\hline Agências de Fomento por Ano & Artigos & Citações & Citações/Artigo & Impacto Normalizado \\
\hline 2008 & --- & --- & --- & --- \\
\hline FAPESP & 2 & 33 & 16,5 & 0,72 \\
\hline 209 & --- & --- & --- & --- \\
CAPES & 1 & 19 & 19 & 0,86 \\
FAPESP & - & 32 & 10,67 & 0,49 \\
CNPq & - & 3 & 0,14 \\
2010 & 1 & 3 & --- & --- \\
FAPESP & --- & --- & 23,67 & 1,18 \\
CNPq & 3 & 71 & 38 & 1,97 \\
2012 & 1 & 38 & --- & --- \\
CAPES & --- & --- & 27 & 1,76 \\
FINEP & 1 & 27 & 37 & 2,44 \\
FAPEMIG & 1 & 37 & 37 & 2,44 \\
FAPESP & 1 & 37 & 18 & 1,17
\end{tabular}


Tabela 104 - Agências de Fomento que apoiaram as pesquisas que geraram as publicações com participação do Docente 12, distribuídas por ano

(conclusão)

Agências de Fomento por Ano Artigos Citações Citações/Artigo Impacto Normalizado

\begin{tabular}{lcccc}
\hline CNPq & 4 & 72 & 18 & 1,17 \\
Nat. Scie. Foundation (NSF) & 1 & 27 & 27 & 1,76 \\
2013 & ------ & -- & - \\
FAPEMIG & 1 & 5 & 5 & 0,41 \\
FAPESP & 2 & 48 & 24 & 1,96 \\
CNPq & 4 & 54 & 13,5 & 1,11 \\
2015 & --- & --- & --- & --- \\
FAPEMIG & 1 & 18 & 18 & 2,81 \\
FAPESP & 2 & 35 & 17,5 & 2,73 \\
CNPq & 2 & 22 & 11 & 1,7 \\
Nat. Scie. Foundation (NSF) & 1 & 4 & 4 & 0,59 \\
Swiss Nat. Scie. Foundation & 1 & 4 & 4 & 0,59 \\
$\mathbf{2 0 1 6}$ & --- & --- & --- & --- \\
FAPESP & 2 & 6 & 3 & 0,84 \\
CNPq & 1 & 1 & 1 & 0,4 \\
\hline \hline
\end{tabular}

Fonte: Incites com dados da WoS Core Collection

- $\quad$ Análise de visibilidade da produção científica

No que diz respeito à visibilidade da produção científica do docente, esta é medida levando em conta a quantidade de artigos registrada no Dedalus (54) e quantidade de artigos indexada na WoS (41), assim o percentual do Docente 12 é de $75,93 \%$.

Outro fator a ser analisado na visibilidade é o percentual de artigos presentes em periódicos de impacto. A Tabela 105 apresenta os artigos do docente publicados em periódicos indexados na WoS Core Collection, distribuídos segundo Ciclos de Avaliação da CAPES e o percentual publicado em periódicos do 1으 Quartil do FI/JCR.

Dos 41 artigos do Docente 12 indexados na WoS Core Collection 48,78\% estão presentes no 1 Q Quartil. Vale ressaltar que o docente tem mantido um percentual médio entre os ciclos, exceto no período da Trienal de 2007 em que ele abaixou em relação aos demais e na Quadrienal de 2017 na qual houve uma intensificação da publicação em periódicos de maior impacto na área. 
Tabela 105 - Artigos publicados pelo Docente 12 distribuídos por Ciclos de Avaliação da CAPES e indexados em periódicos do 1 - Quartil do $\mathrm{FI} / \mathrm{JCR}$

\begin{tabular}{lcc}
\hline Ciclos de Avaliação CAPES & Total de Artigos & \% Artigos no 10. Quartil \\
\hline Trienal 2004 & 4 & $50,00 \%$ \\
Trienal 2007 & 3 & $33,33 \%$ \\
Trienal 2010 & 11 & $45,45 \%$ \\
Trienal 2013 & 9 & $44,44 \%$ \\
Quadrienal 2017 & 14 & $57,14 \%$ \\
\hline \hline Total & $\mathbf{4 1}$ & $\mathbf{4 8 , 7 8 \%}$ \\
\hline
\end{tabular}

Fonte: Incites com dados da WoS Core Collection

Analisando-se a publicação científica mais relacionada aos instrumentos de Avaliação da CAPES, a Tabela 106 apresenta a quantidade de artigos publicados distribuídos pelos Ciclos de Avaliação e classificação nos estratos Qualis da área de avaliação das Geociências.

Verifica-se que 60,98\% dos artigos do Docente 12 encontram-se nos estratos mais altos ( $A, A 1$ e A2), 36,59 em revistas B e B1 e um artigo na Trienal de 2004 foi publicado em um periódico não avaliado pela área. Além disso, verifica-se na Quadrienal de 2017 o aumento da produção de artigos, com 34,15\% da produção correspondendo a somente este ciclo, e aumento também da publicação em periódicos do estrato A1.

Tabela 106 - Artigos publicados pelo Docente 12 distribuídos por Ciclos de Avaliação da CAPES e classificação do periódico nos estratos Qualis da área de avaliação das Geociências

(continua)

\begin{tabular}{|c|c|c|c|c|c|c|c|}
\hline \multirow{2}{*}{ Periódicos e Ciclo de Avaliação } & \multicolumn{6}{|c|}{ Estratos Qualis } & \multirow{2}{*}{ Total } \\
\hline & A & A1 & A2 & B & B1 & --- & \\
\hline 2001-2003 - TRIENAL 2004 & 2 & & & 1 & & 1 & 4 \\
\hline EPISODES & & & & 1 & & & 1 \\
\hline JOURNAL DE PHYSIQUE IV & & & & & & 1 & 1 \\
\hline PRECAMBRIAN RESEARCH & 2 & & & & & & 2 \\
\hline 2004-2006 - TRIENAL 2007 & & 1 & & & 2 & & 3 \\
\hline JOURNAL OF SOUTH AMERICAN EARTH SCIENCES & & & & & 2 & & 2 \\
\hline PRECAMBRIAN RESEARCH & & 1 & & & & & 1 \\
\hline 2007-2009 - TRIENAL 2010 & & 2 & 5 & & 4 & & 11 \\
\hline ANALYTICAL CHEMISTRY & & 1 & & & & & 1 \\
\hline GONDWANA RESEARCH & & 1 & & & & & 1 \\
\hline HOLOCENE & & & 1 & & & & 1 \\
\hline INTERNATIONAL GEOLOGY REVIEW & & & & & 1 & & 1 \\
\hline JOURNAL OF SOUTH AMERICAN EARTH SCIENCES & & & & & 2 & & 2 \\
\hline QUIMICA NOVA & & & & & 1 & & 1 \\
\hline TECTONOPHYSICS & & & 1 & & & & 1 \\
\hline TERRA NOVA & & & 3 & & & & 3 \\
\hline
\end{tabular}


Tabela 106 - Artigos publicados pelo Docente 12 distribuídos por Ciclos de Avaliação da CAPES e classificação do periódico nos estratos Qualis da área de avaliação das Geociências

(conclusão)

\begin{tabular}{|c|c|c|c|c|c|c|c|}
\hline \multirow{2}{*}{ Periódicos e Ciclo de Avaliação } & \multicolumn{6}{|c|}{ Estratos Qualis } & \multirow{2}{*}{ Total } \\
\hline & A & A1 & A2 & B & B1 & -- & \\
\hline 2010-2012 - TRIENAL 2013 & & 5 & 2 & & 2 & & 9 \\
\hline ATMOSPHERIC RESEARCH & & & 1 & & & & 1 \\
\hline EARTH AND PLANETARY SCIENCE LETTERS & & 1 & & & & & 1 \\
\hline GONDWANA RESEARCH & & 1 & & & & & 1 \\
\hline JOURNAL OF AFRICAN EARTH SCIENCES & & & & & 1 & & 1 \\
\hline JOURNAL OF SOUTH AMERICAN EARTH SCIENCES & & & 1 & & & & 1 \\
\hline PRECAMBRIAN RESEARCH & & 2 & & & & & 2 \\
\hline QUATERNARY RESEARCH & & 1 & & & & & 1 \\
\hline QUIMICA NOVA & & & & & 1 & & 1 \\
\hline 2013-2016 - QUADRIENAL 2017 & & 7 & 1 & & 6 & & 14 \\
\hline ATMOSPHERIC CHEMISTRY AND PHYSICS & & 1 & & & & & 1 \\
\hline BRAZILIAN JOURNAL OF GEOLOGY & & & & & 5 & & 5 \\
\hline CHEMICAL GEOLOGY & & 1 & & & & & 1 \\
\hline GONDWANA RESEARCH & & 3 & & & & & 3 \\
\hline JOURNAL OF SOUTH AMERICAN EARTH SCIENCES & & & & & 1 & & 1 \\
\hline LITHOS & & 1 & & & & & 1 \\
\hline ORE GEOLOGY REVIEWS & & & 1 & & & & 1 \\
\hline PRECAMBRIAN RESEARCH & & 1 & & & & & 1 \\
\hline Total & 2 & 15 & 8 & 14 & 1 & 1 & 41 \\
\hline
\end{tabular}

Fonte: Elaborada pelo autor com dados da WoS Core Collection e Qualis/CAPES.

De forma a aprofundar a análise sobre as colaborações e a visibilidade das publicações, a Tabela 107 apresenta as instituições que colaboraram com o Docente 12 em dois ou mais artigos, distribuídas entre os Ciclos de Avaliação da CAPES, com a indicação do percentual dos artigos no 1 은 Quartil do JCR.

Ao todo são quatro instituições com a característica exigida, todas brasileiras, e divididas em somente dois ciclos, Trienal de 2013 e Quadrienal de 2017. A maior produção foi com a UFMG, com quatro artigos e 50\% deles presentes no 10 Quartil. Dessas quatro, a Universidade Federal de Ouro Preto foi a única a não ter presente nenhum artigo no 10 Quartil.

Do total de 11 artigos dessas quatro instituições, quatro artigos foram publicados em periódicos do 10 Quartil, correspondendo a um percentual de 36,36\%. Permitindo afirmar que tais colaborações foram positivas para o Docente 12. 
Tabela 107 - Artigos publicados pelo Docente 12 distribuídos segundo instituições que colaboraram duas ou mais vezes e Ciclos de Avaliação da CAPES, com indicação do percentual de artigos no 1 10 Quartil do JCR

\begin{tabular}{|c|c|c|c|}
\hline Instituição Colaboradora & Trienal 2013 & Quadrienal 2017 & Total \\
\hline \multicolumn{4}{|c|}{ Comissao Nacional de Energia Nuclear (CNEN) } \\
\hline Artigos & 3 & & 3 \\
\hline$\%$ Artigos no 1o. Quartil & $33,33 \%$ & & $33,33 \%$ \\
\hline \multicolumn{4}{|c|}{ Instituto de Pesquisas Energeticas e Nucleares (IPEN) } \\
\hline Artigos & 2 & & 2 \\
\hline$\%$ Artigos no 1o. Quartil & $50,00 \%$ & & $50,00 \%$ \\
\hline \multicolumn{4}{|c|}{ Universidade Federal de Minas Gerais } \\
\hline Artigos & & 4 & 4 \\
\hline$\%$ Artigos no 1o. Quartil & & $50,00 \%$ & $50,00 \%$ \\
\hline \multicolumn{4}{|c|}{ Universidade Federal de Ouro Preto } \\
\hline Artigos & & 2 & 2 \\
\hline$\%$ Artigos no 1o. Quartil & & $0,00 \%$ & $0,00 \%$ \\
\hline Total Artigos & 5 & 6 & 11 \\
\hline Total \% Artigos no 10. Quartil & $40,00 \%$ & $33,33 \%$ & $36,36 \%$ \\
\hline
\end{tabular}

Fonte: Elaborada pelo autor com dados da WoS Core Collection e Qualis/CAPES.

- Análise de impacto da produção científica

Os critérios para a análise de impacto compreendem a análise das citações recebidas e, do total de artigos indexados, a quantidade destes nos Top $10 \%$.

Com base na Tabela 108 pode-se verificar que o Docente 12 em quatro anos (2001, 2007, 2012 e 2015) conseguiu publicar artigos que foram incluídos nos Top 10\%, totalizando cinco documentos.

Além disso, em seis anos o docente atingiu ou superou a média do impacto normalizado de 1,0, com o ano de 2001 sendo o mais alto índice com 3,2 e, por conseguinte, esse é o ano que ele obteve também o mais alto índice de citações por artigo. $\mathrm{O}$ índice pode ser explicado levando-se em conta o fato que artigos com maior idade tendem a receber mais citações. 
Tabela 108 - Impacto dos artigos do Docente 12 distribuídos por ano de publicação

\begin{tabular}{ccccccc}
\hline $\begin{array}{c}\text { Ano de } \\
\text { Publicação }\end{array}$ & $\begin{array}{c}\text { Total de } \\
\text { Art. }\end{array}$ & $\begin{array}{c}\text { \% Art. } \\
\text { Citados }\end{array}$ & Citações & Citações/Art. & $\begin{array}{c}\text { Art. Top } \\
10 \%\end{array}$ & $\begin{array}{c}\text { Impacto } \\
\text { Normalizado }\end{array}$ \\
\hline 2001 & 1 & $100,00 \%$ & 97 & 97,0 & $100,00 \mathrm{bb} \%$ & 3,2 \\
2003 & 3 & $100,00 \%$ & 80 & 26,7 & $0,00 \%$ & 0,9 \\
\hline 2004 & 2 & $100,00 \%$ & 55 & 27,5 & $0,00 \%$ & 1,0 \\
2005 & 1 & $100,00 \%$ & 12 & 12,0 & $0,00 \%$ & 0,4 \\
\hline 2007 & 4 & $100,00 \%$ & 109 & 27,3 & $25,00 \%$ & 1,1 \\
2008 & 4 & $100,00 \%$ & 49 & 12,3 & $0,00 \%$ & 0,6 \\
\hline 2009 & 3 & $100,00 \%$ & 32 & 10,7 & $0,00 \%$ & 0,5 \\
\hline 2010 & 3 & $100,00 \%$ & 71 & 23,7 & $0,00 \%$ & 1,2 \\
\hline 2011 & 1 & $100,00 \%$ & 6 & 6,0 & $0,00 \%$ & 0,4 \\
\hline 2012 & 5 & $80,00 \%$ & 77 & 15,4 & $20,00 \%$ & 1,0 \\
\hline 2013 & 5 & $100,00 \%$ & 56 & 11,2 & $0,00 \%$ & 0,9 \\
\hline 2014 & 1 & $100,00 \%$ & 24 & 24,0 & $0,00 \%$ & 0,9 \\
\hline 2015 & 3 & $100,00 \%$ & 39 & 13,0 & $66,67 \%$ & 2,0 \\
\hline 2016 & 5 & $80,00 \%$ & 13 & 2,6 & $0,00 \%$ & 0,8 \\
\hline \hline Total & $\mathbf{4 1}$ & $\mathbf{9 7 , 1 4 \%}$ & $\mathbf{7 2 0}$ & --- & $\mathbf{1 2 , 2 0 \%}$ & --- \\
\hline
\end{tabular}

Fonte: Incites com dados da WoS Core Collection

- Análise das referências utilizadas

O último item a se analisar são as referências utilizadas pelo docente na redação de seus artigos. Ao todo o Docente 12 utilizou 731 fontes bibliográficas diferentes, citando-as 2.626 vezes em seus 41artigos, gerando uma média de 64,05 referências por trabalho.

Utilizando-se as Zonas de Bradford para analisar as principais publicações citadas nos artigos, pôde-se verificar pelas Tabelas 109 e 110 que, das 2.626 referências utilizadas, o primeiro terço delas (Zona 1 - com 877 referências) estão concentradas em apenas 11 periódicos que correspondem a 1,50\% das publicações; já no segundo terço (Zona 2 - com 875 referências) em 71 publicações, já possuindo uma maior variedade de tipologias de documentos e correspondendo a 9,71\%. O terceiro terço é a zona de maior dispersão com um total de 649 publicações, sendo a maioria delas com baixa frequência de citação (não sendo, portanto, apresentadas na tabela).

Essas 82 publicações somadas correspondem a 11,22\% das publicações, que, por conseguinte, correspondem a $66,72 \%$ de todas as referências citadas. 
Tabela 109 - Lista de Referências utilizadas nos artigos do Docente 12 distribuídas pelas Zonas 1 e 2 de Bradford

(continua)

\begin{tabular}{|c|c|c|c|c|}
\hline \# & Publicações & \multicolumn{2}{|c|}{ Citações\% CitaçõesZona de Bradford } & \multirow{12}{*}{ Zona 1} \\
\hline 1 & PRECAMBRIAN RES & 190 & $7,24 \%$ & \\
\hline 2 & EARTH PLANET SC LETT & 103 & $3,92 \%$ & \\
\hline 3 & J S AM EARTH SCl & 91 & $3,47 \%$ & \\
\hline 4 & GEOLOGY & 85 & $3,24 \%$ & \\
\hline 5 & REV BRASILEIRA GEOCI & 76 & $2,89 \%$ & \\
\hline 6 & GONDWANA RES & 74 & $2,82 \%$ & \\
\hline 7 & CHEM GEOL & 70 & $2,67 \%$ & \\
\hline 8 & GEOCHIM COSMOCHIM AC & 68 & $2,59 \%$ & \\
\hline 9 & ATMOS ENVIRON & 40 & $1,52 \%$ & \\
\hline 10 & NATURE & 40 & $1,52 \%$ & \\
\hline 11 & SCIENCE & 40 & $1,52 \%$ & \\
\hline 1 & CONTRIB MINERAL PETR & 38 & $1,45 \%$ & \\
\hline 2 & PALAEOGEOGR PALAEOCL & 38 & $1,45 \%$ & \\
\hline 3 & J PETROL & 36 & $1,37 \%$ & \\
\hline 4 & THESIS U SAO PAULO & 33 & $1,26 \%$ & \\
\hline 5 & LITHOS & 28 & $1,07 \%$ & \\
\hline 6 & TERRA NOVA & 28 & $1,07 \%$ & \\
\hline 7 & TECTONOPHYSICS & 27 & $1,03 \%$ & \\
\hline 8 & SCI TOTAL ENVIRON & 26 & $0,99 \%$ & \\
\hline 9 & ATMOS CHEM PHYS & 24 & $0,91 \%$ & \\
\hline 10 & GEOL SOC AM BULL & 21 & $0,80 \%$ & \\
\hline 11 & GEONOMOS & 20 & $0,76 \%$ & \\
\hline 12 & J AFR EARTH SCI & 20 & $0,76 \%$ & \\
\hline 13 & GEOL SOC SPEC PUBL & 19 & $0,72 \%$ & Zona 2 \\
\hline 14 & ENVIRON SCI TECHNOL & 19 & $0,72 \%$ & \\
\hline 15 & EARTH-SCI REV & 19 & $0,72 \%$ & \\
\hline 16 & ECON GEOL BULL SOC & 16 & $0,61 \%$ & \\
\hline 17 & REV BRAS GEOC & 16 & $0,61 \%$ & \\
\hline 18 & J GEOPHYS RES-SOL EA & 16 & $0,61 \%$ & \\
\hline 19 & TECTONIC EVOLUTION S & 16 & $0,61 \%$ & \\
\hline 20 & $\mathrm{AM} J \mathrm{SCl}$ & 15 & $0,57 \%$ & \\
\hline 21 & SEDIMENT GEOL & 15 & $0,57 \%$ & \\
\hline 22 & J GEOL SOC LONDON & 14 & $0,53 \%$ & \\
\hline 23 & AN ACAD BRAS CIENC & 13 & $0,50 \%$ & \\
\hline 24 & CAN J EARTH SCI & 13 & $0,50 \%$ & \\
\hline 25 & AM MINERAL & 13 & $0,50 \%$ & \\
\hline
\end{tabular}


Tabela 109 - Lista de Referências utilizadas nos artigos do Docente 12 distribuídas pelas Zonas 1 e 2 de Bradford

\begin{tabular}{|c|c|c|c|c|}
\hline$\#$ & Publicações & \multicolumn{2}{|c|}{ Citações\% CitaçõesZona de Bradford } & \multirow{37}{*}{ Zona 2} \\
\hline 26 & ECON GEOL & 13 & $0,50 \%$ & \\
\hline 27 & C BRASILEIRO GEOLOGI & 12 & $0,46 \%$ & \\
\hline 28 & INT GEOL REV & 12 & $0,46 \%$ & \\
\hline 29 & EPISODES & 11 & $0,42 \%$ & \\
\hline 30 & J GEOPHYS RES & 11 & $0,42 \%$ & \\
\hline 31 & J GEOL & 11 & $0,42 \%$ & \\
\hline 32 & GEOPHYS RES LETT & 10 & $0,38 \%$ & \\
\hline 33 & BASIN RES & 9 & $0,34 \%$ & \\
\hline 34 & ANAIS ACAD BRASILEIR & 9 & $0,34 \%$ & \\
\hline 35 & CR GEOSCI & 9 & $0,34 \%$ & \\
\hline 36 & NEOPROTEROZOIC CAMBR & 9 & $0,34 \%$ & \\
\hline 37 & QUATERNARY SCI REV & 9 & $0,34 \%$ & \\
\hline 38 & APPL GEOCHEM & 8 & $0,30 \%$ & \\
\hline 39 & ANNU REV EARTH PL SC & 8 & $0,30 \%$ & \\
\hline 40 & J STRUCT GEOL & 8 & $0,30 \%$ & \\
\hline 41 & TECTONICS & 8 & $0,30 \%$ & \\
\hline 42 & BRAZ J GEOL & 7 & $0,27 \%$ & \\
\hline 43 & B DIVISAO GEOLOGIA M & 7 & $0,27 \%$ & \\
\hline 44 & REV PALAEOBOT PALYNO & 7 & $0,27 \%$ & \\
\hline 45 & J ANAL ATOM SPECTROM & 7 & $0,27 \%$ & \\
\hline 46 & WATER AIR SOIL POLL & 7 & $0,27 \%$ & \\
\hline 47 & B GEOCIENCIAS PETROB & 6 & $0,23 \%$ & \\
\hline 48 & GEOLOGIA USP SERIE C & 6 & $0,23 \%$ & \\
\hline 49 & DEV PREC G & 6 & $0,23 \%$ & \\
\hline 50 & ENVIRON POLLUT & 6 & $0,23 \%$ & \\
\hline 51 & GEOLOGIA CONTINENTE & 6 & $0,23 \%$ & \\
\hline 52 & 4 S AM S IS GEOL SAL & 6 & $0,23 \%$ & \\
\hline 53 & CR ACAD SCI II & 6 & $0,23 \%$ & \\
\hline 54 & PROGRAMA LEVANTAMENT & 6 & $0,23 \%$ & \\
\hline 55 & SEDIMENTOLOGY & 6 & $0,23 \%$ & \\
\hline 56 & REV EC GEOLOGY & 6 & $0,23 \%$ & \\
\hline 57 & P NATL ACAD SCI USA & 6 & $0,23 \%$ & \\
\hline 58 & S AFR J GEOL & 6 & $0,23 \%$ & \\
\hline 59 & THESIS U BRASILIA & 6 & $0,23 \%$ & \\
\hline 60 & MAR GEOL & 6 & $0,23 \%$ & \\
\hline 61 & PHYS EARTH PLANET IN & 6 & $0,23 \%$ & \\
\hline
\end{tabular}


Tabela 109 - Lista de Referências utilizadas nos artigos do Docente 12 distribuídas pelas Zonas 1 e 2 de Bradford

(conclusão)

\begin{tabular}{|c|c|c|c|c|c|}
\hline & $\#$ & Publicações & Citações\% & 6 CitaçõesZ & na de Bradford \\
\hline & 62 & GEOPH RES ABSTR & 5 & $0,19 \%$ & \multirow{10}{*}{ Zona 2} \\
\hline & 63 & GEOL RUNDSCH & 5 & $0,19 \%$ & \\
\hline & 64 & GEOSTANDARD NEWSLETT & 5 & $0,19 \%$ & \\
\hline & 65 & ENVIRON GEOL & 5 & $0,19 \%$ & \\
\hline & 66 & APPL OPTICS & 5 & $0,19 \%$ & \\
\hline & 67 & 31 INT GEOL C RIO JA & 5 & $0,19 \%$ & \\
\hline & 68 & MINER DEPOSITA & 5 & $0,19 \%$ & \\
\hline & 69 & J GEOPHYS RES-SOLID & 5 & $0,19 \%$ & \\
\hline & 70 & J SEDIMENT PETROL & 5 & $0,19 \%$ & \\
\hline & 71 & S AM S ISOTOPE GEOLO & 5 & $0,19 \%$ & \\
\hline Total & & 82 Títulos & 1.752 & $66,72 \%$ & \\
\hline
\end{tabular}

Fonte: Elaborada pelo autor com dados da WoS Core Collection.

Tabela 110 - Quantidade de publicações citadas pelo Docente 12 distribuídas pelas Zonas de Bradford

\begin{tabular}{lcccc}
\hline Zonas de Bradford & \multicolumn{4}{c}{ Total de Publicações\% PublicaçõesTotal de Citações\% Citações } \\
\hline Zona 1 & 11 & $1,50 \%$ & 877 & $33,40 \%$ \\
Zona 2 & 71 & $9,71 \%$ & 875 & $33,32 \%$ \\
Zona 3 & 649 & $88,78 \%$ & 874 & $33,28 \%$ \\
\hline \hline Total & $\mathbf{7 3 1}$ & $\mathbf{1 0 0 , 0 0 \%}$ & $\mathbf{2 . 6 2 6}$ & $\mathbf{1 0 0 , 0 0 \%}$ \\
\hline
\end{tabular}

Fonte: Elaborada pelo autor com dados da WoS Core Collection.

Tais dados permitem ainda analisar a relação de onde se publica com o que se cita. A Tabela 111 nos apresenta que dos 20 periódicos nos quais foram publicados os 41 artigos do Docente 12 os dois primeiros com maior número de publicações estão presentes na Zona 01, sendo que o primeiro corresponde à primeira publicação mais referenciada e o segundo, à terceira. Dos demais, três pertencem à Zona 1, sete à Zona 2, seis à Zona 3 e dois não foram citados.

Durante a entrevista quando perguntado sobre as publicações mais importantes do seu campo de atuação o Docente 12 indicou dois de abrangência internacional o Gondwana Research e o Precambrian Research, e com abrangência regional o Journal of South American Earth Sciences. Todos os três fazem parte dos periódicos nos quais o docente mais publicou e citou. 
Tabela 111 - Lista de periódicos nos quais o Docente 12 publicou seus artigos com indicação das Zonas de Bradford

\begin{tabular}{lccc}
\hline Título do Periódico & $\begin{array}{c}\text { Total de } \\
\text { Artigos }\end{array}$ & $\begin{array}{c}\text { \% Total de } \\
\text { Artigos }\end{array}$ & $\begin{array}{c}\text { Zonas de } \\
\text { Bradford }\end{array}$ \\
\hline PRECAMBRIAN RESEARCH & 6 & $14,63 \%$ & 1 \\
JOURNAL OF SOUTH AMERICAN EARTH & 6 & $14,63 \%$ & 1 \\
SCIENCES & 5 & $12,20 \%$ & 2 \\
BRAZILIAN JOURNAL OF GEOLOGY & 5 & $12,20 \%$ & 1 \\
GONDWANA RESEARCH & 3 & $7,32 \%$ & 2 \\
TERRA NOVA & 2 & $4,88 \%$ & Não citado \\
QUIMICA NOVA & 1 & $2,44 \%$ & 3 \\
ATMOSPHERIC RESEARCH & 1 & $2,44 \%$ & 2 \\
TECTONOPHYSICS & 1 & $2,44 \%$ & 2 \\
LITHOS & 1 & $2,44 \%$ & 2 \\
EPISODES & 1 & $2,44 \%$ & Não citado \\
JOURNAL DE PHYSIQUE IV & 1 & $2,44 \%$ & 3 \\
ANALYTICAL CHEMISTRY & 1 & $2,44 \%$ & 1 \\
CHEMICAL GEOLOGY & 1 & $2,44 \%$ & 3 \\
JOURNAL OF AFRICAN EARTH SCIENCES & 1 & $2,44 \%$ & 3 \\
ORE GEOLOGY REVIEWS & 1 & $2,44 \%$ & 2 \\
ATMOSPHERIC CHEMISTRY AND PHYSICS & 1 & $2,44 \%$ & 1 \\
\hline EARTH AND PLANETARY SCIENCE LETTERS & 1 & $2,44 \%$ & 3 \\
QUATERNARY RESEARCH & 1 & $2,44 \%$ & 2 \\
INTERNATIONAL GEOLOGY REVIEW & 1 & $2,44 \%$ & 3 \\
\hline HOLOCENE & 41 & $\mathbf{1 0 0 , 0 0 \%}$ & \\
\hline \hline Total Geral & 1 & \\
\hline FOnte: ElabOraA PelO autOr COM dadOS & 1 & \\
\hline
\end{tabular}

Fonte: Elaborada pelo autor com dados da WoS Core Collection.

A Tabela 112 apresenta a idade das referências citadas pelo Docente 12 de acordo com o ano de publicação de cada um de seus artigos. A maior concentração encontra-se em referências de 0 a 5 anos, com 29,28\% e nas faixas de 6 a 10 anos e 11 a 20 , que somadas correspondem a $51,37 \%$. Somando essas três faixas tem-se $80,65 \%$ do total geral de citações de referências com até 20 anos. 
Tabela 112 - Idade das Referências citadas nos artigos do Docente 12

\begin{tabular}{|cccc}
\hline Idade das Referências & & Total de Citações & \% Citações \\
\hline $0-5$ & 769 & $29,28 \%$ \\
& $6-10$ & 651 & $24,79 \%$ \\
& $11-20$ & 698 & $26,58 \%$ \\
& $21-30$ & 315 & $12,00 \%$ \\
& $31-40$ & 117 & $4,46 \%$ \\
& $41-50$ & 45 & $1,71 \%$ \\
& +50 & 28 & $1,07 \%$ \\
\hline \hline Total & Sem Data & 3 & $0,11 \%$ \\
\hline Fonte: Elaborada pelo & $\mathbf{2 . 6 2 6}$ & $\mathbf{1 0 0 , 0 0 \%}$ \\
\hline
\end{tabular}

Fonte: Elaborada pelo autor com dados da WoS Core Collection.

\section{- Informações adicionais}

O Docente 12 tem um perfil de publicação que se encontra em processo de internacionalização, quase internacionalizado. Isso se refletiu ao longo de quase todos os itens analisados em seu Perfil Bibliométrico.

Talvez o item que mereça um fortalecimento seja o de colaboração internacional, uma vez que as que foram identificadas no Perfil tiveram baixo impacto. Nessa mesma linha, somente duas agências de fomento estrangeiras apoiaram as pesquisas do docente em apenas dois artigos publicados e somente um deles obteve um impacto normalizado maior que média esperada.

Os dados apresentados corroboraram a visão do docente demonstrada em sua entrevista, de que seu perfil de publicar internacionalmente e em periódicos de impacto é parte da sua cultura acadêmica e científica.

De fato, o docente demonstra total conhecimento do fluxo da comunicação científica da sua área, selecionando os veículos mais adequados para a publicação dos resultados de suas pesquisas.

Quanto às avaliações o docente também demonstrou estar de acordo com os processos e não se sente pressionado pelos órgãos avaliadores, considerando natural e parte do seu processo pessoal de formação e perfil profissional. 


\section{G. DOCENTE 14}

O Docente 14, conforme apresentado no Quadro 1, obteve um nível de publicação 4 no primeiro subperíodo de ciclos de avaliação da CAPES (2001-2009), com um percentual de publicação em periódicos domésticos de $78,57 \%$. No segundo subperíodo (2010-2016) seu nível de publicação passou para 5, com um percentual de $80 \%$ de publicação em periódicos domésticos. Sua transição seguiu em direção oposta à maioria dos docentes, pois retrocedeu um nível no sentido contrário à internacionalização, resultando num Status Final de extremo-nacionalizado.

Baseada nos dados coletados no Banco Dedalus, a Tabela 113 apresenta a distribuição da produção intelectual do Docente 14 por tipo de publicação.

A produção do Docente 14 possui maior concentração em trabalhos de eventos, totalizando $64,65 \%$ e considerando-se somente a publicação em artigos de periódicos, verifica-se que o docente possui um índice de $28,28 \%$, desse montante apenas $21,43 \%$ foram em periódicos estrangeiros.

Tabela 113 - Produção Intelectual do Docente 14 registrada no Dedalus distribuída por tipo de publicação

\begin{tabular}{lcccccc}
\hline \multirow{2}{*}{ Tipo de Publicação / Ciclo de Avaliação } & \multicolumn{2}{c}{ Doméstico } & \multicolumn{3}{c}{ Estrangeiro } & Total \\
& Docs & \% Docs & Docs & \% Docs & \\
\hline ARTIGO DE PERIODICO & 22 & $78,57 \%$ & 6 & $21,43 \%$ & 28 \\
PARTE DE MONOGRAFIA/LIVRO & 5 & $71,43 \%$ & 2 & $28,57 \%$ & 7 \\
TRABALHO DE EVENTO & 34 & $91,89 \%$ & 3 & $8,11 \%$ & 37 \\
TRABALHO DE EVENTO-RESUMO & 23 & $85,19 \%$ & 4 & $14,81 \%$ & 27 \\
\hline \hline Total & $\mathbf{8 4}$ & $\mathbf{8 4 , 8 5 \%}$ & $\mathbf{1 5}$ & $\mathbf{1 5 , 1 5 \%}$ & $\mathbf{9 9}$ \\
\hline
\end{tabular}

Fonte: Elaborada pelo autor com dados do Dedalus.

Em relação à produção científica do Docente 14 indexada na WoS Core Collection, a Tabela 114 traz os dados referentes aos artigos publicados, distribuídos por periódico. Os periódicos com maior número de publicação, duas cada um, foram o Química Nova (Categorias do JCR: Chemistry e Multidisciplinary; FI de 0,646; Categoria SJR: Chemistry; SJR de 0,255), Journal of Radioanalytical and Nuclear Chemistry (Categorias do JCR: Chemistry: Analytical, Chemistry: Inorganic \& Nuclear e Nuclear Science \& Technology; FI de 1,181; Categorias SJR: Chemistry, Energy, Environmental Science e Medicine; SJR de 0,47) e Science of the Total Environment (Categoria do JCR: 
Environmental Sciences; FI de 4,610; Categoria SJR: Environmental Science; SJR de 1,546). Os três periódicos juntos correspondem a $75 \%$ do total de artigos publicados.

Tabela 114 - Artigos do Docente 14 indexados na WoS Core Collection distribuídos por título de periódico

\begin{tabular}{lcc}
\hline Periódicos & Artigos & $\%$ Artigos \\
\hline JOURNAL OF RADIOANALYTICAL AND NUCLEAR CHEMISTRY & 2 & $\mathbf{2 5 , 0 0 \%}$ \\
\hline QUIMICA NOVA & 2 & $\mathbf{2 5 , 0 0 \%}$ \\
\hline SCIENCE OF THE TOTAL ENVIRONMENT & 2 & $\mathbf{2 5 , 0 0 \%}$ \\
\hline ANAIS DA ACADEMIA BRASILEIRA DE CIENCIAS & 1 & $12,50 \%$ \\
\hline INTERNATIONAL JOURNAL OF PHYTOREMEDIATION & 1 & $\mathbf{1 2 , 5 0 \%}$ \\
\hline \hline Total & $\mathbf{8}$ & $\mathbf{1 0 0 , 0 0 \%}$ \\
\hline
\end{tabular}

Fonte: Elaborada pelo autor com dados da WoS Core Collection.

A seguir apresentam-se os dados de acordo com o Perfil Bibliométrico adaptado da proposta de Gorraiz, Wieland \& Gumpenberger (2016).

- Análise de coautorias

A Tabela 115 apresenta os dados de coautoria do Docente 14, nos quais é possível identificar que a maior concentração de publicações encontra-se em artigos com 3 a 7 autores. A informação é complementada pela Tabela 116 que apresenta a posição do docente nos artigos, demonstrando dos oito artigos publicados em $50 \%$ deles o docente assume a última posição da autoria e nos outros $50 \%$ uma posição central, o que corrobora seu posicionamento apresentado na entrevista, de conceder a posição de primeiro autor aos seus orientandos de pós-graduação, para que estes possam construir seus currículos.

Tabela 115 - Quantidade de autores nos artigos com participação do Docente 14

\begin{tabular}{cccc}
\hline Quantidade de Autores & Total de Artigos & \% Artigos \\
\hline 2 & 1 & $12,50 \%$ \\
3 & 2 & $25,00 \%$ \\
6 & 2 & $25,00 \%$ \\
& 7 & 2 & $25,00 \%$ \\
& 8 & 1 & $12,50 \%$ \\
\hline \hline Total & $\mathbf{8}$ & $\mathbf{1 0 0 , 0 0 \%}$
\end{tabular}

Fonte: Elaborada pelo autor com dados da WoS Core Collection. 
Tabela 116 - Artigos distribuídos por quantidade de autores e posição na autoria do Docente 14 nos artigos em que participa

\begin{tabular}{lcccc}
\multirow{2}{*}{ Quantidade de Autores } & \multicolumn{2}{c}{ Posição na Autoria } & Total \\
& Meio & Último & \\
\hline 2 & & 1 & 1 \\
3 & 1 & 1 & 2 \\
6 ou mais & 3 & 2 & 5 \\
\hline \hline Total & 4 & 4 & 8 \\
\hline
\end{tabular}

Fonte: Elaborada pelo autor com dados da WoS Core Collection.

- Análise da colaboração

Quanto à colaboração na sua produção científica a Tabela 117 demonstra que 75\% dos artigos do Docente 14 foram publicados somente com coautores brasileiros. Em apenas dois artigos houve colaboração com mais de um país além do Brasil.

Tabela 117 - Quantidade de países dos autores que publicaram nos artigos com participação do Docente 14

\begin{tabular}{rrcc}
\hline Quantidade de Países & Total de Artigos & \% Artigos \\
\hline & 1 & 6 & $75,00 \%$ \\
& 2 & 1 & $12,50 \%$ \\
\hline \hline Total & 1 & $12,50 \%$ \\
\hline
\end{tabular}

Fonte: Elaborada pelo autor com dados da WoS Core Collection.

Na Tabela 118 podem-se identificar os países colaboradores. Ao todo foram três países que colaboraram com o docente, França, Inglaterra e Rússia, porém somente uma vez cada.

Tabela 118 - Países dos autores que publicaram nos artigos com participação do Docente 14

\begin{tabular}{lcc}
\hline Países & Total de Artigos & $\%$ Artigos \\
\hline Brasil & 6 & $75,00 \%$ \\
França & 1 & $12,50 \%$ \\
Inglaterra & 1 & $12,50 \%$ \\
Russia & 1 & $12,50 \%$ \\
\hline \hline Total & $\mathbf{8}$ & --- \\
\hline
\end{tabular}

Fonte: Elaborada pelo autor com dados da WoS Core Collection. 
A Tabela 119 traz a quantidade de instituições dos coautores desses artigos destacando-se uma maior concentração naqueles com três instituições (duas além da USP) com 37,50\%; e aqueles com uma (USP) corresponderam a $25 \%$.

Tabela 119 - Quantidade de instituições dos autores que publicaram nos artigos com participação do Docente 14

\begin{tabular}{lccc}
\hline Quantidade de Instituições & Total de Artigos & \% Artigos \\
\hline 1 & 2 & $25,00 \%$ \\
& 2 & 1 & $12,50 \%$ \\
& 3 & 3 & $37,50 \%$ \\
& 4 & 1 & $12,50 \%$ \\
\hline \hline Total & 1 & 1 & $12,50 \%$ \\
\hline
\end{tabular}

Fonte: Elaborada pelo autor com dados da WoS Core Collection apresentados via Incites.

Para completar a análise, a Tabela 120 apresenta as instituições e seus respectivos países, permitindo observar que a colaboração se distribui em um conjunto significativo de instituições, com redundância apenas com três instituições brasileiras.

Tabela 120 - Distribuição das Instituições por países dos autores que publicaram com o Docente 14

\begin{tabular}{ll}
\hline País/Instituição & Artigos \\
\hline Brasil & \\
Comissao Nacional de Energia Nuclear (CNEN) & 4 \\
Instituto de Pesquisas Energeticas e Nucleares (IPEN) & 4 \\
Universidade Estadual de Campinas & 2 \\
Universidade Estadual de Santa Cruz & 1 \\
Universidade Estadual Paulista & 1 \\
Universidade Federal de Mato Grosso do Sul & 1 \\
França & \\
Aix-Marseille Universite & 1 \\
Centre National de la Recherche Scientifique (CNRS) & 1 \\
College de France & 1 \\
Institut de Recherche pour le Developpement (IRD) & 1 \\
Institut National de la Recherche Agronomique (INRA) & 1 \\
PSL Research University Paris (ComUE) & 1 \\
Inglaterra & \\
NERC Centre for Ecology \& Hydrology & 1 \\
NERC Natural Environment Research Council & 1 \\
University of Reading & 1 \\
Russia & \\
Russian Academy of Sciences & 1 \\
\hline \hline
\end{tabular}

Fonte: Incites com dados da WoS Core Collection. 
- Análise dos financiamentos de pesquisa recebidos

A presente análise verifica quais foram as Agências de Fomento que apoiaram as pesquisas realizadas pelo Docente 14 . Cabe destacar que a WoS somente padronizou os dados de Agências de Fomento de 2008 para frente e, portanto, dos 8 artigos do Docente 14 indexados na WoS somente 2 puderam ser analisados, uma vez que os outros 6 são anteriores a esse período.

A Tabela 121 apresenta as informações das agências de fomento que apoiaram as pesquisas publicadas pelo Docente 14 . Verifica-se que somente agências nacionais financiaram as pesquisas do docente e quanto ao impacto (Citações / Artigo) somente o artigo de 2011 recebeu citações, além disso, nenhum dos dois atingiu a média esperada $(1,0)$ para o impacto normalizado.

Tabela 121 - Agências de Fomento que apoiaram as pesquisas que geraram as publicações com participação do Docente 14, distribuídas por ano

\begin{tabular}{lcccc}
\hline Agências de Fomento por Ano & Artigos & Citações & Citações/Art. Impacto Normalizado \\
\hline 2011 & 1 & 10 & 10 & 0,42 \\
$\quad$ FAPESP & 1 & 10 & 10 & 0,42 \\
$\quad$ CNPq & & & & 0 \\
2012 & 1 & 0 & 0 & 0 \\
\hline CNPq & & & \\
\hline \hline
\end{tabular}

Fonte: Incites com dados da WoS Core Collection

\section{- Análise de visibilidade da produção científica}

No que diz respeito à visibilidade da produção científica do docente, esta é medida levando em conta a quantidade de artigos registrada no Dedalus (28) e quantidade de artigos indexada na WoS (8), assim o percentual do Docente 14 é de $28,57 \%$.

Outro fator de análise é o percentual de artigos presentes em periódicos de impacto. A Tabela 122 apresenta os artigos do docente publicados em periódicos indexados na WoS Core Collection, distribuídos segundo Ciclos de Avaliação da CAPES e percentual publicado em periódicos do 1 으 Quartil do FI/JCR. Dos oito artigos do Docente 14 indexados na WoS Core Collection 25\% estão presentes no 10 Quartil. 
Tabela 122 - Artigos publicados pelo Docente 14 distribuídos por Ciclos de Avaliação da CAPES e indexados em periódicos do 1 으 Quartil do $\mathrm{Fl} / \mathrm{JCR}$

\begin{tabular}{lcc}
\hline Ciclos de Avaliação CAPES & Total de Artigos & \% Artigos no 10. Quartil \\
\hline Trienal 2004 & 1 & $100,00 \%$ \\
Trienal 2007 & 2 & $50,00 \%$ \\
Trienal 2010 & 2 & $0,00 \%$ \\
Trienal 2013 & 3 & $0,00 \%$ \\
\hline \hline Total & $\mathbf{8}$ & $\mathbf{2 5 , 0 0 \%}$ \\
\hline
\end{tabular}

Fonte: Incites com dados da WoS Core Collection

Analisando-se a publicação científica relacionada aos instrumentos de Avaliação da CAPES, a Tabela 123 apresenta a quantidade de artigos publicados distribuídos pelos Ciclos de Avaliação e classificação nos estratos Qualis da área de avaliação das Geociências.

Verifica-se que $50 \%$ dos artigos do Docente 14 encontram-se no estrato B1 e os demais estão distribuídos entre $A, A 2, B 3$, além de um artigo em um periódico não avaliado pela área.

O docente demonstra uma evolução modesta, com o crescimento de um artigo aproximadamente por ciclo.

Tabela 123 - Artigos publicados pelo Docente 14 distribuídos por Ciclos de Avaliação da CAPES e classificação do periódico nos estratos Qualis da área de avaliação das Geociências

\begin{tabular}{|c|c|c|c|c|c|c|}
\hline \multirow{2}{*}{ Periódicos e Ciclo de Avaliação } & \multicolumn{5}{|c|}{ Estratos Qualis } & \multirow{2}{*}{ Tota } \\
\hline & $\mathbf{A}$ & A2 & B1 & B3 & -- & \\
\hline 2001-2003 - TRIENAL 2004 & 1 & & & & & 1 \\
\hline SCIENCE OF THE TOTAL ENVIRONMENT & 1 & & & & & 1 \\
\hline 2004-2006 - TRIENAL 2007 & & 1 & & 1 & & 2 \\
\hline JOURNAL OF RADIOANALYTICAL AND NUCLEAR CHEMISTRY & & & & 1 & & 1 \\
\hline SCIENCE OF THE TOTAL ENVIRONMENT & & 1 & & & & 1 \\
\hline 2007-2009 - TRIENAL 2010 & & & 2 & & & 2 \\
\hline JOURNAL OF RADIOANALYTICAL AND NUCLEAR CHEMISTRY & & & 1 & & & 1 \\
\hline QUIMICA NOVA & & & 1 & & & 1 \\
\hline 2010-2012 - TRIENAL 2013 & & & 2 & & 1 & 3 \\
\hline ANAIS DA ACADEMIA BRASILEIRA DE CIENCIAS & & & 1 & & & 1 \\
\hline INTERNATIONAL JOURNAL OF PHYTOREMEDIATION & & & & & 1 & 1 \\
\hline QUIMICA NOVA & & & 1 & & & 1 \\
\hline Total & 1 & 1 & 4 & 1 & 1 & 8 \\
\hline
\end{tabular}

Fonte: Elaborada pelo autor com dados da WoS Core Collection e Qualis/CAPES. 
De forma a aprofundar a análise sobre as colaborações e a visibilidade das publicações, a Tabela 124 apresenta as instituições que colaboraram com o Docente 14 em dois ou mais artigos, distribuídas entre os Ciclos de Avaliação da CAPES, com a indicação do percentual dos artigos no 1으 Quartil do JCR.

Duas instituições se adequam à característica exigida e somente no ciclo de avaliação Trienal de 2007. Cada uma participou com dois artigos e tiveram um deles publicado em um periódico do 1으 Quartil.

Tabela 124 - Artigos publicados pelo Docente 14 distribuídos segundo instituições que colaboraram duas ou mais vezes e Ciclos de Avaliação da CAPES, com indicação do percentual de artigos no 10 Quartil do JCR

\begin{tabular}{lcc}
\hline Ciclos & Trienal 2007 & Total \\
\hline Comissao Nacional de Energia Nuclear (CNEN) & 2 & 2 \\
$\quad \begin{array}{l}\text { Artigos } \\
\text { \% Artigos no 10. Quartil }\end{array}$ & $50,00 \%$ & $50,00 \%$ \\
Instituto de Pesquisas Energeticas e Nucleares (IPEN) & & \\
$\quad$ Artigos & 2 & 2 \\
$\quad \%$ Artigos no 10. Quartil & $50,00 \%$ & $50,00 \%$ \\
\hline \hline Total Artigos & $\mathbf{4}$ & $\mathbf{4}$ \\
\hline \hline Total \% Arts. no 10. Quartil & $\mathbf{5 0 , 0 0 \%}$ & $\mathbf{5 0 , 0 0 \%}$
\end{tabular}

Fonte: Elaborada pelo autor com dados da WoS Core Collection e Qualis/CAPES.

\section{- Análise de impacto da produção científica}

Os critérios para a análise de impacto compreendem a análise das citações recebidas e, do total de artigos indexados, a quantidade destes nos Top 10\%. Nenhum dos artigos do Docente 14 se encontra presente no Top 10\%, portanto decidiu-se basear a análise no Impacto Normalizado.

A Tabela 125 traz os dados de total de artigos, percentual de artigos citados, total de citações, citações por artigo e o Impacto Normalizado. Verifica-se que nos anos de 2001 e 2005 o Docente 14 atingiu ou superou a média esperada para a área $(1,0)$ no impacto normalizado e nesses mesmos anos o docente obteve seus mais altos índices de citações por artigo. 
Tabela 125 - Impacto dos artigos do Docente 14 distribuídos por ano de publicação

\begin{tabular}{cccccc}
\hline $\begin{array}{c}\text { Ano de } \\
\text { Publicação }\end{array}$ & $\begin{array}{c}\text { Total de } \\
\text { Art. }\end{array}$ & $\begin{array}{c}\text { \% Art. } \\
\text { Citados }\end{array}$ & Citações & $\begin{array}{c}\text { Impacto da } \\
\text { Citação }\end{array}$ & $\begin{array}{c}\text { Impacto } \\
\text { Normalizado }\end{array}$ \\
\hline 2001 & 1 & $100,00 \%$ & 34 & 34,0 & 1,0 \\
2005 & 2 & $100,00 \%$ & 72 & 36,0 & 1,2 \\
2008 & 1 & $100,00 \%$ & 9 & 9,0 & 0,3 \\
2009 & 1 & $100,00 \%$ & 12 & 12,0 & 0,9 \\
2011 & 1 & $100,00 \%$ & 10 & 10,0 & 0,4 \\
2012 & 2 & $50,00 \%$ & 5 & 2,5 & 0,1 \\
\hline \hline Total & $\mathbf{8}$ & $\mathbf{9 1 , 6 7 \%}$ & $\mathbf{1 4 2}$ & --- & --- \\
\hline
\end{tabular}

Fonte: Incites com dados da WoS Core Collection

- Análise das referências utilizadas

O último item a se analisar são as referências utilizadas pelo Docente na redação de seus artigos. Ao todo o Docente 14 utilizou 142 fontes bibliográficas diferentes, citando-as 283 vezes em seus oito artigos, gerando uma média de 35,37 referências por trabalho.

Utilizando-se as Zonas de Bradford para analisar as principais publicações citadas nos artigos, pôde-se verificar pelas Tabelas 126 e 127 que, das 283 referências utilizadas, o primeiro terço delas (Zona 1 - com 95 referências) estão concentradas em 16 periódicos que correspondem a 11,27\% das publicações; já no segundo terço (Zona 2 com 94 referências) em 47 publicações, já possuindo uma maior variedade de tipologias de documentos e correspondendo a 33,10\%. O terceiro terço é a zona de maior dispersão com um total de 94 publicações, sendo a maioria delas com baixa frequência de citação (não sendo, portanto, apresentadas na tabela).

Essas 63 publicações somadas correspondem a $44,37 \%$ do total, que, por conseguinte, correspondem a $66,78 \%$ de todas as referências citadas. 
Tabela 126 - Lista de Referências utilizadas nos artigos do Docente 14 distribuídas pelas Zonas 1 e 2 de Bradford

\begin{tabular}{|c|c|c|c|c|}
\hline$\#$ & Publicações & Citações & \% Citações & $\begin{array}{l}\text { (continua } \\
\text { Zona de } \\
\text { Bradford }\end{array}$ \\
\hline 1 & SCI TOTAL ENVIRON & 17 & $6,01 \%$ & \multirow{16}{*}{ Zona 1} \\
\hline 2 & ENVIRON POLLUT & 16 & $5,65 \%$ & \\
\hline 3 & ENVIRON SCI TECHNOL & 12 & $4,24 \%$ & \\
\hline 4 & GEODERMA & 6 & $2,12 \%$ & \\
\hline 5 & $\begin{array}{l}\text { ANTHROPOGENIC PLATINUM-GROUP ELEMENT } \\
\text { EMISSIONS }\end{array}$ & 5 & $1,77 \%$ & \\
\hline 6 & THESIS U SAO PAULO & 5 & $1,77 \%$ & \\
\hline 7 & CAN J FISH AQUAT SCI & 4 & $1,41 \%$ & \\
\hline 8 & MICROBIOLOGY+ & 4 & $1,41 \%$ & \\
\hline 9 & AN ACAD BRAS CIENC & 4 & $1,41 \%$ & \\
\hline 10 & J ENVIRON QUAL & 4 & $1,41 \%$ & \\
\hline 11 & HYDROBIOLOGIA & 4 & $1,41 \%$ & \\
\hline 12 & B ENVIRON CONTAM TOX & 3 & $1,06 \%$ & \\
\hline 13 & CHEMOSPHERE & 3 & $1,06 \%$ & \\
\hline 14 & STAND METH EX WAT WA & 3 & $1,06 \%$ & \\
\hline 15 & SOIL SCl & 3 & $1,06 \%$ & \\
\hline 16 & FEMS MICROBIOL ECOL & 2 & $0,71 \%$ & \\
\hline 1 & BRAZ ARCH BIOL TECHN & 2 & $0,71 \%$ & \multirow{28}{*}{ Zona 2} \\
\hline 2 & EARTH-SCI REV & 2 & $0,71 \%$ & \\
\hline 3 & REV CETESB & 2 & $0,71 \%$ & \\
\hline 4 & ANU I GEOC & 2 & $0,71 \%$ & \\
\hline 5 & REV BRASILEIRA GEOCI & 2 & $0,71 \%$ & \\
\hline 6 & ENVIRON SCI POLLUT R & 2 & $0,71 \%$ & \\
\hline 7 & REV BRAS ZOOL & 2 & $0,71 \%$ & \\
\hline 8 & CHEM ECOL & 2 & $0,71 \%$ & \\
\hline 9 & REV BRAS BIOL & 2 & $0,71 \%$ & \\
\hline 10 & B DNPM DGM & 2 & $0,71 \%$ & \\
\hline 11 & RES 9 C EC BRAS SAO & 2 & $0,71 \%$ & \\
\hline 12 & GEOCIENCIAS & 2 & $0,71 \%$ & \\
\hline 13 & REL FIN & 2 & $0,71 \%$ & \\
\hline 14 & ENVIRON TOXICOL CHEM & 2 & $0,71 \%$ & \\
\hline 15 & QUIM NOVA & 2 & $0,71 \%$ & \\
\hline 16 & ENG SANIT AMBIENT & 2 & $0,71 \%$ & \\
\hline 17 & QUATERN INT & 2 & $0,71 \%$ & \\
\hline 18 & CLAYS CLAY MINERALS & 2 & $0,71 \%$ & \\
\hline 19 & PHYSIS & 2 & $0,71 \%$ & \\
\hline 20 & BRAZILIAN JOURNAL OF BIOLOGY & 2 & $0,71 \%$ & \\
\hline 21 & PANTANAL MATO GROSSO & 2 & $0,71 \%$ & \\
\hline 22 & B LAB HIDROBIOL & 2 & $0,71 \%$ & \\
\hline 23 & P NATL ACAD SCI USA & 2 & $0,71 \%$ & \\
\hline 24 & ARCH HYDROBIOL & 2 & $0,71 \%$ & \\
\hline 25 & NEW PHYTOL & 2 & $0,71 \%$ & \\
\hline 26 & REV GEOC UNESP & 2 & $0,71 \%$ & \\
\hline 27 & MITT INT VER LIMNOL & 2 & $0,71 \%$ & \\
\hline 28 & FUNDAMENTOS LIMNOLOG & 2 & $0,71 \%$ & \\
\hline
\end{tabular}


Tabela 126 - Lista de Referências utilizadas nos artigos do Docente 14 distribuídas pelas Zonas 1 e 2 de Bradford

\begin{tabular}{|c|c|c|c|c|}
\hline$\#$ & Publicações & Citações & \% Citações & $\begin{array}{l}\text { Zona de } \\
\text { Bradford }\end{array}$ \\
\hline 29 & MICROBIOL-SGM & 2 & $0,71 \%$ & \multirow{19}{*}{ Zona 2} \\
\hline 30 & EXTREMOPHILES & 2 & $0,71 \%$ & \\
\hline 31 & VERH INT VEREIN LIMN & 2 & $0,71 \%$ & \\
\hline 32 & TECTONICS & 2 & $0,71 \%$ & \\
\hline 33 & LIMNOL OCEANOGR & 2 & $0,71 \%$ & \\
\hline 34 & WATER AIR SOIL POLL & 2 & $0,71 \%$ & \\
\hline 35 & LAUDO PERICIAL & 2 & $0,71 \%$ & \\
\hline 36 & ECOLOGY & 2 & $0,71 \%$ & \\
\hline 37 & J GEOCHEM EXPLOR & 2 & $0,71 \%$ & \\
\hline 38 & DIAGN IMPR SAL ALK S & 2 & $0,71 \%$ & \\
\hline 39 & WATER RESOUR RES & 2 & $0,71 \%$ & \\
\hline 40 & S REC NAT SOC PANT C & 2 & $0,71 \%$ & \\
\hline 41 & INT REV GES HYDROBIO & 2 & $0,71 \%$ & \\
\hline 42 & SSSA MISC PUBLICAT & 2 & $0,71 \%$ & \\
\hline 43 & INT J REMOTE SENS & 2 & $0,71 \%$ & \\
\hline 44 & BRAZILIAN J AGR RES & 2 & $0,71 \%$ & \\
\hline 45 & ADV TR SUB & 2 & $0,71 \%$ & \\
\hline 46 & BIOMONITORING TRACE & 2 & $0,71 \%$ & \\
\hline 47 & 45 C BRAS GEOL BEL B & 2 & $0,71 \%$ & \\
\hline $\begin{array}{l}\text { Tot } \\
\text { al }\end{array}$ & 63 Títulos & 189 & $66,78 \%$ & \\
\hline
\end{tabular}

Fonte: Elaborada pelo autor com dados da WoS Core Collection.

Tabela 127 - Quantidade de publicações citadas pelo Docente 14 distribuídas pelas Zonas de Bradford

\begin{tabular}{lcccc}
\hline Zonas de Bradford & Total de Publicações & \% Publicações & Total de Citações & \% Citações \\
\hline Zona 1 & 16 & $11,27 \%$ & 95 & $33,57 \%$ \\
\hline Zona 2 & 47 & $33,10 \%$ & 94 & $33,22 \%$ \\
\hline Zona 3 & $\mathbf{7 9}$ & $55,63 \%$ & 94 & $33,22 \%$ \\
\hline \hline Total & $\mathbf{1 4 2}$ & $\mathbf{1 0 0 , 0 0 \%}$ & $\mathbf{2 8 3}$ & $\mathbf{1 0 0 , 0 0 \%}$ \\
\hline
\end{tabular}

Fonte: Elaborada pelo autor com dados da WoS Core Collection.

Tais dados permitem ainda analisar a relação de onde se publica com o que se cita. A Tabela 128 nos apresenta que dos cinco periódicos nos quais foram publicados os oito artigos do Docente 14 apenas um dos três primeiros com maior número de publicações está presente na Zona 01 (Science of the Total Environment). Dos quatro restantes, um pertence à Zona 1, um à Zona 2, um à Zona 3 e um não foi citado. 
Durante a entrevista quando perguntado sobre as publicações mais importantes do seu campo de atuação o Docente 14 citou os periódicos Anais da Academia Brasileira de Ciências e Química Nova, que se encontram respectivamente na Zona 1 e Zona 2.

Tabela 128 - Lista de periódicos nos quais o Docente 14 publicou seus artigos com indicação das Zonas de Bradford

\begin{tabular}{lccc}
\hline Título do Periódico & $\begin{array}{c}\text { Total de } \\
\text { Artigos }\end{array}$ & $\begin{array}{c}\text { \% Total de } \\
\text { Artigos }\end{array}$ & $\begin{array}{c}\text { Zonas de } \\
\text { Bradford }\end{array}$ \\
\hline QUIMICA NOVA & 2 & $25,00 \%$ & 2 \\
SCIENCE OF THE TOTAL ENVIRONMENT & 2 & $25,00 \%$ & 1 \\
JOURNAL OF RADIOANALYTICAL AND & 2 & $25,00 \%$ & 3 \\
NUCLEAR CHEMISTRY & 1 & $12,50 \%$ & 1 \\
ANAIS DA ACADEMIA BRASILEIRA DE CIENCIAS & 1 & $12,50 \%$ & Não citado \\
$\begin{array}{l}\text { INTERNATIONAL JOURNAL OF } \\
\text { PHYTOREMEDIATION }\end{array}$ & $\mathbf{8}$ & $\mathbf{1 0 0 , 0 0 \%}$ & \\
\hline \hline Total Geral &
\end{tabular}

Fonte: Elaborada pelo autor com dados da WoS Core Collection.

A Tabela 129 apresenta a idade das referências citadas pelo Docente 14 de acordo com o ano de publicação de cada um de seus artigos. A maior concentração encontra-se em referências na faixa de 0 a 5 anos, com 27,92\%, que somada às faixas de 6 a 10 e 11 a 20 correspondem a 76,33\% do total geral das referências com até 20 anos.

Tabela 129 - Idade das Referências citadas nos artigos do Docente 14

\begin{tabular}{cccc|}
\hline Idade das Referências & Total de Citações & \% Citações \\
\hline $0-5$ & 79 & $27,92 \%$ \\
$6-10$ & 71 & $25,09 \%$ \\
$11-20$ & 66 & $23,32 \%$ \\
$21-30$ & 41 & $14,49 \%$ \\
& $31-40$ & 14 & $4,95 \%$ \\
& $41-50$ & 4 & $1,41 \%$ \\
\hline \hline Total & +50 & 8 & $2,83 \%$ \\
\hline
\end{tabular}

Fonte: Elaborada pelo autor com dados da WoS Core Collection.

- Informações adicionais

Devido ao baixo índice de publicações indexadas na WoS, as análises realizadas no Perfil Bibliométrico não propiciaram análises mais aprofundadas. 
Entretanto, pôde-se constatar que o docente apresenta um perfil nacionalizado, o que corrobora suas afirmações durante a entrevista de que trabalha com temas muito regionais e que não está preocupado em publicar bastante.

O docente também deixa claro em sua entrevista que não possui interesse na visibilidade da sua pesquisa, mas sim na formação dos profissionais e inovações que redundem em melhorias sociais, industriais e tecnológicas.

E quanto aos processos de avaliação, comenta que pesquisas que geram melhoria social não geram impacto válido para a CAPES. Considera que é um trabalho dificultoso inserir a pesquisa de impacto social nos modelos rígidos de avaliação atuais, pois estes se baseiam na qualificação da revista ( $A 1, A 2, B 1, B 2$ e B3) em que o estudo foi publicado e não necessariamente esta é uma classificação justa para aquilo que está sendo publicado. E reitera que há trabalhos muito importantes que podem mudar uma técnica, porém estão publicados em periódicos de estratos mais baixos e, assim, os resultados dessa pesquisa não recebem a devida importância. 


\section{H. DOCENTE 15}

O Docente 15, conforme apresentado no Quadro 1, obteve um nível de publicação 4 no primeiro subperíodo de ciclos de avaliação da CAPES (2001-2009), com um percentual de publicação em periódicos domésticos de $66,67 \%$, porém cabe destacar que seu nível de produtividade nesse subperíodo foi baixo em decorrência de ter sido contratado durante o período do segundo ciclo, (Trienal 2007). Entretanto, no segundo subperíodo (2010-2016) seu nível de publicação se alterou e passou para 1, com um percentual de $12,12 \%$ de publicação em periódicos domésticos e com um aumento considerável da sua produtividade. Dessa forma, o docente teve uma transição de três níveis rumo à internacionalização, resultando num Status Final internacionalizado.

Baseada nos dados coletados no Banco Dedalus, a Tabela 130 apresenta a distribuição da produção intelectual do Docente 15 por tipo de publicação.

A maior concentração da produção do Docente 15 está registrada em eventos, correspondendo a $64,29 \%$ e considerando-se somente a publicação em artigos de periódicos sua produção corresponde a 32,14\%, com um percentual de publicação em periódicos estrangeiros de $83,33 \%$.

Tabela 130 - Produção Intelectual do Docente 15 registrada no Dedalus distribuída por tipo de publicação

\begin{tabular}{lccccc}
\hline \multirow{2}{*}{ Tipo de Publicação / Ciclo de Avaliação } & \multicolumn{2}{c}{ Doméstico } & \multicolumn{2}{c}{ Estrangeiro } & \multirow{2}{*}{ Total } \\
& Docs & \% Docs & Docs & $\%$ Docs & \\
\hline ARTIGO DE PERIODICO & 6 & $16,67 \%$ & 30 & $83,33 \%$ & 36 \\
ARTIGO DE PERIODICO-DEP/ENTR & 1 & $100,00 \%$ & 0 & $0,00 \%$ & 1 \\
\hline PARTE DE MONOGRAFIA/LIVRO & 2 & $66,67 \%$ & 1 & $33,33 \%$ & 3 \\
\hline TRABALHO DE EVENTO & 25 & $100,00 \%$ & 0 & $0,00 \%$ & 25 \\
\hline TRABALHO DE EVENTO-ANAIS PERIODICO & 0 & $0,00 \%$ & 1 & $100,00 \%$ & 1 \\
\hline TRABALHO DE EVENTO-RESUMO & 44 & $95,65 \%$ & 2 & $4,35 \%$ & 46 \\
\hline \hline Total & $\mathbf{7 8}$ & $\mathbf{6 9 , 6 4 \%}$ & $\mathbf{3 4}$ & $\mathbf{3 0 , 3 6 \%}$ & $\mathbf{1 1 2}$ \\
\hline
\end{tabular}

Fonte: Elaborada pelo autor com dados do Dedalus.

Em relação à produção científica do Docente 15 indexada na WoS Core Collection, a Tabela 131 traz os dados referentes aos artigos publicados, percebe-se uma 
grande dispersão de títulos de periódicos, sendo que os 31 artigos indexados foram publicados em 21 diferentes periódicos.

Os periódicos com maior número de publicação foram o Quaternary Geochronology (Categoria do JCR: Geography, Physical e Geosciences, Multidisciplinary; FI de 3,440; Categoria SJR: Earth and Planetary Sciences: miscellaneous; Geology; e Stratigraphy; SJR de 1,972) e Sedimentary Geology (Categoria do JCR: Geology; FI de 2,575; Categoria SJR: Earth and Planetary Sciences: Geology; e Stratigraphy; SJR de 1,277) ambos com três artigos cada.

Tabela 131 - Artigos do Docente 15 indexados na WoS Core Collection distribuídos por título de periódico

\begin{tabular}{lcc}
\hline Periódicos & Artigos & \%Artigos \\
\hline QUATERNARY GEOCHRONOLOGY & 3 & $9,68 \%$ \\
\hline SEDIMENTARY GEOLOGY & 3 & $9,68 \%$ \\
\hline SCIENTIFIC DRILLING & 2 & $6,45 \%$ \\
\hline MARINE GEOLOGY & 2 & $6,45 \%$ \\
\hline GLOBAL CHANGE BIOLOGY & 2 & $6,45 \%$ \\
\hline RADIATION MEASUREMENTS & 2 & $6,45 \%$ \\
\hline BRAZILIAN JOURNAL OF GEOLOGY & 2 & $6,45 \%$ \\
\hline GEOMORPHOLOGY & 2 & $6,45 \%$ \\
\hline JOURNAL OF COASTAL RESEARCH & 1 & $3,23 \%$ \\
\hline INTERNATIONAL JOURNAL OF COAL GEOLOGY & 1 & $3,23 \%$ \\
\hline MARINE AND PETROLEUM GEOLOGY & 1 & $3,23 \%$ \\
\hline SCIENTIFIC REPORTS & 1 & $3,23 \%$ \\
\hline JOURNAL OF SOUTH AMERICAN EARTH SCIENCES & 1 & $3,23 \%$ \\
\hline CLIMATE OF THE PAST & 1 & $3,23 \%$ \\
\hline SEDIMENTOLOGY & 1 & $3,23 \%$ \\
\hline REVIEW OF PALAEOBOTANY AND PALYNOLOGY & 1 & $3,23 \%$ \\
\hline GEOCHIMICA ET COSMOCHIMICA ACTA & 1 & $3,23 \%$ \\
\hline ANAIS DA ACADEMIA BRASILEIRA DE CIENCIAS & 1 & $3,23 \%$ \\
\hline PLOS ONE & 1 & $3,23 \%$ \\
\hline QUATERNARY INTERNATIONAL & 1 & $3,23 \%$ \\
\hline QUATERNARY SCIENCE REVIEWS & $3,23 \%$ \\
\hline \hline TOtal & 1 & $\mathbf{1 0 0 , 0 0 \%}$ \\
\hline FOnt: EIADOFA PE aU & $\mathbf{3 1}$ & \\
\hline
\end{tabular}

Fonte: Elaborada pelo autor com dados da WoS Core Collection.

A seguir apresentam-se os dados de acordo com o Perfil Bibliométrico adaptado da proposta de Gorraiz, Wieland \& Gumpenberger (2016). 
- Análise de coautorias

A Tabela 132 apresenta os dados de coautoria do Docente 15, nos quais é possível identificar que a maior concentração de publicações encontra-se em artigos com 4, 6 e 7 autores. A informação é complementada pela Tabela 133 que apresenta a posição do docente nos artigos, demonstrando que em 64,52\% ele assumiu uma posição central, entretanto em $25,81 \%$ dos artigos ele foi o primeiro autor. Quanto à ordem dos autores nos artigos o docente comentou em sua entrevista que para ele o primeiro autor são os pós-doutorandos ou doutorandos e o segundo/terceiro são supervisores/orientadores, ou seja, são aqueles que efetivamente realizaram a redação do artigo. Os outros são os que participaram de partes específicas da pesquisa, como laboratório e campo. E às vezes o último é o líder do grupo.

Tabela 132 - Quantidade de autores nos artigos com participação do Docente 15

\begin{tabular}{cccc}
\hline Quantidade de Autores & Total de Artigos & \% Artigos \\
\hline 2 & 1 & 1 & $3,23 \%$ \\
& 4 & 5 & $3,23 \%$ \\
& 5 & 3 & $16,13 \%$ \\
& 6 & 6 & $9,68 \%$ \\
& 7 & 4 & $19,35 \%$ \\
& 8 & 3 & $12,90 \%$ \\
& 9 & 3 & $9,68 \%$ \\
& 11 & 2 & $9,68 \%$ \\
& 13 & 1 & $6,45 \%$ \\
& 14 & 1 & $3,23 \%$ \\
\hline \hline Total & 17 & 1 & $3,23 \%$ \\
\hline
\end{tabular}

Fonte: Elaborada pelo autor com dados da WoS Core Collection.

Tabela 133 - Artigos distribuídos por quantidade de autores e posição na autoria do Docente 15 nos artigos em que participa

\begin{tabular}{lcccc} 
& Quantidade de Autores & \multicolumn{2}{c}{ Posição na Autoria } & \\
& Primeiro & Meio & Último & Total \\
\hline 2 & & & 1 & 1 \\
3 & 1 & & & 1 \\
4 & 1 & 4 & & 5 \\
5 & & 3 & & 3 \\
6 ou mais & 6 & 13 & 2 & 21 \\
\hline \hline Total & 8 & 20 & 3 & 31 \\
\hline
\end{tabular}

Fonte: Elaborada pelo autor com dados da WoS Core Collection. 
- Análise da colaboração

A colaboração internacional, como demonstrado pela maioria dos docentes entrevistados é fundamental para obtenção de financiamentos e estabelecimento de redes de pesquisa multidisciplinares. Nesse sentido, a Tabela 134 mostra que a maior concentração dos artigos do docente encontra-se em artigos produzidos somente com colaboração nacional e com um país além do Brasil, ambas 12 artigos e correspondendo juntas a $77,42 \%$.

Tabela 134 - Quantidade de países dos autores que publicaram nos artigos com participação do Docente 15

\begin{tabular}{lccc}
\hline Quantidade de Países & & Total de Artigos & $\%$ Artigos \\
\hline & 1 & 12 & $38,71 \%$ \\
& 2 & 12 & $38,71 \%$ \\
& 3 & 3 & $9,68 \%$ \\
\hline \hline Total & 4 & 4 & $12,90 \%$ \\
\hline
\end{tabular}

Fonte: Elaborada pelo autor com dados da WoS Core Collection.

A Tabela 135 apresenta os países colaboradores, com destaque para os Estados Unidos com a maior participação em artigos, superando inclusive aqueles produzidos exclusivamente com colaboração nacional. Ao todo foram 11 países representados pelos coautores, dos quais cinco colaboraram mais de uma vez.

Tabela 135 - Países dos autores que publicaram nos artigos com participação do Docente 15

\begin{tabular}{lcc}
\hline Países & Total de Artigos & \% Artigos \\
\hline Alemanha & 4 & $12,90 \%$ \\
\hline Austrália & 2 & $6,45 \%$ \\
Brasil & 12 & $38,71 \%$ \\
\hline Canadá & 1 & $3,23 \%$ \\
Chile & 1 & $3,23 \%$ \\
China & 1 & $3,23 \%$ \\
Colômbia & 1 & $3,23 \%$ \\
Equador & 1 & $3,23 \%$ \\
Estados Unidos & 14 & $45,16 \%$ \\
\hline França & 2 & $6,45 \%$ \\
Suécia & 2 & $6,45 \%$ \\
Suíça & 1 & $3,23 \%$ \\
\hline \hline Total & 31 & --- \\
\hline Fonte: Elabra peloutor
\end{tabular}

Fonte: Elaborada pelo autor com dados da WoS Core Collection. 
Na Tabela 136 podemos verificar a quantidade de instituições dos autores desses artigos destacando-se uma maior concentração naqueles com duas $(25,81 \%)$ e três $(22,58 \%)$ instituições, demonstrando que o docente procura manter uma constante colaboração com várias instituições. Artigos produzidos somente com coautores da própria USP foram apenas três.

Tabela 136 - Quantidade de instituições dos autores que publicaram nos artigos com participação do Docente 15

\begin{tabular}{cccc}
\hline Quantidade de Instituições & Total de Artigos & \% Artigos \\
\hline 1 & 3 & $9,68 \%$ \\
& 2 & 8 & $25,81 \%$ \\
& 3 & 7 & $22,58 \%$ \\
& 4 & 5 & $16,13 \%$ \\
& 5 & 4 & $12,90 \%$ \\
& 6 & 1 & $3,23 \%$ \\
& 7 & 1 & $3,23 \%$ \\
\hline \hline Total & 11 & 1 & $3,23 \%$ \\
\hline
\end{tabular}

Fonte: Elaborada pelo autor com dados da WoS Core Collection apresentados via Incites.

Para completar a análise, a Tabela 137 apresenta as instituições e seus respectivos países, permitindo observar que a colaboração se distribui em um conjunto significativo de instituições, 57 no total, com redundância com instituições alemãs, brasileiras, estadunidenses (mais fortemente), francesas e suecas.

Tabela 137 - Distribuição das Instituições por países dos autores que publicaram com o Docente 15

(continua)

\section{País/Instituição}

Artigos

\section{Alemanha}

Alfred Wegener Institute; Helmholtz Centre for Polar \& Marine Research 2

Helmholtz Association 2

Humboldt University of Berlin $\quad 1$

Leibniz Institut fur Evolutions und Biodiversitatsforschung 1

University of Bremen 3

University of Gottingen $\quad 1$

\section{Austrália}

Australian National University

Flinders University South Australia 
Tabela 137 - Distribuição das Instituições por países dos autores que publicaram com o Docente 15

(continuação)

País/Instituição

Brasil

Centro de Desenvolvimento da Tecnologia Nuclear (CDTN) 1

Comissao Nacional de Energia Nuclear (CNEN) 1

Instituto de Botanica - Sao Paulo 1

Instituto Federal de Goias (IFG) 1

Instituto Nacional de Pesquisas Espaciais (INPE) 3

Universidade de Brasilia 1

Universidade Estadual de Campinas $\quad 2$

Universidade Estadual Paulista $\quad 1$

Universidade Federal de Minas Gerais $\quad 1$

Universidade Federal de Sao Paulo (UNIFESP) 3

Universidade Federal do ABC (UFABC) 1

Universidade Federal do Ceara 3

Universidade Federal do Para 3

Universidade Federal do Parana 2

Universidade Federal do Rio Grande $\quad 1$

Universidade Federal do Rio Grande do Sul 1

Canadá

Carleton University 1

\section{Chile}

Universidad Austral de Chile $\quad 1$

China

\section{Estados Unidos}

Desert Research Institute NSHE $\quad 1$

Duke University $\quad 1$

East Carolina University 3

Los Alamos National Laboratory $\quad 2$

Louisiana State University $\quad 1$

Louisiana State University System $\quad 1$

Nevada System of Higher Education (NSHE) 1

Oklahoma State University - Stillwater 4

Oklahoma State University System 4

State University System of Florida $\quad 1$

Texas State University San Marcos 1

Texas State University System 1

United States Department of Energy (DOE) 2

University of Florida 1

University of Kentucky 1

University of Washington 2

University of Washington Seattle $\quad 2$

Vanderbilt University 1 
Tabela 137 - Distribuição das Instituições por países dos autores que publicaram com o Docente 15

(conclusão)

\begin{tabular}{lc}
\hline País/Instituição & Artigos \\
\hline França & 1 \\
Aix-Marseille Universite & 1 \\
CEA & 2 \\
Centre National de la Recherche Scientifique (CNRS) & 1 \\
College de France & 1 \\
Institut de Recherche pour le Developpement (IRD) & 1 \\
Languedoc-Roussillon Universites (ComUE) & 1 \\
PSL Research University Paris (ComUE) & 1 \\
Universite de Montpellier & 1 \\
Universite Paris Saclay (ComUE) & 1 \\
University of Versailles Saint-Quentin-En-Yvelines & \\
Suécia & 2 \\
Linkoping University & \\
Suiça & 1 \\
University of Geneva & \\
\hline \hline
\end{tabular}

Fonte: Incites com dados da WoS Core Collection.

- Análise dos financiamentos de pesquisa recebidos

O presente item de análise considera os financiamentos recebidos pelas pesquisas publicadas. É importante destacar que a WoS somente padronizou os dados de Agências de Fomento de 2008 para frente e, portanto, dos 31 artigos do Docente 15 indexados na WoS somente 22 puderam ser analisados, uma vez que os outros nove são anteriores a esse período.

A Tabela 138 apresenta as informações das agências de fomento que apoiaram as pesquisas publicadas pelo Docente 15, com destaque para o ano de 2016 com participação de oito agências e com três superando a média esperada $(1,0)$ no impacto normalizado.

E verificando especificamente este indicador podemos verificar que os anos de 2014 e 2015 concentraram os maiores índices. E o artigo publicado com o apoio da National Geographic Society obteve o índice de 4,54, ou seja, atingiu quatro vezes e meia a média esperada e, por conseguinte, obteve também o mais alto índice de citações por artigo, 31,0. 
Tabela 138 - Agências de Fomento que apoiaram as pesquisas que geraram as publicações com participação do Docente 15, distribuídas por ano

\begin{tabular}{|c|c|c|c|c|}
\hline Agências de Fomento por Ano & $\begin{array}{c}\text { Artigo } \\
\mathrm{s}\end{array}$ & $\begin{array}{l}\text { Citaçõe } \\
\text { s }\end{array}$ & $\begin{array}{c}\text { Citações/Artig } \\
0\end{array}$ & $\begin{array}{c}\text { Impacto } \\
\text { Normalizado }\end{array}$ \\
\hline \multicolumn{5}{|l|}{2008} \\
\hline FAPESP & 1 & 20 & 20 & 0,82 \\
\hline \multicolumn{5}{|l|}{2009} \\
\hline CNPq & 2 & 18 & 9 & 0,59 \\
\hline FAPESP & 1 & 16 & 16 & 1,06 \\
\hline \multicolumn{5}{|l|}{2011} \\
\hline CNPq & 2 & 29 & 14,5 & 0,87 \\
\hline FAPESP & 4 & 72 & 18 & 1,22 \\
\hline \multicolumn{5}{|l|}{2012} \\
\hline FAPESP & 1 & 10 & 10 & 0,63 \\
\hline \multicolumn{5}{|l|}{2013} \\
\hline FAPESP & 1 & 4 & 4 & 0,33 \\
\hline \multicolumn{5}{|l|}{2014} \\
\hline Australian Res. Council & 1 & 17 & 17 & 1,64 \\
\hline FAPESP & 3 & 53 & 17,67 & 1,75 \\
\hline \multicolumn{5}{|l|}{2015} \\
\hline CNPq & 1 & 7 & 7 & 1,48 \\
\hline FAPESP & 3 & 10 & 3,33 & 0,64 \\
\hline Nat. Geographic Society & 1 & 31 & 31 & 4,54 \\
\hline \multicolumn{5}{|l|}{2016} \\
\hline CAPES & 1 & 1 & 1 & 0,3 \\
\hline CNPq & 4 & 15 & 3,75 & 1,06 \\
\hline FAPESP & 4 & 17 & 4,25 & 1,15 \\
\hline $\begin{array}{l}\text { German Res. Foundation (DFG) } \\
\text { Nat. Aeron. \& Space Adm. }\end{array}$ & 1 & 6 & 6 & 1,72 \\
\hline (NASA) & 1 & 1 & 1 & 0,3 \\
\hline Nat. Nat. Sci. Found. of China & 1 & 1 & 1 & 0,3 \\
\hline Nat. Sci.Foundation (NSF) & 1 & 1 & 1 & 0,3 \\
\hline Swedish Res. Council & 1 & 9 & 9 & 2,3 \\
\hline
\end{tabular}

Fonte: Incites com dados da WoS Core Collection

- Análise de visibilidade da produção científica

No que diz respeito à visibilidade da produção científica do docente, esta é medida levando em conta a quantidade de artigos registrada no Dedalus (36) e quantidade de artigos indexada na WoS (31), assim o percentual do Docente 15 é de $86,11 \%$.

Outra análise utilizada para mensurar a visibilidade da produção do docente é a verificação do percentual de artigos presentes em periódicos de impacto. A Tabela 139 apresenta os artigos do docente publicados em periódicos indexados na WoS Core 
Collection, distribuídos segundo Ciclos de Avaliação da CAPES e percentual publicado em periódicos do 1으 Quartil do Fl/JCR. Dos 31 artigos do Docente 15 indexados na WoS Core Collection $61,29 \%$ estão presentes no 1 ㅇ Quartil - vale ressaltar que nos últimos ciclos se intensifica a publicação em periódicos de maior impacto na área.

Tabela 139 - Artigos publicados pelo Docente 15 distribuídos por Ciclos de Avaliação da CAPES e indexados em periódicos do 1으 Quartil do FI/JCR

\begin{tabular}{lcc}
\hline Ciclos de Avaliação CAPES & Total de Artigos & \% Artigos no 10. Quartil \\
\hline Trienal 2007 & 1 & $0,00 \%$ \\
Trienal 2010 & 3 & $100,00 \%$ \\
Trienal 2013 & 5 & $60,00 \%$ \\
Quadrienal 2017 & 22 & $59,09 \%$ \\
\hline \hline Total & $\mathbf{3 1}$ & $\mathbf{6 1 , 2 9 \%}$ \\
\hline
\end{tabular}

Fonte: Incites com dados da WoS Core Collection

Analisando-se a publicação científica relacionada aos instrumentos de Avaliação da CAPES, a Tabela 140 apresenta a quantidade de artigos publicados distribuídos pelos Ciclos de Avaliação e classificação nos estratos Qualis da área de avaliação das Geociências.

Verifica-se que $64,15 \%$ dos artigos do Docente 15 encontram-se nos estratos mais altos ( $A 1$ e $A 2$ ), 29,03\% em periódicos $B 1$ e os demais em B2 e B3. Além disso, confirma-se na Quadrienal de 2017 o aumento da produção do docente, já identificado nas análises anteriores, e em periódicos do estrato A1 e A2. Nota-se ainda que alguns periódicos nos quais o docente publica são altamente especializados, porém possuem baixo impacto, devido ao público de leitores/pesquisadores ser restrito. 
Tabela 140 - Artigos publicados pelo Docente 15 distribuídos por Ciclos de Avaliação da CAPES e classificação do periódico nos estratos Qualis da área de avaliação das Geociências

\begin{tabular}{|c|c|c|c|c|c|c|}
\hline \multirow{2}{*}{ Periódicos e Ciclo de Avaliação } & \multicolumn{5}{|c|}{ Estratos Qualis } & \multirow{2}{*}{ Total } \\
\hline & A1 & A2 & B1 & B2 & B3 & \\
\hline 2004-2006 - TRIENAL 2007 & & & & & 1 & 1 \\
\hline JOURNAL OF COASTAL RESEARCH & & & & & 1 & 1 \\
\hline 2007-2009 - TRIENAL 2010 & 1 & 1 & 1 & & & 3 \\
\hline QUATERNARY SCIENCE REVIEWS & 1 & & & & & 1 \\
\hline REVIEW OF PALAEOBOTANY AND PALYNOLOGY & & & 1 & & & 1 \\
\hline SEDIMENTARY GEOLOGY & & 1 & & & & 1 \\
\hline 2010-2012 - TRIENAL 2013 & 3 & 1 & 1 & & & 5 \\
\hline JOURNAL OF SOUTH AMERICAN EARTH SCIENCES & & 1 & & & & 1 \\
\hline MARINE GEOLOGY & 1 & & & & & 1 \\
\hline QUATERNARY GEOCHRONOLOGY & 2 & & & & & 2 \\
\hline RADIATION MEASUREMENTS & & & 1 & & & 1 \\
\hline 2013-2016 - QUADRIENAL 2017 & 5 & 9 & 7 & 1 & & 22 \\
\hline ANAIS DA ACADEMIA BRASILEIRA DE CIENCIAS & & & 1 & & & 1 \\
\hline BRAZILIAN JOURNAL OF GEOLOGY & & & 2 & & & 2 \\
\hline CLIMATE OF THE PAST & 1 & & & & & 1 \\
\hline GEOCHIMICA ET COSMOCHIMICA ACTA & 1 & & & & & 1 \\
\hline GEOMORPHOLOGY & & 2 & & & & 2 \\
\hline GLOBAL CHANGE BIOLOGY & 2 & & & & & 2 \\
\hline INTERNATIONAL JOURNAL OF COAL GEOLOGY & & 1 & & & & 1 \\
\hline MARINE AND PETROLEUM GEOLOGY & & 1 & & & & 1 \\
\hline MARINE GEOLOGY & & 1 & & & & 1 \\
\hline PLOS ONE & & 1 & & & & 1 \\
\hline QUATERNARY GEOCHRONOLOGY & & 1 & & & & 1 \\
\hline QUATERNARY INTERNATIONAL & & & 1 & & & 1 \\
\hline RADIATION MEASUREMENTS & & & & 1 & & 1 \\
\hline SCIENTIFIC DRILLING & & & 2 & & & 2 \\
\hline SCIENTIFIC REPORTS & & & 1 & & & 1 \\
\hline SEDIMENTARY GEOLOGY & & 2 & & & & 2 \\
\hline SEDIMENTOLOGY & 1 & & & & & 1 \\
\hline Total & 9 & 11 & 9 & 1 & 1 & 31 \\
\hline
\end{tabular}

Fonte: Elaborada pelo autor com dados da WoS Core Collection e Qualis/CAPES.

De forma a aprofundar a análise sobre as colaborações e a visibilidade das publicações, a Tabela 141 apresenta as instituições que colaboraram com o Docente 15 em dois ou mais artigos, distribuídas entre os Ciclos de Avaliação da CAPES, com a indicação do percentual dos artigos no 1 Q Quartil do JCR.

Ao todo são oito instituições com a característica exigida e representadas em apenas dois ciclos (Trienal de 2013 e Quadrienal de 2017). Nota-se que todos os artigos publicados com instituições alemãs foram em periódicos do 1 으 Quartil. 
O percentual dos artigos dessas colaborações publicados em periódicos do 1으 Quartil nesses dois ciclos foi de $68,42 \%$.

Tabela 141 - Artigos publicados pelo Docente 15 distribuídos segundo instituições que colaboraram duas ou mais vezes e Ciclos de Avaliação da CAPES, com indicação do percentual de artigos no 1으 Quartil do JCR

\begin{tabular}{|c|c|c|c|}
\hline Instituição Colaboradora & Trienal 2013 & Quadrienal 2017 & Total \\
\hline \multicolumn{4}{|c|}{$\begin{array}{l}\text { Alfred Wegener Institute; Helmholtz } \\
\text { Centre for Polar \& Marine Research }\end{array}$} \\
\hline Artigos & & 2 & 2 \\
\hline$\%$ Artigos no 1o. Quartil & & $100,00 \%$ & $100,00 \%$ \\
\hline \multicolumn{4}{|l|}{ East Carolina University } \\
\hline Artigos & & 2 & 2 \\
\hline$\%$ Artigos no 1o. Quartil & & $0,00 \%$ & $0,00 \%$ \\
\hline \multicolumn{4}{|l|}{ Helmholtz Association } \\
\hline Artigos & & 2 & 2 \\
\hline$\%$ Artigos no 1o. Quartil & & $100,00 \%$ & $100,00 \%$ \\
\hline \multicolumn{4}{|c|}{ Oklahoma State University - Stillwater } \\
\hline Artigos & 3 & & 3 \\
\hline$\%$ Artigos no 1o. Quartil & $66,67 \%$ & & $66,67 \%$ \\
\hline \multicolumn{4}{|c|}{ Oklahoma State University System } \\
\hline Artigos & 3 & & 3 \\
\hline$\%$ Artigos no 1o. Quartil & $66,67 \%$ & & $66,67 \%$ \\
\hline \multicolumn{4}{|c|}{ Universidade Federal de Sao Paulo (UNIFESP) } \\
\hline Artigos & & 3 & 3 \\
\hline$\%$ Artigos no 1o. Quartil & & $66,67 \%$ & $66,67 \%$ \\
\hline \multicolumn{4}{|l|}{ Universidade Federal do Para } \\
\hline Artigos & & 2 & 2 \\
\hline$\%$ Artigos no 1o. Quartil & & $50,00 \%$ & $50,00 \%$ \\
\hline \multicolumn{4}{|l|}{ University of Bremen } \\
\hline Artigos & & 2 & 2 \\
\hline$\%$ Artigos no 1o. Quartil & & $100,00 \%$ & $100,00 \%$ \\
\hline Total Artigos & 6 & 13 & 19 \\
\hline Total \% Artigos no 10. Quartil & $66,67 \%$ & $69,23 \%$ & $68,42 \%$ \\
\hline
\end{tabular}

Fonte: Elaborada pelo autor com dados da WoS Core Collection e Qualis/CAPES.

- Análise de impacto da produção científica

Os critérios para a análise de impacto compreendem a análise das citações recebidas e, do total de artigos indexados, a quantidade destes nos Top $10 \%$.

De acordo com Tabela 142, o Docente 15 teve ao todo três artigos presentes nos Top 10\%. Analisando-se o Impacto Normalizado do docente, verifica-se que em quatro 
anos ele superou a média de citações esperada $(1,0)$, três deles nos três últimos anos de análise, 2014-2016.

Tabela 142 - Impacto dos artigos do Docente 15 distribuídos por ano de publicação

\begin{tabular}{ccccccc}
\hline $\begin{array}{c}\text { Ano de } \\
\text { Publicação }\end{array}$ & $\begin{array}{c}\text { Total de } \\
\text { Art. }\end{array}$ & $\begin{array}{c}\text { \% Art. } \\
\text { Citados }\end{array}$ & Citações & $\begin{array}{c}\text { Citações / } \\
\text { Art. }\end{array}$ & $\begin{array}{c}\text { Art. Top } \\
\mathbf{1 0 \%}\end{array}$ & $\begin{array}{c}\text { Impacto } \\
\text { Normalizado }\end{array}$ \\
\hline 2006 & 1 & $100,00 \%$ & 7 & 7,0 & $0,00 \%$ & 0,3 \\
2008 & 1 & $100,00 \%$ & 20 & 20,0 & $0,00 \%$ & 0,8 \\
2009 & 2 & $100,00 \%$ & 18 & 9,0 & $0,00 \%$ & 0,6 \\
2011 & 4 & $100,00 \%$ & 72 & 18,0 & $0,00 \%$ & 1,2 \\
2012 & 1 & $100,00 \%$ & 10 & 10,0 & $0,00 \%$ & 0,6 \\
\hline 2013 & 4 & $100,00 \%$ & 22 & 5,5 & $0,00 \%$ & 0,5 \\
\hline 2014 & 4 & $100,00 \%$ & 56 & 14,0 & $25,00 \%$ & 1,4 \\
\hline 2015 & 7 & $71,43 \%$ & 56 & 8,0 & $28,57 \%$ & 1,6 \\
\hline 2016 & 7 & $100,00 \%$ & 27 & 3,9 & $0,00 \%$ & 1,1 \\
\hline \hline Total & $\mathbf{3 1}$ & $\mathbf{9 6 , 8 3 \%}$ & $\mathbf{2 8 8}$ & --- & $\mathbf{9 , 6 8 \%}$ & --- \\
\hline
\end{tabular}

Fonte: Incites com dados da WoS Core Collection

Analisando-se as citações por artigo nota-se que os anos de 2008, 2011 e 2014 o docente obteve seus melhores índices. Porém, a análise de citações deve levar em consideração a comparação do tempo de exposição dos artigos, uma vez que artigos com maior idade tendem a receber mais citações. Nesse sentido, considerando que nos últimos anos o docente aumentou sua produtividade e focou em periódicos de alto impacto, tal ação corroborada pelo seu indicador de impacto normalizado, é possível prever que os artigos de 2014 a 2016 obterão em alguns anos os mais altos índices de impacto.

\section{- Análise das referências utilizadas}

O último item a se analisar são as referências utilizadas pelo Docente na redação de seus artigos. Ao todo o Docente 15 utilizou 551 fontes bibliográficas diferentes, citando-as 1.763 vezes em seus 31 artigos, gerando uma média de 56,87 referências por trabalho.

Utilizando-se as Zonas de Bradford para analisar as principais publicações citadas nos artigos, pôde-se verificar pelas Tabelas 143 e 144 que, das 1.547 referências utilizadas, o primeiro terço delas (Zona 1 - com 594 referências) estão concentradas em 16 periódicos que correspondem a 2,90\% das publicações; já no segundo terço (Zona 2 
- com 589 referências) em 83 publicações, já possuindo uma maior variedade de tipologias de documentos e correspondendo a 15,06\%. O terceiro terço é a zona de maior dispersão com um total de 452 publicações, sendo a maioria delas com baixa frequência de citação (não sendo, portanto, apresentadas na tabela).

Essas 99 publicações somadas correspondem a 17,97\% das publicações, que, por conseguinte, correspondem a $67,10 \%$ de todas as referências citadas.

Tabela 143 - Lista de Referências utilizadas nos artigos do Docente 15 distribuídas pelas Zonas 1 e 2 de Bradford

(continua)

\begin{tabular}{|c|c|c|c|c|}
\hline$\#$ & Publicações & Citações & \% Citações & $\begin{array}{l}\text { Zona de } \\
\text { Bradford }\end{array}$ \\
\hline 1 & RADIAT MEAS & 90 & $5,10 \%$ & \multirow{16}{*}{ Zona 1} \\
\hline 2 & QUATERNARY SCI REV & 59 & $3,35 \%$ & \\
\hline 3 & MAR GEOL & 52 & $2,95 \%$ & \\
\hline 4 & SEDIMENT GEOL & 48 & $2,72 \%$ & \\
\hline 5 & QUAT GEOCHRONOL & 45 & $2,55 \%$ & \\
\hline 6 & SCIENCE & 42 & $2,38 \%$ & \\
\hline 7 & NATURE & 37 & $2,10 \%$ & \\
\hline 8 & J SEDIMENT PETROL & 35 & $1,99 \%$ & \\
\hline 9 & PALAEOGEOGR PALAEOCL & 33 & $1,87 \%$ & \\
\hline 10 & GEOMORPHOLOGY & 27 & $1,53 \%$ & \\
\hline 11 & GEOCHIM COSMOCHIM AC & 25 & $1,42 \%$ & \\
\hline 12 & EARTH PLANET SC LETT & 23 & $1,30 \%$ & \\
\hline 13 & THESIS U SAO PAULO & 22 & $1,25 \%$ & \\
\hline 14 & QUATERNARY RES & 20 & $1,13 \%$ & \\
\hline 15 & EARTH-SCI REV & 18 & $1,02 \%$ & \\
\hline 16 & GEOLOGY & 18 & $1,02 \%$ & \\
\hline 1 & J S AM EARTH SCI & 18 & $1,02 \%$ & \multirow{15}{*}{ Zona 2} \\
\hline 2 & AN ACAD BRAS CIENC & 17 & $0,96 \%$ & \\
\hline 3 & REV BRASILEIRA GEOCI & 16 & $0,91 \%$ & \\
\hline 4 & SEDIMENTOLOGY & 16 & $0,91 \%$ & \\
\hline 5 & NAT GEOSCI & 16 & $0,91 \%$ & \\
\hline 6 & J COASTAL RES & 15 & $0,85 \%$ & \\
\hline 7 & INT J COAL GEOL & 14 & $0,79 \%$ & \\
\hline 8 & LECT NOTES EARTH SCI & 14 & $0,79 \%$ & \\
\hline 9 & QUATERN INT & 14 & $0,79 \%$ & \\
\hline 10 & GLOBAL BIOGEOCHEM CY & 12 & $0,68 \%$ & \\
\hline 11 & LIMNOL OCEANOGR & 12 & $0,68 \%$ & \\
\hline 12 & J GEOPHYS RES-ATMOS & 12 & $0,68 \%$ & \\
\hline 13 & CLIM PAST & 11 & $0,62 \%$ & \\
\hline 14 & GEOPHYS RES LETT & 11 & $0,62 \%$ & \\
\hline 15 & J GEOL & 11 & $0,62 \%$ & \\
\hline
\end{tabular}


Tabela 143 - Lista de Referências utilizadas nos artigos do Docente 15 distribuídas pelas Zonas 1 e 2 de Bradford

\begin{tabular}{|c|c|c|c|c|}
\hline$\#$ & Publicações & Citações & \% Citações & $\begin{array}{l}\text { Zona de } \\
\text { Bradford }\end{array}$ \\
\hline 16 & J CLIMATE & 11 & $0,62 \%$ & \multirow{40}{*}{ Zona 2} \\
\hline 17 & ORG GEOCHEM & 11 & $0,62 \%$ & \\
\hline 18 & CHEM GEOL & 10 & $0,57 \%$ & \\
\hline 19 & ANCIENT TL & 10 & $0,57 \%$ & \\
\hline 20 & GEOL SOC AM BULL & 10 & $0,57 \%$ & \\
\hline 21 & AAPG BULL & 10 & $0,57 \%$ & \\
\hline 22 & J QUATERNARY SCI & 10 & $0,57 \%$ & \\
\hline 23 & PALEOCEANOGRAPHY & 10 & $0,57 \%$ & \\
\hline 24 & GEOCHRONOMETRIA & 9 & $0,51 \%$ & \\
\hline 25 & GEOLOGIA USP C & 8 & $0,45 \%$ & \\
\hline 26 & RADIAT PROT DOSIM & 8 & $0,45 \%$ & \\
\hline 27 & MAR PETROL GEOL & 8 & $0,45 \%$ & \\
\hline 28 & CONTRIB MINERAL PETR & 7 & $0,40 \%$ & \\
\hline 29 & CATENA & 7 & $0,40 \%$ & \\
\hline 30 & GEOCHEM GEOPHY GEOSY & 7 & $0,40 \%$ & \\
\hline 31 & J GEOPHYS RES-BIOGEO & 7 & $0,40 \%$ & \\
\hline 32 & J PHYS D APPL PHYS & 7 & $0,40 \%$ & \\
\hline 33 & NUCL TRACKS RAD MEAS & 7 & $0,40 \%$ & \\
\hline 34 & BOREAS & 6 & $0,34 \%$ & \\
\hline 35 & GLOBAL PLANET CHANGE & 6 & $0,34 \%$ & \\
\hline 36 & BIOGEOCHEMISTRY & 6 & $0,34 \%$ & \\
\hline 37 & HOLOCENE & 6 & $0,34 \%$ & \\
\hline 38 & B GEOCIENCIAS PETROB & 6 & $0,34 \%$ & \\
\hline 39 & COASTAL EVOLUTION LA & 6 & $0,34 \%$ & \\
\hline 40 & J GEOPHYS RES-OCEANS & 6 & $0,34 \%$ & \\
\hline 41 & MONTE VERDE LATE PLE & 6 & $0,34 \%$ & \\
\hline 42 & RADIOCARBON & 6 & $0,34 \%$ & \\
\hline 43 & PRECAMBRIAN RES & 6 & $0,34 \%$ & \\
\hline 44 & INT J CLIMATOL & 5 & $0,28 \%$ & \\
\hline 45 & ARCHAEOMETRY & 5 & $0,28 \%$ & \\
\hline 46 & B PARANAENSE GEOCIEN & 5 & $0,28 \%$ & \\
\hline 47 & GEOGR ANN A & 5 & $0,28 \%$ & \\
\hline 48 & GLOBAL CHANGE BIOL & 5 & $0,28 \%$ & \\
\hline 49 & EPISODES & 5 & $0,28 \%$ & \\
\hline 50 & SPECIAL PUBLICATION & 5 & $0,28 \%$ & \\
\hline 51 & TECTONOPHYSICS & 5 & $0,28 \%$ & \\
\hline 52 & RADIAT EFF DEFECT S & 5 & $0,28 \%$ & \\
\hline 53 & NAT COMMUN & 5 & $0,28 \%$ & \\
\hline 54 & PACT & 5 & $0,28 \%$ & \\
\hline 55 & Z GEOMORPHOL & 5 & $0,28 \%$ & \\
\hline
\end{tabular}


Tabela 143 - Lista de Referências utilizadas nos artigos do Docente 15 distribuídas pelas Zonas 1 e 2 de Bradford

(conclusão)

\begin{tabular}{|c|c|c|c|c|}
\hline$\#$ & Publicações & Citações & \% Citações & $\begin{array}{l}\text { Zona de } \\
\text { Bradford }\end{array}$ \\
\hline 56 & ANNU REV EARTH PL SC & 4 & $0,23 \%$ & \multirow{28}{*}{ Zona 2} \\
\hline 57 & GEOL SOC SPEC PUBL & 4 & $0,23 \%$ & \\
\hline 58 & ANAIS ACAD BRASILEIR & 4 & $0,23 \%$ & \\
\hline 59 & EARTH SURF PROC LAND & 4 & $0,23 \%$ & \\
\hline 60 & APPL ENVIRON MICROB & 4 & $0,23 \%$ & \\
\hline 61 & $\begin{array}{l}\text { AMAZONIA: LANDSCAPE AND SPECIES } \\
\text { EVOLUTION: A LOOK INTO THE PAST }\end{array}$ & 4 & $0,23 \%$ & \\
\hline 62 & INTRO OPTICAL DATING & 4 & $0,23 \%$ & \\
\hline 63 & ENVIRON SCI TECHNOL & 4 & $0,23 \%$ & \\
\hline 64 & GONDWANA RES & 4 & $0,23 \%$ & \\
\hline 65 & FLUVIAL SEDIMENTOLOG & 4 & $0,23 \%$ & \\
\hline 66 & AMAZONIA FUNDAMENTOS & 4 & $0,23 \%$ & \\
\hline 67 & FUEL & 4 & $0,23 \%$ & \\
\hline 68 & HEAVY MINERALS COLOU & 4 & $0,23 \%$ & \\
\hline 69 & PROCEDURES SEDIMENTA & 4 & $0,23 \%$ & \\
\hline 70 & NUCL INSTRUM METH A & 4 & $0,23 \%$ & \\
\hline 71 & PHYS CHEM MINER & 4 & $0,23 \%$ & \\
\hline 72 & REV PALAEOBOT PALYNO & 4 & $0,23 \%$ & \\
\hline 73 & REV GEOPHYS & 4 & $0,23 \%$ & \\
\hline 74 & PALEOAMERICAN ODYSSE & 4 & $0,23 \%$ & \\
\hline 75 & CARTA GEOLOGICA BRAS & 3 & $0,17 \%$ & \\
\hline 76 & B PARANAENSE GEOC & 3 & $0,17 \%$ & \\
\hline 77 & COMPUT GEOSCI-UK & 3 & $0,17 \%$ & \\
\hline 78 & EARTH SURF PROCESSES & 3 & $0,17 \%$ & \\
\hline 79 & AM MINERAL & 3 & $0,17 \%$ & \\
\hline 80 & CLIM DYNAM & 3 & $0,17 \%$ & \\
\hline 81 & GEOLOGICAL SOC LONDO & 3 & $0,17 \%$ & \\
\hline 82 & APPL RADIAT ISOTOPES & 3 & $0,17 \%$ & \\
\hline 83 & INDIAN J PURE AP PHY & 3 & $0,17 \%$ & \\
\hline $\begin{array}{l}\text { Tot } \\
\text { al }\end{array}$ & 99 Títulos & 1.183 & $67,10 \%$ & \\
\hline
\end{tabular}

Fonte: Elaborada pelo autor com dados da WoS Core Collection. 
Tabela 144 - Quantidade de publicações citadas pelo Docente 15 distribuídas pelas Zonas de Bradford

Zonas de Bradford Total de Publicações \% Publicações Total de Citações \% Citações

\begin{tabular}{lcccc}
\hline Zona 1 & 16 & $2,90 \%$ & 594 & $33,69 \%$ \\
Zona 2 & 83 & $15,06 \%$ & 589 & $33,41 \%$ \\
Zona 3 & 452 & $82,03 \%$ & 580 & $32,90 \%$ \\
\hline \hline Total & $\mathbf{5 5 1}$ & $\mathbf{1 0 0 , 0 0 \%}$ & $\mathbf{1 . 7 6 3}$ & $\mathbf{1 0 0 , 0 0 \%}$ \\
\hline
\end{tabular}

Fonte: Elaborada pelo autor com dados da WoS Core Collection.

Tais dados permitem ainda analisar a relação de onde se publica com o que se cita. A Tabela 145 nos apresenta que dos 21 periódicos nos quais foram publicados os 31 artigos do Docente 15 os dois primeiros com maior número de publicações estão presentes na Zona 01, sendo que o primeiro corresponde à quinta publicação mais referenciada e o segundo, à quarta. Dos restantes, cinco pertencem à Zona 1, dez à Zona 2, dois à Zona 3 e dois não foram citados em nenhum trabalho.

Durante a entrevista quando perguntado sobre às publicações mais importantes do seu campo de atuação o Docente 15 indicou os periódicos: Earth and Planetary Science Letters, Geology, Global Change Biology, Journal of Biogeography, Quaternary Science Reviews, Quaternary Research, Geomorphology e Quaternary Geochronology. Desses oito títulos, sete fazem parte da Zona 1 e um da Zona 2; além disso, em quatro deles o docente publicou artigos.

Tabela 145 - Lista de periódicos nos quais o Docente 15 publicou seus artigos com indicação das Zonas de Bradford

(continua)

\begin{tabular}{lccc}
\hline Título do Periódico & $\begin{array}{c}\text { Total de } \\
\text { Artigos }\end{array}$ & $\begin{array}{c}\text { \% Total de } \\
\text { Artigos }\end{array}$ & $\begin{array}{c}\text { Zonas de } \\
\text { Bradford }\end{array}$ \\
\hline QUATERNARY GEOCHRONOLOGY & 3 & $9,68 \%$ & 1 \\
\hline SEDIMENTARY GEOLOGY & 3 & $9,68 \%$ & 1 \\
\hline SCIENTIFIC DRILLING & 2 & $6,45 \%$ & Não citado \\
\hline MARINE GEOLOGY & 2 & $6,45 \%$ & 1 \\
\hline GLOBAL CHANGE BIOLOGY & 2 & $6,45 \%$ & 2 \\
\hline RADIATION MEASUREMENTS & 2 & $6,45 \%$ & 1 \\
\hline BRAZILIAN JOURNAL OF GEOLOGY & 2 & $6,45 \%$ & 3 \\
\hline GEOMORPHOLOGY & 2 & $6,45 \%$ & 1 \\
\hline JOURNAL OF COASTAL RESEARCH & 1 & $3,23 \%$ & 2 \\
\hline INTERNATIONAL JOURNAL OF COAL & 1 & $3,23 \%$ & 2 \\
GEOLOGY & 1 & $3,23 \%$ & 2 \\
MARINE AND PETROLEUM GEOLOGY & 1 & $3,23 \%$ & Não citado \\
\hline SCIENTIFIC REPORTS & & &
\end{tabular}


Tabela 145 - Lista de periódicos nos quais o Docente 15 publicou seus artigos com indicação das Zonas de Bradford

\begin{tabular}{|c|c|c|c|}
\hline Título do Periódico & $\begin{array}{l}\text { Total de } \\
\text { Artigos }\end{array}$ & $\begin{array}{l}\% \text { Total de } \\
\text { Artigos }\end{array}$ & $\begin{array}{l}\text { Zonas de } \\
\text { Bradford }\end{array}$ \\
\hline $\begin{array}{l}\text { JOURNAL OF SOUTH AMERICAN EARTH } \\
\text { SCIENCES }\end{array}$ & 1 & $3,23 \%$ & 2 \\
\hline CLIMATE OF THE PAST & 1 & $3,23 \%$ & 2 \\
\hline SEDIMENTOLOGY & 1 & $3,23 \%$ & 2 \\
\hline $\begin{array}{l}\text { REVIEW OF PALAEOBOTANY AND } \\
\text { PALYNOLOGY }\end{array}$ & 1 & $3,23 \%$ & 2 \\
\hline GEOCHIMICA ET COSMOCHIMICA ACTA & 1 & $3,23 \%$ & 1 \\
\hline $\begin{array}{l}\text { ANAIS DA ACADEMIA BRASILEIRA DE } \\
\text { CIENCIAS }\end{array}$ & 1 & $3,23 \%$ & 2 \\
\hline PLOS ONE & 1 & $3,23 \%$ & 3 \\
\hline QUATERNARY INTERNATIONAL & 1 & $3,23 \%$ & 2 \\
\hline QUATERNARY SCIENCE REVIEWS & 1 & $3,23 \%$ & 1 \\
\hline Total Geral & 31 & $100,00 \%$ & \\
\hline
\end{tabular}

Fonte: Elaborada pelo autor com dados da WoS Core Collection.

A Tabela 146 apresenta a idade das referências citadas pelo Docente 15 de acordo com o ano de publicação de cada um de seus artigos. A maior concentração encontra-se em referências da faixa de 0 a 5 anos, com 31,59\% e se somar-se a ela as faixas de 6 a 10 e de 11 a 20 anos, tem-se 78,33\% do total geral das referências com até 20 anos.

Tabela 146 - Idade das Referências citadas nos artigos do Docente 15

\begin{tabular}{cccc}
\hline Idade das Referências & Total de Citações & \% Citações \\
\hline $0-5$ & 557 & $31,59 \%$ \\
& $6-10$ & 363 & $20,59 \%$ \\
& $11-20$ & 461 & $26,15 \%$ \\
& $21-30$ & 203 & $11,51 \%$ \\
& $31-40$ & 95 & $5,39 \%$ \\
& $41-50$ & 43 & $2,44 \%$ \\
\hline \hline Total & +50 & 41 & $2,33 \%$ \\
\hline Fonte: & & $\mathbf{1 . 7 6 3}$ & $\mathbf{1 0 0 , 0 0 \%}$ \\
\hline
\end{tabular}

Fonte: Elaborada pelo autor com dados da WoS Core Collection.

- Informações adicionais

O perfil bibliométrico do Docente 15 confirma em todos os itens analisados a constatação da análise amostral de que seu perfil é altamente internacionalizado. Tal 
fato se evidencia principalmente na constância de suas principais colaborações e no impacto normalizado obtido, especialmente nos últimos anos analisados.

$\mathrm{Na}$ entrevista realizada com o docente foi possível identificar também seu perfil internacionalizado pelo domínio do fluxo da comunicação científica em sua área e em suas estratégias de publicação.

Quanto às avaliações o posicionamento do docente é consistente, demonstrando entender os processos, conhecer as regas do jogo e se adequar a elas.

A despeito de seu perfil internacionalizado, o docente mantém uma alta produção regional, contribuindo para o desenvolvimento da área no Brasil por meio de suas publicações em anais de eventos e em periódicos domésticos. Esse equilíbrio da sua produção intelectual tem Ihe garantido bons resultados. 


\section{DOCENTE 25}

O Docente 25, conforme apresentado no Quadro 1, obteve um nível de publicação 1 no primeiro subperíodo de ciclos de avaliação da CAPES (2001-2009), com um percentual de publicação em periódicos domésticos de $0 \%$, entretanto nesse subperíodo o docente teve apenas três artigos registrados, sendo categorizado com baixa produtividade. No entanto, cabe destacar que o docente participou apenas de um ciclo de avaliação nesse subperíodo. No segundo subperíodo (2010-2016) no qual já havia uma produção bem maior registrada foi verificado que seu nível de publicação era 4, com um percentual de $66,67 \%$ de publicação em periódicos domésticos, apresentando, assim, uma transição de três níveis rumo à nacionalização, resultando num Status Final nacionalizado.

Baseada nos dados coletados no Banco Dedalus, a Tabela 147 apresenta a distribuição da produção intelectual do Docente 25 por tipo de publicação.

Nota-se que a maior concentração da produção do Docente 25 está registrada em eventos, totalizando $45,28 \%$, fato corroborado pela entrevista, na qual o docente afirma valorizar os eventos.

Considerando-se somente a publicação em artigos de periódicos, verifica-se que este tipo de publicação corresponde a $39,62 \%$ do total; e dos artigos publicados, $42,86 \%$ foram em periódicos estrangeiros.

Tabela 147 - Produção Intelectual do Docente 25 registrada no Dedalus distribuída por tipo de publicação

\begin{tabular}{lccccc}
\hline \multirow{2}{*}{ Tipo de Publicação / Ciclo de Avaliação } & \multicolumn{2}{c}{$\begin{array}{c}\text { Doméstico } \\
\text { \%ocs }\end{array}$} & $\begin{array}{c}\text { Estrangeiro } \\
\text { Docs }\end{array}$ & $\begin{array}{c}\text { Total } \\
\text { Docs }\end{array}$ & \\
\hline ARTIGO DE JORNAL & 1 & $100,00 \%$ & 0 & $0,00 \%$ & 1 \\
\hline ARTIGO DE JORNAL-DEP/ENTR & 3 & $100,00 \%$ & 0 & $0,00 \%$ & 3 \\
\hline ARTIGO DE PERIODICO & 12 & $57,14 \%$ & 9 & $42,86 \%$ & 21 \\
\hline ARTIGO DE PERIODICO-CARTA/EDITORIAL & 1 & $100,00 \%$ & 0 & $0,00 \%$ & 1 \\
\hline PARTE DE MONOGRAFIA/LIVRO & 1 & $50,00 \%$ & 1 & $50,00 \%$ & 2 \\
\hline TEXTO NA WEB & 1 & $100,00 \%$ & 0 & $0,00 \%$ & 1 \\
\hline TRABALHO DE EVENTO & 5 & $71,43 \%$ & 2 & $28,57 \%$ & 7 \\
\hline TRABALHO DE EVENTO-ANAIS PERIODICO & 1 & $100,00 \%$ & 0 & $0,00 \%$ & 1 \\
\hline TRABALHO DE EVENTO-RESUMO & 11 & $68,75 \%$ & 5 & $31,25 \%$ & 16 \\
\hline \hline Total & $\mathbf{3 6}$ & $\mathbf{6 7 , 9 2 \%}$ & $\mathbf{1 7}$ & $\mathbf{3 2 , 0 8 \%}$ & $\mathbf{5 3}$ \\
\hline FOTE: & & & & & \\
\hline
\end{tabular}

Fonte: Elaborada pelo autor com dados do Dedalus. 
Em relação à produção científica do Docente 25 indexada na WoS Core Collection, a Tabela 148 traz os dados referentes aos artigos publicados, distribuídos por periódico. Os periódicos com maior número de publicação foram o Anais da Academia Brasileira de Ciências (Categoria do JCR: Multidisciplinary Sciences; FI de 0,956; Categoria SJR: Multidisciplinary; SJR de 0,418) e Journal of South American Earth Sciences (Categoria do JCR: Geoscience e Multidisciplinary; FI de 1,639; Categoria SJR: Earth and Planetary Sciences; SJR de 0,82) ambos com dois artigos. Os dois periódicos juntos correspondem a $44,44 \%$ do total de artigos publicados.

Tabela 148 - Artigos do Docente 25 indexados na WoS Core Collection distribuídos por título de periódico

\begin{tabular}{lcc}
\hline Periódicos & Artigos & \%Artigos \\
\hline ANAIS DA ACADEMIA BRASILEIRA DE CIENCIAS & 2 & $22,22 \%$ \\
\hline JOURNAL OF SOUTH AMERICAN EARTH SCIENCES & 2 & $22,22 \%$ \\
\hline JOURNAL OF CONTAMINANT HYDROLOGY & 1 & $11,11 \%$ \\
ENVIRONMENTAL EARTH SCIENCES & 1 & $11,11 \%$ \\
PROCEDIA EARTH AND PLANETARY SCIENCE & 1 & $11,11 \%$ \\
\hline JOURNAL OF HYDROLOGY & 1 & $11,11 \%$ \\
APPLIED GEOCHEMISTRY & 1 & $11,11 \%$ \\
\hline \hline Total & $\mathbf{9}$ & $\mathbf{1 0 0 , 0 0 \%}$ \\
\hline
\end{tabular}

Fonte: Elaborada pelo autor com dados da WoS Core Collection.

A seguir apresentam-se os dados de acordo com o Perfil Bibliométrico adaptado da proposta de Gorraiz, Wieland \& Gumpenberger (2016).

- Análise de coautorias

A Tabela 149 apresenta os dados de coautoria do Docente 25 , nos quais é possível identificar que a maior concentração de publicações encontra-se em artigos com 4 a 6 autores. A informação é complementada pela Tabela 150 que apresenta a posição do docente nos artigos, demonstrando uma maior quantidade de artigos nos quais ele figura como o primeiro autor, correspondendo a $55,55 \%$. 
Tabela 149 - Quantidade de autores nos artigos com participação do Docente 25

\begin{tabular}{cccc}
\hline Quantidade de Autores & Total de Artigos & $\%$ Artigos \\
\hline 3 & 1 & $11,11 \%$ \\
& 4 & 2 & $22,22 \%$ \\
& 5 & 2 & $22,22 \%$ \\
& 6 & 2 & $22,22 \%$ \\
& 18 & 1 & $11,11 \%$ \\
\hline \hline Total & 1 & $11,11 \%$ \\
\hline
\end{tabular}

Fonte: Elaborada pelo autor com dados da WoS Core Collection.

Tabela 150 - Artigos distribuídos por quantidade de autores e posição na autoria do Docente 25 nos artigos em que participa

\begin{tabular}{|c|c|c|c|c|}
\hline \multirow{2}{*}{ Quantidade de Autores } & \multicolumn{3}{|c|}{ Posição na Autoria } & \multirow{2}{*}{ Tota } \\
\hline & Primeiro & Meio & Último & \\
\hline 3 & & 1 & & 1 \\
\hline 4 & 2 & & & 2 \\
\hline 5 & & 2 & & 2 \\
\hline 6 ou mais & 3 & & 1 & 4 \\
\hline Total & 5 & 3 & 1 & 9 \\
\hline
\end{tabular}

Fonte: Elaborada pelo autor com dados da WoS Core Collection.

- Análise da colaboração

Em termos de colaboração internacional a Tabela 151 apresenta que 66,67\% dos artigos do docente foram publicados com coautores de mais de um país.

Tabela 151 - Quantidade de países dos autores que publicaram nos artigos com participação do Docente 25

\begin{tabular}{rccc}
\hline Quantidade de Países & Total de Artigos & \% Artigos \\
& 1 & 3 & $33,33 \%$ \\
& 2 & 5 & $55,56 \%$ \\
\hline \hline Total & 1 & $11,11 \%$ \\
\hline
\end{tabular}

Fonte: Elaborada pelo autor com dados da WoS Core Collection.

A Tabela 152 apresenta os países colaboradores, quatro ao todo, com destaque para Canadá e República Checa que colaboraram em mais de um artigo com o Docente 25. 
Tabela 152 - Países dos autores que publicaram nos artigos com participação do Docente 25

\begin{tabular}{lcc} 
Países & Total de Artigos & $\%$ Artigos \\
\hline Brasil & 3 & $33,33 \%$ \\
Canadá & 2 & $22,22 \%$ \\
França & 1 & $11,11 \%$ \\
República Checa & 3 & $33,33 \%$ \\
Rússia & 1 & $11,11 \%$ \\
\hline \hline Total & $\mathbf{9}$ & --- \\
\hline
\end{tabular}

Fonte: Elaborada pelo autor com dados da WoS Core Collection.

Na Tabela 153 podemos verificar a quantidade de instituições dos autores desses artigos destacando-se uma maior concentração naqueles com duas instituições (uma além da USP) com 33,33\%.

Tabela 153 - Quantidade de instituições dos autores que publicaram nos artigos com participação do Docente 25

\begin{tabular}{cccc}
\hline Quantidade de Instituições & Total de Artigos & $\%$ Artigos \\
\hline 1 & 2 & $22,22 \%$ \\
& 2 & 3 & $33,33 \%$ \\
3 & 2 & $22,22 \%$ \\
& 5 & 1 & $11,11 \%$ \\
\hline \hline Total & 1 & $11,11 \%$ \\
\hline Fonte Elabor
\end{tabular}

Fonte: Elaborada pelo autor com dados da WoS Core Collection apresentados via Incites.

Para completar a análise, a Tabela 154 apresenta as instituições e seus respectivos países. Ao todo foram dez instituições, com redundância apenas com a Palacky University Olomouc da República Checa. 
Tabela 154 - Distribuição das Instituições por países dos autores que publicaram com o Docente 25

\begin{tabular}{lc}
\hline País/Instituição & Artigos \\
\hline Brasil & 1 \\
$\quad$ Universidade Federal de Mato Grosso do Sul & 1 \\
Universidade Federal de Pernambuco & 1 \\
Canadá & 1 \\
$\quad$ University of Guelph & \\
$\quad$ University of Waterloo & 1 \\
França & 1 \\
$\quad$ Bureau de Recherches Geologiques et Minieres & 1 \\
Centre National de la Recherche Scientifique (CNRS) & \\
$\quad$ University of Rennes 1 & 1 \\
República Checa & 2 \\
$\quad$ Masaryk University Brno & \\
$\quad$ Palacky University Olomouc & 1 \\
\hline Rússia & \\
\hline \hline
\end{tabular}

Fonte: Incites com dados da WoS Core Collection.

- Análise dos financiamentos de pesquisa recebidos

A presente análise verifica quais foram as Agências de Fomento que apoiaram as pesquisas realizadas pelo Docente 25 . Cabe destacar que a WoS somente padronizou os dados de Agências de Fomento de 2008 para frente e, portanto, dos nove artigos do Docente 25 indexados na WoS oito puderam ser analisados.

A Tabela 155 apresenta as informações das agências de fomento que apoiaram as pesquisas publicadas pelo Docente 25. Duas agências nacionais e uma estrangeira financiaram as pesquisas publicadas pelo docente.

Apesar de $66.67 \%$ dos artigos do docente terem sido publicados em colaboração com instituições estrangeiras, apenas um deles recebeu financiamento.

Considerando-se o indicador de impacto normalizado, podemos constatar que em apenas duas ocasiões a média de citações esperada $(1,0)$ foi atingida e ultrapassada, em 2013 pela FAPESP e em 2016 pela French National Research Agency (ANR).

Quanto às citações, os maiores índices estão concentrados nos artigos mais antigos, de 2009 e 2011, confirmando o fato de que artigos com maior tempo de exposição tendem a receber mais citações. 
Tabela 155 - Agências de Fomento que apoiaram as pesquisas que geraram as publicações com participação do Docente 25, distribuídas por ano

\begin{tabular}{lcccc}
\hline Agências de Fomento por Ano & Artigos & Citações & Citações/Artigo & Impacto Normalizado \\
\hline 2009 & 1 & 21 & 21 & 0,84 \\
$\quad$ CNPq & 1 & 21 & 21 & 0,84 \\
$\quad$ FAPESP & & & & \\
2011 & 3 & 32 & 10,67 & 0,56 \\
$\quad$ CNPq & 4 & 47 & 11,75 & 0,64 \\
$\quad$ FAPESP & 1 & 1 & 1 & 1,34 \\
2013 & 1 & 3 & 3 & 0,47 \\
$\quad$ FAPESP & 1 & 3 & 3 & 0,47 \\
2015 & & & & 1,78 \\
$\quad$ CNPq & 1 & 6 & 6 & \\
$\quad$ FAPESP & 1 & & \\
2016 & French Nat. Res. Agency (ANR) & 1 & & \\
\hline \hline
\end{tabular}

Fonte: Incites com dados da WoS Core Collection

- Análise de visibilidade da produção científica

No que diz respeito à visibilidade da produção científica do docente, esta é medida levando em conta a quantidade de artigos registrada no Dedalus (21) e quantidade de artigos indexada na WoS (9), assim o percentual do Docente 25 é de $42,86 \%$.

Outro fator analisado é o percentual de artigos presentes em periódicos de impacto. A Tabela 156 apresenta os artigos do docente publicados em periódicos indexados na WoS Core Collection, distribuídos segundo Ciclos de Avaliação da CAPES e percentual publicado em periódicos do 10 Quartil do FI/JCR. Dos nove artigos do Docente 25 indexados na WoS Core Collection, apenas um está presente no 1ㅇ Quartil, tendo sido publicado durante o período coberto pela Trienal de 2007.

Tabela 156 - Artigos publicados pelo Docente 25 distribuídos por Ciclos de Avaliação da CAPES e indexados em periódicos do 10 Quartil do FI/JCR

\begin{tabular}{lcc}
\hline Ciclos de Avaliação CAPES & Total de Artigos & \% Artigos no 10. Quartil \\
\hline Trienal 2007 & 1 & $100,00 \%$ \\
Trienal 2010 & 1 & $0,00 \%$ \\
Trienal 2013 & 4 & $0,00 \%$ \\
Quadrienal 2017 & 3 & $0,00 \%$ \\
\hline \hline Total & $\mathbf{9}$ & $\mathbf{1 1 , 1 1 \%}$
\end{tabular}

Fonte: Incites com dados da WoS Core Collection 
Analisando-se a publicação científica relacionada aos instrumentos de Avaliação da CAPES, a Tabela 157 apresenta a quantidade de artigos publicados distribuídos pelos Ciclos de Avaliação e classificação nos estratos Qualis da área de avaliação das Geociências.

Verifica-se que $44,44 \%$ dos artigos do Docente 25 encontram-se no estrato $A 2$, outros $44,44 \%$ no B1 e por fim um artigo no B3. Além disso, verifica-se na Trienal de 2013 que dos quatro artigos publicados nesse período, três foram em revistas A2. No entanto no período coberto pela Quadrienal de 2017 dos três artigos publicados nenhum estava presente nos estratos mais altos.

Tabela 157 - Artigos publicados pelo Docente 25 distribuídos por Ciclos de Avaliação da CAPES e classificação do periódico nos estratos Qualis da área de avaliação das Geociências

\begin{tabular}{|c|c|c|c|c|}
\hline \multirow{2}{*}{ Periódicos e Ciclo de Avaliação } & \multicolumn{3}{|c|}{ Estratos Qualis } & \multirow{2}{*}{ Total } \\
\hline & A2 & B1 & B3 & \\
\hline 2004-2006 - TRIENAL 2007 & 1 & & & 1 \\
\hline JOURNAL OF HYDROLOGY & 1 & & & 1 \\
\hline 2007-2009 - TRIENAL 2010 & & 1 & & 1 \\
\hline ANAIS DA ACADEMIA BRASILEIRA DE CIENCIAS & & 1 & & 1 \\
\hline 2010-2012 - TRIENAL 2013 & 3 & 1 & & 4 \\
\hline ANAIS DA ACADEMIA BRASILEIRA DE CIENCIAS & & 1 & & 1 \\
\hline APPLIED GEOCHEMISTRY & 1 & & & 1 \\
\hline JOURNAL OF SOUTH AMERICAN EARTH SCIENCES & 2 & & & 2 \\
\hline 2013-2016 - QUADRIENAL 2017 & & 2 & 1 & 3 \\
\hline ENVIRONMENTAL EARTH SCIENCES & & 1 & & 1 \\
\hline JOURNAL OF CONTAMINANT HYDROLOGY & & 1 & & 1 \\
\hline PROCEDIA EARTH AND PLANETARY SCIENCE & & & 1 & 1 \\
\hline Total & 4 & 4 & 1 & 9 \\
\hline
\end{tabular}

Fonte: Elaborada pelo autor com dados da WoS Core Collection e Qualis/CAPES.

De forma a aprofundar a análise sobre as colaborações e a visibilidade das publicações, a Tabela 158 apresenta as instituições que colaboraram com o Docente 25 em dois ou mais artigos, distribuídas entre os Ciclos de Avaliação da CAPES, com a indicação do percentual dos artigos no 1ㅇ Quartil do JCR.

Somente uma instituição atendeu ao critério estabelecido, Palacky University Olomouc da República Checa e sua participação se restringiu somente à Trienal de 2013 e nenhum dos artigos foi publicado em periódicos do 1‥ Quartil. 
Tabela 158 - Artigos publicados pelo Docente 25 distribuídos segundo instituições que colaboraram duas ou mais vezes e Ciclos de Avaliação da CAPES, com indicação do percentual de artigos no 1 - Quartil do JCR

\begin{tabular}{lcc}
\hline Ciclos & Trienal $\mathbf{2 0 1 3}$ & Total \\
\hline Palacky University Olomouc & & \\
$\quad$ Artigos & 2 & 2 \\
$\%$ Artigos no 10. Quartil & $0,00 \%$ & $0,00 \%$ \\
\hline \hline Total Artigos & $\mathbf{2}$ & $\mathbf{2}$ \\
\hline \hline Total \% Arts. no 10. Quartil & $\mathbf{0 , 0 0 \%}$ & $\mathbf{0 , 0 0 \%}$ \\
\hline
\end{tabular}

Fonte: Elaborada pelo autor com dados da WoS Core Collection e Qualis/CAPES.

\section{- Análise de impacto da produção científica}

Os critérios para a análise de impacto compreendem a análise das citações recebidas e, do total de artigos indexados, a quantidade destes nos Top 10\%. Nenhum dos artigos do Docente 25 se encontrava presente no Top 10\%, portanto decidiu-se basear a análise Impacto da Citação e no Impacto Normalizado.

A Tabela 159 traz os dados de total de artigos, percentual de artigos citados, total de citações, citações por artigo e o Impacto Normalizado. Verifica-se que nos anos de 2013 e 2016 o Docente 25 esteve acima da média esperada $(1,0)$ no impacto normalizado. Quanto às citações por artigo o destaque fica para os anos de $2009 \mathrm{com}$ um índice 21,0 e nos anos de 2006 e 2011 com 12,0 e 11,8 respectivamente. Cabe destacar que o tempo de exposição do artigo é um fator preponderante para recebimento de doações, pois quanto maior a idade do artigo, maiores as chances ele tem de obter mais citações.

Tabela 159 - Impacto dos artigos do Docente 25 distribuídos por ano de publicação

\begin{tabular}{cccccc}
$\begin{array}{c}\text { Ano de } \\
\text { Publicação }\end{array}$ & $\begin{array}{c}\text { Total de } \\
\text { Art. }\end{array}$ & $\begin{array}{c}\text { \% Art. } \\
\text { Citados }\end{array}$ & Citações & $\begin{array}{c}\text { Impacto da } \\
\text { Citação }\end{array}$ & $\begin{array}{c}\text { Impacto } \\
\text { Normalizado }\end{array}$ \\
\hline 2006 & 1 & $100,00 \%$ & 12 & 12,0 & 0,5 \\
2009 & 1 & $100,00 \%$ & 21 & 21,0 & 0,8 \\
2011 & 4 & $100,00 \%$ & 47 & 11,8 & 0,6 \\
2013 & 1 & $100,00 \%$ & 1 & 1,0 & 1,3 \\
2015 & 1 & $100,00 \%$ & 3 & 3,0 & 0,5 \\
2016 & 1 & $100,00 \%$ & 6 & 6,0 & 1,8 \\
\hline \hline Total & 9 & $\mathbf{1 0 0 , 0 0 \%}$ & $\mathbf{9 0}$ & --- & --- \\
\hline
\end{tabular}

Fonte: Incites com dados da WoS Core Collection 
- Análise das referências utilizadas

O último item a se analisar são as referências utilizadas pelo Docente na redação de seus artigos. Ao todo o Docente 25 utilizou 181 fontes bibliográficas diferentes, citando-as 325 vezes em seus nove artigos, gerando uma média de 36,11 referências por trabalho.

Utilizando-se as Zonas de Bradford para analisar as principais publicações citadas nos artigos, pôde-se verificar pelas Tabelas 160 e 161 que, das 325 referências utilizadas, o primeiro terço delas (Zona 1 - com 108 referências) estão concentradas em 20 periódicos que correspondem a 11,05\% das publicações; já no segundo terço (Zona 2 com 108 referências) em 52 publicações, já possuindo uma maior variedade de tipologias de documentos e correspondendo a $28,73 \%$. O terceiro terço é a zona de maior dispersão com um total de 109 publicações, sendo a maioria delas com baixa frequência de citação (não sendo, portanto, apresentadas na tabela).

Essas 72 publicações somadas correspondem a 39,78\% das publicações, que, por conseguinte, correspondem a $66,46 \%$ de todas as referências citadas.

Tabela 160 - Lista de Referências utilizadas nos artigos do Docente 25 distribuídas pelas Zonas 1 e 2 de Bradford

(continua)

\begin{tabular}{|c|c|c|c|c|}
\hline$\#$ & Publicações & Citações & \% Citações & Zona de Bradford \\
\hline 1 & J HYDROL & 13 & $4,00 \%$ & \multirow{20}{*}{ Zona 1} \\
\hline 2 & ENVIRON SCI TECHNOL & 11 & $3,38 \%$ & \\
\hline 3 & APPL GEOCHEM & 11 & $3,38 \%$ & \\
\hline 4 & THESIS U SAO PAULO & 8 & $2,46 \%$ & \\
\hline 5 & REV BRASILEIRA GEOCI & 8 & $2,46 \%$ & \\
\hline 6 & GEODERMA & 7 & $2,15 \%$ & \\
\hline 7 & SCI TOTAL ENVIRON & 5 & $1,54 \%$ & \\
\hline 8 & J GEOCHEM EXPLOR & 4 & $1,23 \%$ & \\
\hline 9 & CHEM GEOL & 4 & $1,23 \%$ & \\
\hline 10 & P NATL ACAD SCI USA & 4 & $1,23 \%$ & \\
\hline 11 & AN ACAD BRAS CIENC & 4 & $1,23 \%$ & \\
\hline 12 & MICROBIOLOGY+ & 4 & $1,23 \%$ & \\
\hline 13 & HYDROBIOLOGIA & 4 & $1,23 \%$ & \\
\hline 14 & GEOLOGY & 3 & $0,92 \%$ & \\
\hline 15 & HYDROGEOL J & 3 & $0,92 \%$ & \\
\hline 16 & ENVIRON GEOL & 3 & $0,92 \%$ & \\
\hline 17 & SCIENCE & 3 & $0,92 \%$ & \\
\hline 18 & GROUNDWATER & 3 & $0,92 \%$ & \\
\hline 19 & WATER RESOUR RES & 3 & $0,92 \%$ & \\
\hline 20 & GEOCHEMISTRY GROUNDW & 3 & $0,92 \%$ & \\
\hline
\end{tabular}


Tabela 160 - Lista de Referências utilizadas nos artigos do Docente 25 distribuídas pelas Zonas 1 e 2 de Bradford

(continuação)

\begin{tabular}{|c|c|c|c|}
\hline$\#$ & Publicações & Citações & \% Citações \\
\hline 1 & WATER RES & 3 & $0,92 \%$ \\
\hline 2 & BRAZ J GEOL & 3 & $0,92 \%$ \\
\hline 3 & J S AM EARTH SCI & 3 & $0,92 \%$ \\
\hline 4 & GROUND WATER & 3 & $0,92 \%$ \\
\hline 5 & ECOLOGY & 2 & $0,62 \%$ \\
\hline 6 & GEOCHEM-EXPLOR ENV A & 2 & $0,62 \%$ \\
\hline 7 & B DNPM DGM & 2 & $0,62 \%$ \\
\hline 8 & MICROBIOL-SGM & 2 & $0,62 \%$ \\
\hline 9 & EPA600391021 & 2 & $0,62 \%$ \\
\hline 10 & SOIL SCI SOC AM J & 2 & $0,62 \%$ \\
\hline 11 & BRAZILIAN JOURNAL OF BIOLOGY & 2 & $0,62 \%$ \\
\hline 12 & MAPEAMENTO VULNERABI & 2 & $0,62 \%$ \\
\hline 13 & APPL ENVIRON MICROB & 2 & $0,62 \%$ \\
\hline 14 & LIMNOL OCEANOGR & 2 & $0,62 \%$ \\
\hline 15 & FEMS MICROBIOL ECOL & 2 & $0,62 \%$ \\
\hline 16 & TECTONICS & 2 & $0,62 \%$ \\
\hline 17 & ENV TRACERS SUBSURFA & 2 & $0,62 \%$ \\
\hline 18 & J HAZARD MATER & 2 & $0,62 \%$ \\
\hline 19 & DIAGN IMPR SAL ALK S & 2 & $0,62 \%$ \\
\hline 20 & VERH INT VEREIN LIMN & 2 & $0,62 \%$ \\
\hline 21 & STAND METH EX WAT WA & 2 & $0,62 \%$ \\
\hline 22 & J ENVIRON QUAL & 2 & $0,62 \%$ \\
\hline 23 & AQUAT CONSERV & 2 & $0,62 \%$ \\
\hline 24 & J CONTAM HYDROL & 2 & $0,62 \%$ \\
\hline 25 & MITT INT VER LIMNOL & 2 & $0,62 \%$ \\
\hline 26 & INT REV GES HYDROBIO & 2 & $0,62 \%$ \\
\hline 27 & FUNDAMENTOS LIMNOLOG & 2 & $0,62 \%$ \\
\hline 28 & INT J REMOTE SENS & 2 & $0,62 \%$ \\
\hline 29 & EXTREMOPHILES & 2 & $0,62 \%$ \\
\hline 30 & S REC NAT SOC PANT C & 2 & $0,62 \%$ \\
\hline 31 & PANTANAL MATO GROSSO & 2 & $0,62 \%$ \\
\hline 32 & WETLANDS & 2 & $0,62 \%$ \\
\hline 33 & ENV GEOCHEMISTRY & 2 & $0,62 \%$ \\
\hline 34 & REVISTA BRASILEIRA DE BOTANICA & 2 & $0,62 \%$ \\
\hline 35 & EARTH-SCI REV & 2 & $0,62 \%$ \\
\hline 36 & GROUNDW QUAL STAT SA & 2 & $0,62 \%$ \\
\hline 37 & CLAYS CLAY MINERALS & 2 & $0,62 \%$ \\
\hline 38 & AM MINERAL & 2 & $0,62 \%$ \\
\hline 39 & BRAZILIAN J AGR RES & 2 & $0,62 \%$ \\
\hline 40 & 994259 US GEOL SURV & 2 & $0,62 \%$ \\
\hline
\end{tabular}

Zona 2 
Tabela 160 - Lista de Referências utilizadas nos artigos do Docente 25 distribuídas pelas Zonas 1 e 2 de Bradford

(conclusão)

\begin{tabular}{|c|c|c|c|c|}
\hline \# & Publicações & Citações & \% Citações & Zona de Bradford \\
\hline 41 & B IG USP SERIE CIENT & 2 & $0,62 \%$ & \multirow{12}{*}{ Zona 2} \\
\hline 42 & REL EST VAL OR SOL A & 2 & $0,62 \%$ & \\
\hline 43 & ARCH HYDROBIOL & 2 & $0,62 \%$ & \\
\hline 44 & GEOLOGIA USP SERIE C & 2 & $0,62 \%$ & \\
\hline 45 & TRAC-TREND ANAL CHEM & 2 & $0,62 \%$ & \\
\hline 46 & GEOLOGIA CONTINENTE & 2 & $0,62 \%$ & \\
\hline 47 & ANU I GEOC & 2 & $0,62 \%$ & \\
\hline 48 & GEOCIENCIAS & 2 & $0,62 \%$ & \\
\hline 49 & QUATERN INT & 2 & $0,62 \%$ & \\
\hline 50 & 1406C US GEOL SURV & 2 & $0,62 \%$ & \\
\hline 51 & GEOPHYS J INT & 2 & $0,62 \%$ & \\
\hline 52 & GROUND WATER MONIT R & 2 & $0,62 \%$ & \\
\hline Total & 72 Títulos & 216 & $66,46 \%$ & \\
\hline
\end{tabular}

Fonte: Elaborada pelo autor com dados da WoS Core Collection.

Tabela 161 - Quantidade de publicações citadas pelo Docente 25 distribuídas pelas Zonas de Bradford

\begin{tabular}{lcccc}
\hline Zonas de Bradford & Total de Publicações & \% Publicações & Total de Citações & \% Citações \\
\hline Zona 1 & 20 & $11,05 \%$ & 108 & $33,23 \%$ \\
\hline Zona 2 & 52 & $28,73 \%$ & 108 & $33,23 \%$ \\
Zona 3 & 109 & $60,22 \%$ & 109 & $33,54 \%$ \\
\hline \hline Total & $\mathbf{1 8 1}$ & $\mathbf{1 0 0 , 0 0 \%}$ & $\mathbf{3 2 5}$ & $\mathbf{1 0 0 , 0 0 \%}$ \\
\hline
\end{tabular}

Fonte: Elaborada pelo autor com dados da WoS Core Collection.

Tais dados permitem ainda analisar a relação de onde se publica com o que se cita. A Tabela 162 apresenta sete periódicos nos quais foram publicados os nove artigos do Docente 25. Dos dois primeiros com maior número de publicações um está presente na Zona 1 e o outro na Zona 2, do restante dois estão na Zona 1, um na Zona 2 e dois não foram citados.

Durante a entrevista quando perguntado sobre as publicações mais importantes do seu campo de atuação o Docente 25 citou os periódicos: Applied Geochemistry, Journal of Hydrology, Hydrogeology Journal e Geologia USP. Série Científica. Dessas quatro, três estão na Zona 1 e uma na Zona 2, além disso o docente teve publicação nas duas primeiras. 
Tabela 162 - Lista de periódicos nos quais o Docente 25 publicou seus artigos com indicação das Zonas de Bradford

\begin{tabular}{lccc}
\hline Título do Periódico & $\begin{array}{c}\text { Total de } \\
\text { Artigos }\end{array}$ & $\begin{array}{c}\% \text { Total de } \\
\text { Artigos }\end{array}$ & $\begin{array}{c}\text { Zonas de } \\
\text { Bradford }\end{array}$ \\
\hline $\begin{array}{l}\text { ANAIS DA ACADEMIA BRASILEIRA DE } \\
\text { CIENCIAS }\end{array}$ & 2 & $22,22 \%$ & 1 \\
$\begin{array}{l}\text { JOURNAL OF SOUTH AMERICAN EARTH } \\
\text { SCIENCES }\end{array}$ & 2 & $22,22 \%$ & 2 \\
JOURNAL OF CONTAMINANT HYDROLOGY & 1 & $11,11 \%$ & 2 \\
ENVIRONMENTAL EARTH SCIENCES & 1 & $11,11 \%$ & Não citado \\
\hline $\begin{array}{l}\text { PROCEDIA EARTH AND PLANETARY } \\
\text { SCIENCE }\end{array}$ & 1 & $11,11 \%$ & Não citado \\
\hline JOURNAL OF HYDROLOGY & 1 & $11,11 \%$ & 1 \\
\hline APPLIED GEOCHEMISTRY & 1 & $11,11 \%$ & 1 \\
\hline \hline Total Geral & 9 & $\mathbf{1 0 0 , 0 0 \%}$ & \\
\hline Fonte: Elaborada & &
\end{tabular}

Fonte: Elaborada pelo autor com dados da WoS Core Collection.

A Tabela 163 apresenta a idade das referências citadas pelo Docente 25 de acordo com o ano de publicação de cada um de seus artigos. A maior concentração encontra-se em referências da faixa de 11 a 20 anos, com 33,54\%, que somada às faixas de 0 a 5 e 6 a 10 anos correspondem a 80,31\% do total geral das referências com até 20 anos.

Tabela 163 - Idade das Referências citadas nos artigos do Docente 25

\begin{tabular}{cccc}
\hline Idade das Referências & Total de Citações & \% Citações \\
\hline $0-5$ & 76 & $23,38 \%$ \\
& $6-10$ & 76 & $23,38 \%$ \\
$11-20$ & 109 & $33,54 \%$ \\
& $21-30$ & 24 & $7,38 \%$ \\
& $31-40$ & 28 & $8,62 \%$ \\
& $41-50$ & 6 & $1,85 \%$ \\
& +50 & 6 & $1,85 \%$ \\
\hline \hline Total & & 325 & $100,00 \%$ \\
\hline Fonte: Elabora
\end{tabular}

Fonte: Elaborada pelo autor com dados da WoS Core Collection.

- Informações adicionais

O perfil de publicação do Docente 25 , identificado por ter poucos artigos indexados na WoS, corrobora a informação obtida durante sua entrevista. Quando perguntado sobre sua estratégia de publicação o docente respondeu que publicar, em 
seu campo de atuação, não é tão importante quanto os projetos que desenvolve e o impacto causado pelos resultados, que modificam ou geram políticas públicas.

Para o docente, isso é muito mais relevante do que publicar em um periódico internacional e aumentar seus indicadores pessoais de citação (Índice H). Assim, o instrumento qualitativo (entrevista) foi fundamental para entender melhor o perfil nacionalizado do docente.

Quanto aos processos avaliativos o docente destaca que o modelo CNPq acaba servindo de modelo para os outros processos e que ser avaliado é um processo normal, todavia destaca que é necessário levar em conta que há profissionais com perfil de docência, profissionais com perfil de pesquisa e outros com perfil administrativo. E todos devem coexistir e serem valorizados, independentemente da quantidade e impacto da sua produção científica.

Reforça ainda que se deve encontrar um meio termo, avaliando o grau de comprometimento do indivíduo com a instituição, independente da área em que atua.

De fato, a USP contrata um único tipo de perfil docente, o qual deve atender a todos os diferentes papéis: ministração de aulas, pesquisa, orientação e administração. Dessa forma, equilibrar o tempo para atender a todos esses papéis torna-se uma tarefa deveras dificultosa. 


\subsection{Discussão geral}

Os perfis bibliométricos, complementados com as informações obtidas com as entrevistas com os docentes da amostra, propiciaram uma análise qualitativa e quantitativa dos docentes analisados.

Permitiram evidenciar aspectos que somente os dados não permitiriam identificar, como por exemplo: as escolhas por produzir mais nacionalmente do que internacionalmente para alguns docentes; e o posicionamento das autorias nos artigos, que segue um padrão próprio e é utilizado pela maioria dos entrevistados, o qual cede a primeira autoria aos pós-graduandos.

Apesar de ser esta uma pesquisa acerca de avaliação em nível individual de pesquisadores, considerou-se, para fins de análise geral, lançar um olhar sobre alguns dos dados representados nos perfis bibliométricos de forma estruturada. Nesse sentido, o Quadro 2 apresenta uma análise comparativa dos docentes da amostra:

Pode-se verificar que dois docentes da amostra não tiveram evolução do seu nível de publicação rumo à internacionalização entre os dois subperíodos dos ciclos de avaliação da CAPES. Um deles teve decréscimo, Docente 14, e um, Docente 12, mantevese com o nível 2 de publicação internacional (acima de 60\%). A mediana do Status Final de todos os docentes também foi de nível 2.

Quanto à visibilidade da produção científica registrada no Dedalus e indexada na WoS, seis docentes obtiveram um percentual acima de $60 \%$. A mediana do conjunto dos nove docentes foi de $68,75 \%$, tendo como maior percentual o Docente 15 e como menor o Docente 08.

Considerando-se os artigos publicados no 1 Q Quartil de periódicos do JCR, a mediana foi de $41,18 \%$, com cinco docentes iguais ou acima desse percentual e tendo como o maior índice o Docente 15 com 61,29\%. E quanto aos estratos Qualis, cinco docentes também obtivem um percentual de publicação em periódicos $A, A 1$ e $A 2$ superior a $50 \%$, com uma mediana de $57,57 \%$, tendo o Docente 01 obtido o maior percentual, $68,18 \%$.

No que diz respeito à Colaboração Internacional sete docentes obtiveram um percentual acima de 50\%, com uma mediana de 56,10\%. Com destaque para o Docente 05 com 89,71\%, sendo o maior índice e o Docente 14 com o menor, correspondendo a $25 \%$. 


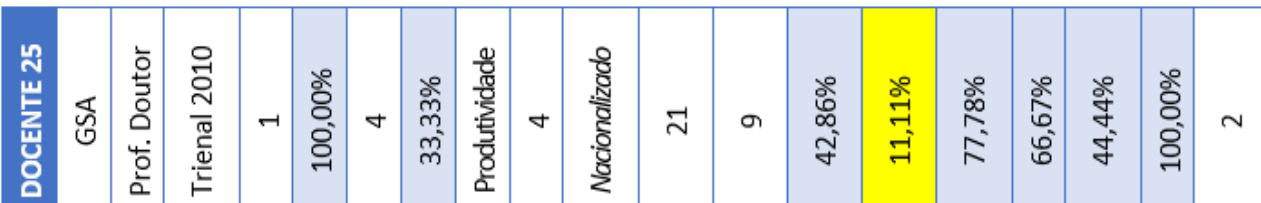

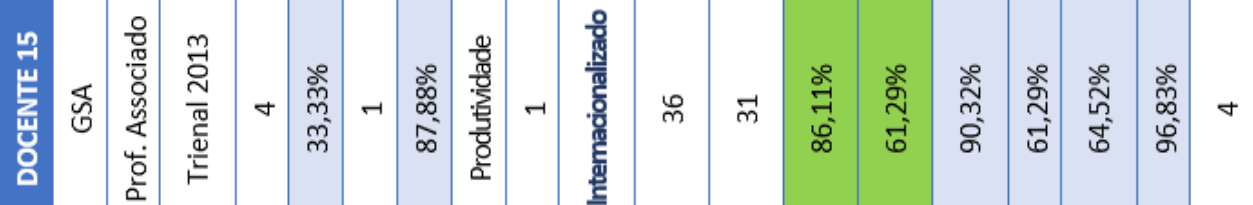

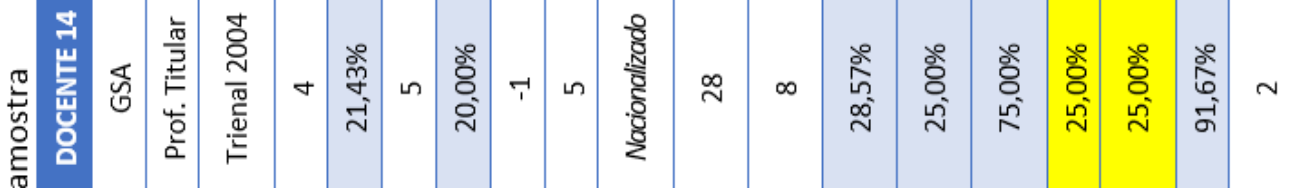

중

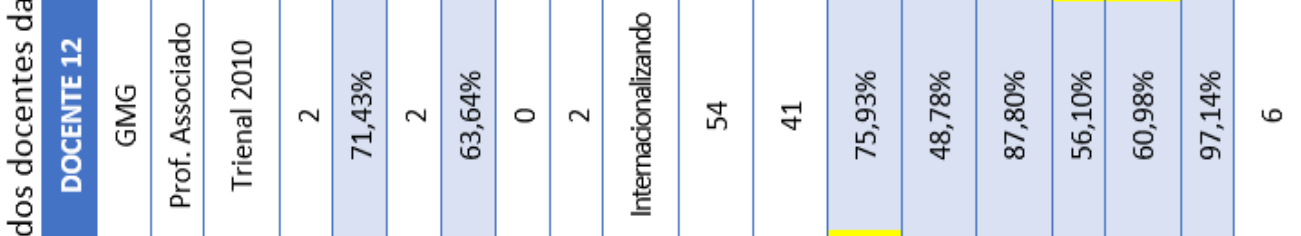

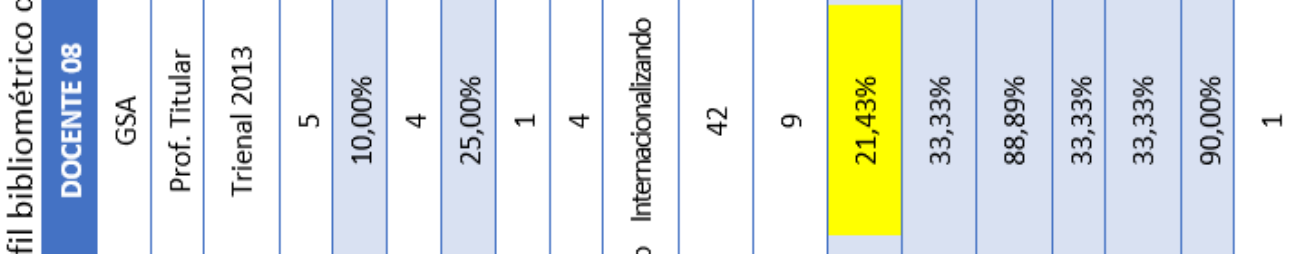

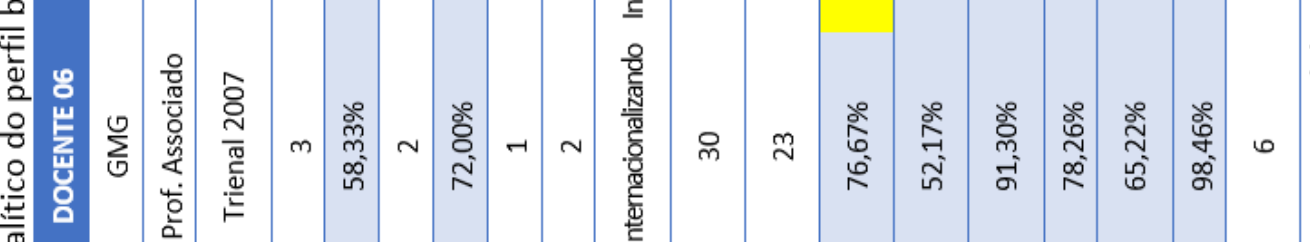

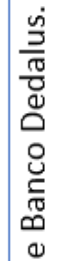

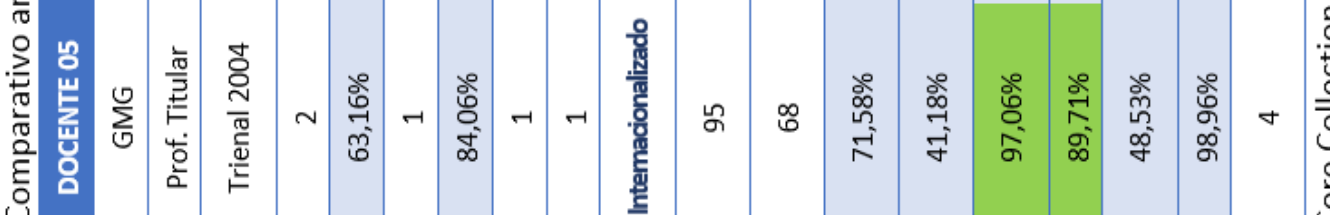

은 
E em relação à colaboração nacional, ou seja, artigos com colaboração de instituições brasileiras, a mediana foi de $87,80 \%$, um índice alto, comprovando que em tempos atuais, com as pressões por prazos e publicação, não se pode fazer ciência sozinho.

Quanto ao tipo dos status finais, apenas dois docentes estabeleceram um perfil nacionalizado, três já se encontram internacionalizados e quatro em processo de internacionalização da sua produção.

Pôde-se verificar também que os três docentes com menos publicações indexadas na WoS são do Departamento GSA (Docentes 08, 14 e 25). Eles também foram os que obtiveram os menores percentuais em visibilidade e artigos nos estratos mais altos do Qualis.

No entanto, desses três docentes, dois deles comentaram em suas entrevistas o caráter aplicado das suas áreas de atuação, o que, talvez, possa explicar esses índices mais baixos. Ao mesmo tempo, este tipo de resultado deve, antes de sugerir a baixa performance dos docentes, sinalizar que estudos devem primar por fontes mais abrangentes, no que diz respeito à produção científica em âmbito local.

Dessa forma, os dados apresentados demonstram um perfil de publicação dos docentes do IGc/USP voltado à colaboração internacional, que tem gerado boa visibilidade para sua produção, porém uma estratégia interessante seria intensificar sua produção em periódicos com maior impacto, tanto domésticos com perfil internacionalizado, quanto em estrangeiros. Inclusive, assumir um papel de liderança nos projetos de pesquisas e se apresentar mais como autor correspondente, pode elevar o status do docente e gerar colaborações internacionais profícuas, propiciando maior visibilidade, que poderão trazer consigo novas opções de financiamentos de pesquisa (DUDZIAK, 2018).

Todavia, há que se dosar tais estratégias a fim de que não se perca a essência da área e o compromisso da instituição em gerar conhecimento e inovar, por meio da pesquisa científica, as práticas profissionais locais/regionais. Publicar em eventos e em revistas domésticas na língua pátria são importantes estratégias para que o conhecimento atinja tanto os parceiros da indústria local, quanto os profissionais em atividade. A cultura de publicação de uma área, de um país, de uma instituição, não deveria ser compelida a se adequar às culturas externas ditadas por empresas 
detentoras de bases de dados indexadores, tampouco por grandes corporações editoriais.

Afinal, como bem destacado na discussão teórica, as políticas nacionais de incentivo à qualificação da produção científica não devem se basear exclusivamente em padrões de qualidade e/ou excelência internacionais com o objetivo de "recuperar o atraso" em relação aos países líderes da ciência.

A área de Geociências na CAPES tem tentado nas últimas avaliações utilizar critérios mais compreensivos, como por exemplo o uso do SJR em detrimento ao JIF/JCR. No entanto, periódicos domésticos não figuram nos dois mais altos extratos (A1 e A2) do Qualis Periódicos. E um fato interessante, analisando-se a produção de artigos científicos dos docentes do IGc/USP no período de 2001-2016 registrados no Banco Dedalus, é que dos três periódicos com maior número de publicações, os dois primeiros são domésticos: o Brazilian Journal of Geology (Extrato B1 - bem conceituado pela comunidade e publicado totalmente em inglês); e o Geologia USP: Série Científica (Extrato B2 - publicado em português e importante veículo de divulgação das pesquisas nacionais). Porém, pelos critérios estabelecidos no Qualis, não atingem patamares mais altos.

Por fim, retomando-se as 10 ações que não devem ser empreendidas ao se produzir uma análise bibliométrica individual alertadas por Glänzel \& Wouters (2013) podemos confirmar que o presente estudo atendeu a todos os critérios:

$\checkmark$ Não reduza o desempenho individual a um único número: foram utilizados vários indicadores para delineamento dos perfis bibliométricos, bem como informações complementares oriundas das entrevistas;

$\checkmark$ Não use o Fator de Impacto como medida de qualidade: o FI foi utilizado na adaptação do método somente como ferramentas para análise da visibilidade dos periódicos nos quais os docentes publicaram, porém não em números absolutos, mas sim utilizando-se o enquadramento deles no 1‥ Quartil, o que minimiza o problema de comparabilidade entre diferentes áreas/subáreas;

$\checkmark$ Não aplique "filtros bibliométricos" (secretos) para seleção: os filtros de seleção aplicados para obtenção dos dados de publicação dos docentes da amostra foram, como pode-se verificar nos Procedimentos Metodológicos, apresentados de forma transparente e aplicados a toda a amostra; 
$\checkmark$ Não aplique pesos arbitrários à coautoria: uma das principais preocupações do método, como se pode verificar tanto na entrevista como no perfil bibliométrico, diz respeito à verificação da sequência de coautoria dos trabalhos publicados pelos docentes da amostra. De maneira geral todos apresentaram uma prática de que a primeira autoria do trabalho é do pesquisador principal, em geral, os pós-graduandos. Ademais, o método não prevê aplicação de pesos, pois trata-se de um perfil bibliométrico voltado à uma avaliação qualitativa;

$\checkmark$ Não classifique os cientistas de acordo com um único indicador: como já dito anteriormente foram utilizados vários indicadores e mesmo nesta análise geral foram verificadas outras variáveis, assim como abordagem qualitativa, além dos indicadores absolutos;

$\checkmark$ Não combine medidas incomensuráveis: durante toda a adaptação e aplicação do método este foi um ponto norteador e daí o motivo do perfil bibliométrico ser dividido em seções e cada uma delas com indicadores apropriados, todos oriundos da mesma fonte de dados (WoS);

$\checkmark$ Não use estatísticas defeituosas: para evitar esse tipo de falha no método tomou-se a precaução de utilizar somente indicadores reconhecidos pela comunidade da bibliometria;

$\checkmark$ Não acredite cegamente nos "one-hit wonders" (um único hit de sucesso): na adaptação do método utilizamos formas de apresentação que privilegiassem a análise temporal, verificando tendências de publicação e impacto, justamente para evitar possíveis considerações baseadas em indicadores de dados agrupados e que porventura tivessem picos de alto impacto;

$\checkmark$ Não compare maçãs e laranjas: apesar de se considerar este método aplicável a diversas outras áreas do conhecimento, adaptações foram realizadas para melhor atender à área das Geociências, como por exemplo a adição do Qualis Periódicos específico da área e do indicador de Impacto de Citação Normalizado pela Categoria;

$\checkmark$ Não permita que prazos e carga de trabalho obriguem você a descartar boas práticas: todos os dados foram tratados e revisados para evitar possíveis falhas de análise, seguindo, dessa forma, as boas práticas que devem sempre ser utilizadas em trabalhos desse tipo. 
Pode-se considerar que o método de Gorraiz, Wieland \& Gumpenberger (2016), adaptado nesta pesquisa, mostrou-se funcional e atento às melhores práticas propostas pelos pesquisadores da Bibliometria (INSTITUT DE FRANCE; ACADÉMIE DES SCIENCES, 2011; GLÄNZEL; WOUTERS, 2013; HICKS et al., 2015), apresentando-se como uma alternativa aos modelos utilizados para as avaliações institucionais, como a da USP por exemplo, bem como naquela realizada pela CAPES para avaliar os PPGs. 


\section{CONSIDERAÇÕES FINAIS}

Retomando a proposição inicial, vislumbrou-se a necessidade de se propor um modelo de avaliação, baseado na análise bibliométrica individual, com uma abordagem compreensiva e contextual, mesclando os aspectos quantitativos e qualitativos da carreira dos docentes do Instituto de Geociências da Universidade de São Paulo.

Nesse sentido, este estudo constatou a aplicabilidade do método da Universidade de Viena, adaptando-o às necessidades desta pesquisa, assim como à comunidade estudada. Além disso, foi possível complementar a análise com dados oriundos do Sistema de Avaliação da CAPES, como o Qualis, além dos dados de produção obtidos da base de produção intelectual do Banco Dedalus, tornando seus resultados personalizados, e principalmente, reprodutíveis em qualquer outra área do conhecimento. Outros tipos de adaptação são igualmente possíveis, já que cada área se insere num universo próprio de fazeres e saberes, impondo a necessidade de análise contextualizada.

Além disso, o estudo resultou em um diagnóstico da produção científica, que permitiu identificar melhores práticas de comunicação científica entre os docentes do IGc/USP. Assim, levando-se em consideração alguns dos itens analisados nos perfis bibliométricos dos docentes da amostra, pode-se destacar algumas dessas práticas:

- Análise da cooperação do docente: foi possível identificar, com base nas tabelas de colaboração e no Quadro 2, que há uma relação direta entre o percentual de colaboração internacional e o percentual de artigos indexados na WoS (visibilidade). Para a maioria dos docentes que obteve o percentual mais alto de colaboração internacional, seu percentual de artigos indexados na WoS também ficou entre os mais altos. Além disso, o impacto dos artigos publicados com colaboradores internacionais também foi maior para a maioria dos docentes.

- Análise dos financiamentos de pesquisa recebidos: artigos publicados com apoio de agências de fomento do exterior (item relacionado diretamente à colaboração internacional) em geral tiveram maior impacto normalizado e, por conseguinte, mais citações por artigo. Além disso, essas publicações com 
maior impacto ocasionaram, consequentemente, aumento do impacto para as agências de fomento brasileiras.

- Análise de impacto da produção científica: docentes que publicaram em periódicos mais especializados (por exemplo Gondwana Research, Lithos e Precambrian Research), presentes no JCR e nos estratos mais altos do Qualis, obtiveram, especialmente nos últimos três anos avaliados (2014-2016), um índice acima da média esperada no impacto normalizado. Tais docentes também publicaram em periódicos regionais de menor impacto, entretanto sua estratégia de equilibrar e selecionar os veículos mais adequados para publicarem seus resultados tem resultado em um efeito positivo, posto que por um lado geram e compartilham o conhecimento de forma regionalizada, por outro divulgam seus resultados em veículos internacionais conceituados.

Destaca-se ainda que os resultados individuais obtidos, como se pôde verificar, foram detalhados e aprofundados, considerando vários indicadores bem como as opiniões e posicionamentos obtidos por meio da entrevista com os docentes, oferecendo subsídios para uma melhor compreensão do fenômeno analisado, como o suporte à identificação, desambiguação, coleta e análise dos dados utilizados no desenvolvimento do perfil bibliométrico.

Cabe aqui indicar as limitações da pesquisa, como a não realização de dois outros procedimentos metodológicos adotados pela equipe da Universidade de Viena (discussão e validação dos resultados com o pesquisador em avaliação e análises opcionais), que subsidiariam uma revisão, caso necessário, do Relatório Bibliométrico, no entanto o tempo reduzido da pesquisa de mestrado não permitiria uma segunda reunião com os docentes. Essa reanálise permitiria ainda uma melhor contextualização dos dados e dos resultados obtidos.

Certamente há muitos subsídios para uma maior contextualização, no entanto tal conteúdo não seria passível de publicação, uma vez que o Termo de Consentimento Livre e Esclarecido assinado pelo docente e por este pesquisador assegura o anonimato do sujeito em avaliação. E pelo fato de o IGc/USP possuir uma comunidade docente ativa diminuta, quaisquer dados contextualizados adicionais infringiria o Termo assinado. 
Entretanto, a aplicação dessas fases em um ambiente controlado e sem publicização permitiriam o uso de indicadores qualitativos que analisariam fatores além daqueles relativos à produtividade docente, como por exemplo: total de disciplinas ministradas por ano; total de orientações (graduandos e pós-graduandos) em andamento e concluídas; projetos de pesquisa em andamento e concluídos; tempo de contrato e idade; participação em comissões e/ou atividades administrativas do Instituto ou da USP; dentre outros.

Outra condição limitante identificada na pesquisa diz respeito à infraestrutura de pesquisa, em especial à falta de qualidade dos dados obtidos via WoS. Bases como esta, que são altamente utilizadas para estudos bibliométricos, deveriam primar pela qualidade de seus metadados, no entanto o que se constatou foram as muitas falhas de padronização de afiliação e de marcação de metadados (especialmente nas referências citadas).

Essa falta de qualidade nos dados pode gerar discrepâncias e resultar em subnotificação da produção de um indivíduo em análise, no caso de uma avaliação institucional baseada puramente em indicadores de produtividade.

Importante ressaltar ainda que a apesar de a pesquisa levar em conta a atividade de pesquisa do docente, em especial sua produção científica, a USP não possui esse tipo de função em seu quadro. O indivíduo é contratado como Servidor Docente, todavia, lhe é exigido diversos papéis, em especial o de pesquisador, pois sua produção é fator preponderante para sua evolução na carreira.

A cultura de pesquisa da área é um elemento-chave a ser considerado nas avaliações, uma vez que o tempo para a obtenção dos resultados de pesquisa difere entre as áreas. Nas Geociências esse tempo tende a ser maior do que em outras áreas das Ciências Exatas, uma vez que depende de um processo extenso que compreende o trabalho de campo para a coleta, preparo e análise da amostra a ser analisada. Portanto, um modelo de avaliação que empreende um olhar contextualizado é fundamental para uma instituição composta por centenas de cursos de graduação e pós-graduação e com dezenas de unidades de ensino, institutos especializados e museus como a USP.

Pode-se concluir que a utilização do método como um todo, para fins de avaliações institucionais, pode trazer benefícios, pelo fato de permitir uma análise 
detalhada da produção e impacto da pesquisa realizada, com o adicional de não fazê-la de maneira estática, mas considerando evoluções ao longo do tempo.

Ademais, a pesquisa pôde avançar com o método proposto por Gorraiz; Wieland; Gumpenberger (2016), no sentido de ter ampliado as fontes de dados; compreendido dados qualitativos da carreira do pesquisador utilizando para isso sistemas da própria Universidade e permitindo uma comparação entre o que o indivíduo efetivamente produziu (Dedalus - base inclusiva) e o que se encontra indexado em bases de dados internacionais (WoS - base seletiva); e ampliado o escopo das perguntas no questionário de entrevista e incluído questões pertinentes à visão e conhecimento do indivíduo acerca dos processos de avaliação e de internacionalização.

Como em toda pesquisa, percebe-se que, na pretensão de finalizá-la, enxerga-se mais adiante, sugerindo sua continuidade. Nota-se que o exercício realizado aponta a outros instrumentos metodológicos, a fim de tornar a análise mais abrangente. Pode-se apontar principalmente a baixa cobertura das bases de dados indexadoras como a WoS e a carência de conteúdos regionais, frente a produção dos docentes registradas no Dedalus, como se pôde perceber. Todavia, diante da necessidade de fontes de informação que viabilizem a análise de impacto, vislumbra-se num futuro próximo a possibilidade de se contar com o SciELO Citation Index, garantindo assim, análises mais contextualizadas sobre a produção nacional.

Por fim, considerando-se os processos de avaliação da CAPES, principais agentes temporais e analíticos deste estudo, pode-se ponderar que o método aqui apresentado auxiliaria sobremaneira as Comissões de Avaliação, que, como dito anteriormente, avaliam em nível Macro, baseados em indicadores de nível Meso. Os PPGs são compostos de pesquisadores e seu acompanhamento no nível Micro pode elucidar caminhos para agregação dos dados no nível do PPG, e então viabilizar análises comparativas mais apropriadas; assim como se deu nesta pesquisa, que avaliou em nível Micro, gerando indicadores para sustentar a análise Meso. 


\section{REFERÊNCIAS}

ABRAMO, G.; CICERO, T.; D'ANGELO, C. A. Individual research performance: A proposal for comparing apples to oranges. Journal of Informetrics, v. 7, n. 2, p. 528-539, 2013. Disponível em: <http://doi.org/10.1016/j.joi.2013.01.013>. Acesso em: 19 jun. 2017.

ARCHAMBAULT, É.; LARIVIÈRE, V. History of the journal impact factor: Contingencies and consequences. Scientometrics, v. 79, n. 3, p. 635-649, jun. 2009. Disponível em: <http://link.springer.com/10.1007/s11192-007-2036-x>. Acesso em: 6 jun. 2017.

ARCHAMBAULT, É.; LARIVIÈRE, V. The limits of bibliometrics for the analysis of the social sciences and humanities literature. In: World Social Science Report Knowledge: Knowledge Divides. Paris: United Nations Educational, Scientific and Cultural Organization, 2010. p. 251-254. Disponível em:

<http://unesdoc.unesco.org/images/0018/001883/188333e.pdf>. Acesso em: 17 jun. 2017.

BALBACHEVSKY, E. A pós-graduação no brasil novos desafios para uma política bemsucedida. In: SCHWARTZMAN, S.; BROCK, C. (Ed.). Os desafios da Educação no Brasil. Rio de Janeiro: Nova Fronteira, 2005. p. 275-304. Disponível em:

$<$ https://portais.ufg.br/up/67/o/Pos-Graduacao Brasil 2.pdf>. Acesso em: 30 maio 2017.

BALBACHEVSKY, E. Processos decisórios em política científica, tecnológica e de inovação no Brasil: análise crítica. São Paulo: Centro de Gestão e Estudos Estratégicos, 2010. . Disponível em:

<http://www.cgee.org.br/atividades/redirect.php?idProduto=6233 $>$. Acesso em: 3 jun. 2017.

BORNMANN, L.; LEYDESDORFF, L. Scientometrics in a changing research landscape: Bibliometrics has become an integral part of research quality evaluation and has been changing the practice of research. EMBO reports, v. 15, n. 12, p. 1228-1232, 1 dez. 2014. Disponível em:

<http://embor.embopress.org/cgi/doi/10.15252/embr.201439608>. Acesso em: 3 jun. 2017.

BORNMANN, L.; MUTZ, R. Growth rates of modern science: a bibliometric analysis based on the number of publications and cited references. Journal of the Association for Information Science and Technology, v. 66, n. 11, p. 2215-2222, nov. 2015. Disponível em: <http://doi.wiley.com/10.1002/asi.23329>. Acesso em: 3 jun. 2017.

BRADFORD, S. C. Sources of information on specific subjects. Engineering: an Illustrated Weekly Journal, v. 137, n. 3550, p. 85-86, 1934.

BRASIL. Lei n. 9394 de 20 de dezembro de 1996 que estabelece as diretrizes e bases da educação nacional. Diário Oficial [da República Federativa do Brasil], v. 134, n. 248, p. 29, 23 dez. 1996. Disponível em:

<http://www.planalto.gov.br/ccivil 03/leis/L9394compilado.htm>. Acesso em: 19 jun. 
2017.

BUELA-CASAL, G.; PERAKAKIS, P.; TAYLOR, M.; CHECA, P. Measuring internationality: Reflections and perspectives on academic journals. Scientometrics, v. 67, n. 1, p. 4565, 2006. Disponível em: <http://doi.org/10.1556/Scient.67.2006.1.4>. Acesso em: 12 ago. 2018.

CLARIVATE ANALYTICS. In Memoriam: Dr Eugene Garfield. Disponível em: <http://clarivate.com/dr-garfield/>. Acesso em: 17 jun. 2017a.

CLARIVATE ANALYTICS. Web of Science Fact Book. [s.I.] Clarivates Analytics, 2017b. . Disponível em:

<http://images.info.science.thomsonreuters.biz/Web/ThomsonReutersScience/\%7Bd6 b7faae-3cc2-4186-8985a6ecc8cce1ee\%7D Crv WoS Upsell Factbook A4 FA LR edits.pdf>. Acesso em: 17 jun. 2017.

COMISSÃO PERMANENTE DE AVALIAÇÃO. Avaliação Institucional USP 2010-2014 - 40. Ciclo: Unidade. São Paulo: Universidade de São Paulo, 2014a. . Disponível em: <http://sites.usp.br/gvr/wp-content/uploads/sites/17/2014/12/Formulario-Aval-InstitUnidades-CPA-Nov-2014.pdf>. Acesso em: 21 jun. 2017.

COMISSÃO PERMANENTE DE AVALIAÇÃO. Avaliação Institucional USP 2010-2014 - 40 Ciclo: Departamento. São Paulo: Universidade de São Paulo, 2014b. . Disponível em: <http://sites.usp.br/gvr/wp-content/uploads/sites/17/2014/12/Formul-AvaliaçãoInstituc-Deptos-CPA-Nov-2014.pdf>. Acesso em: 21 jun. 2017.

COMISSÃO PERMANENTE DE AVALIAÇÃO. Avaliação Institucional USP 2010-2014. São Paulo: Universidade de São Paulo, 2016. . Disponível em: <http://sites.usp.br/gvr/wpcontent/uploads/sites/17/2016/04/Relatório-de-Avaliação-Institucional-2010-2014Apresentação-e-Análise-dos-Resultados-pela-CPA-11042016.pdf>. Acesso em: 21 jun. 2017.

COSTAS, R. Discussões gerais sobre as características mais relevantes de infraestruturas de pesquisa para a cientometria. In: MUGNAINI, R.; FUJINO, A.; KOBASHI, N. Y. (Ed.). Bibliometria e cientometria no Brasil: infraestrutura para avaliação da pesquisa científica na era do Big Data. São Paulo: Universidade de São Paulo. Escola de Comunicações e Artes, 2017. p. 19-42. Disponível em: $<$ http://www.livrosabertos.sibi.usp.br/portaldelivrosUSP/catalog/book/129>. Acesso em: 03 jun. 2017.

COSTAS, R.; VAN LEEUWEN, T. N.; BORDONS, M. A bibliometric classificatory approach for the study and assessment of research performance at the individual level: The effects of age on productivity and impact. Journal of the American Society for Information Science and Technology, v. 61, n. 8, p. 1564-1581, 2010. Disponível em: <http://doi.wiley.com/10.1002/asi.21348>. Acesso em: 22 jun. 2017.

DAVYT, A.; VELHO, L. A avaliação da ciência e a revisão por pares: passado e presente. Como será o futuro? História, Ciências, Saúde-Manguinhos, v. 7, n. 1, p. 93-116, jun. 
2000. Disponível em: <http://www.scielo.br/scielo.php?script=sci arttext\&pid=S0104-

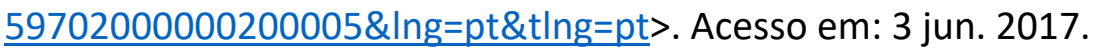

DUDZIAK, E. A. Quantidade ou qualidade: o que vale mais na produção científica?

Disponível em: <http://www.sibi.usp.br/noticias/quantidade-ou-qualidade-o-que-valemais-na-producao-cientifica/>. Acesso em: 26 jul. 2018.

ELSEVIER. Scopus ${ }^{\circledast}$. Disponível em: <https://www.elsevier.com/solutions/scopus>. Acesso em: 17 jun. 2017.

FAUSTO, S.; MUGNAINI, R. Os rankings como objeto dos estudos métricos da informação. In: Encontro Nacional de Pesquisa em Ciência da Informação (ENANCIB), XIV, Florianópolis. Anais... Florianópolis: Universidade Federal de Santa Catarina, 2013. Disponível em:

<http://enancib2013.ufsc.br/index.php/enancib2013/XIVenancib/paper/view/458>. Acesso em: 3 jun. 2017.

GARFIELD, E. Citation Indexes for Science: A New Dimension in Documentation through Association of Ideas. Science, v. 122, n. 3159, p. 108-111, 15 jul. 1955. Disponível em: <http://www.sciencemag.org/cgi/doi/10.1126/science.122.3159.108>. Acesso em: 3 jun. 2017.

GARFIELD, E. The mystery of the transposed journal lists -- wherein Bradford's law of scattering is generalized according to Garfield's law of concentration. Essays of an Information Scientist, v. 1, n. 1, p. 222-223, 1971. Disponível em:

<http://www.garfield.library.upenn.edu/essays/V1p222y1962-73.pdf>. Acesso em: 15 jun. 2017.

GARFIELD, E. Citation Analysis as a Tool in Journal Evaluation: Journals can be ranked by frequency and impact of citations for science policy studies. Science, v. 178, n. 4060, p. 471-479, 3 nov. 1972. Disponível em:

<http://www.sciencemag.org/cgi/doi/10.1126/science.178.4060.471>. Acesso em: 6 jun. 2017.

GARFIELD, E. Journal impact factor: a brief review. CMAJ : Canadian Medical

Association journal, v. 161, n. 8, p. 979-80, 19 out. 1999. Disponível em:

<http://www.cmaj.ca/content/161/8/979.full>. Acesso em: 6 jun. 2017.

GARFIELD, E. The History and Meaning of the Journal Impact Factor. JAMA, v. 295, n. 1, p. 90, 4 jan. 2006. Disponível em:

$<$ http://jama.jamanetwork.com/article.aspx?doi=10.1001/jama.295.1.90>. Acesso em: 3 jun. 2017.

GARVEY, W. D. Communication: the Essence of Science. New York: Pergamon Press Ltd., 1979. Disponível em: <http://doi.org/10.1016/B978-0-08-023344-4.50002-7>. Acesso em: 3 jun. 2017.

GLÄNZEL, W. Bibliometrics as a research field: a course on theory and application of bibliometric indicatorsCourse Handouts. [s.I: s.n.]. Disponível em: 
<https://www.researchgate.net/publication/242406991 Bibliometrics as a research field A course on theory and application of bibliometric indicators $>$. Acesso em: 3 jun. 2017.

GLÄNZEL, W. Analysis of co-authorship patterns at the individual level.

Transinformação, v. 26, n. 3, p. 229-238, dez. 2014. Disponível em:

$<$ http://www.scielo.br/scielo.php?script=sci arttext\&pid=S010337862014000300229\&Ing=en\&tlng=en>. Acesso em: 3 jun. 2017.

GLÄNZEL, W.; DEBACKERE, K. On the opportunities and limitations in using bibliometric indicators in a policy relevant context. In: BALL, R. (Ed.). Bibliometric analysis in science and research: applications, benefits and limitations (2nd Conference of the Central Library, Jülich 5.- 7. November 2003) - Conference Proceedings). [s.I.] Forschungszentrum Jülich, 2003. p. 225-236. Disponível em: <http://juser.fzjuelich.de/record/34921/files/Bibliometric Analysis.pdf>. Acesso em: 3 jun. 2017.

GLÄNZEL, W.; WOUTERS, P. The dos and don'ts in individual - level bibliometrics. In: 14th International Society of Scientometrics and Informetrics Conference, Viena.

Anais... Viena: International Society of Scientometrics and Informetrics, 2013. Disponível em: <https://www.slideshare.net/paulwouters1/issi2013-wg-pw>. Acesso em: 3 jun. 2017.

GORRAIZ, J.; WIELAND, M.; GUMPENBERGER, C. Individual bibliometric assessment at University of Vienna: From numbers to multidimensional profiles. El Profesional de la Información, v. 25, n. 6, p. 901, 14 nov. 2016. Disponível em:

<http://www.elprofesionaldelainformacion.com/contenidos/2016/nov/07.html>. Acesso em: 3 jun. 2017.

GROSS, P. L. K.; GROSS, E. M. College libraries and chemical education. Science, v. 66, n. 1713, p. 385-389, 28 out. 1927. Disponível em:

<http://www.sciencemag.org/cgi/doi/10.1126/science.66.1713.385>. Acesso em: 17 jun. 2017.

GUMPENBERGER, C.; SORZ, J.; WIELAND, M.; GORRAIZ, J. Humanities and social sciences in the bibliometric spotlight - Research output analysis at the University of Vienna and considerations for increasing visibility. Research Evaluation, v. 25, n. 3, p. 271-278, jul. 2016. Disponível em: <https://academic.oup.com/rev/articlelookup/doi/10.1093/reseval/rvw013>. Acesso em: 3 jun. 2017.

HAUSTEIN, S.; LARIVIÈRE, V. The Use of Bibliometrics for Assessing Research: Possibilities, Limitations and Adverse Effects. In: Incentives and Performance. Cham, Switzerland: Springer International Publishing, 2015. p. 121-139. Disponível em: <http://doi.org/10.1007/978-3-319-09785-5 8>. Acesso em: 17 jun. 2017.

HICKS, D. The difficulty of achieving full coverage of international social science literature and the bibliometric consequences. Scientometrics, v. 44, n. 2, p. 193-215, 1999. Disponível em: <https://link.springer.com/article/10.1007/BF02457380>. Acesso em: 17 jun. 2017. 
HICKS, D.; WOUTERS, P.; WALTMAN, L.; DE RIJCKE, S.; RAFOLS, I. Bibliometrics: The Leiden Manifesto for research metrics. Nature, v. 520, n. 7548, p. 429-431, 22 abr. 2015. Disponível em: <http://www.nature.com/doifinder/10.1038/520429a>. Acesso em: 6 jun. 2017.

HOOD, W. W.; WILSON, C. S. The literature of bibliometrics, scientometrics and informetrics. Scientometrics, v. 52, n. 2, p. 291-314, 2001. Disponível em: <http://link.springer.com/10.1023/A:1017919924342>. Acesso em: 15 jun. 2017.

HUANG, M.-H. A comparison of three major academic rankings for world universities: from a research evaluation perspective. Journal of Library and Information Studies, v. 9, n. 1, p. 1-25, 2011. Disponível em: <http://jlis.lis.ntu.edu.tw/article/v9-1-1.pdf>. Acesso em: 19 jun. 2017.

INSTITUT DE FRANCE; ACADÉMIE DES SCIENCES. On the Proper Use of Bibliometrics To Evaluate Individual ResearchersRapport de l'Académie des sciences. Paris: Institut de France, Académie des Sciences, 2011. . Disponível em: <http://www.academiesciences.fr/en/Advice-Notes-and-Reports/on-the-proper-use-of-bibliometrics-toevaluate-individual-researchers.html>. Acesso em: 3 jun. 2017.

LARIVIÈRE, V.; ARCHAMBAULT, É.; GINGRAS, Y.; VIGNOLA-GAGNE, É. The place of serials in referencing practices: Comparing natural sciences and engineering with social sciences and humanities. Journal of the American Society for Information Science and Technology, v. 57, n. 8, p. 997-1004, jun. 2006. Disponível em: <http://doi.wiley.com/10.1002/asi.20349>. Acesso em: 17 jun. 2017.

LARIVIÈRE, V.; HAUSTEIN, S.; MONGEON, P. The Oligopoly of Academic Publishers in the Digital Era. PLOS ONE, v. 10, n. 6, p. e0127502, 10 jun. 2015. Disponível em: <http://dx.plos.org/10.1371/journal.pone.0127502>. Acesso em: 3 jun. 2017.

MARCOVITCH, J. Monitoramento das Métricas de Desempenho Acadêmico. In: MARCOVITCH, J. (Ed.). Repensar a universidade: desempenho acadêmico e comparações internacionais. São Paulo: Com-Arte; Fapesp, 2018. p. 95-109. Disponível em: <http://doi.org.br/10.11606/9788571661868>. Acesso em: 10 out. 2018.

MARGINSON, S.; VAN DER WENDE, M. To Rank or To Be Ranked: The Impact of Global Rankings in Higher Education. Journal of Studies in International Education, v. 11, n. 3-4, p. 306-329, 2007. Disponível em:

$<$ http://jsi.sagepub.com/cgi/doi/10.1177/1028315307303544>. Acesso em: 19 jun. 2017.

MARRARA, T. Internacionalização da Pós-Graduação: objetivos, formas e avaliação. Revista Brasileira de Pós-Graduação, v. 4, n. 8, p. 245-262, 2007. Disponível em: <http://ojs.rbpg.capes.gov.br/index.php/rbpg/article/view/132>. Acesso em: 30 maio. 2017.

MEADOWS, A. J. A comunicação científica. Brasília: Briquet de Lemos/Livros, 1999.

MÉTRICAS de Desempenho Universitário para Efeito de Comparação Internacional. 
Disponível em: <http://metricas.usp.br>. Acesso em: 10 out. 2018.

MINISTÉRIO DA EDUCAÇÃO. CAPES. Documento de Área: Geociências (A. Roisenberg, M. M. Mahiques, E. A. Mitishita, Eds.). Brasília, DF, Brasil: CAPES, 2016. . Disponível em: <http://www.capes.gov.br/images/documentos/Documentos de area_2017/05 GEO C docarea 2016.pdf>. Acesso em: 17 maio. 2018.

MINISTÉRIO DA EDUCAÇÃO. CAPES. Avaliação quadrienal. Disponível em: <http://avaliacaoquadrienal.capes.gov.br/>. Acesso em: 13 jun. 2017a.

MINISTÉRIO DA EDUCAÇÃO. CAPES. Avaliação. Disponível em: <http://www.capes.gov.br/avaliacao/>. Acesso em: 13 jun. 2017b.

MINISTÉRIO DA EDUCAÇÃO. INEP. Instituto Nacional de Estudos e Pesquisas Educacionais Anísio Teixeira. Disponível em: <http://portal.inep.gov.br/>. Acesso em: 19 jun. 2017.

MONGEON, P.; PAUL-HUS, A. The journal coverage of Web of Science and Scopus: a comparative analysis. Scientometrics, v. 106, n. 1, p. 213-228, 2016. Disponível em: <http://doi.org/10.1007/s11192-015-1765-5>. Acesso em: 17 jun. 2017.

MOTOYAMA, S. (ed.). FAPESP : uma história de política científica e tecnológica. São Paulo: FAPESP, 1999. Disponível em: <http://www.bv.fapesp.br/pt/102/fapesp-umahistoria-de-politica-cientifica-e-tecnologica/>. Acesso em: 13 jun. 2017.

MUELLER, S. P. M. O crescimento da ciência, o comportamento científico e a comunicação científica: algumas reflexões. Revista da Escola de Biblioteconomia da UFMG, v. 24, n. 1, p. 63-84, 1995. Disponível em:

<http://www.brapci.ufpr.br/brapci/v/2743>. Acesso em: 3 jun. 2017.

MUELLER, S. P. M.; PASSOS, E. As questões da comunicação científica e a ciência da informação. In: MUELLER, S. P. M.; PASSOS, E. (Ed.). Comunicação científica. Brasília: Ciência da Informação, 2000. p. 13-22.

MUGNAINI, R. Caminhos para adequação da avaliação da produção científica brasileira: impacto nacional versus internacional. 2006. Universidade de São Paulo, São Paulo, 2006. Disponível em:

<http://www.teses.usp.br/teses/disponiveis/27/27151/tde-11052007-091052/>.

Acesso em: 3 jun. 2017.

MUGNAINI, R. 40 anos de Bibliometria no Brasil: da bibliografia estatística à avaliação da produção científica nacional. In: HAYASHI, M. C. P. I.; LETA, J. (Ed.). Bibliometria e cientometria: reflexões teóricas e interfaces. São Carlos: Pedro e João Editores, 2013. p. 37-58.

MUGNAINI, R. Ciclo avaliativo de periódicos no Brasil: caminho virtuoso ou colcha de retalhos? In: Encontro Nacional de Pesquisa em Ciência da Informação (ENANCIB), XVI, João Pessoa/PB. Anais... João Pessoa/PB: ANCIB, 2015. Disponível em:

$<$ https://www.researchgate.net/profile/Rogerio_Mugnaini/publication/281863179_Cic 
lo avaliativo de periodicos no Brasil caminho virtuoso ou colcha de retalhos/link s/55fc28cc08aeba1d9f3b7332.pdf>. Acesso em: 15 jun. 2017.

MUGNAINI, R. O Fator de Impacto: sua popularidade, seus impactos e a necessidade de preservação do processo de geração do conhecimento científico. Revista da Escola de Enfermagem da USP, v. 50, n. 5, p. 720-721, out. 2016. Disponível em:

$<$ http://www.scielo.br/scielo.php?script=sci arttext\&pid=S0080$62342016000500722 \&$ lng=en\&tlng=en>. Acesso em: 15 jun. 2017.

OLIVEIRA, P. V.; AGOPYAN, V. Avaliação Institucional na USP. In: MUGNAINI, R.; FUJINO, A.; KOBASHI, N. Y. (Ed.). Bibliometria e cientometria no Brasil: infraestrutura para avaliação da pesquisa científica na era do Big Data. São Paulo: Universidade de São Paulo. Escola de Comunicações e Artes, 2017. p. 111-132. Disponível em: <http://www.livrosabertos.sibi.usp.br/portaldelivrosUSP/catalog/book/129>. Acesso em: 03 jun. 2017.

OTLET, P. Traité de Documentation: le livre sur le livre - théorie et pratique. Bruxelles: Editiones Mundaneum, 1934. Disponível em:

<https://archive.org/details/OtletTraitDocumentationUgent>. Acesso em: 6 jun. 2017.

PRITCHARD, A. Statistical bibliography or bibliometrics? Journal of Documentation, $v$. 25, n. 4, p. 348-349, abr. 1969. Disponível em:

<http://www.emeraldinsight.com/doi/10.1108/eb026482>. Acesso em: 6 jun. 2017.

RAFOLS, I.; MOLAS-GALLART, J.; CHAVARRO, D. A.; ROBINSON-GARCIA, N. On the Dominance of Quantitative Evaluation in Peripherall Countries: Auditing Research with Technologies of Distance. SSRN, n. January 2016, 2016. Disponível em:

$<$ http://www.ssrn.com/abstract=2818335 $>$. Acesso em: 3 jun. 2017.

RAUHVARGERS, A. Global university rankings and their impact: report II. Brussels, Belgium: European University Association asbl, 2013. . Disponível em:

$<$ http://www.eua.be/Libraries/publications-homepage-

list/EUA Global University Rankings and Their Impact - Report II>. Acesso em: 19 jun. 2017.

SANTA, S.; HERRERO-SOLANA, V. Cobertura de la ciencia de América Latina y el Caribe en scopus vs web of science. Investigacion Bibliotecologica, v. 24, n. 52, p. 13-27, 2010. Disponível em:

<http://revistas.unam.mx/index.php/ibi/article/viewFile/27451/25443>. Acesso em: 17 jun. 2017.

SANTANA, A.; MUGNAINI, R. Internacionalização e impacto nas Geociências: estudo sobre a performance individual de pesquisadores. In: $6^{\circ}$ Encontro Brasileiro de Bibliometria e Cientometria, Rio de Janeiro. Anais... Rio de Janeiro: Universidade Federal do Rio de Janeiro, 2018. Disponível em:

$<$ https://www.researchgate.net/publication/325828423 Internacionalizacao e impac to nas Geociencias estudo sobre a performance individual de pesquisadores $>$. Acesso em: 18 jun. 2018. 
SANTOS, S. M. dos. O desempenho das universidades brasileiras nos rankings internacionais: áreas de destaque da produção científica brasileira. 2015. Universidade de São Paulo, São Paulo, 2015. Disponível em:

<http://www.teses.usp.br/teses/disponiveis/27/27151/tde-26052015-122043/>. Acesso em: 3 jun. 2017.

SANTOS, S. M. dos; MUGNAINI, R. Comunicação científica em periódicos e a internacionalização das ciências brasileiras. In: NETO, A. F.; CARNEIRO, F. F. B.; SANTOS, W. DOS (Ed.). Comunicação científica em periódicos. (No Prelo), 2018.

SÃO PAULO. CONSELHO ESTADUAL DE EDUCAÇÃO. Deliberação CEE n. 04/2000. Dispõe sobre o processo de avaliação de Universidade e de Centro Universitário do Sistema Estadual de Ensino. Disponível em: <http://www.lite.fe.unicamp.br/cee/d0400.html>. Acesso em: 19 jun. 2017.

SPIER, R. The history of the peer-review process. Trends in Biotechnology, v. 20, n. 8, p. 357-358, ago. 2002. Disponível em:

<http://linkinghub.elsevier.com/retrieve/pii/S0167779902019856>. Acesso em: 15 jun. 2017.

THELWALL, M. Bibliometrics to webometrics. Journal of Information Science, v. 34, n. 4, p. 605-621, ago. 2008. Disponível em:

<http://journals.sagepub.com/doi/10.1177/0165551507087238>. Acesso em: 3 jun. 2017.

THOMSON REUTERS. InCites: Indicators Handbook. Philadelphia: Thomson Reuters, 2014. Disponível em: <http://ipscience-help.thomsonreuters.com/inCites2Live/8980TRS/version/default/part/AttachmentData/data/InCites-Indicators-Handbook-6 19.pdf>. Acesso em: 30 jun. 2018.

UNIVERSIDADE DE SÃO PAULO. INSTITUTO DE GEOCIÊNCIAS. Instituto de Geociências USP. Disponível em: <http://www.igc.usp.br>. Acesso em: 23 jun. 2017.

UNIVERSIDADE DE SÃO PAULO. Resolução no. 2858. Estabelece diretrizes e procedimentos para promover e assegurar a coleta da produção intelectual gerada nas Unidades da USP e a posterior transferência da informação à Coordenação do SIBI. Disponível em: <http://www.leginf.usp.br/?resolucao=resolucao-no-2858-de-1de-fevereiro-de-1985>. Acesso em: 3 jun. 2017.

UNIVERSIDADE DE SÃO PAULO. Resolução no. 7222. Baixa o Regimento da Comissão Permanente de Avaliação. Disponível em:

$<$ http://www.leginf.usp.br/?resolucao=resolucao-no-7272-de-23-de-novembro-de2016>. Acesso em: 21 jun. 2017a.

UNIVERSIDADE DE SÃO PAULO. Resolução no. 7271. Baixa o Estatuto do Docente da Universidade de São Paulo. Disponível em:

<http://www.leginf.usp.br/?resolucao=resolucao-no-7271-23-de-novembro-de-2016>. Acesso em: 21 jun. 2017b. 
UNIVERSIDADE DE SÃO PAULO. DataUSP. Disponível em:

$<$ https://uspdigital.usp.br/datausp/publico/apresentacao.jsp?codmnu=6489 $>$. Acesso em: 27 jun. 2017.

VAN RAAN, A. F. J. On growth, ageing, and fractal differentiation of science.

Scientometrics, v. 47, n. 2, p. 347-362, 2000. Disponível em:

<http://link.springer.com/10.1023/A:1005647328460>. Acesso em: 3 jun. 2017.

VINKLER, P. An attempt of surveying and classifying bibliometric indicators for scientometric purposes. Scientometrics, v. 13, n. 5-6, p. 239-259, maio 1988.

Disponível em: <http://link.springer.com/10.1007/BF02019961>. Acesso em: 14 jun. 2017.

WEINGART, P. Impact of bibliometrics upon the science system: Inadvertent consequences? Scientometrics, v. 62, n. 1, p. 117-131, jan. 2005. Disponível em: <http://link.springer.com/10.1007/s11192-005-0007-7>. Acesso em: 6 jun. 2017.

WILDGAARD, L. A Critical Cluster Analysis of 44 Indicators of Author-Level Performance. Journal of Informetrics, v. 10, n. 4, p. 1055-1078, nov. 2016. Disponível em: <http://linkinghub.elsevier.com/retrieve/pii/S1751157716301171>. Acesso em: 3 jun. 2017.

WOUTERS, P. Bibliometrics of individual researchers. Disponível em:

$<$ https://citationculture.wordpress.com/2013/07/29/bibliometrics-of-individualresearchers/>. Acesso em: 17 mar. 2017.

ZITT, M.; BASSECOULARD, E. Internationalization of scientific journals: a measurement based on publication and citation scope. Scientometrics, v. 41, n. 1-2, p. 255-271, 1998. Disponível em: <http://doi.org/10.1007/BF02457982>. Acesso em: 12 set. 2018. 


\section{Apêndice A - Questionário para elaboração do Relatório/Perfil Bibliométrico}

Versão em Português traduzida livremente do original de Gorraiz; Wieland; Gumpenberger (2016, p. 903-904)

1. Quais fontes de dados você usa regularmente para recuperar literatura em seu campo de pesquisa? Você usa serviços de alerta?

2. Você usa identificadores únicos pessoais (como Orcid, ResearcherID etc.)?

3. Você possui um registro completo no nosso Sistema de Informação de Pesquisa (CRIS)?

4. Você usa repositórios?

5. Você já submeteu pre-prints de forma a obter prioridade na publicação?

6. Quais são as publicações mais importantes em seu campo (especial ênfase em monografias, capítulos de livros, patentes, se apropriado)?

7. A ordem dos autores (primeiro, último ou autor correspondente) desempenha um papel no seu campo de pesquisa? Se não, por que não?

8. Quais critérios são relevantes para sua estratégia de publicação?

9. O Open Access também é um critério válido de acordo com a recomendação da nossa universidade? Se não, por que não?

10. Você participa ativamente de conferências?

11. Você é editor de uma ou mais revistas científicas? Se sim, quais?

12. Você apoia ativamente o sistema de revisão por pares revisando documentos? Se sim, quantos por mês?

13. Você mantém um site pessoal? Uma entrada no Wikipédia? Um perfil de citações do Google Scholar?

14. Você usa um sistema de gerenciamento de referência? Se sim, qual deles? Por que você acha útil?

15. Você se envolve ativamente em listas de discussão ou blogs? Se sim, quais?

16. Você usa outras ferramentas de mídia social? Se sim, quais?

17. O que você pensa sobre métricas de uso (downloads) e altimetria?

18. Você gera dados de pesquisa? Se sim, como você os gerencia e os arquiva? 
19. Você seleciona e avalia colegas ou potenciais colaboradores? Se sim, você também adota métodos quantitativos para esta atividade?

20. Há algo mais que não cobrimos até agora e que gostaria de compartilhar? 


\section{Apêndice B - Adaptação do questionário para elaboração do Relatório/Perfil Bibliométrico de Gorraiz; Wieland; Gumpenberger (2016)}

As adaptações deste questionário em relação ao seu original encontram-se destacadas em negrito.

1. Quais fontes de dados você usa regularmente para recuperar literatura em seu campo de pesquisa? Você usa serviços de alerta?

2. Você usa identificadores únicos pessoais (como Orcid, ResearcherID etc.)?

3. Você envia regularmente para a biblioteca sua produção intelectual para cadastro no Banco de Dados Bibliográfico Dedalus?

4. Você usa utiliza plataformas de armazenamento eletrônico de produções intelectuais (como ResearchGate ou Academia.edu)?

5. Você já submeteu pre-prints para alguma plataforma de forma a obter maior visibilidade para sua publicação?

6. Quais são as publicações mais importantes em seu campo?

7. A ordem dos autores (primeiro, último ou autor correspondente) desempenha um papel no seu campo de pesquisa? Se não, por que não?

8. Quais critérios são relevantes para sua estratégia de publicação?

9. Publicar em Open Access/Acesso Aberto é um critério na sua estratégia? Se não, por que não?

10. Você participa ativamente de eventos científicos?

11. Você é editor de uma ou mais revistas científicas? Se sim, quais?

12. Você apoia ativamente o sistema de revisão por pares revisando documentos? Se sim, quantos por mês? Se não, por quê?

13. Você mantém um site pessoal? Uma entrada no Wikipédia?

14. Você usa um sistema de gerenciamento de referência? Se sim, qual deles? Por que você acha útil?

15. Você se envolve ativamente em listas de discussão ou blogs? Se sim, quais?

16. Você usa outras ferramentas de mídia social? Se sim, quais? 
17. O que você pensa sobre métricas de impacto (citações), de uso (downloads) e altimetria?

18. Você gera dados de pesquisa? Se sim, como você os gerencia e os arquiva?

19. Você seleciona e avalia colegas ou potenciais colaboradores? Se sim, você também adota métodos quantitativos para esta atividade?

20. Considerando a CAPES como uma instância de avaliação que, ao propor critérios para o Programa, estabelece diretrizes para o pesquisador, você poderia nomear outra(s) instância(s) de avaliação que se vê submetido explícita ou implicitamente?

21. Você foi selecionado para esta amostra, dado o seu perfil de publicação em periódicos que apresentou um de três aspectos: nível de produtividade, publica prioritariamente em periódicos internacionais; evidente alteração do perfil de publicação rumo à publicação em periódicos internacionais.

a. Você diria que esta característica de sua produção (publicar majoritariamente em periódico internacional ou nacional) é inerente ao campo em que atua?

b. Você se sente pressionado por alguma instância de avaliação que estimula/exige a internacionalização? Caso positivo, você diria que os critérios são explícitos e bem definidos, ou são implícitos? Explique.

21. Há algum assunto similar que não tratamos e que gostaria de compartilhar? 


\section{Apêndice C - Carta convite para participação em entrevista para pesquisa de mestrado}

São Paulo, 14 de maio de 2018

Prezado(a) Prof. Dr(a). «NOME»,

Entro em contato para consultá-lo(a) sobre a possibilidade de realizar com V. Sa. uma entrevista sobre produção científica e perfil de publicação.

Tal entrevista é parte da metodologia da minha dissertação de mestrado no Programa de Pós-Graduação em Ciência da Informação da Escola de Comunicações e Artes da USP sob orientação do Prof. Dr. Rogério Mugnaini.

O título provisório da pesquisa é "Avaliação bibliométrica em nível individual: traçando estratégias de comunicação científica para docentes do Instituto de Geociências da Universidade de São Paulo" e objetiva analisar a produção científica de professores com dedicação exclusiva à docência e à pesquisa, com vistas à proposição de um manual de estratégias de comunicação científica, com base em indicadores que evidenciem boas práticas.

Para a realização desta pesquisa analisamos toda a produção científica (artigos) dos docentes do IGc complementando-a com dados dos Sistemas USP e CAPES e estabelecemos uma amostra de docentes baseada em seus perfis de publicação. Assim, definimos três aspectos: nível de produtividade dos docentes; docentes que publicam prioritariamente em periódicos internacionais; e docentes que evidenciaram uma alteração do perfil de publicação rumo à publicação em periódicos internacionais.

Nesse sentido, esperamos contar com sua colaboração nesta pesquisa concedendo, se possível, um tempo em sua agenda, no dia e horário que melhor Ihe convier, para que possamos aplicar nosso roteiro de entrevista.

Agradecemos sua atenção e nos colocamos a disposição para os esclarecimentos adicionais que se fizerem necessários.

Atenciosamente,

Anderson de Santana

Bibliotecário do IGc/USP
Prof. Dr. Rogério Mugnaini

ECA/USP 


\section{Apêndice D - Termo de Consentimento Livre e Esclarecido}

\section{TERMO DE CONSENTIMENTO LIVRE E ESCLARECIDO}

Eu, Anderson de Santana, número USP 3576871, estudante do Mestrado Profissional do Programa de Pós-Graduação em Ciência da Informação da Escola de Comunicações e Artes da Universidade de São Paulo, estou realizando uma pesquisa intitulada de AVALIAÇÃO BIBLIOMÉTRICA EM NÍVEL INDIVIDUAL: TRAÇANDO ESTRATÉGIAS DE COMUNICAÇÃO CIENTÍFICA PARA DOCENTES DO INSTITUTO DE GEOCIÊNCIAS DA UNIVERSIDADE DE SÃO PAULO, sob a orientação do Prof. Dr. Rogério Mugnaini.

Essa pesquisa objetiva analisar a produção científica de professores com dedicação exclusiva à docência e pesquisa com vistas à proposição de um modelo de avaliação bibliométrica em nível individual, que redunde em um manual de estratégias de comunicação científica, e subsidie futura avaliação institucional.

Para tanto, gostaria que V. Sa. participasse desta pesquisa, na qual me comprometo a seguir o Código de Ética da USP (Resolução no 4871, de 22 de outubro de 2001) bem como as declarações e convenções sobre Direitos Humanos, na Constituição Federal e na legislação específica, relacionadas à Pesquisa com Seres Humanos, respeitando o seu direito de:

1. Ter liberdade de participar ou deixar de participar do estudo, sem que isso the traga algum prejuízo ou risco;

2. Manter o seu nome em sigilo absoluto, sendo que o que disser não the resultará em qualquer dano à sua integralidade;

3. Interromper a participação na pesquisa caso se sinta incomodado(a) com a mesma;

4. Responder as questões levantadas pelo pesquisador caso seja solicitado(a) para uma entrevista, onde será marcado um local na instituição, horário e data em que possa se sentir mais confortável;

5. Garantia de receber uma resposta a alguma dúvida durante ou após a entrevista.

Esclareço-Ihe que o tempo estimado de sua participação será de no máximo 60 minutos.

A sua participação nesta pesquisa propiciará um melhor entendimento do modus operandi da área de Geociências e subsidiará o pesquisador no que tange as análises dos resultados da pesquisa.

Este Termo de Consentimento será emitido em duas vias, sendo que uma via ficará em poder do pesquisador e a outra em poder do participante. 
Grato pela atenção

Anderson de Santana Pós-graduando do PPGCI ECA/USP Chefe do Serviço de Biblioteca e Documentação do Instituto de Geociências da USP
Prof. Dr. Rogério Mugnaini Orientador e Docente do PPGCI ECA/USP

Declaro que, após convenientemente esclarecido pelo pesquisador e ter entendido o que me foi explicado, consinto em participar da presente Pesquisa.

São Paulo, de de 2018.

Nome do(a) Entrevistado(a): «NOME»

Assinatura do Entrevistado: 


\section{Apêndice E - Síntese das entrevistas realizadas com os Docentes da amostra}

\section{PERGUNTAS}

1. Quais fontes de dados você usa regularmente para recuperar literatura em seu campo de pesquisa? Você usa serviços de alerta?

2. Você usa identificadores únicos pessoais (como Orcid, ResearcherID etc.)?

3. Você envia regularmente para a biblioteca sua produção intelectual para cadastro no Banco de Dados Bibliográfico Dedalus?

4. Você usa utiliza plataformas de armazenamento eletrônico de produções intelectuais (como

ResearchGate ou Academia.edu)?

5. Você já submeteu pre-prints para alguma plataforma Não.

de forma a obter maior visibilidade para sua publicação?

6. Quais são as publicações mais importantes em seu Precambrian Research campo?

7. A ordem dos autores (primeiro, último ou autor correspondente) desempenha um papel no seu campo de pesquisa? Se não, por que não?

8. Quais critérios são relevantes para sua estratégia de publicação?

9. Publicar em Open Access/Acesso Aberto é um critério na sua estratégia? Se não, por que não?

10. Você participa ativamente de eventos científicos?

11. Você é editor de uma ou mais revistas científicas? Se sim, quais?

12. Você apoia ativamente o sistema de revisão por pares revisando documentos? Se sim, quantos por mês? Se não, por quê?

13. Você mantém um site pessoal? Uma entrada no Não. Wikipédia?

14. Você usa um sistema de gerenciamento de referência? Se sim, qual deles? Por que você acha útil?

15. Você se envolve ativamente em listas de discussão ou blogs? Se sim, quais?

16. Você usa outras ferramentas de mídia social? Se sim, quais?

17. O que você pensa sobre métricas de impacto (citações), de uso (downloads) e altimetria?

18. Você gera dados de pesquisa? Se sim, como você os gerencia e os arquiva?

19. Você seleciona e avalia colegas ou potenciais colaboradores? Se sim, você também adota métodos quantitativos para esta atividade?

\section{DOCENTE 01}

Revistas principalmente. Não usa alertas.

Não. Tem ResearcherID mas não utiliza.

Não.

Sim. O ResearchGate.

A primeira autoria tem importância, porém no IGc temse como regra colocar os pós-graduandos como primeiro autor dos trabalhos para dar um apoio na carreira dele.

Não possui estratégia. Mas seleciona a revista com base na qualidade do artigo e abrangência, e prioriza revistas com maior impacto.

Não possui uma estratégia.

Mais ou menos. Não gosta muito de Congressos. Participa pouco (um a cada 3 anos) e sem preferência de abrangência (nacional ou internacional).

Não.

Sim. 2 artigos por semestre.

Sim. O Mendeley, mas de forma simples, especialmente para buscar bibliografia.

Não.

Não.

Essas métricas são utilizadas como avaliação da qualidade da produção científica e concorda com o uso delas.

Não.

Sim. Utiliza, mas não somente esses métodos. Considera importante, mas não decisivo. 
20. Considerando a CAPES como uma instância de avaliação que, ao propor critérios para o Programa, estabelece diretrizes para o pesquisador, você poderia nomear outra(s) instância(s) de avaliação que se vê submetido explícita ou implicitamente?

21. Você foi selecionado para esta amostra, dado o seu perfil de publicação em periódicos que apresentou um de três aspectos: nível de produtividade, publica prioritariamente em periódicos internacionais; evidente alteração do perfil de publicação rumo à publicação em periódicos internacionais.

a. Você diria que esta característica de sua produção (publicar majoritariamente em periódico internacional ou nacional) é inerente ao campo em que atua?
Não. Mas entende que a avaliação das agências de fomento é fundamental para se conseguir apoio financeiro e que essa é a regra do jogo.

Para o trabalho que faz publicar internacionalmente dá maior visibilidade, mas não é algo inerente ao campo. Além disso o fato de participar de grupos/redes internacionais torna obrigatória a publicação em revistas internacionais.

b. Você se sente pressionado por alguma instância de

Não. avaliação que estimula/exige a internacionalização?

Caso positivo, você diria que os critérios são explícitos e bem definidos, ou são implícitos? Explique. 
PERGUNTAS

1. Quais fontes de dados você usa regularmente para recuperar literatura em seu campo de pesquisa? Você usa serviços de alerta?

2. Você usa identificadores únicos pessoais (como Orcid, ResearcherID etc.)?

3. Você envia regularmente para a biblioteca sua produção intelectual para cadastro no Banco de Dados Bibliográfico Dedalus?

4. Você usa utiliza plataformas de armazenamento eletrônico de produções intelectuais (como

ResearchGate ou Academia.edu)?

\section{Você já submeteu pre-prints para alguma plataforma Não. Porém os alunos inserem no ResearchGate.} de forma a obter maior visibilidade para sua publicação?

6. Quais são as publicações mais importantes em seu campo?

\section{A ordem dos autores (primeiro, último ou autor correspondente) desempenha um papel no seu campo de pesquisa? Se não, por que não?}

8. Quais critérios são relevantes para sua estratégia de publicação?
Sim, por exigência da Universidade e das agências de fomento. ORCID e ResearcherID.

Não.

Sim. O ResearchGate, mas por iniciativa dos alunos. Journal of Petrology; Lithos; Chemical Geology; Journal of Volcanology and Geothermal Research; Bulletin of Volcanology; Contributions to Mineralogy and Petrology; Precambrian Research.

Sim. O primeiro autor é aquele que liderou a pesquisa. E a sequência é por grau de envolvimento. Quase todos os trabalhos que publicou nos últimos cinco anos tem sido o segundo ou o terceiro autor, por ser o orientador.

Não. E comenta que na atual fase da carreira publicar não é tão decisivo. Sua publicação vem das pesquisas de seus orientandos. Todavia tem clara noção das exigências (pressão) das Agências de Fomento acerca da necessidade de publicar em revistas de impacto.

\begin{abstract}
9. Publicar em Open Access/Acesso Aberto é um critério na sua estratégia? Se não, por que não?
\end{abstract}

10. Você participa ativamente de eventos científicos?
Não, porém tem alunos que preferem publicar em Acesso Aberto.

Sim. Nacionais: Congresso Brasileiro de Geologia; e evento bianual de Vulcanismo (não identificado). Internacionais: Goldschmidt Conference; Hutton Symposium on Granites and Related Rocks; e esporadicamente em encontros da American Geophysical Union e Geological Society of America.

11. Você é editor de uma ou mais revistas científicas? Se sim, quais?

12. Você apoia ativamente o sistema de revisão por Sim. Geologia USP. E foi editor de edições especiais da Brazilian Journal of Geology.

Sim. 10 por ano.

pares revisando documentos? Se sim, quantos por mês? Se não, por quê?

\section{Você mantém um site pessoal? Uma entrada no Wikipédia?}

14. Você usa um sistema de gerenciamento de referência? Se sim, qual deles? Por que você acha útil?
Não.

Sim, EndNote. Considera útil para manter sua bibliografia organizada.
15. Você se envolve ativamente em listas de discussão ou blogs? Se sim, quais?
16. Você usa outras ferramentas de mídia social? Se sim, quais?
17. O que você pensa sobre métricas de impacto (citações), de uso (downloads) e altimetria?
Não.
Não.
Considera que as métricas no nível do artigo são uma forma de avaliação de fato e que elas são úteis.
18. Você gera dados de pesquisa? Se sim, como você os gerencia e os arquiva?
Sim. Mas não possui uma forma de organização ou local de depósito. 
19. Você seleciona e avalia colegas ou potenciais colaboradores? Se sim, você também adota métodos quantitativos para esta atividade?

20. Considerando a CAPES como uma instância de avaliação que, ao propor critérios para o Programa, estabelece diretrizes para o pesquisador, você poderia nomear outra(s) instância(s) de avaliação que se vê submetido explícita ou implicitamente?

21. Você foi selecionado para esta amostra, dado o seu perfil de publicação em periódicos que apresentou um de três aspectos: nível de produtividade, publica prioritariamente em periódicos internacionais; evidente alteração do perfil de publicação rumo à publicação em periódicos internacionais.

a. Você diria que esta característica de sua produção (publicar majoritariamente em periódico internacional ou nacional) é inerente ao campo em que atua?
Sim. E considera que os métodos quantitativos são um apoio, mas não um fator decisório.

A FAPES, CNPq e a USP.

Não é inerente, uma vez que a Geologia tem aspectos regionais e é necessário produzir regionalmente. A área em que atua é ciência pura e naturalmente internacional. Todavia, a Geologia aplicada não deve ser desmerecida, pois tem um papel social relevante e com foco nacionalizado.

b. Você se sente pressionado por alguma instância de avaliação que estimula/exige a internacionalização? Caso positivo, você diria que os critérios são explícitos e bem definidos, ou são implícitos? Explique.
Sim. Entende que a pressão está presente o tempo todo, principalmente pelas agências de fomento. Cita a CAPES que pressiona a publicar em periódicos dos estratos mais altos para buscar uma melhor avaliação do seu programa de pós. E se por um lado é parte do jogo da produção científica, por outro é o problema. Considera que os critérios são explícitos
Há algum assunto similar que não tratamos e que gostaria de compartilhar?

Observações a serem destacadas
Não.

Considera que incluir as publicações no ResearchGate é uma boa alternativa para o acesso à informação e visibilidade, todavia compreende que é prejudicial para o fluxo da produção científica uma vez que há um custo para manutenção dos periódicos. Comenta também que o sistema de revisão por pares está em declínio pois há muito o que se avaliar e poucas pessoas para darem pareceres. 
PERGUNTAS

1. Quais fontes de dados você usa regularmente para recuperar literatura em seu campo de pesquisa? Você usa serviços de alerta?

2. Você usa identificadores únicos pessoais (como Orcid, ResearcherID etc.)?

3. Você envia regularmente para a biblioteca sua produção intelectual para cadastro no Banco de Dados Bibliográfico Dedalus?

4. Você usa utiliza plataformas de armazenamento eletrônico de produções intelectuais (como

ResearchGate ou Academia.edu)?

\section{Você já submeteu pre-prints para alguma plataforma Não.}

de forma a obter maior visibilidade para sua publicação?

6. Quais são as publicações mais importantes em seu campo?

7. A ordem dos autores (primeiro, último ou autor correspondente) desempenha um papel no seu campo de pesquisa? Se não, por que não?

8. Quais critérios são relevantes para sua estratégia de publicação?

Não.

\section{DOCENTE 05}

Revistas pelo acesso fornecido pela USP. Não utiliza alerta. Acessa diretamente os títulos.

Sim. ResearcherID

Sim. ResearchGate.

Ore Geology Reviews; Precambrian Research; e Gondwana Research (basicamente as da Elsevier).

Depende do pesquisador. Trabalhos baseados em teses o primeiro autor é sempre o orientando e ele em segundo. Porém quando ele escreve o trabalho assume a primeira autoria.

Não possui uma tática para publicar, porém sua área de pesquisa facilita a publicação pois gera muitos dados (Nota do Entrevistador: ele trabalha em um laboratório de análises geocronológicas o qual realiza análises para vários parceiros internacionais). Utiliza normalmente um padrão de itens que coloca nos trabalhos e dependendo do assunto vai sendo feito. Não utiliza técnicas de direcionamento de pesquisa (citar autores e escrever textos que auxiliem a publicação).

Publica pouco em Acesso Aberto, porém considera importante em termos de maior visibilidade pois permite que mais gente leia. Ressalta que a qualidade de parte daquilo que se publica em acesso aberto é questionável, se comparado às revistas comerciais citadas anteriormente.

10. Você participa ativamente de eventos científicos?

Já participou mais e atualmente se limita a participar de um por ano, independentemente de ser nacional ou internacional. Porém tem participado mais dos internacionais.

11. Você é editor de uma ou mais revistas científicas? Não.

Se sim, quais?

12. Você apoia ativamente o sistema de revisão por

Sim. Revisa em média 8 artigos por ano. pares revisando documentos? Se sim, quantos por mês? Se não, por quê?
13. Você mantém um site pessoal? Uma entrada no
Não. Wikipédia?

14. Você usa um sistema de gerenciamento de

Não referência? Se sim, qual deles? Por que você acha útil?

15. Você se envolve ativamente em listas de discussão Não. ou blogs? Se sim, quais?

16. Você usa outras ferramentas de mídia social? Se sim, quais?

Não. 


\begin{abstract}
17. O que você pensa sobre métricas de impacto (citações), de uso (downloads) e altimetria?
\end{abstract}

Todas essas ferramentas dão uma ideia da produtividade das pessoas. Porém não se pode utilizar os números como eles vem, pois há formas de driblá-los como a autocitação em grupo [Nota do Entrevistador: citation stacking]. Quando coordenador de área do CNPQ utilizou esses dados (citações e índice H) mas para classificar "bandas" para reunir grupos e utilizar outros critérios. A vantagem das métricas é que são números e simples de gerar. Mas servem somente para lhe fornecer uma base.
18. Você gera dados de pesquisa? Se sim, como você os gerencia e os arquiva?
19. Você seleciona e avalia colegas ou potenciais colaboradores? Se sim, você também adota métodos quantitativos para esta atividade?

20. Considerando a CAPES como uma instância de avaliação que, ao propor critérios para o Programa, estabelece diretrizes para o pesquisador, você poderia nomear outra(s) instância(s) de avaliação que se vê submetido explícita ou implicitamente?

21. Você foi selecionado para esta amostra, dado o seu perfil de publicação em periódicos que apresentou um de três aspectos: nível de produtividade, publica prioritariamente em periódicos internacionais; evidente alteração do perfil de publicação rumo à publicação em periódicos internacionais.

a. Você diria que esta característica de sua produção (publicar majoritariamente em periódico internacional ou nacional) é inerente ao campo em que atua?
Sim. Os dados pessoais não têm organização e os salva no computador. Mas os do laboratório utilizam plataformas próprias para armazenamento.

Para concursos são vários os critérios e usa os dados quantitativos também. Para trabalhar em projetos não utiliza métodos quantitativos, mas se baseia no que o indivíduo tem a oferecer.

Basicamente todas as agências financiadoras (FAPESP, CAPES, CNPq) te avaliam quando solicita apoio. Além das agências internacionais (NSF por exemplo).

Não. É inerente quanto a forma que atua. Por exemplo não publica sozinho, participa de grupos de pesquisadores multidisciplinares em geral do exterior. $\mathrm{Na}$ Geologia há basicamente 3 tipos de trabalho que você faz: estudo dos processos geológicos que pode ser aplicado a qualquer região do mundo e que permite publicar em qualquer revista internacional pois o tema é internacionalizado; trabalhos descritivos, os quais descrevem regiões específicas (em geral são estudos regionais) que não são publicados em revistas internacionais, mas nacionalmente; e existem as pesquisas híbridas nas quais você descreve uma região, porém utiliza processos geológicos e ferramentas internacionais para análise, permitindo a publicação em revistas internacionais pois pessoas que estejam utilizando o mesmo processo geológico quererão ler independente da região analisada. Assim, dependendo do perfil de atuação do docente ele tem mais ou menos condições de publicar. 
b. Você se sente pressionado por alguma instância de avaliação que estimula/exige a internacionalização?

Caso positivo, você diria que os critérios são explícitos e bem definidos, ou são implícitos? Explique.
Pressionado todos são, especialmente se você quer obter financiamentos ou gerenciar projetos você está submetido a avaliações. Porém a USP não exige/pressiona para isso, pois há colegas que não tem produção e ficam somente dando aula. Todavia, não trazem benefícios para a instituição como laboratórios. Os critérios são explícitos, por exemplo as exigências do CNPq para as bolsas de produtividade. Um passo interessante para a internacionalização é trazer pósgraduandos de outros países e assim aumentar sua rede de colaboração, uma vez que quando eles retornam para seus países os vínculos aqui formados permanecem.
Há algum assunto similar que não tratamos e que gostaria de compartilhar?

Observações a serem destacadas
Não.

Existem várias áreas dentro das Geociência, uma relacionada à Depósitos Minerais que é muito lida por geólogos das companhias de mineração, mas que não gera citações uma vez que estes, em geral, não têm tempo para publicar ou como são dados da empresa estes não podem ser publicados. Este tipo de uso não é possível ser medido. Outro tipo de publicação é o de síntese [revisões de literatura] nos quais você não traz nada de novo apenas reúne dados sobre um tema e este estoura de citações (experiência própria). Destaca que há excelentes docentes que não possuem a menor afinidade para a escrita de artigos científicos, porém serão mal avaliados pelas métricas existentes. 
PERGUNTAS

1. Quais fontes de dados você usa regularmente para recuperar literatura em seu campo de pesquisa? Você usa serviços de alerta?
DOCENTE 06

Revistas Científicas, por meio dos Portais de Revistas. Costuma usar as bases de dados para verificar áreas de maior impacto. Usa alerta de revistas e por isso não utiliza bases de dados para localizar pesquisas. Sim.

2. Você usa identificadores únicos pessoais (como Orcid, ResearcherID etc.)?

3. Você envia regularmente para a biblioteca sua Não. produção intelectual para cadastro no Banco de Dados Bibliográfico Dedalus?

4. Você usa utiliza plataformas de armazenamento eletrônico de produções intelectuais (como ResearchGate ou Academia.edu)?

Sim e não. Inclui somente aquilo que as licenças de uso das revistas permitem. Tem receio de incluir itens licenciados. Caso existisse na USP uma plataforma na qual alguém validasse tal questão utilizaria.
Não. Mas coautores sim. Se preocupa com o direito autoral.

de forma a obter maior visibilidade para sua

publicação?

6. Quais são as publicações mais importantes em seu campo?

7. A ordem dos autores (primeiro, último ou autor correspondente) desempenha um papel no seu campo de pesquisa? Se não, por que não?

8. Quais critérios são relevantes para sua estratégia de publicação?

9. Publicar em Open Access/Acesso Aberto é um critério na sua estratégia? Se não, por que não?

10. Você participa ativamente de eventos científicos?

De referência: Nature; e Science. Específicas: Planetary Science Letters. lugar. internacionalmente. publicações mais reconhecidas.
Precambrian Research; Gondwana Research; Earth and

Não. A única regra que segue é que se a publicação é parte de uma pesquisa de um estudante e o conteúdo é parte da dissertação/tese este aparecerá em primeiro

São duas coisas: Temática e Abrangência. Dependendo do tema e seu impacto publica-se nacionalmente ou

Acesso Aberto é uma coisa nova e dá preferência às

Sim. Participa regularmente de eventos nacionais pois suas áreas de atuação são no Brasil. E de forma mais contida no exterior. Prefere eventos mais focados do que eventos grandiosos e com inúmeras temáticas.

\section{Você é editor de uma ou mais revistas científicas? Se sim, quais?}

12. Você apoia ativamente o sistema de revisão por pares revisando documentos? Se sim, quantos por mês? Se não, por quê?

\section{Você mantém um site pessoal? Uma entrada no Wikipédia?}

Sim. Geologia USP. Série Científica. E como membro do corpo editorial da Estudos Geológicos da Universidade Federal de Pernambuco.

Sim. 2 por mês. Porém o trabalho como editor demanda outras análises.

Sim. ResearchGate; Scopus (automática); Lattes e CNPq; e Mendeley. Portais que só entra com os dados.

14. Você usa um sistema de gerenciamento de referência? Se sim, qual deles? Por que você acha útil?

Sim. Mendeley. É útil para acompanhar a produção da área.

15. Você se envolve ativamente em listas de discussão ou blogs? Se sim, quais?

16. Você usa outras ferramentas de mídia social? Se sim, quais?

17. O que você pensa sobre métricas de impacto (citações), de uso (downloads) e altimetria?
Sim, eventualmente. A experiência não é interessante. Não.

As métricas de citação são um parâmetro importante para verificar o quanto que aquilo que você produz está atingindo o público. Quanto aos Downloads não identifica o que eles efetivamente revelam sobre a pesquisa. E não acredita nas Altimetrias. 
18. Você gera dados de pesquisa? Se sim, como você os gerencia e os arquiva?

19. Você seleciona e avalia colegas ou potenciais colaboradores? Se sim, você também adota métodos quantitativos para esta atividade?

\section{Considerando a CAPES como uma instância de} avaliação que, ao propor critérios para o Programa, estabelece diretrizes para o pesquisador, você poderia nomear outra(s) instância(s) de avaliação que se vê submetido explícita ou implicitamente?
Sim. Gera e os guarda no computador. Caso a USP tivesse um repositório, o utilizaria.

Sim, seleciona. Não utiliza dados quantitativos, mas sim verifica se as temáticas se complementam e seus resultados são consistentes. Verifica suas publicações, mas não foca em métricas de impacto.

CNPq e à FAPESP. Nos quais você busca subsídios e que te avaliam em função do que você realiza e do mérito do projeto que submete. A USP também, porém é uma avaliação que olha para o lado acadêmico e para o científico. Ela pega um atalho verificando o nível do pesquisador no CNPq por exemplo. Um pesquisador com bolsa de produtividade do CNPQ, por exemplo, já possui uma chancela e a USP tem levado isso em consideração, afinal o pesquisador/docente já está avaliado por esses órgãos.

\begin{abstract}
21. Você foi selecionado para esta amostra, dado o seu perfil de publicação em periódicos que apresentou um de três aspectos: nível de produtividade, publica prioritariamente em periódicos internacionais; evidente alteração do perfil de publicação rumo à publicação em periódicos internacionais.

a. Você diria que esta característica de sua produção (publicar majoritariamente em periódico internacional ou nacional) é inerente ao campo em que atua?
\end{abstract}

Não. Porquê da mesma forma ele poderia publicar nacionalmente. É uma estratégia dele publicar internacionalmente para levar os resultados de sua pesquisa para uma comunidade mais ampla e internacional. b. Você se sente pressionado por alguma instância de avaliação que estimula/exige a internacionalização? Caso positivo, você diria que os critérios são explícitos e bem definidos, ou são implícitos? Explique.
Sim, a começar pela USP. Os critérios da USP, por sua natureza de universidade que é um misto de ensino e pesquisa, não é claro. Há colegas que têm um alto índice de publicação nacional que atingiram o nível de professor titular. Porém para outros órgãos não, como o CNPq por exemplo que para obter uma bolsa de produtividade sua produção deve ser majoritariamente internacional.

\begin{tabular}{ll} 
Há algum assunto similar que não tratamos e que & Não. \\
gostaria de compartilhar? & --- \\
\hline Observações a serem destacadas & -- \\
\hline
\end{tabular}


PERGUNTAS

1. Quais fontes de dados você usa regularmente para recuperar literatura em seu campo de pesquisa? Você usa serviços de alerta?

2. Você usa identificadores únicos pessoais (como Orcid, ResearcherID etc.)?

3. Você envia regularmente para a biblioteca sua produção intelectual para cadastro no Banco de Dados Bibliográfico Dedalus?

4. Você usa utiliza plataformas de armazenamento eletrônico de produções intelectuais (como ResearchGate ou Academia.edu)?

5. Você já submeteu pre-prints para alguma plataforma de forma a obter maior visibilidade para sua publicação?

6. Quais são as publicações mais importantes em seu campo?

7. A ordem dos autores (primeiro, último ou autor correspondente) desempenha um papel no seu campo de pesquisa? Se não, por que não? publicação?

DOCENTE 12

ResearchGate atualmente e alerta da Geochemical Society. Antes disso usava a Scopus e alertas de revistas. Hoje não usa mais.

Sim. Porque é uma exigência da USP (ORCID) e da FAPESP (ResearcherID dentre outros).

Não.

Sim. O ResearchGate e considera que poderia explorar muito mais esse recurso.

Não. Mas conhece muitas pessoas que fazem. Mas envia e inclui, eventualmente, seus artigos no ResearchGate. Acredita que essa demanda ocorrerá e que terá que se adequar.

Gondwana Research; Precambrian Research (aquelas nas quais publica e lê). Regionais: Journal of South America Earth Sciences (Fator de Impacto menor).

Sim. E é diferente das outras áreas, como as da saúde, nas quais o último autor é o mais importante. Nas Geociências o primeiro autor é quem realmente lidera/coordena, quem escreve e a ordem dos autores reflete a ordem (nível) de participação naquela pesquisa, ou seja, o último não ajudou na pesquisa, mas colaborou com verba ou com alguma participação.

Sim, nunca começa uma pesquisa sem ter uma pergunta para responder. Avalia a abrangência e o impacto da pesquisa e seleciona onde publicar. Cita que atualmente não se consegue financiamento (FAPESP por exemplo) sem ter uma pesquisa multidisciplinar e com importância global.

\section{Publicar em Open Access/Acesso Aberto é um critério na sua estratégia? Se não, por que não?}

\section{Você participa ativamente de eventos científicos?}

11. Você é editor de uma ou mais revistas científicas? Se sim, quais?

12. Você apoia ativamente o sistema de revisão por pares revisando documentos? Se sim, quantos por mês? Se não, por quê?
Não necessariamente. O que importa é a qualidade. Qualidade com Acesso Aberto é perfeito. Destaca positivamente a abrangência de acesso à revistas (e conteúdos) que a USP dispõe em relação a outras instituições.

Sim. Simpósio Sul-Americano de Geologia Isotópica; Goldschmidt Conference; Congresso Brasileiro de Geologia

Sim, editor-associado da Brazilian Journal of Geology. E já editou volumes especiais da Gondwana Research e Precambrian Research.

Sim. 15 por ano.

\section{Você mantém um site pessoal? Uma entrada no Wikipédia?}

14. Você usa um sistema de gerenciamento de referência? Se sim, qual deles? Por que você acha útil?
Não.

Não, mas compreende que eles beneficiariam seu trabalho.
15. Você se envolve ativamente em listas de discussão Não. ou blogs? Se sim, quais?

16. Você usa outras ferramentas de mídia social? Se sim, quais?
Não. 

17. O que você pensa sobre métricas de impacto
(citações), de uso (downloads) e altimetria?
18. Você gera dados de pesquisa? Se sim, como você os gerencia e os arquiva?

19. Você seleciona e avalia colegas ou potenciais colaboradores? Se sim, você também adota métodos quantitativos para esta atividade?

20. Considerando a CAPES como uma instância de avaliação que, ao propor critérios para o Programa, estabelece diretrizes para o pesquisador, você poderia nomear outra(s) instância(s) de avaliação que se vê submetido explícita ou implicitamente?

21. Você foi selecionado para esta amostra, dado o seu perfil de publicação em periódicos que apresentou um de três aspectos: nível de produtividade, publica prioritariamente em periódicos internacionais; evidente alteração do perfil de publicação rumo à publicação em periódicos internacionais.

a. Você diria que esta característica de sua produção (publicar majoritariamente em periódico internacional ou nacional) é inerente ao campo em que atua?
É um indicador e tem sua importância. Mas nem sempre reproduz uma verdade. As vezes as citações são por conta de artigos negando a teoria apresentada. É importante para se situar nesse mundo. Tem um lado bom e tem um lado perverso.

Sim. Entende a necessidade e importância de compartilhar os dados. Usa os repositórios das próprias revistas em que publica seus artigos.

Sim. Seleciona pessoas: colaboradores, que tenham um perfil parecido e que tenham com o que contribuir; para a seleção de docentes utiliza sim métodos quantitativos.

A Universidade, que cobra e deve cobrar. CNPq. FAPESP. E a pessoal.

Não. É cultural, devido a formação e o modo de publicação empreendido. b. Você se sente pressionado por alguma instância de avaliação que estimula/exige a internacionalização? Caso positivo, você diria que os critérios são explícitos e bem definidos, ou são implícitos? Explique.
Não sente pressão, considera como parte da sua formação e perfil profissional. 
PERGUNTAS

1. Quais fontes de dados você usa regularmente para recuperar literatura em seu campo de pesquisa? Você usa serviços de alerta?

\section{DOCENTE 14}

Varia muito. Desde de revisão pela internet em revistas até solicitar aos alunos que façam o levantamento bibliográfico com um determinado enfoque. As vezes até o Google, dependendo do cenário da pesquisa. Uma quantidade grande de orientandos (8) não permite que o próprio professor faça o levantamento, assim cada aluno busca bibliografia para uma determinada área e o orientador avalia se há necessidade de mais informações ou não. Possui a bibliografia básica a disposição dos alunos para que esta sirva de base para iniciar o levantamento.

Não. Somente o ResearchGate.

2. Você usa identificadores únicos pessoais (como Orcid, ResearcherID etc.)?

3. Você envia regularmente para a biblioteca sua produção intelectual para cadastro no Banco de Dados Bibliográfico Dedalus?

4. Você usa utiliza plataformas de armazenamento eletrônico de produções intelectuais (como ResearchGate ou Academia.edu)?

5. Você já submeteu pre-prints para alguma plataforma Não. Somente o ResearchGate. de forma a obter maior visibilidade para sua publicação?

6. Quais são as publicações mais importantes em seu campo?

7. A ordem dos autores (primeiro, último ou autor correspondente) desempenha um papel no seu campo de pesquisa? Se não, por que não?

Não. Mas mantém o Lattes atualizado e uma pasta no computador com os principais documentos.

Sim. ResearchGate.

Anais da Academia Brasileira de Ciências; Química Nova;

Não se preocupa com isso e sabe que isso dá prejuízo no momento da disputa por uma bolsa de produtividade do CNPq pois eles entendem que se você não aparece como primeiro autor você está usando os demais autores. Prefere que os orientandos apareçam em primeiro para fazerem currículo.

\section{Quais critérios são relevantes para sua estratégia de} publicação?

Não dá pra ter estratégia pois algumas revistas criaram um núcleo de publicação para um grupo específico. Quando o trabalho é muito bom traduz e submete para uma revista internacional que pode levar até 2 anos para ser publicado. Trabalha com temas muito regionais. A estratégia é tentar publicar onde der para publicar se achar que é importante. Não está preocupado em publicar bastante.

\section{Publicar em Open Access/Acesso Aberto é um critério na sua estratégia? Se não, por que não?}

10. Você participa ativamente de eventos científicos?
Não. Não leva isso em consideração, mas publica em revistas de Acesso Aberto.

Não, considera uma perda de tempo. Vai eventualmente e preferencialmente nos internacionais. Já foi muito, porém prefere dar atenção aos alunos.

Não. Mas já editou.

11. Você é editor de uma ou mais revistas científicas? Se sim, quais?

12. Você apoia ativamente o sistema de revisão por pares revisando documentos? Se sim, quantos por mês? benefício em ser revisor.

Se não, por quê?

13. Você mantém um site pessoal? Uma entrada no Não.
Wikipédia?

14. Você usa um sistema de gerenciamento de

Não. Mas os alunos sim. referência? Se sim, qual deles? Por que você acha útil? 


$\begin{array}{ll}\begin{array}{l}\text { 15. Você se envolve ativamente em listas de discussão } \\ \text { ou blogs? Se sim, quais? }\end{array} & \text { Não. } \\ \begin{array}{ll}\text { 16. Você usa outras ferramentas de mídia social? Se } \\ \text { sim, quais? }\end{array} & \text { Não. } \\ \begin{array}{ll}\text { 17. O que você pensa sobre métricas de impacto } \\ \text { (citações), de uso (downloads) e altimetria? }\end{array} & \begin{array}{l}\text { É uma questão complicada. Pesquisas que geram } \\ \text { melhoria social não geram impacto válido para a CAPES. } \\ \end{array} \\ \begin{array}{l}\text { É difícil para quem está tentando colocar isso no } \\ \text { cenário encontrar um caminho que seja justo naquilo }\end{array} \\ \text { que está sendo publicado. Não necessariamente } \\ \text { mostrará o grande significado que um trabalho está } \\ \text { representando. Baseiam-se na qualificação da revista } \\ \text { (A1, A2, B1, B2 e B3) que não necessariamente seja uma } \\ \text { classificação justa para aquilo que está sendo } \\ \text { publicado. Podem ter trabalhos muito importantes que } \\ \text { mudam uma técnica e estão publicados em revistas B3, } \\ \text { assim o sujeito fica fora dessa importância. }\end{array}$

18. Você gera dados de pesquisa? Se sim, como você os Não. gerencia e os arquiva?

19. Você seleciona e avalia colegas ou potenciais colaboradores? Se sim, você também adota métodos quantitativos para esta atividade?
OBS.: Não respondeu a pergunta diretamente, todavia por meio de seu perfil é possível constatar que avalia sim, porém não entende o sistema de métricas.

\section{Considerando a CAPES como uma instância de} avaliação que, ao propor critérios para o Programa, estabelece diretrizes para o pesquisador, você poderia nomear outra(s) instância(s) de avaliação que se vê submetido explícita ou implicitamente?

21. Você foi selecionado para esta amostra, dado o seu perfil de publicação em periódicos que apresentou um de três aspectos: nível de produtividade, publica prioritariamente em periódicos internacionais; evidente alteração do perfil de publicação rumo à publicação em periódicos internacionais.

a. Você diria que esta característica de sua produção (publicar majoritariamente em periódico internacional ou nacional) é inerente ao campo em que atua?

b. Você se sente pressionado por alguma instância de avaliação que estimula/exige a internacionalização? Caso positivo, você diria que os critérios são explícitos e bem definidos, ou são implícitos? Explique.
CNPq (Comitê), Revistas e FAPESP.

Não.

Não. Porém, comenta que o CNPq pressiona e quando o faz pode ser tanto explícito quanto implícito. 
Observações a serem destacadas
Trabalha prioritariamente com Geologia Aplicada e para tanto a busca bibliográfica é fundamental para confirmar o ineditismo da pesquisa. Foca em projetos que resultem em retorno financeiro. Não vê interesse na visibilidade da pesquisa, mas sim na formação dos profissionais e inovações que redundem em melhorias sociais, industriais e tecnológicas. Faz seu trabalho do ponto de vista do que acha que tem que fazer. As revistas são engessadas e não sabem lidar com a heterogeneidade e multidisciplinaridade, dificultando a publicação. OBS.: Não entende o sistema de métricas. 
PERGUNTAS

1. Quais fontes de dados você usa regularmente para recuperar literatura em seu campo de pesquisa? Você usa serviços de alerta?
DOCENTE 15

Periódicos e consulta em bases de dados, em especial Google Scholar e de vez em quando o Web of Science e Scopus. Recebe alertas, mas não usa muito.

Usa o ORCID por conta de demanda da USP e dos periódicos.

Não.

3. Você envia regularmente para a biblioteca sua produção intelectual para cadastro no Banco de Dados Bibliográfico Dedalus?

4. Você usa utiliza plataformas de armazenamento Sim. ResearchGate. eletrônico de produções intelectuais (como ResearchGate ou Academia.edu)?

5. Você já submeteu pre-prints para alguma plataforma Não. de forma a obter maior visibilidade para sua publicação?

6. Quais são as publicações mais importantes em seu campo?

Revistas: Science, Nature e PNAS (mais gerais). Na área especifica: Earth and Planetary Science Letters, Geology, Global Change Biology, Journal of Biogeography, Quaternary Science Reviews, Quaternary Research, Geomorphology e Quaternary Geochronology. Além das versões Open Access: Science Reports e Science Advances.

7. A ordem dos autores (primeiro, último ou autor correspondente) desempenha um papel no seu campo de pesquisa? Se não, por que não?

Sim. O primeiro (pós-doutorando ou doutorando) e o segundo/terceiro (supervisor/orientador) autores são aqueles que efetivamente realizaram a redação do artigo. Os outros são os que participaram de partes específicas da pesquisa, como laboratório e campo. E as vezes o último é o líder do grupo.

8. Quais critérios são relevantes para sua estratégia de publicação?

9. Publicar em Open Access/Acesso Aberto é um critério na sua estratégia? Se não, por que não?

10. Você participa ativamente de eventos científicos?

\section{Você é editor de uma ou mais revistas científicas?} Se sim, quais?

12. Você apoia ativamente o sistema de revisão por pares revisando documentos? Se sim, quantos por mês? Se não, por quê?
13. Você mantém um site pessoal? Uma entrada no
Não. Wikipédia?

14. Você usa um sistema de gerenciamento de

Não. Sem tempo para aprender.

A longo prazo a estratégia é buscar o tema mais amplo, de interesse geral e de maior impacto. $E$ durante a pesquisa surgem os temais mais específicos (de interesse de comunidade menores e específicas) sendo estes de menor impacto.

Não, por conta do custo da APC. Teria que ter um fator de impacto alto e que gerasse impacto alto.

Sim. Eventos da área específica: Conference on Luminescence and Electron Spin Resonance Dating e New World Luminescence Dating Workshop. Não participa de eventos grandes.

Parte do corpo editorial da Quaternary International e Ancient TL.

Sim. 3 a 5 por ano.

15. Você se envolve ativamente em listas de discussão Não. ou blogs? Se sim, quais?

16. Você usa outras ferramentas de mídia social? Se Não. sim, quais?

17. O que você pensa sobre métricas de impacto

Considera as citações, as demais são as vezes artificiais. (citações), de uso (downloads) e altimetria? 
18. Você gera dados de pesquisa? Se sim, como você os gerencia e os arquiva?

\author{
19. Você seleciona e avalia colegas ou potenciais \\ colaboradores? Se sim, você também adota métodos \\ quantitativos para esta atividade?
}

Sim. Gera mas não tem um armazenamento. Eles estão distribuídos. Os de laboratório ficam no servidor do próprio laboratório. E tem anexado nas revistas como Dados Suplementares. Na área de Quaternário há alguns repositórios.

Sim. Para os colaboradores há uma soma de critérios, mais especialmente por conta das habilidades e experiência. Mas dados quantitativos não são preponderantes. Para docência é importante selecionar alguém que tenha uma atividade intensa de pesquisa.

Agências de fomento (FAPESP, CNPq e algumas internacionais), Periódicos e a progressão na carreira.
20. Considerando a CAPES como uma instância de avaliação que, ao propor critérios para o Programa, estabelece diretrizes para o pesquisador, você poderia nomear outra(s) instância(s) de avaliação que se vê submetido explícita ou implicitamente?

21. Você foi selecionado para esta amostra, dado o seu perfil de publicação em periódicos que apresentou um de três aspectos: nível de produtividade, publica prioritariamente em periódicos internacionais; evidente alteração do perfil de publicação rumo à publicação em periódicos internacionais.

a. Você diria que esta característica de sua produção (publicar majoritariamente em periódico internacional ou nacional) é inerente ao campo em que atua? b. Você se sente pressionado por alguma instância de avaliação que estimula/exige a internacionalização? Caso positivo, você diria que os critérios são explícitos e bem definidos, ou são implícitos? Explique.
Não. Isso é inerente às questões que está trabalhando. Se quiser participar do jogo tem que estar em um grupo internacional. Considera os critérios mais implícitos.
Há algum assunto similar que não tratamos e que gostaria de compartilhar?

Observações a serem destacadas
Cita um estudo interessante sobre o perfil de pesquisa realizado pela Comissão de Pesquisa. 
PERGUNTAS

1. Quais fontes de dados você usa regularmente para recuperar literatura em seu campo de pesquisa? Você usa serviços de alerta?

2. Você usa identificadores únicos pessoais (como Orcid, ResearcherID etc.)?

3. Você envia regularmente para a biblioteca sua produção intelectual para cadastro no Banco de Dados Bibliográfico Dedalus?

4. Você usa utiliza plataformas de armazenamento eletrônico de produções intelectuais (como

ResearchGate ou Academia.edu)?

5. Você já submeteu pre-prints para alguma plataforma Não. de forma a obter maior visibilidade para sua publicação?

6. Quais são as publicações mais importantes em seu campo?

\begin{abstract}
7. A ordem dos autores (primeiro, último ou autor correspondente) desempenha um papel no seu campo de pesquisa? Se não, por que não?
\end{abstract}

8. Quais critérios são relevantes para sua estratégia de publicação?

\section{DOCENTE 25}

Scopus, sites de revistas (revistas que publica) para verificar os perfis. Alerta usa pouco.

Não.

Não.

Não.

Applied Geochemistry; Journal of Hydrology; Hydrogeology Journal; Geologia USP. Série Científica (são revistas que não tem um Fl alto mas são as melhores da área que trabalha)

Não. Colocam como primeiro autor o aluno que desenvolve o estudo. E depois o orientador. Sente que para evolução na carreira interna é um valor aparecer como primeiro autor nos artigos. Assim, periodicamente é importante se colocar como o primeiro autor de um artigo.

Publicar, em seu campo de atuação não é tão importante, mas sim os projetos que desenvolve e o impacto causado pelos resultados que modificam ou geram políticas públicas. Isso é muito mais relevante do que publicar em um periódico internacional e aumentar seus indicadores pessoais de citação (Índice H). Faz o suficiente para ser respeitado. Estratégia é: publicar o suficiente em revistas internacionais para ter um currículo mais internacional.
9. Publicar em Open Access/Acesso Aberto é um critério na sua estratégia? Se não, por que não?

10. Você participa ativamente de eventos científicos?
Não pensa em estratégias, mas sim em necessidade. Quando precisa publicar com maior rapidez envia para revistas com menor prazo para publicação (Ex. Journal of Water Resource and Protection [Open Access] artigo publicado em um mês). Se fosse submetido para revistas mais especializadas demoraria muito mais a publicação.

Sim. Seminários no Brasil (como palestrante) na temática de áreas contaminadas. Participa no exterior: Congress of International Association of Hydrogeologists (IAH); Conference of National Groundwater Association (NGWA); Seminário EKOS Brasil (membro da organização); Congresso Brasileiro de Águas Subterrâneas; e eventos específicos focados em águas subterrâneas.

11. Você é editor de uma ou mais revistas científicas? Se sim, quais?

12. Você apoia ativamente o sistema de revisão por Sim. Geologia USP. Série Científica e até 2015 da Revista Águas Subterrâneas - ABAS.

Sim. Em 13 revistas (metade internacional) com uma pares revisando documentos? Se sim, quantos por mês? média de 2 artigos por mês. E como editor tem o Se não, por quê?

trabalho de verificar os artigos a serem publicados. Um total de 5 a 6 artigos por mês.
13. Você mantém um site pessoal? Uma entrada no Wikipédia?
Não. Somente o do grupo de pesquisas. 
14. Você usa um sistema de gerenciamento de

Não. Já usou o Mendeley mas não suscitou interesse. referência? Se sim, qual deles? Por que você acha útil?

15. Você se envolve ativamente em listas de discussão

Não. ou blogs? Se sim, quais?

16. Você usa outras ferramentas de mídia social? Se Não. sim, quais?

17. O que você pensa sobre métricas de impacto (citações), de uso (downloads) e altimetria?

Todos os índices vão refletir a importância da obra da pessoa. São indicadores interessantes. O Índice H é simples e genial e mede o grau de comprometimento e destaque do pesquisador com a área acadêmica/científica.

18. Você gera dados de pesquisa? Se sim, como você os gerencia e os arquiva?

19. Você seleciona e avalia colegas ou potenciais colaboradores? Se sim, você também adota métodos quantitativos para esta atividade?

20. Considerando a CAPES como uma instância de avaliação que, ao propor critérios para o Programa, estabelece diretrizes para o pesquisador, você poderia nomear outra(s) instância(s) de avaliação que se vê submetido explícita ou implicitamente?

Sim. Não possui sistema de gerenciamento. Delega aos alunos para organizar. Ao término dos projetos os alunos organizam tudo em uma pasta.

Sim. Não utiliza métodos quantitativos. O que leva em consideração é o conteúdo e perfil.

O CNPq, que serve como um parâmetro para todas as outras avaliações. Quanto à USP acha que é normal ser avaliado, mas esta precisa ser justa. Deve levar em conta que há profissionais com perfil de docência, profissionais com perfil de pesquisa e outros com perfil administrativo. E todos devem coexistir e serem valorizados, independentemente da quantidade e impacto da sua produção científica. Há que se encontrar um meio termo. Deve-se avaliar o grau de comprometimento do indíviduo com a instituição, independente da área em que atua. A impressão que tem é que se valoriza mais a produção científica.

21. Você foi selecionado para esta amostra, dado o seu perfil de publicação em periódicos que apresentou um de três aspectos: nível de produtividade, publica prioritariamente em periódicos internacionais; evidente alteração do perfil de publicação rumo à publicação em periódicos internacionais.

a. Você diria que esta característica de sua produção (publicar majoritariamente em periódico internacional ou nacional) é inerente ao campo em que atua?
A publicação tanto nacional quanto internacional existe de maneira equilibrada. Espera-se com a pesquisa que esta sirva de ponte entre o que se tem de melhor lá fora, além de trazer essa cultura de inovação para o mercado interno. A Geologia Aplicada identifica o que tem de ferramentas utilizadas lá fora para serem incorporadas nas atividades no Brasil. E para isso é importante ter projetos internacionais e, portanto, publicar internacionalmente faz parte das colaborações. Publicar nacionalmente não é uma exigência. Há um compromisso com os parceiros do exterior para essa publicação. "Publicar internacionalmente e publicizar nacionalmente".

Sim. Considera que são avaliados por sua produtividade. Tem-se dinheiro nas agências de fomento ou no próprio IGc/USP quando a produção/projeto é internacionalizada. Os critérios são mais que implícitos, são intuitivos.

Recomendou ao Entrevistador/Pesquisador que aumente sua população e ouvir outros pesquisadores que não publicam tanto. Não deve entrevistar só quem tem publicação regular, mas quem também não publica. Para poder ter um comparativo. 
A Geologia comparada com outras áreas tem um tempo de produção muito maior, uma vez que os dados são gerados em campo e não em laboratórios. Há todo um trabalho prévio, durante e posterior à coleta de dados. A dinâmica dos projetos é totalmente diferente das demais áreas e, portanto, não se pode comparar com a Geologia. E isso acontece com outras áreas. Ressalta que é injusto ser avaliado institucionalmente por pessoas que não entendem o modus operandi da área e que no fim taxarão o Instituto como improdutivo. 
Apêndice F - Mapeamento da inserção da comunidade de docentes do IGc/USP em plataformas de identificação de autores e registro da produtividade científica 


\begin{tabular}{|c|c|c|c|c|c|c|c|c|c|c|c|c|}
\hline NOME & DEPTO & JORNADA & FUNCAO & CATEGORA & GENERO & BVFAPESP & LATTES & GOOGIE_SAHOLAR & SCOPUS_D & RESEARGIER_D & RESEARGHGATE & ORCD \\
\hline AdrianaAlves & GMG & RDIDP & ProfDoutor & Ativo & $\mathrm{F}$ & 56006 & 4150079998802134 & flZ2tPIOAAAAI & 56817899500 & & Adriana_Aves2 & \\
\hline AlbertoPacheco & GSA & RDIDP & ProfAssociado & Aposentado & M & 3550 & 8034236297446600 & & 7102576051 & & & \\
\hline Alexandra VieiraSuhogusoff & GSA & RDIDP & ProfDoutor & Ativo & $\mathrm{F}$ & 52646 & 7822926225210525 & ZunfNKKAAAAAI & 16176631800 & $\mathrm{~N}-7310-2013$ & Alexandra_Suhogusoff & $00000001-7925-4094$ \\
\hline AndreOliveiraSawakuchi & GSA & RDIDP & ProfAssociado & Ativo & M & 9028 & 3999005419444953 & DX13yg8AAAAI & 15840884400 & D-1445-2013 & Andre_Sawakuchi & $0000001-5016-2428$ \\
\hline AndréPiresNegão & GSA & RDIDP & ProfDoutor & Ativo & $M$ & & 3591878978683550 & & 56717482100 & & & \\
\hline AntonioCarlos RochaCampos & GSA & RDIDP & Prof Ttular & Sênior & M & 106195 & 8862922803945594 & OSWAGMOAAAAN & 6603588535 & & Antonio_Rocha_Campos & \\
\hline AntonioRomalinoSantosFragoso Cesar & GSA & RDIDP & ProfDoutor & Aposentado & $M$ & 3573 & 7927072595964583 & & 23090533800 & & & \\
\hline ArleiBeneditoMacedo & GSA & RDIDP & ProfAssociado & Sênior & $M$ & 3594 & 0301558581420770 & & 7101906731 & & Arlei_Macedo & \\
\hline Benjamim BleydeBritoNeves & GMG & RDIDP & Prof Ttular & Sênior & $M$ & 3949 & 4141785292003086 & CGIWmBOAAAAI & 8428809700 & & & \\
\hline CaetanoJuliani & GSA & RDIDP & Prof Ttitar & Ativo & M & 5060 & 7747851025823425 & & 8337108300 & E-2069-2014 & Caetano_Juliani & $00000002-0128-993 x$ \\
\hline CarlosjoseArchanjo & GMG & RDIDP & ProfAssociado & Ativo & $M$ & 3644 & 0302090618069167 & blrahaEAAAA & 6603397081 & E-9062-2012 & Carlos__Archanjo & $00000003-4618-7790$ \\
\hline CelsodeBarrosGomes & GMG & RDIDP & ProfTtular & Sênior & $M$ & 723 & 7134568867786123 & & 7101706960 & & Celso_Gomes4 & \\
\hline ChristinelaureManieBourotte & GSA & RDIDP & ProfDoutor & Ativo & $\mathrm{F}$ & 51627 & 0013459450420724 & 47WaOWCAAAA & 8618872000 & & Christine_Bourotte & $00000002-2821-1059$ \\
\hline GroTexeiraComea & GMG & RDIDP & ProfAssociado & Aposentado & $M$ & 87160 & 1315778332459754 & 7nBYSOCAAAAI & 7007018620 & C-6682-2016 & Gro_Correia & \\
\hline Claudia ReginaPassarelli & GMG & RDIDP & ProfDoutor & Ativo & $\mathrm{F}$ & 52835 & 0953877748626839 & P9l1yo8AAAA & 6701647860 & L-1697-2013 & Caudia__assarelli2 & \\
\hline CaudioRicomini & GSA & RDIDP & Prof Ttular & Sênior & M & 3280 & 8670893946594677 & AZOEfmYAAAAI & 55962364100 & G-17642010 & Caudio_Ricoomini & $00000002-7249-5706$ \\
\hline ColomboCeso Gaeta Tassinari & GMG & RDIDP & Prof Ttular & Ativo & $M$ & 954 & 5788186365234727 & & 57195987615 & D-2258-2012 & Colombo_Tassinari & $00000003-0200-2889$ \\
\hline DanielAtencio & GMG & RDIDP & Prof Ttular & Ativo & $M$ & 5578 & 3083598884160278 & abTrRIAAAAA & 6603818657 & $C-1626-2013$ & Daniel_Atencio & $00000002-6943-5227$ \\
\hline DarcyPedroSvizzero & GMG & RDIDP & Prof Ttiular & Aposentado & $M$ & & 5014755186375050 & & & & & \\
\hline DenisedelaCorteBacd & GSA & RDIDP & ProfDoutor & Ativo & $\mathrm{F}$ & 33634 & 9191802374278641 & & 6506776807 & & Denise_Bacci2 & \\
\hline EdilsonPissato & GSA & RDIDP & ProfDoutor & Ativo & $M$ & & 0689920013290117 & & & & & \\
\hline ElianeAparedidaDellama & GMG & RDIDP & ProfAssociado & Ativo & $\mathrm{F}$ & 8237 & 9470552671926304 & IBDrZCAAAAl & 6506366155 & D-9722-2012 & Eliane_Del_lama & $0000003-15840670$ \\
\hline ExcelsoRuberti & GMG & RDIDP & Prof Ttular & Sênior & M & 31558 & 2964243091972280 & & 6506791361 & $H-2367-2012$ & & $00000003-2375-9004$ \\
\hline FabioRamosDiasdeAndrade & GMG & RDIDP & ProfAssociado & Ativo & $M$ & 7331 & 6287624855922912 & & 7005816440 & & & $00000001-8848-0130$ \\
\hline FabioTaioli & GSA & RDIDP & Prof Ttular & Aposentado & $M$ & 3817 & 4841497440452266 & KyA99L8AAAA & 11241370500 & $F-3692-2010$ & Fabio_Taioli & $00000001-5564942 x$ \\
\hline FranoiscoRubensAves & GMG & RDIDP & ProfDoutor & Aposentado & M & & & & & & & \\
\hline
\end{tabular}




\begin{tabular}{|c|c|c|c|c|c|c|c|c|c|c|c|c|}
\hline NOME & DEPTO & JORNADA & FUNCAO & CATEGORIA & GENERO & BVFAPESP & LATTES & GOOGIE_SOHOLAR & Scopus_ID & RESEARGHER_D & RESEARCHGATE & ORaD \\
\hline FrandiscoWilliamdaCuzzJúnior & GSA & RDIDP & ProfAssociado & Ativo & $M$ & 2912 & 8502253983979576 & ggrgAAAA & 8287100700 & & Francisco_Cnzu4 & $00000002-4030-4581$ \\
\hline FredericoMeiraFaleiros & GMG & RDIDP & ProfDoutor & Ativo & $M$ & 36453 & 1460935168710629 & PYgo5zoAAAA & 16318324300 & $F-6138-2010$ & Frederio__Faleiros & $0000003-2199-8116$ \\
\hline GastonEduardoEnnich Rojas & GMG & RDIDP & ProfDoutor & Ativo & $M$ & 36120 & 1023722688858336 & tuf-2EAAAAI & 25654949100 & $H-3898-2012$ & Gaston_Enrich_Rojas & $0000-0002-9422-3189$ \\
\hline GeorgRobertSadowski & GMG & RDIDP & Prof Ttular & Sênior & $M$ & & 1134083284908388 & juGdmXAAAAJ & 7004410705 & $E-9010-2012$ & & $00000001-7694-6482$ \\
\hline GergelyAndresJulioSzabo & GMG & RDIDP & ProfDoutor & Ativo & $M$ & 3294 & 3214753331766412 & 128KOYgAAAA & 13406295000 & & Gergely_Szabo7 & \\
\hline GiannaMariaGarda & GMG & RDIDP & ProfDoutor & Ativo & $\mathrm{F}$ & 6492 & 4230078159279230 & & 6603487967 & C-4916-2012 & Gianna_Garda & $00000002-7433-0796$ \\
\hline GinaldoAdemardaCruzCampanha & GMG & RDIDP & ProfAssociado & Ativo & $M$ & 5897 & 2971347311613974 & JqM9OSYAAAA & 6507597686 & J-9121-2012 & Ginaldo_Campanha & \\
\hline Horstpeter HerbertoGustavoJose Ullbrich & GMG & RDIDP & Prof Ttular & Sênior & $M$ & 5067 & 6235905323627933 & & 7004150346 & & & \\
\hline lanMcreath & GMG & RDIDP & ProfAssociado & Sênior & $M$ & 5281 & $529985125216 / 587$ & & 6603306134 & & lan_Mcreath & \\
\hline IvoKarmann & GSA & RDIDP & ProfAssociado & Ativo & $M$ & 5556 & $14307 / 2154904124$ & & 6508314561 & & No_Karmann & \\
\hline JoaoBatistaMoreschi & GSA & RDIDP & ProfDoutor & Sênior & $M$ & & 7832236252992590 & & & & & \\
\hline JoelBarbujianisgolo & GSA & RDIDP & Prof Ttular & Ativo & M & 5214 & 5920864355787944 & ZXoPZWgAAAAI & 6507408848 & & Joe__Sigolo & $00000002-1921-8857$ \\
\hline JohannHlans DanielSchorscher & GMG & RDIDP & Prof Ttular & Sênior & $M$ & 4912 & 3118759000575877 & & 6603347101 & & & \\
\hline JorgeHachiro & GSA & RDIDP & ProfDoutor & Aposentado & $M$ & 7225 & 7749140965535641 & & 8928734400 & & & \\
\hline JorgeKazuoYamamoto & GSA & RDIDP & Prof Ttular & Sênior & $M$ & 3209 & 5967114171471437 & & 7402741893 & & & \\
\hline JorgeSilvaBettencourt & GMG & RDIDP & Prof Ttular & Sênior & $M$ & 5421 & 5988912158119845 & WjhkWWAAAAJ & 35565731500 & & Jorge_Bettencourt & \\
\hline JoseBarbosadeMadureiraFitho & GMG & RDIDP & ProfDoutor & Aposentado & M & 5740 & 4183640915141049 & & 6504339005 & & & \\
\hline JoseDomingosFaraco Gallas & GSA & RDIDP & ProfDoutor & Ativo & $M$ & 7918 & 5527768246129523 & & 11240681500 & & Jose_Gallas & \\
\hline JoseRobertoCanuto & GSA & RDIDP & ProfDoutor & Aposentado & $M$ & 6394 & 1019237202350298 & & 6506006819 & & & \\
\hline JulianadeMoraesLemeBasso & GSA & RDIDP & ProfDoutor & Ativo & $\mathrm{F}$ & 33633 & 2373797577822902 & & 57196114087 & C-3335-2012 & & $00000002-5833-4885$ \\
\hline KenitiroSuguio & GSA & RDIDP & Prof Ttular & Sênior & $M$ & 5029 & 1984455567101057 & & 7003743970 & & K_Suguio & \\
\hline LenaVirginiaSoares Monteiro & GSA & RDIDP & ProfAssociado & Ativo & $\mathrm{F}$ & 34614 & 6455990478032543 & 4LOVBLOAAAAI & 7103010497 & $E-5887-2012$ & Lena_Monteiro & 0000-0003-3999-026x \\
\hline LiliaMascarenhasSant/Agostino & GSA & RDIDP & ProfDoutor & Aposentado & $\mathrm{F}$ & 6455 & 4811627485197610 & & 6505794005 & & & \\
\hline LuceleneMartins & GMG & RDIDP & ProfDoutor & Ativo & $\mathrm{F}$ & 34768 & 8977923384078832 & kee8SWUAAAA & 13609552600 & E-8501-2012 & Lucelene_Martins & \\
\hline LuizEduardoAnelli & GSA & RDIDP & ProfDoutor & Ativo & $M$ & 6963 & 5644021995247693 & & 13105574500 & & Luiz_Anelli & $00000002-5228-9833$ \\
\hline Mabel NormaCostasdeUlbrich & GMG & RDIDP & ProfDoutor & Aposentado & $\mathrm{F}$ & & 8567359788625568 & & 7004482055 & & Mabel_Ulbrich & \\
\hline
\end{tabular}




\begin{tabular}{|c|c|c|c|c|c|c|c|c|c|c|c|c|}
\hline NOME & DEPTO & JORNADA & FUNCAO & CATEGORA & GENERO & BVFAPESP & LATIES & GOOGIE_SOHOLAR & SCOPUS_D & RESEARGHER_D & RESEAROHGATE & ORCD \\
\hline MarceloMonteirodaRocha & GSA & RDIDP & ProfAssociado & Ativo & M & 55856 & 0462977339002325 & CnEOKOUAAAA & $5566 / 522800$ & & Marcelo_Monteiro_Da_Rocha & \\
\hline MarcosEgydiodaSilva & GMG & RDIDP & ProfTtular & Ativo & M & 5367 & 8522863394780322 & & 6602344892 & G-1819-2012 & Marcos_Egydio-Silva & $00000002-8758-2175$ \\
\hline MariaAngebFomoniCandia & GMG & RDIDP & ProfDoutor & Aposentado & $\mathrm{F}$ & 5565 & 9320657129072582 & & 6602074807 & & & \\
\hline MariadaGloriaMottaGarcia & GMG & RDIDP & ProfDoutor & Ativo & $\mathrm{F}$ & 8358 & 9356898170253840 & OZsaz3cAAAA & 7404278031 & C-2330-2013 & Maria_da_Gloria_Garcia & \\
\hline MariaHelenaBezerraMaiadeHollanda & GMG & RDIDP & ProfAssociado & Ativo & $\mathrm{F}$ & 2715 & 9796891555451415 & ZXGXYGAAAAAI & 9640103400 & D-5614-2012 & Maria_Bezerra_Maia_de_Hollanda & \\
\hline MarialreneBartolomeu Raposo & GMG & RDIDP & ProfDoutor & Ativo & $\mathrm{F}$ & 2220 & 8743556058222610 & 4qZZOWKAAAAI & 55981722000 & D-6896-2013 & Irene_Raposo & \\
\hline MariodaCostaCampos Neto & GMG & RDIDP & ProfTtular & Ativo & M & 4036 & 5560012608843035 & ZUEZZOAAAAI & 8742531300 & & Mario_Campos_Neto & $00000002-9203-0439$ \\
\hline MarlyBabinski & GMG & RDIDP & ProfAssociado & Ativo & $\mathrm{F}$ & 5173 & 4670096853727080 & MLSEhtOAAAAI & 56262678600 & B-9403-2013 & Marly_Babinski & \\
\hline MaryElizabethCemutiBemardes deOliveira & GSA & RDIDP & ProfDoutor & Sênior & $\mathrm{F}$ & 538 & 4338294847576707 & VOOYCDMAAAI & 16634415400 & & Mary_Bemardes-De-Oliveira2 & $0000003-1749-7650$ \\
\hline MiguelAngeloStipp Basei & GMG & RDIDP & ProfTtular & Ativo & M & 213 & 4470314114687099 & OASHXOWAAAA & 6602668732 & C-1915-2013 & Miguel_Basei & \\
\hline OswaldoSigaJunior & GMG & RDIDP & ProfAssociado & Sênior & M & 6787 & 3132797041451029 & 9jOXWHOAAAAI & 6506179002 & & & \\
\hline Paticio RodrigoMonteainosMuñoz & GMG & RDIDP & ProfDoutor & Ativo & M & 101985 & 9792696736684088 & & 8274373700 & & Patrico_Monteainos & $0000001-5468-176 x$ \\
\hline PauloCesar Boggiani & GSA & RDIDP & ProfAssociado & Ativo & M & 7916 & 0326579897116378 & XQd_EAAAA & 35274386900 & D-7029-2016 & Paulo_Boggiani & $0000002-8355-6228$ \\
\hline PauloCesarFonsecaGiannini & GSA & RDIDP & ProfTtular & Ativo & M & 6416 & 7132401562335161 & CqauhdAAAAAJ & 7004349366 & & & \\
\hline PauloEduardodeOliveira & GSA & RDIDP & ProfDoutor & Ativo & $\mathrm{M}$ & 91742 & 5484363129827679 & 8ZZOXhAAAAAI & 7102812852 & B-4559-2017 & Paulo_OlineiraA4 & \\
\hline PauloRobertodosSantos & GSA & RDIDP & Prof Ttitar & Sênior & M & 92353 & 4315521095711567 & & 7006685643 & & P_Santos2 & \\
\hline RainerAloysSchultzGuttler & GMG & RDIDP & ProfAssociado & Sênior & M & & 2657648974128663 & & 6507838225 & & Rainer_Guttler & \\
\hline RaphaelHypolito & GSA & RDIDP & ProfTtular & Sênior & M & 3676 & 6098454056703540 & NUg2WIIAAAA & 6602405936 & C6902-2012 & & \\
\hline ReginaldoAntonioBertolo & GSA & RDIDP & ProfDoutor & Ativo & M & 8387 & 5875316548046037 & ElÖ̈HkAAAAJ & 14420880800 & $E-4833-2012$ & Reginaldo_Bertolo & \\
\hline RenatodeMoraes & GMG & RDIDP & ProfAssociado & Ativo & M & 8061 & 3666520216687501 & tkaelyoAAAAJ & 56359502600 & $\mathrm{~F}-7421-2014$ & Renato_Moraes2 & $0000001-6917-3696$ \\
\hline RenatoPaesdeAlmeida & GSA & RDIDP & ProfAssociado & Ativo & $\mathrm{M}$ & 8587 & 0581949996647434 & jODeVAAAAA & 55019193400 & G-2567-2013 & Renato_Ameida6 & $00000003-3664-1558$ \\
\hline RicardoCesarAokiHirata & GSA & RDIDP & ProfTtular & Ativo & M & 3720 & 1937005354598601 & drEeWFCAAAAJ & 35585210200 & D-8610-2012 & Ricardo_Hirata3 & $0000001-9683-1244$ \\
\hline RogérioGuitarariAzzone & GMG & RDIDP & ProfDoutor & Ativo & M & 38957 & 6600544102749994 & KKZW2OAAAAI & 35274638500 & K-4379-2012 & Rogerio_Azzone & \\
\hline RomuloMadhado & GSA & RDIDP & ProfTtrular & Ativo & M & 4020 & 1221667877631959 & 30Z7nYAAAA & 13608077500 & & Romulo_Machado & \\
\hline SetembrinoPetri & GSA & RDIDP & ProfTtular & Sênior & M & 5206 & 1194621385265171 & f379ZUAAAAI & 7004691225 & & & \\
\hline SilioRobertoFarias Vach & GMG & RDIDP & ProfTtular & Ativo & M & 33632 & 8146704740674855 & jqUOЗYMAAAAI & 7801645255 & $F-7476-2012$ & Silvio_Vlach & $00000001-9877-057 x$ \\
\hline
\end{tabular}




\begin{tabular}{|c|c|c|c|c|c|c|c|c|c|c|c|c|}
\hline NOME & DEPTO & JOPNADA & FUNCAO & CATEGORIA & GENERO & BVFAPESP & LATTES & GOOGIE_SAHOLAR & SCOPUS_D & RESEARCHER_D & RESEARQHGATE & ORCD \\
\hline SoniaMariaBarrosdeOliveira & GSA & RDIDP & ProfTtiular & Ativo & $\mathrm{F}$ & 5389 & 0643730644808524 & & 35564969000 & & & \\
\hline TeodorolsnardRibeirodeAlmeida & GSA & RDIDP & ProfAssociado & Sênior & M & 4896 & 7880612373807710 & FoM182MAAAA & 7004093054 & $\mathrm{~N}-3306-2016$ & Teodoro_snard & \\
\hline Thomas RichFairchild & GSA & RDIDP & ProfDoutor & Sênior & M & 5129 & 5131197655654574 & 3CVdULEAAAA & 6603996444 & & Thomas_Fairchild2 & \\
\hline UmbertoGiuseppe Cordani & GSA & RDIDP & ProfTtiular & Sênior & M & 759 & 0822799877686090 & MdMAh7QAAAAI & 6701378571 & $F-3686-2014$ & Umberto_Cordani & $00000003-4425-5905$ \\
\hline UnielDuarte & GSA & RDDP & ProfTtular & Sênior & M & 5230 & 4590871099715580 & dyIZGWAAAAI & 6507071354 & & & \\
\hline ValdeardeAssisJanasi & GMG & RDIDP & ProfTtrular & Ativo & M & 3241 & 2249074352821232 & 1AtKBiAAAAA & 6506859039 & & Valdeai__anasi & $00000001-7606-982 x$ \\
\hline VeridianaTexeriadeSouzaMartins & GSA & RDDP & ProfDoutor & Ativo & $\mathrm{F}$ & 40603 & 2202735443360991 & HSLAPJAAAAAI & 55392499900 & $0-4235-2015$ & Veridiana_Martins & $00000002-5886-4974$ \\
\hline VicenteAntonio VitorioGirardi & GMG & RDIDP & Prof Ttiular & Sênior & M & 453 & 6876269679513816 & & 6701833467 & & V_Girardi & \\
\hline WisonTeixeira & GMG & RDIDP & ProfTtular & Sênior & M & 3924 & 9157226124301186 & XMWAOSWAAAAI & 7006494182 & B-7570-2013 & Wilson_Texeira & $0000003-15786846$ \\
\hline YushiroKhara & GMG & RTC & ProfDoutor & Sênior & M & & 8154688854194029 & & 24401091600 & & Yushiro_Khara & \\
\hline
\end{tabular}


Apêndice G - Credenciamento dos docentes da amostra nos ciclos de Avaliação da CAPES

\begin{tabular}{|c|c|c|c|c|c|}
\hline Docentes / Ciclos Credenciados & $\mathrm{T} 1$ & T2 & T3 & T4 & Q1 \\
\hline Docente 01 & $\sqrt{ }$ & $\sqrt{ }$ & $\sqrt{ }$ & $\sqrt{ }$ & $\sqrt{ }$ \\
\hline Docente 04 & & & & $\sqrt{ }$ & $\sqrt{ }$ \\
\hline Docente 05 & $\sqrt{ }$ & $\sqrt{ }$ & $\sqrt{ }$ & $\sqrt{ }$ & $\sqrt{ }$ \\
\hline Docente 06 & & $\sqrt{ }$ & $\sqrt{ }$ & $\sqrt{ }$ & $\sqrt{ }$ \\
\hline Docente 08 & & & & $\sqrt{ }$ & $\sqrt{ }$ \\
\hline Docente 12 & & & $\sqrt{ }$ & $\sqrt{ }$ & $\sqrt{ }$ \\
\hline Docente 14 & $\sqrt{ }$ & $\sqrt{ }$ & & $\sqrt{ }$ & $\sqrt{ }$ \\
\hline Docente 15 & & & & $\sqrt{ }$ & $\sqrt{ }$ \\
\hline Docente 25 & & & $\sqrt{ }$ & $\sqrt{ }$ & $\sqrt{ }$ \\
\hline
\end{tabular}

T1-Ciclo de Avaliação Trienal 2004 | T2-Trienal 2007 | T3-Trienal 2010 | T4-Trienal 2013 | Q1 -Quadrienal 2017

Fonte: Elaborado pelo autor com dados do Sistema Janus/USP. 